MARCEL PEREZ PEREIRA

SISTEMA AGROINDUSTRIAL DO PESCADO E OS SERVIÇOS OFICIAIS REGULADORES: DIFICULDADES, DESAFIOS E PERSPECTIVAS 


\section{SISTEMA AGROINDUSTRIAL DO PESCADO E OS SERVIÇOS OFICIAIS REGULADORES: DIFICULDADES, DESAFIOS E PERSPECTIVAS}

Dissertação apresentada ao Programa de PósGraduação em Epidemiologia Experimental Aplicada às Zoonoses da Faculdade de Medicina Veterinária e Zootecnia da Universidade de São Paulo para a obtenção do título de Mestre em Medicina Veterinária

\section{Departamento:}

Medicina Veterinária Preventiva e Saúde Animal

Área de concentração:

Epidemiologia Experimental Aplicada às Zoonoses

Orientador:

Profa. Dra. Simone de Carvalho Balian

\section{São Paulo}


Autorizo a reprodução parcial ou total desta obra, para fins acadêmicos, desde que citada a fonte.

BIBLIOTECA VIRGINIE BUFF D'APICE

FACULDADE DEMEDICINA VETERINARIA

E ZOOTECNIA DA USP

$31 / 7109$

\section{DADOS INTERNACIONAIS DE CATALOGAÇÃO-NA-PUBLICAÇÃO}

(Biblioteca Virginie Buff D'Ápice da Faculdade de Medicina Veterinária e Zootecnia da Universidade de Säo Paulo)

T.2152

FMVZ
Pereira, Marcel Perez

Sistema agroindustrial do pescado e os serviços oficiais reguladores: dificuldades, desafios e perspectivas / Marcel Perez Pereira. - São Paulo: M. P. Pereira, 2009. 229 f. : il.

Dissertação (mestrado) - Universidade de São Paulo. Faculdade de Medicina Veterinária e Zootecnia. Departamento de Medicina Veterinária Preventiva e Saúde Animal, 2009.

Programa de Pós-Graduação: Epidemiologia Experimental e Aplicada às Zoonoses.

Área de concentração: Epidemiologia Experimental e Aplicada às Zoonoses.

Orientador: Profa. Dra. Simone de Carvalho Balian.

1. Pescado. 2. Sistema agroindustrial. 3. Órgãos oficiais. 4. Entraves. I. Título. 


\section{CERTIFICADO}

Certificamos que o Projeto intitulado "Sistema agroindustrial do pescado e os serviços oficiais regulamentadores: diculdades, desafios e perspectivas", protocolado sob o $\mathrm{n}^{\circ} 1668 / 2009$, não utilizando animais, sob a responsabilidade da Profa Dra Simone de Carvalho Balian, está de acordo com os princípios éticos de experimentação animal da Comissão de Bioética da Faculdade de Medicina Veterinária e Zootecnia da Universidade de São Paulo e foi aprovado em reunião de 17/06/09.

We certify that the Research "Fishery agro-industrial system and the regulatory official services: difficulties, challenges and perspectives", protocol number 1668/2009, under the Profa Dra Simone de Carvalho Balian, agree with Ethical Principles in Animal Research adopted by Bioethic Commission of the School of Veterinary Medicine and Animal Science of University of São Paulo and was approved in the meeting of day 06/17/09.

São Paulo, 17 de junho de 2009

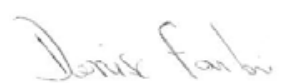

Profa Dra Denise Tabacchi Fantoni

Presidente da Comissão de Bioética FMVZ/USP 


\section{FOLHA DE AVALIAÇÃO}

Nome: PEREIRA, Marcel Perez

Título: Sistema agroindustrial do pescado e os serviços oficiais reguladores: dificuldade, desafios e perspectivas

Dissertação apresentada ao Programa de PósGraduação em Epidemiologia Experimental Aplicada às Zoonoses da Faculdade de Medicina Veterinária e Zootecnia da Universidade de São Paulo para a obtenção do título de Mestre em Medicina Veterinária

Data:

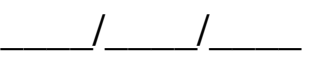

Banca Examinadora

Prof. Dr. Instituição:

Assinatura: Julgamento:

Prof. Dr. Instituição:

Assinatura: Julgamento:

Prof. Dr. Instituição:

Assinatura: Julgamento: 
À minha família, Cleber, Rosane e Daniel, e à Flávia,

todos sempre presentes. 
Agradeço...

.... primeiramente à minha família, Cleber, Rosane e Daniel, e à minha namorada Flávia, sem o apoio dos quais a realização deste trabalho seria impossível. Muito obrigado por todo o companheirismo, afeto, incentivo, colaboração e apoio durante todo esse período. Amo muito vocês.

... à Profa. Simone de Carvalho Balian por encarar o desafio de realizar um trabalho tão peculiar à Medicina Veterinária e, apesar das diversas dificuldades durante o período, persistir e auxiliar na conclusão dentro do prazo determinado. Muito obrigado.

... ao Prof. Ricardo Augusto Dias por ter sugerido o tema deste trabalho e auxiliado em diversos aspectos durante sua execução, fornecendo contatos, sugerindo literatura, ajudando na elaboração de artigo e discutindo sobre as dificuldades encontradas durante o trabalho. Muito obrigado.

... aos professores Reinaldo Pacheco da Costa e Dario Ikuo Miyake, ambos do Departamento de Engenharia de Produção da Escola Politécnica da Universidade de São Paulo, e Arlindo Phiippi Jr., da Faculdade de Saúde Pública da Universidade de São Paulo, agradeço por permitirem que um Médico Veterinário se aventurasse em áreas tão diferentes das quais está habituado, além de incentivarem tal atitude. Muito obrigado.

... aos professores da Faculdade de Medicina Veterinária e Zootecnia da Universidade de São Paulo, Denise Tabacchi Fantoni, Fernando José Benesi, Julia Maria Matera, Maria Cláudia Araripe Sucupira, Paulo Cesar Maiorka e Silvia Regina Ricci Lucas, por terem me ouvido nos momentos de dificuldade, orientado nos momentos de decisão e continuarem a ensinar. Minha sincera gratidão.

... aos funcionários da Secretaria Especial da Aquicultura e Pesca, Guilherme Crispim Hundley e Francisco Abraão Gomes de Oliveira Neto, por colaborarem com informações relevantes ao trabalho, indicarem pessoas para contato e caminhos para trilhar durante a execução do trabalho. Muito obrigado. 
... aos funcuonários da secretaria de pós-graduação Cláudia Lima, Dayse Maria Alves Flexa, Carlos Alberto da Silva Vasconcelos e Joana Ferreira Dias Vasconcelos, pelo apoio acadêmico durante esse perído.

... aos funcionários Elza Maria Rosa Bernardo Faquim, Fernanda Cezar Ribeiro, Solange Alves Santana e "Tia" Elena Aparecida Tanganini, da Biblioteca Virginie Buff D'Ápice da Faculdade de Medicina Veterinária e Zootecnia da Universidade de São Paulo , Wagner Pinheiro, da Biblioteca Prof. Dr. Gelso Vazzoler do Instituto Oceanográfico da Universidade de São Paulo, e Maria Lúcia de Faria Ferraz e Jose Estorniolo Filho, da Biblioteca Centro de Informação e Referência em Saúde Pública da Faculdade de Saúde Pública da Universidade de São Paulo, e a todos os demais que colaboraram com a pesquisa e organização do trabalho. Muito obrigado.

... aos amigos, que não vou nomear aqui para não correr o risco de esquecer de alguém, principalmente o famigerado Grupo E, que estiveram presentes em muitos dos poucos momentos de descanso, reclamando da falta de tempo, dinheiro e preguiça que passamos nesse período. Vocês são demais.

.... e a todos que participaram deste projeto e que não foram nomeados. Muito obrigado. 


\section{RESUMO}

PEREIRA, M. P. Sistema agroindustrial do pescado e os serviços oficiais reguladores: dificuldade, desafios e perspectivas. [Fishery agro-industrial system and the regulatory official services: difficulties, challenges and perspectives]. 2009. 229 f. Dissertação (Mestrado em Medicina Veterinária) - Faculdade de Medicina Veterinária e Zootecnia, Universidade de São Paulo, São Paulo, 2009.

Apesar de o Brasil ser um país de destaque na produção e comercialização de produtos agropecuários, o setor produtivo de pescado ainda está em desenvolvimento no país. Os estudos sobre os sistemas agroalimentares são importantes ferramentas que permitem conhecer as cadeias produtivas, identificar entraves, formular estratégias e políticas públicas e privadas, visando o desenvolvimento do setor. Dessa forma, este trabalho teve como objetivo caracterizar o sistema agroindustrial do pescado no Brasil, identificar seus principais entraves e analisar a atuação governamental perante tais problemas. Para tal, foram consultados órgãos governamentais, associações, bancos de dados, publicações e pessoas relacionadas ao segmento. O sistema agroindustrial, dividido em pesca, aquicultura, indústria e comércio, foi caracterizado quanto ao volume de produção, valores financeiros e número de estabelecimentos e trabalhadores. Após a identificação de entraves ao desenvolvimento do setor, como o estado de sobrepesca dos principais recursos pesqueiros, os diversos problemas enfrentados pela aquicultura, a baixa qualidade higiênico-sanitária dos produtos comercializados, a escassez de informações setoriais publicadas e o baixo consumo de pescado no Brasil, a atuação dos serviços oficiais foi analisada e discutida. Foram identificados como problemas de gestão governamental a sobreposição de funções dos diversos órgãos administradores, a falta de coordenação entre esses órgãos, a ausência de fiscalização do cumprimento da legislação, a carência de políticas públicas claras, a dificuldade na obtenção de crédito para o investimento, a escassez de informações setoriais publicadas, entre outros. Algumas sugestões para o ordenamento do segmento do pescado foram feitas, como a reorganização institucional e definição de governança, a atualização da legislação, a contratação e treinamento de pessoas para a fiscalização, a definição de políticas claras para a aquicultura, o incentivo a pesquisas por informações setoriais e divulgação de dados confiáveis e atualizados. Apesar do desenvolvimento setorial após a criação da Secretaria Especial de Pesca 
e Aquicultura, o setor ainda enfrenta muitos problemas que necessitam solução a fim de desenvolver esse sistema produtivo e elevar o Brasil a um nível de maior importância na produção mundial de pescado.

Palavras-chave: Pescado. Sistema agroindustrial. Órgãos oficiais. Entraves. 


\section{ABSTRACT}

PEREIRA, M. P. Fishery agro-industrial system and the regulatory official services: difficulties, challenges and perspectives. [Sistema agroindustrial do pescado e os serviços oficiais reguladores: dificuldade, desafios e perspectivas]. 2009. 229 f. Dissertação (Mestrado em Medicina Veterinária) - Faculdade de Medicina Veterinária e Zootecnia, Universidade de São Paulo, São Paulo, 2009.

Although Brazil is a prominent country in agricultural products production and commercialization, the fishery productive sector is still in development in this country. The agri-food systems studies are important tools that allow us to know the product chains, to identify impediments, to formulate strategies and private and public policies, aiming to develop the sector. Therefore, this work had as objective to characterize the Brazilian fishery agri-industrial system, to identify its main impediments and to analyse the governmental performance in the presence of such problems. Hence, governmental agencies, associations, databases, publications and people related to the segment were consulted. The agri-food system, split in fishery, aquaculture, industry and commence, were characterized in terms of production, financial values and establishments and workers number. After the identification of the impediments to the sector development, such as the main fishery resources stocks in overfished state, the various issues faced by aquaculture, the low hygienicsanitary quality of the commercialized products, the shortage sectorial information and the low fishery products consumption in Brazil, the governmental agencies performance was analysed and discussed. The agencies overlapping functions, the lack of coordination between these agencies, the deprivation of inspection, the absence of clear public policies, the difficulties to acquire credit to invest, the shortage sectorial information, among others, were identified as governmental management problems. Some suggestions were made in order to organize the sector, like the institutional reorganization and the governance definition, the legislation update, hiring and training people to inspect, defining clear policies for aquaculture, stimulating the sectorial researches and spreading trustworthy and up to date data. In spite of the sectorial development after the creation of Special Secretariat of Fishery and Aquaculture, the sector still faces many issues that have to be solved in order to develop this production system and to raise Brazil to a level of bigger importance in the worldwide fishery production. 
Keywords: Fishery. Agro-industrial system. Governmental agencies. Impediments. 


\section{LISTA DE ABREVIATURAS E SIGLAS}

ABIA: Associação Brasileira das Indústrias da Alimentação

ABRAS: Associação Brasileira dos Supermercados

Anvisa: Agência Nacional de Vigilância Sanitária

APPCC: Análise de Perigos e Pontos Críticos de Controle

CNAE: Comissão Nacional de Atividades Econômicas

CNPq: Conselho Nacional de Desenvolvimento Científico e Tecnológico

CONCLA: Comissão Nacional de Classificação

CONEPE: Conselho Nacional de Pesca e Aquicultura

DIPES: Divisão de Inspeção de Pescados e Derivados

DTA: Doença transmitida por Alimento

FAO: Food and Agriculture Organization of United States

FNDE: Fundo Nacional de Desenvolvimento da Educação

IBAMA: Instituto Brasileiro do Meio Ambiente e dos Recursos Naturais Renováveis

IBGE: Instituto Brasileiro de Geografia e Estatística

MAPA: Ministério da Agricultura, Pecuária e Abastecimento

MDIC: Ministério do Desenvolvimento, Indústria e Comércio Exterior

MMA: Ministério do Meio Ambiente

MS: Ministério da Saúde

MTE: Ministério do Trabalho e Emprego

RAIS: Relação Anual de Informações Sociais

REVIZEE: Programa de Avaliação do Potencial Sustentável de Recursos Vivos na Zona Econômica Exclusiva

SEAP: Secretaria Especial da Aquicultura e Pesca

SEBRAE: Serviço Brasileiro de Apoio às Micro e Pequenas Empresas

SIF: Serviço de Inspeção Federal

SINDIPI: Sindicato das Indústrias da Pesca de Itajaí e Região

SIPESCA: Sindicato da Indústria da Pesca dos estados do Pará e Amapá

SUS: Sistema Único de Saúde

ZEE: Zona Econômica Exclusiva 


\section{LISTA DE QUADROS}

Quadro 1 - Principais problemas na regulamentação pesqueira no Sul do Brasil. .125

Quadro 2 - Áreas de Proteção Ambiental relacionadas ao ambiente marinho. ......134

Quadro 3 - Principais entraves ao complexo agroindustrial do pescado no Brasil.171 


\section{LISTA DE TABELAS}

Tabela 1 - Perfil das regiões brasileiras para a pesca marinha.

Tabela 2 - Produção e vendas dos produtos industriais derivados do pescado

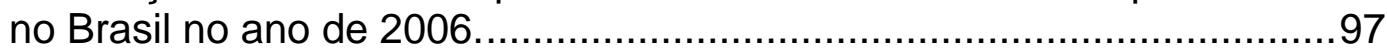

Tabela 3 - Aquisição domiciliar per capita anual de pescado, em Kg/hab/ano 2002-2003. ................................................................................ 106 


\section{LISTA DE GRÁFICOS}

Gráfico 1 - Produção de pescado no mundo - 1950-2006..............................29

Gráfico 2 - Produção pesqueira mundial - 1950-2006. ..................................30

Gráfico 3 - Os dez maiores produtores na pesca marinha e continental - 2006......31

Gráfico 4 - Produção de pescado no Brasil - 1997-2006..................................73

Gráfico 5 - Evolução do número de estabelecimentos e de trabalhadores do setor primário de pescado no Brasil - 1995-2005..............................74

Gráfico 6 - Produção de pescado por regiões do Brasil - 1996-2006. ....................76

Gráfico 7 - Distribuição da produção de pescado por unidade federativa no

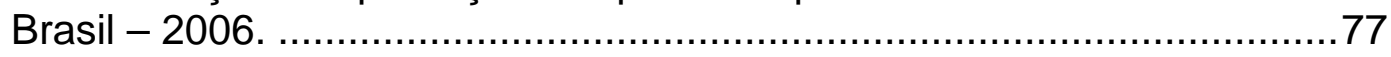

Gráfico 8 - Distribuição da produção pesqueira brasileira por tipo de produção

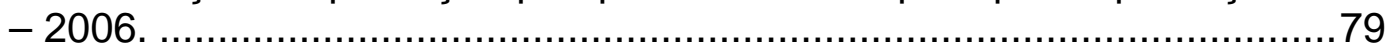

Gráfico 9 - Remuneração média dos trabalhadores brasileiros da pesca,

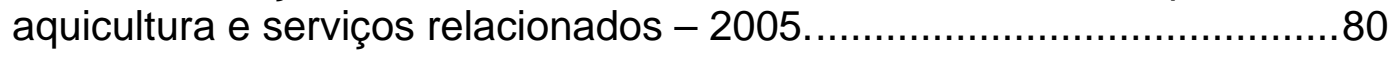

Gráfico 10 - Distribuição da produção da pesca marinha brasileira por unidade

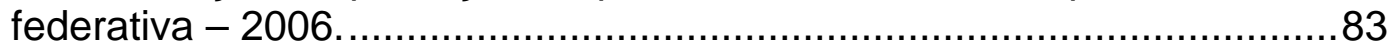

Gráfico 11 - Distribuição da produção da pesca continental brasileira por unidade federativa - 2006.

Gráfico 12 - Distribuição dos estabelecimentos de pesca e serviços

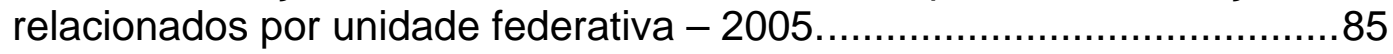

Gráfico 13 - Principais ocupações da pesca e serviços relacionados - 2005. ........86

Gráfico 14 - Distribuição da produção da maricultura brasileira por unidade federativa - 2006 .

Gráfico 15 - Distribuição da produção da aquicultura continental brasileira por unidade federativa - 2006.

Gráfico 16 - Distribuição dos estabelecimentos de aquicultura e serviços relacionados por unidade federativa - 2005 .

Gráfico 17 - Principais ocupações da aquicultura e serviços relacionados 2005.

Gráfico 18 - Evolução do número de estabelecimentos e de trabalhadores do setor industrial de pescado brasileiro - 1995-2005.

Gráfico 19 - Distribuição dos estabelecimentos da indústria de pescado por unidade federativa - 2005

Gráfico 20 - Remuneração média dos trabalhadores brasileiros da indústria de

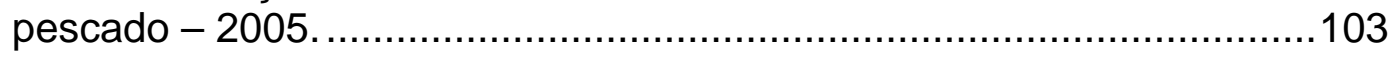

Gráfico 21 - Principais ocupações da indústria de pescado - 2005. ....................104

Gráfico 22 - Aquisição domiciliar de pescado per capita anual (Kg) - 2003. ..........107 
Gráfico 23 - Aquisição de pescado domiciliar per capita anual por situação do domicílio - 2003.

Gráfico 24 - Aquisição de pescado domiciliar per capita anual por classes de rendimento monetário e não monetário mensal familiar- 2003.

Gráfico 25 - Percentual médio do dispêndio com pescado em relação aos locais de compra de pescado - 2003.

Gráfico 26 - Aquisição alimentar domiciliar per capita anual, por grandes regiões segundo grupos de produtos - 2003.

Gráfico 27 - Participação relativa de alimentos e grupos de alimentos no total de calorias determinado pela aquisição alimentar domiciliar, por grandes regiões e situação do domicílio - 2003.

Gráfico 28 - Exportação e importação de pescado - 1997-2007.

Gráfico 29 - Evolução do número de estabelecimentos e de trabalhadores do comércio atacadista de pescado brasileiro - 1995-2005.

Gráfico 30 - Distribuição dos estabelecimentos de comércio atacadista de pescado por Unidade Federativa - 2005

Gráfico 31 - Remuneração média dos trabalhadores brasileiros do comércio atacadista de pescado - 2005 .

Gráfico 32 - Principais ocupações do comércio atacadista de pescado - 2005....118

Gráfico 33 - Evolução das capturas de Sardinella brasiliensis nos estados do Rio de Janeiro, Santa Catarina e São Paulo - 1964-1991 e 20002006.

Gráfico 34 - Evolução das diferentes modalidades de captura de Camarão-rosa nos estados do Espírito Santo, Paraná, Rio de Janeiro, Santa Catarina e São Paulo - 1965-1999.

Gráfico 35 - Número de surtos e de doentes relacionados às doenças transmitidas por alimentos no Brasil - 1999-2007.

Gráfico 36 - Notificação de surtos de doenças transmitidas por alimentos no Brasil - 1999-ago. 2008.

Gráfico 37 - Principais causas dos surtos de doenças transmitidas por alimentos o Brasil - 1999-ago. 2008.

Gráfico 38 - Principais agentes causadores dos surtos de doenças transmitidas por alimentos o Brasil entre 1999 e agosto de 2008.

Gráfico 39 - Principais alimentos veículos de doenças transmitidas por alimentos - 1999-ago. 2008.

Gráfico 40 - Principais locais de ocorrência de surtos de doenças transmitidas por alimentos - 1999-ago. 2008.

Gráfico 41 - Evolução do número de estabelecimentos e de trabalhadores do setor primário de pescado da região Norte do Brasil - 1995-2005. 200

Gráfico 42 - Evolução do número de estabelecimentos e de trabalhadores do setor primário de pescado da região Nordeste do Brasil - 1995-2005...200 
Gráfico 43 - Evolução do número de estabelecimentos e de trabalhadores do setor primário de pescado da região Sudeste do Brasil - 1995-2005 ...201

Gráfico 44 - Evolução do número de estabelecimentos e de trabalhadores do setor primário de pescado da região Sul do Brasil - 1995-2005.

Gráfico 45 - Evolução do número de estabelecimentos e de trabalhadores do setor primário de pescado da região Centro-oeste do Brasil - 19952005.

Gráfico 46 - Evolução do número de estabelecimentos e de trabalhadores do setor industrial de pescado da região Norte do Brasil - 1995-2005.

Gráfico 47 - Evolução do número de estabelecimentos e de trabalhadores do setor industrial de pescado da região Nordeste do Brasil - 19952005.

Gráfico 48 - Evolução do número de estabelecimentos e de trabalhadores do setor industrial de pescado da região Sudeste do Brasil - 1995-2005...204

Gráfico 49 - Evolução do número de estabelecimentos e de trabalhadores do setor industrial de pescado da região Sul do Brasil - 1995-2005...........205

Gráfico 50 - Evolução do número de estabelecimentos e de trabalhadores do setor industrial de pescado da região Centro-oeste do Brasil - 19952005.

Gráfico 51 - Evolução do número de estabelecimentos e de trabalhadores do comércio atacadista de pescado da região Norte do Brasil - 19952005.

Gráfico 52 - Evolução do número de estabelecimentos e de trabalhadores do comércio atacadista de pescado da região Nordeste do Brasil 1995-2005.

Gráfico 53 - Evolução do número de estabelecimentos e de trabalhadores do comércio atacadista de pescado da região Sudeste do Brasil - 19952005.

Gráfico 54 - Evolução do número de estabelecimentos e de trabalhadores do comércio atacadista de pescado da região Sul do Brasil - 19952005.

Gráfico 55 - Evolução do número de estabelecimentos e de trabalhadores do comércio atacadista de pescado da região Centro-oeste do Brasil 1995-2005. 


\section{LISTA DE FIGURAS}

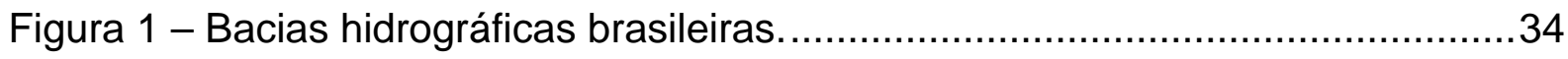

Figura 2 - Correntes marítimas do Brasil.......................................................... 38

Figura 3 - Áreas de ressurgência importantes para a pesca e aquicultura................39

Figura 4 - Fluxo do sistema agroalimentar. ...................................................... 45

Figura 5 - Esquema inicial do complexo agroindustrial do pescado no Brasil. .........65

Figura 6 - Complexo agroindustrial do pescado após ajustes e correções. ..............70 


\section{SUMÁRIO}

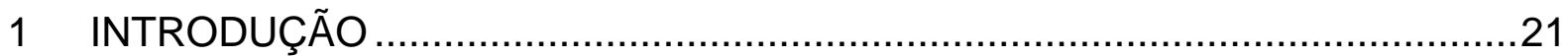

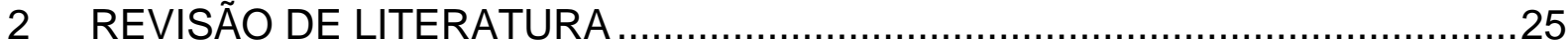

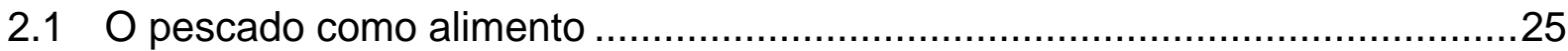

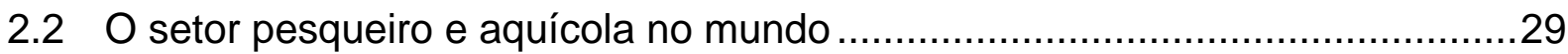

2.3 As características do Brasil para o setor pesqueiro e aquícola ........................33

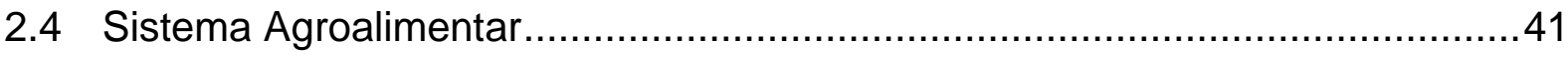

2.5 Estudos sobre o complexo agroindustrial do pescado..................................47

2.6 A gestão do complexo agroindustrial do pescado no brasil .............................55

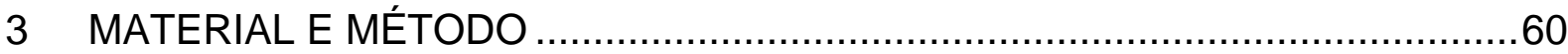

3.1 Método

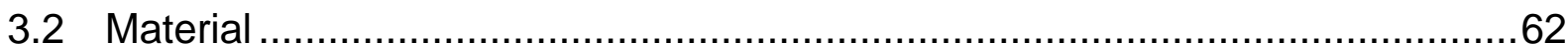

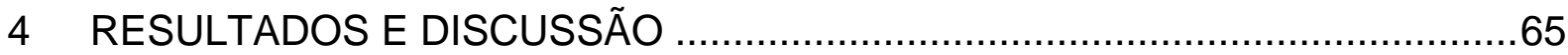

4.1 Caracterização do complexo agroindustrial do pescado....................................65

4.1.1 Setor produtivo pesqueiro e aquícola ................................................... 72

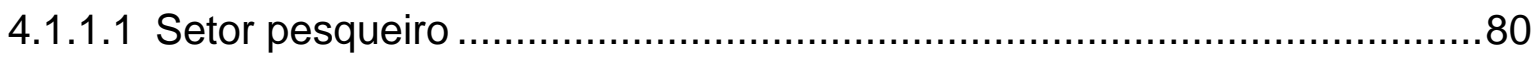

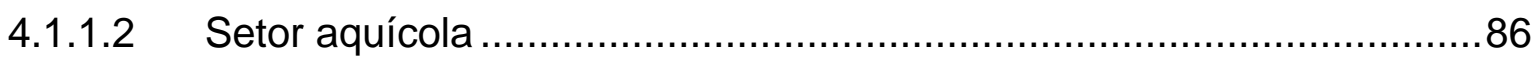

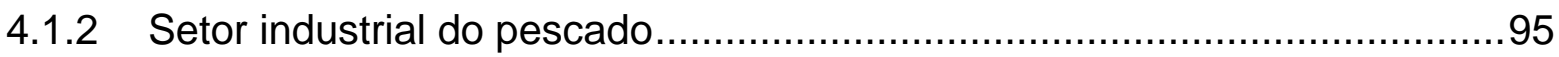

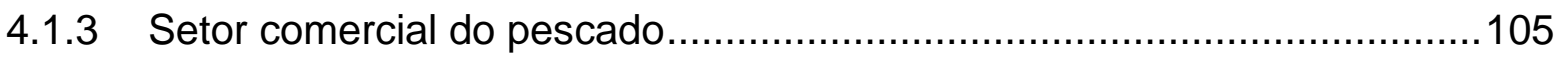

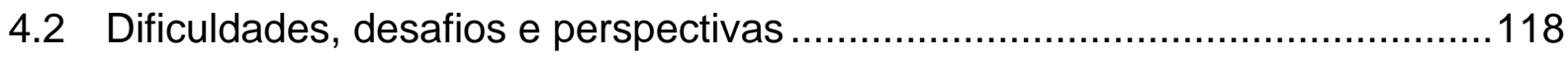

4.2.1 O setor pesqueiro em estado de sobrepesca ....................................119

4.2.1.1 O caso da sardinha-verdadeira ....................................................119

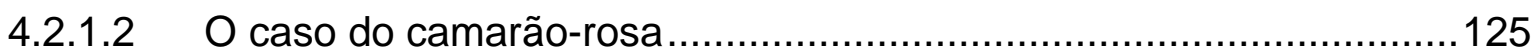

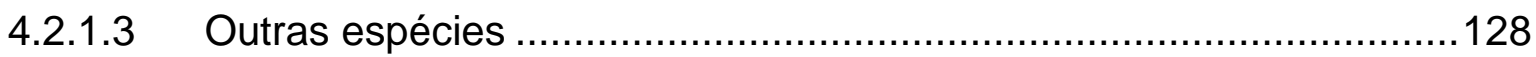

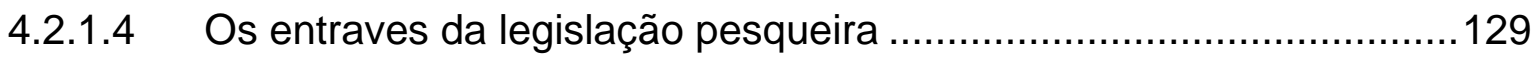

4.2.1.5 Sugestões para o ordenamento do setor ........................................130

4.2.2 As dificuldades enfrentadas pela aquicultura .......................................136

4.2.2.1 Sugestões para melhoramento do setor aquícola ............................142

4.2.3 A questão da qualidade higiênico-sanitária do pescado comercializado ..144

4.2.3.1 Publicações sobre as condições higiênico-sanitárias do pescado

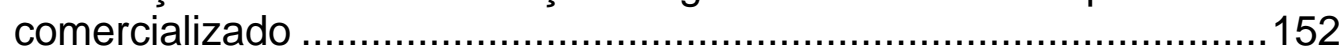

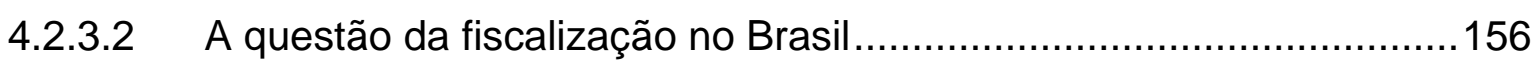

4.2.3.3 Sugestões para a oferta de pescado com melhor qualidade higiênico-sanitária ao consumidor 
4.2.4 A escassez de informações publicadas e as dificuldades na obtenção de dados sobre o complexo agroindustrial do pescado

4.2.4.1 Sugestões para a geração e divulgação de dados ..............................161

4.2.5 O baixo consumo de pescado no Brasil.................................................163

4.2.5.1 Sugestões para o aumento do consumo de pescado ........................168

4.2.6 Síntese dos entraves existentes ao complexo agroindustrial do

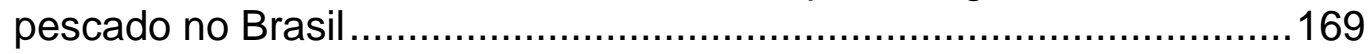

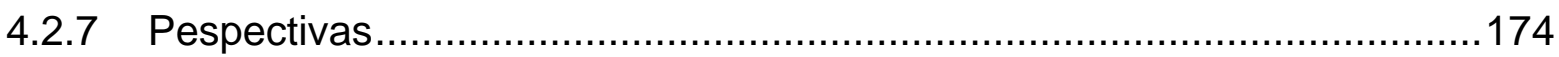

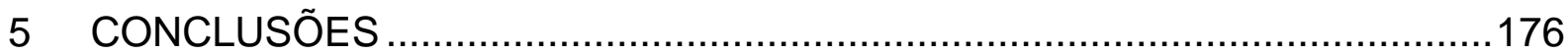

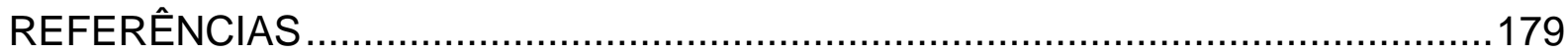

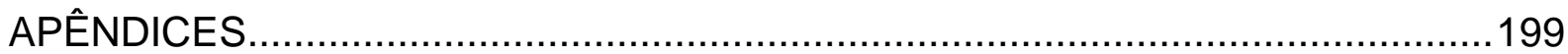

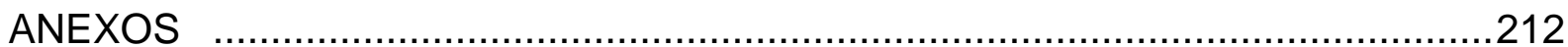




\section{INTRODUÇÃO}

Os alimentos de origem animal constituem uma importante fonte nutricional para o homem devido às suas características proteicas. Contudo, tais alimentos não são completamente isentos de risco à saúde do consumidor (GERMANO; GERMANO, 2001). A Rome Declaration on World Food Security e o World Food Summit Plan of Action, realizados pela Food and Agriculture Organization of the United Nations (FAO), estabeleceram trajetórias que devem ser seguidas a fim de atingir a segurança alimentar em todos os níveis, do individual ao mundial. É dito que a segurança alimentar existe quando, a todo o momento, as pessoas têm acesso físico e econômico a alimentos seguros, nutritivos e suficientes para que satisfaçam suas necessidades dietéticas e preferências alimentares, para que tenham uma vida ativa e saudável (FAO, 1996).

De acordo com Ford (2003), o conceito de segurança alimentar é amplo e integrado e, para atingir seu objetivo, deve-se promover a produtividade, enfrentar a vulnerabilidade e o risco, assegurar os padrões de inocuidade e fornecer à população alimentos nutritivos, desafiar as desigualdades causadas pela falta de oportunidades que servem como obstáculo ao acesso, proteger os direitos dos grupos vulneráveis, desenvolver sistemas de vida sustentáveis, além de sempre reconhecer como direito básico o valor intrínseco do melhoramento das capacidades humanas.

Sendo o Brasil o maior produtor e exportador mundial de produtos agropecuários, dentre eles soja, suco de laranja, café, açúcar e algodão, além dos produtos de origem animal, o país apresenta grande responsabilidade em relação à segurança alimentar. Em 2006, o país era o segundo maior produtor e o maior exportador de soja no mundo; o maior produtor e exportador mundial de suco de laranja, café e açúcar e o quinto maior produtor e exportador de algodão no mundo (COUNCIL; HANRAHAN, 2006). Em relação aos produtos de origem animal, no cenário mundial, o país possui o segundo maior rebanho de bovinos de corte, é o quarto maior produtor e primeiro exportador de carne bovina; na avicultura de corte é o terceiro maior produtor e primeiro exportador de carne de aves; na suinocultura ocupa o 
quarto lugar em relação ao rebanho, produção e exportaçãoo de carne suína (ANUALPEC, 2006). Apesar do elevado potencial para a produção de pescado (BRASIL, [2008?a]), de acordo com a FAO, o Brasil nem sequer aparece dentre os dez maiores produtores (FAO, 2007).

A aquicultura brasileira é considerada como uma atividade em desenvolvimento. A redução da produção observada na pesca extrativista e o desenvolvimento da aquicultura ampliam as perspectivas para a consolidação dessa atividade como o principal setor produtivo fornecedor de proteína animal em médio e longo prazo. Porém, o sistema agroindustrial do pescado ainda não está completamente coordenado, convivendo com pontos de estrangulamento e entraves, o que dificulta a sua consolidação como setor produtivo (FIRETTI et al., 2006).

A atual valorização do pescado, devido às suas qualidades nutricionais, tem contribuído para um aumento na demanda do mercado interno. O potencial para o crescimento do setor é elevado, uma vez que o consumo brasileiro médio anual de pescado é de apenas 6,8 $\mathrm{Kg}$ per capita (BRASIL, [2008?a]). Em termos comparativos, países industrializados apresentavam, em 2003, um consumo médio anual per capita de 29,7 Kg (FAO, 2007). Segundo Wiefels (2003), o Brasil apresenta condições plenas para elevar o consumo anual de pescado para $30 \mathrm{Kg}$ per capita.

Estudos relacionados aos sistemas agroalimentares fornecem subsídios importantes, tanto ao setor público quanto ao setor privado, porque podem fomentar desde estratégias e campanhas de marketing empresariais até a formulação de políticas industriais públicas e privadas (BATALHA, 1997). Outro ponto de importância, destacado por Zylbersztajn (2000a), é a redução dos custos de transação das formas contratuais, possibilitando o desenho de contratos mais eficientes.

São poucos os estudos realizados sobre o sistema agroalimentar do pescado no Brasil. Em nível nacional, apenas foi encontrado o trabalho de Soares (2007), que caracterizou o mercado interno para o pescado, identificando as principais potencialidades e restrições para o aumento da oferta, enquanto que alguns poucos 
estudos regionais foram identificados, como os de Martins e Martins (1999), Chaves, Pichler e Robert (2002), Castro et al. (2005), Dutra, Azevedo e Elias (2008), que serão discutidos posteriormente. Dessa forma, fica evidente a carência de informações técnico-científicas sobre esse segmento produtivo.

É sob esse contexto que o presente trabalho tem como objetivo geral a descrição do complexo agroindustrial do pescado no Brasil, tendo em vista a identificação dos principais pontos de estrangulamento do setor e a análise da atuação governamental perante tais problemas. Já em relação aos objetivos específicos, este trabalho visa:

I) Identificar e descrever os integrantes do complexo agroindustrial do pescado no Brasil;

II) Identificar e caracterizar as principais dificuldades existentes no setor;

III) Analisar a atuação dos órgãos e serviços oficiais junto a esses problemas;

IV) Propor sugestões para melhorar a atuação governamental junto às dificuldades identificadas, objetivando a promoção e o desenvolvimento desse segmento produtivo, bem como a segurança alimentar.

Partindo da constatação de que o setor produtivo de pescado não está bem caracterizado, devido à escassez de trabalhos sobre o segmento, e que dessa forma a elaboração de políticas públicas fica prejudicada, o presente trabalho pretende responder às seguintes questões:

a) Quais são as características do complexo agroindustrial do pescado no Brasil?

b) Como os órgãos e serviços oficiais atuam em relação às principais dificuldades e entraves vivenciados pelos agentes do setor?

Para tal, a Revisão de Literatura aponta seis importantes tópicos que servem como base teórica para a pesquisa. Primeiramente, o pescado é apresentado através da descrição das características nutricionais, do processo de deterioração e das alterações sofridas pelo mesmo nesse processo. A seguir, o setor produtivo mundial 
é descrito, desde a produção até o comércio. O tópico seguinte refere-se à descrição das características do Brasil, mostrando as potencialidades geográficas do país para o setor aquícola e pesqueiro. Os fundamentos teóricos relacionados aos estudos dos sistemas agroalimentares são abordados na sequência, destacando a importância desse tipo de estudo para o desenvolvimento das cadeias produtivas. Posteriormente, são apresentados alguns trabalhos sobre os sistemas agroindustriais no Brasil e em outros países, tendo como foco o pescado, a fim de verificar a abordagem de cada projeto e os resultados obtidos. Por fim, são apresentados os órgãos e serviços oficiais que administram o complexo agroindustrial do pescado no Brasil e as respectivas competências dos mesmos perante o setor.

Após a apresentação da metodologia utilizada no trabalho, o capítulo Resultados e Discussão descreve o complexo agroindustrial do pescado no Brasil e, a partir daí, os principais entraves identificados são discutidos, tendo em vista a atuação dos órgãos reguladores para o desenvolvimento do setor.

Por fim, nas Conclusões, são abordados os principais pontos referentes à situação atual do sistema agroindustrial do pescado no Brasil, dificuldades enfrentadas por seus agentes, ações dos seviços oficiais, desafios ao desenvolvimento do setor e perspectivas para o futuro. 


\section{REVISÃO DE LITERATURA}

\subsection{O PESCADO COMO ALIMENTO}

Pescado é o termo genérico que compreende os peixes, crustáceos, moluscos, anfíbios, quelônios e mamíferos de água doce ou salgada, usados na alimentação humana (BRASIL, 1952). É uma fonte proteica tão importante para o homem quanto às demais, correspondendo a $15,6 \%$ do total de proteína animal consumida mundialmente (CATO, 1998). A variedade de peixes é numerosa e muito apreciada no consumo humano, e por esse motivo, o pescado tem grande valor econômico (SALINAS, 2002).

Diversos estudos comprovaram as vantagens do consumo de pescado, principalmente pela presença dos ácidos graxos da série ômega-3. Os principais benefícios já relatados são a redução de incidência de doenças cardiovasculares, como o infarto de miocárdio, doenças coronárias, arritmia e a parada cardíaca; redução progressiva da aterosclerose em pacientes com alterações coronárias; auxilia em dietas de redução de peso; auxilia no tratamento de alterações mentais, como alteração de humor; entre outros (KRIS-ETHERTON; HARRIS; APPEL, 2002; MOZAFFARIAN et al., 2003; PARRA et al., 2007; ROSS; SEGUIN; SIESWERDA, 2007; LEE et al., 2008).

Devido à quantidade mínima de tecido conjuntivo presente na musculatura (GERMANO; GERMANO; OLIVEIRA, 2001), a carne de peixe apresenta maior digestibilidade quando comparada com a bovina e a de aves (SALINAS, 2002), sendo então recomendada para pessoas de todas as idades (RUITER, 1995). Além disso, é fonte de proteínas de elevado valor biológico (SALINAS, 2002), fornecendo todos os aminoácidos essenciais (NETTLETON, 1985; RUITER, 1995). Inversamente ao que ocorre nas carnes de outras espécies animais, a gordura do pescado é composta predominantemente por ácidos graxos poliinsaturados (SALINAS, 2002). Dentre esses, os principais são o eicosapentaenóico e o docosaexanóico, ambos da série ômega-3 que, no homem, estão presentes nas 
células nervosas, retina, cérebro e espermatozóides (NETTLTON, 1985; MERCK, 2005). O conteúdo vitamínico é muito semelhante ao conteúdo das carnes vermelhas (SALINAS, 2002). Quase todos os minerais estão presentes no pescado, com destaque para o potássio, cálcio, zinco, sódio, fósforo, magnésio, ferro, cobre, cobalto, enxofre, cloro, flúor e iodo (OGAWA; MAIA, 1999).

O pescado é, geralmente, mais perecível que outros animais utilizados para a alimentação, mesmo quando mantido sob condições de refrigeração. Em função disso, a qualidade do produto é alterada desde a partir da retirada do animal do ambiente aquático (POTTER, 1989). A metodologia empregada no armazenamento do pescado afeta diretamente as suas características, principalmente as sensoriais e de composição (HUSS, 1995; MARTINSDÓTTIR, 2002). A fim de manter por maior tempo possível as melhores condições de frescor e a qualidade higiênico-sanitária nas fases subsequentes das cadeias produtivas, após a atividade de captura ou despesca, o produto deve ser mantido e transportado sempre sob ação do gelo e/ou refrigeração (RODRÍGUEZ et al., 2004). A manipulação higiênica também assume grande importância para a qualidade higiênico-sanitária dos produtos (GERMANO; GERMANO; OLIVEIRA, 2001).

O pescado apresenta características que facilitam sua deterioração, dentre as quais o pH pouco ácido, elevada atividade de água nos tecidos, altos teores de nutrientes disponíveis e de fosfolipídios e a ação enzimática deteriorante acelerada, fazendo com que esse seja um dos produtos de origem animal mais susceptível ao processo de decomposição (BRESSAN; PEREZ, 2001; VIEIRA, 2004). Este processo ocorre pela ação conjunta de processos físico-químicos, microbiológicos e autolíticos (ÓLAFSDÓTTIR et al., 1997).

A microbiota do pescado vivo e saudável está concentrada em algumas regiões, como no trato digestivo e no muco de superfície, enquanto outras apresentam-se estéreis, como a musculatura. Com a morte do animal, os micro-organismos atacam os constituintes dos diversos tecidos do organismo, atingindo gradativamente as regiões anteriormente estéreis (POTTER, 1989). As bactérias psicrotolerantes e as mesófilas com atividade proteolítica desempenham importante função no processo de putrefação, levando a alterações de coloração, aroma e sabor da carne do 
pescado (KIETZMANN et al., 1974). Uma vez que essas bactérias vivem em animais pecilotérmicos e em baixas temperaturas oceânicas, elas estão bem adaptadas às baixas temperaturas e continuam a se multiplicar sob condições normais de refrigeração (POTTER, 1989).

Com a retirada dos animais do ambiente aquático, esses sufocam até a morte. Parte do estoque de glicogênio existente na musculatura é utilizada, e uma menor quantidade será convertida em ácido lático após a morte. Com menor formação de ácido lático, o pH fica pouco ácido, prejudicando a preservação do pescado por não limitar de maneira adequada a multiplicação bacteriana. Esse é um fator importante para a preservação dos produtos derivados do pescado, em contraste ao que ocorre em outras espécies. Os bovinos, por exemplo, passam por um período de descanso anterior ao abate a fim de repor as reservas de glicogênio (POTTER, 1989).

Outra característica importante para a deterioração do pescado é a associação de fosfolipídios ricos em trimetilamina à gordura. Os animais vivos ou recém retirados da água apresentam pouco ou nenhum odor. Com o passar do tempo, por ação bacteriana ou de enzimas endógenas, ocorre a separação da trimetilamina dos fosfolipídios, o que apresenta uma forte relação com o odor do pescado. Esse odor causado pela liberação da trimetilamina é posteriormente potencializado pelo odor produzido por produtos da degradação da gordura, que é facilmente oxidada por ser altamente insaturada, resultando na rancidez do pescado (POTTER, 1989).

Diversas alterações físicas, químicas e organolépticas que ocorrem durante a deterioração do pescado podem ser detectadas e utilizadas como indicativo da qualidade dos produtos. As principais alterações encontradas são a desidratação e retração dos tecidos, sendo bem observados nos olhos; o aumento no valor de $\mathrm{pH}$, devido à alteração na concentração de íons de hidrogênio livre, como consequência da ação bacteriana e enzimática; alterações na condutividade elétrica da musculatura, por variação de pH; aumento da concentração de trimetilamina, por redução do óxido de trimetilamina por ação bacteriana; aumento da concentração de substâncias nitrogenadas voláteis e de aminoácidos livres e aminas, devido à degradação do pescado; aumento da concentração de peróxidos, ácidos, cetonas, aldeídos e derivados do carbono, devido à degradação da gordura; alterações de 
sabor e odor, por degradação de gordura, formação de trimetilamina, ação bacteriana, entre outros (KIETZMANN et al., 1974).

Assim como outros alimentos, o pescado pode ser veículo de transmissão de diversos agentes causadores de doenças. Dentre os principais agentes bacterianos, são destacados o Staphylococcus aureus, Clostridium botulinum, Salmonella spp, Escherichia coli, Vibrio parahaemolyticus, Aeromonas spp, Vibrio vulnificus e o Vibrio cholerae (VIEIRA, 2004). Em relação aos endoparasitas, pode-se citar o trematódeo Ascocotyle (Phagicola) longa e os nematóides da família Anisakidae, gêneros Contracaecum, Phocanema e Anisakis (GERMANO; GERMANO; OLIVEIRA, 2001). Dentre os agentes causadores de intoxicação, vale ressaltar o ácido domóico, a ciguatoxina, o ácido okadaico, a brevetoxina, a saxitoxina, a tetrodotoxina e a histamina (JOHSON; SCHANTZ, 2002).

Em trabalhos como o de Soares et al. (1998), foram detectados níveis de substâncias indicadoras do grau de deterioração, como bases voláteis, histamina e gás sulfídrico, acima do previsto pela legislação brasileira; Silva et al. (2002), onde foi constatada a presença de Escherichia coli e Salmonella sp acima dos padrões legais; e Prado e Capuano (2006), no qual foi verificada a presença de nematóides em quantidade superior ao regulamentado, exemplificam a comercialização do pescado de baixa qualidade higiênico-sanitária no Brasil. Além da ameaça à saúde pública (TENUTA FILHO, 2003), a existência desses problemas sanitários faz com que o consumidor opte por outras fontes proteicas que não o pescado (GAGLEAZZI et al., 2002).

Atualmente, o Brasil apresenta um baixo consumo per capita de pescado quando comparado a países industrializados: 6,8 Kg (BRASIL, [2008?a]) contra 29,7 Kg (FAO, 2007), respectivamente. Além disso, marcantes características do hábito de consumo de pescado pela população brasileira podem ser observadas, como uma maior aquisição pela população do meio rural em todas as regiões do país; marcante regionalização do consumo, com maior obtenção na região Norte; e o hábito de maior consumo pela população de menor renda, quando comparado ao consumo das classes de maior receita (IBGE, 2004a). 


\subsection{O SETOR PESQUEIRO E AQUÍCOLA NO MUNDO}

Até o momento da elaboração deste trabalho, os dados oficiais mais recentes sobre a situação do setor produtivo de pescado no mundo são relativos ao ano de 2006, publicados pela FAO em 2009. Dessa forma, serão apresentadas neste capítulo algumas das infrormações mais relevantes extraídas de tal documento, com a finalidade de descrever o setor no âmbito mundial.

Em 2006, o foram produzidas aproximadamente 143,6 milhões de toneladas de pescado no mundo (Gráfico 1 ), dos quais 110,4 milhões de toneladas $(76,88 \%)$ foram destinadas ao consumo humano, promovendo um suprimento per capita aparente de $16,7 \mathrm{Kg}$, sendo o maior valor registrado até o momento. Desse total produzido, a aquicultura foi responsável por 51,7 milhões de toneladas (36\%), porém, do total destinado ao consumo humano, a aquicultura contribuiu com 51,8 milhões de toneladas (47\%) (FAO, 2009).

\section{Million tonnes}

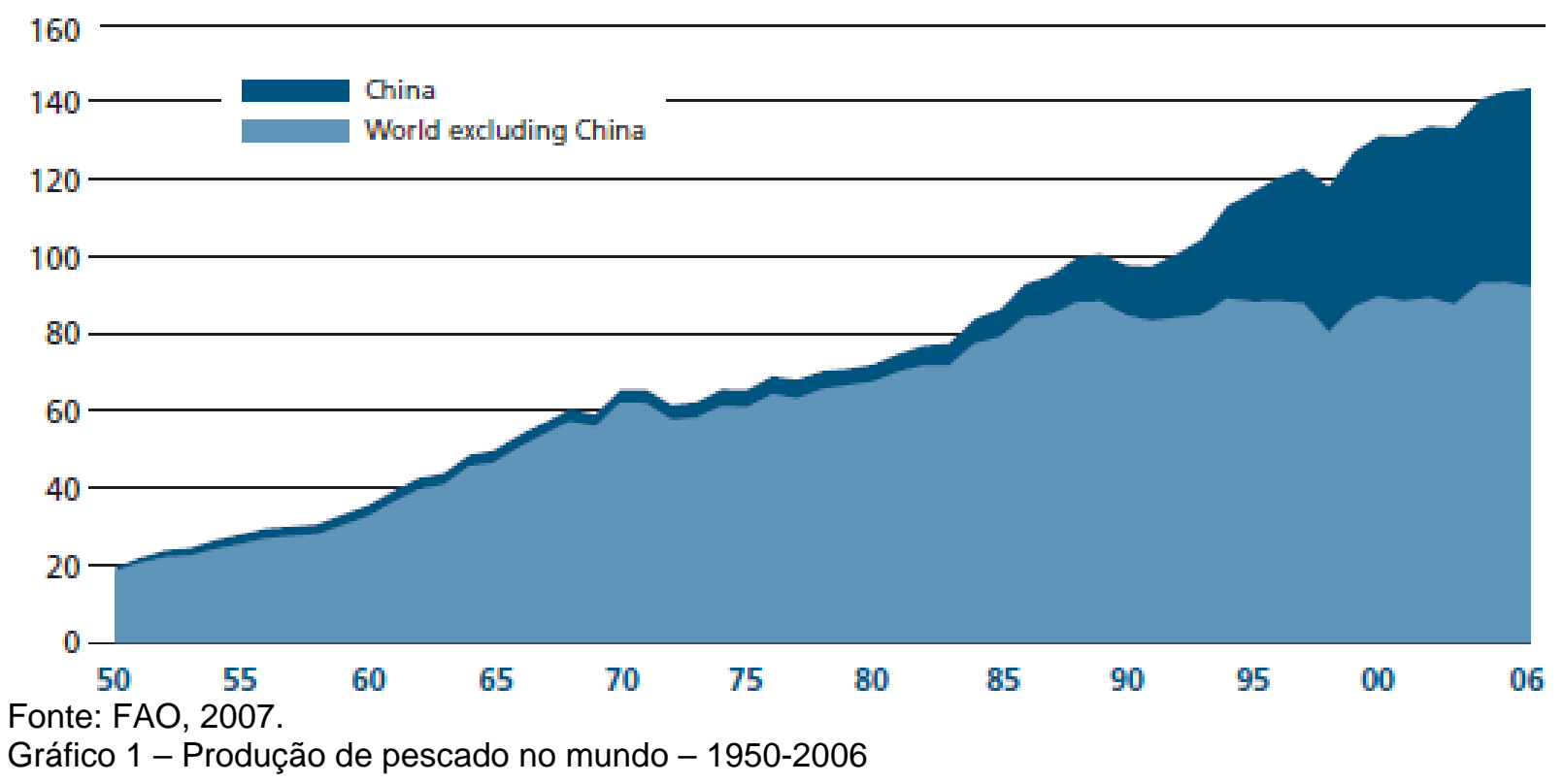

A China lidera como o país de mair produção de pescado no mundo, produzindo 51,5 milhões de toneladas em 2006 (35,86\% da produção mundial total), sendo a 
aquicultura responsável por 34,4 milhões de toneladas $(66,79 \%$ da produção total chinesa), promovendo um suprimento doméstico de 29,4Kg per capita (FAO, 2009).

O setor extrativista atingiu produção de 92 milhões de toneladas em 2006 (64,06\% da produção mundial total) (Gráfico 2), com valor de venda estimado em US\$91,2 bilhões. A produção deste segmento manteve-se relativamente estável durante a década de 90. A pesca marinha produziu 82 milhões de toneladas $(57,10 \%$ da produção mundial total). A China, o Peru e os estados Unidos foram os países que mais produziram pescado através da atividade extrativista em 2006 (Gráfico 3) (FAO, 2007).

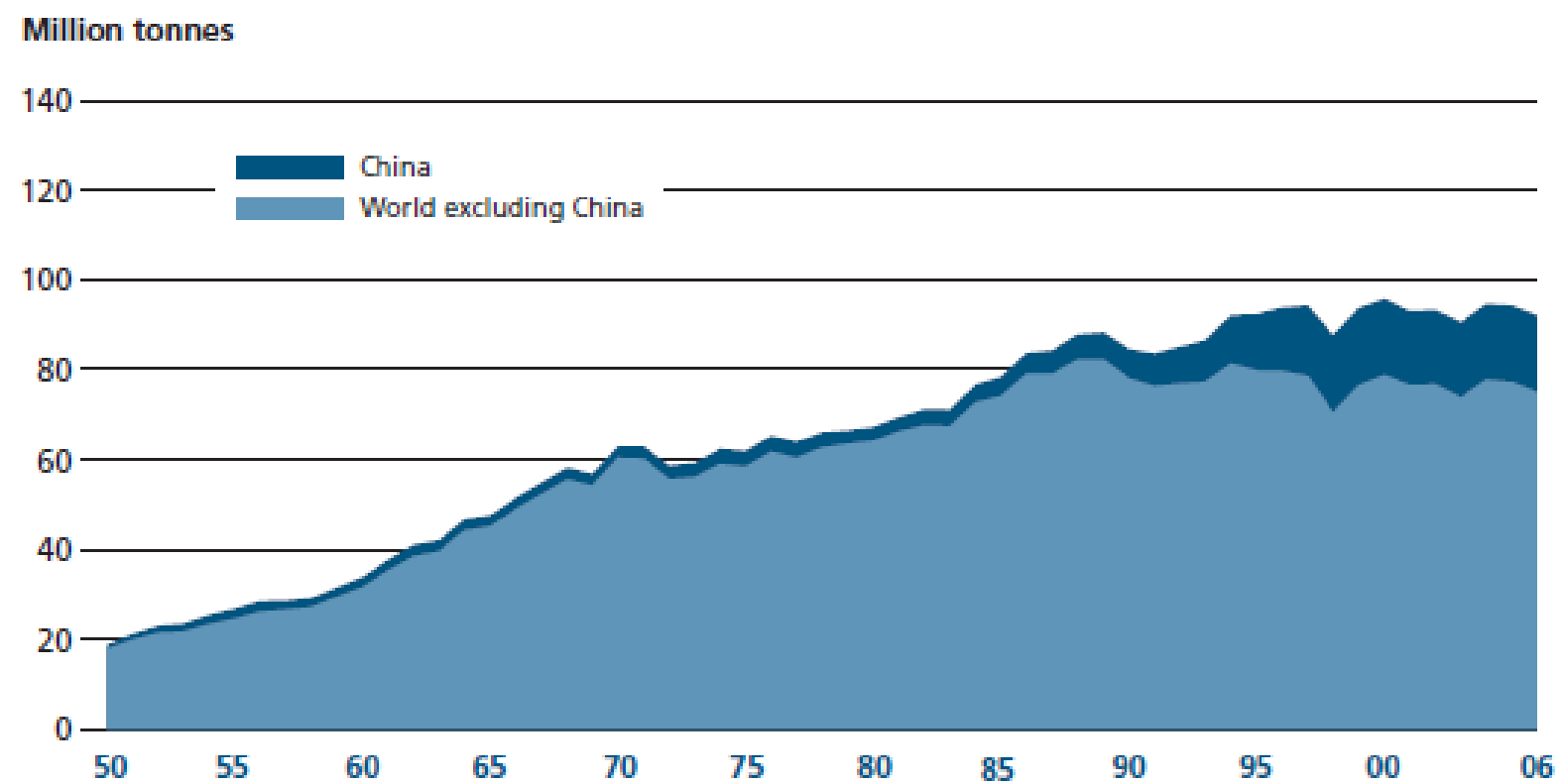

Fonte: FAO, 2007.

Gráfico 2 - Produção pesqueira mundial - 1950-2006 


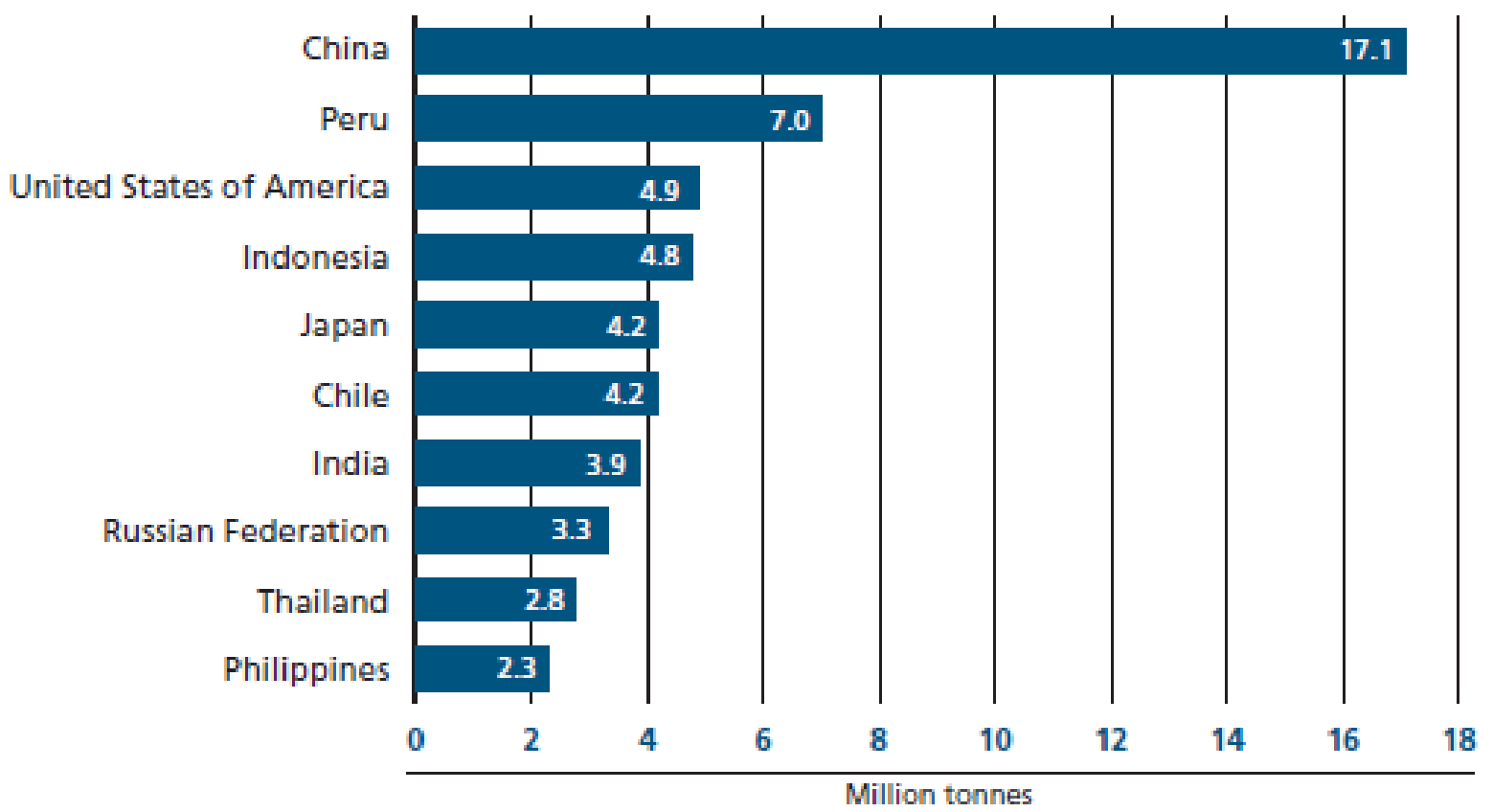

Fonte: FAO, 2007.

Gráfico 3 - Os dez maiores produtores na pesca marinha e continental - 2006

Atualmente, a aquicultura é o setor de produção animal para o consumo humano que cresce mais rapidamente, apresentando crescimento médio do suprimento per capita de 6,9\% ao ano desde 1970 (FAO, 2009). Comparativamente, entre 1970 e 2004, a pesca apresentou um crescimento médio mundial de suprimento per capita de $1,2 \%$ ao ano, enquanto os demais setores de produção terrestre, 2,8\% ao ano (FAO, 2007). Em 2006, a aquicultura foi responsável pela comercialização de 51,7 milhões de toneladas ( $36 \%$ da produção mundial total), aproximadamente US $\$ 78,8$ bilhões (FAO, 2009).

Desde a década de 70, o número de pescadores e aquaculturistas cresceu mais rapidamente do que a população mundial e do que os trabalhadores da agropecuária. Estima-se que em 2006, 43,5 milhões de pessoas trabalhavam como pescadores ou aquaculturistas em período parcial ou integral, e outros 4 milhões como empregados ocasionais. A aquicultura empregou aproximadamente 9 milhões de pessoas em 2006 (20,69\% da mão-de-obra mundial). Neste mesmo ano, a China tinha a maior força trabalhadora do mundo nesse segmento, contando com 8,1 milhões de operários (28,96\% da mão-de-obra mundial). Estima-se que o setor secundário, composto pelas indústrias e empresas que prestam a serviços a elas, empregou 170 milhões de trabalhadores em 2006 (FAO, 2007). 
Em 2004, a frota pesqueira mundial contou com 4 milhões de unidades, das quais 1,3 milhões (32,50\%) eram embarcações com convés e 2,7 milhões (67,50\%) eram embarcações abertas. Enquanto que virtualmente todas as embarcações com convés eram mecanizadas, aproximadamente um terço das embarcações abertas tinha motores, enquanto que as demais eram operadas por remos e velas (FAO, 2007).

Do total produzido em 2006, aproximadamente 110 milhões de toneladas foram utilizadas para a alimentação humana. Desse total, aproximadamente 53 milhões de toneladas $(48,5 \%)$ foram comercializadas nas formas viva e fresca, que geralmente são as formas de produto preferidas e de maior valor. Aproximadamente 77 milhões de toneladas (54\% da produção mundial total) passam por algum tipo de processamento, dos quais 57 milhões de toneladas (74\% do total processado) são utilizados na produção de produtos para alimentação humana nas formas congelada, curada e em conserva. O resfriamento é o principal método de processamento empregado no beneficiamento do pescado para o consumo humano, seguido pela conserva e a cura (50\%, 29\% e 21\% do total industrializado para o consumo humano, respectivamente). Aproximadamente 33 milhões de toneladas do total produzido pelo setor primário foram destinadas à produção de produtos não alimentícios, particularmente as rações para peixes e o óleo animal (FAO, 2009).

O comércio mundial de pescado e produtos derivados atingiu recorde em 2006, totalizando US\$85,9 bilhões em valores de exportação, o que representa um crescimento de $62,7 \%$ em relação ao ano de 1996. Desde 2002, a China foi o país com o maior volume de exportação de pescado e produtos derivados, comercializando aproximadamente US\$9 bilhões em 2006. Neste mesmo ano, os países com maior volume de exportação foram a China, Noruega, Tailândia, estados Unidos e Canadá; já os maiores importadores foram o Japão, estados Unidos, Espanha, França e Itália. O camarão é a commodity comercializada de maior importância em termos de valor, respondendo por $17 \%$ do pescado comercializado (FAO, 2009). 


\subsection{AS CARACTERÍSTICAS DO BRASIL PARA O SETOR PESQUEIRO E AQUÍCOLA}

O Brasil possui elevado potencial para o setor pesqueiro e aquícola, uma vez que apresenta algumas características de importância para ambos os segmentos, como um litoral com $8.500 \mathrm{~km}$ de extensão, um área marítima aproximada de 3.500 .000 $\mathrm{km}^{2}$ de Zona Econômica Exclusiva (ZEE), os 5,5 milhões de hectares de reservatórios de água doce (aproximadamente 12\% da água doce disponível no planeta), o clima favorável ao crescimento de organismos cultivados, a disponibilidade de terras para produção, a mão-de-obra abundante e a crescente demanda por pescado no mercado interno (SEAP; GEOBRASIL, 2002).

Para compreender todo este potencial, é importante conhecer algumas das características gerais dos recursos hídricos de cada região brasileira. De acordo com o Instituto Brasileiro de Geografia e Estatística (IBGE ${ }^{1}, 1988$ apud DIEGUES, 2002, p. 14), o Brasil está subdividido em 5 bacias hidrográficas: Bacia Amazônica, Bacia Tocantins-Araguaia, Bacia Platina (subdividida em Bacia do Paraguai, Bacia do Uruguai e Bacia do Paraná), Bacia do São Francisco e as Bacias Secundárias (que são as Bacias do Nordeste, do Leste e do Sul-Sudeste) (Figura 1).

\footnotetext{
${ }^{1}$ IBGE. INSTITUTO BRASILEIRO DE GEOGRAFIA E ESTATÍSTICA. Anuário estatístico do Brasil: 1987/1988. Rio de Janeiro: IBGE, 1988, v. 48, 736 p.
} 


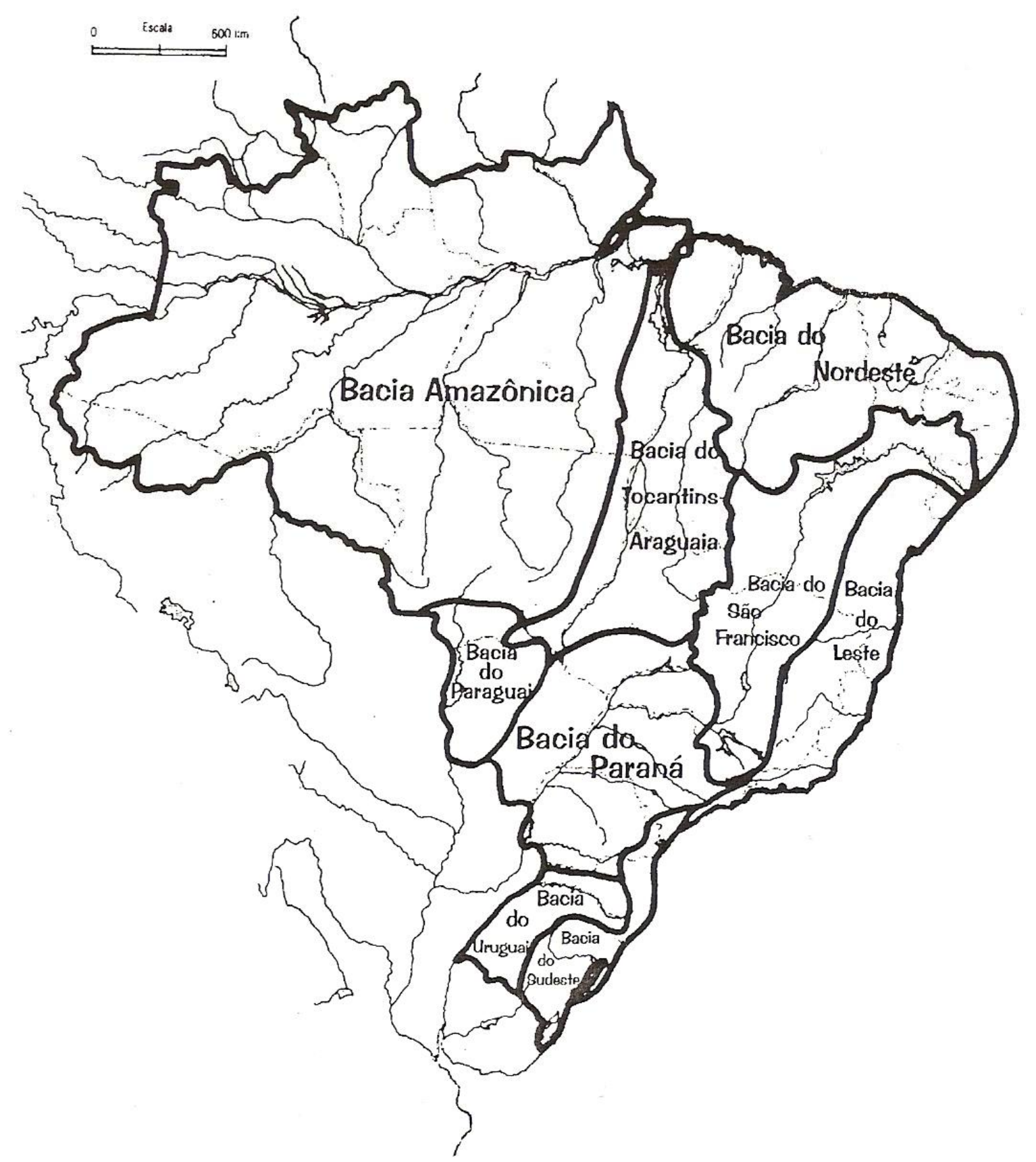

Fonte: IBGE (1988) apud DIEGUES (2002).

Figura 1 - Bacias hidrográficas brasileiras

A Bacia Amazônica situa-se ao sul do Planalto das Guianas, ao norte do Planalto Central, a leste da Cordilheira dos Andes e a oeste do Oceano Atlântico, drenando terras do Brasil e mais oito países latino-americanos, totalizando uma área de 6.500.000 milhões de $\mathrm{Km}^{2}$, dos quais 3.984.487 $\mathrm{Km}^{2}(61,30 \%)$ estão no Brasil, ocupando os estados do Acre, Amazonas, Roraima, Pará, Amapá, Rondônia e a porção noroeste do estado de Mato Grosso, o que representa cerca de 47\% de todo o território nacional. Tem como principal rio o Amazonas, que nasce na vertente 
oriental da Cordilheira dos Andes, percorre $6.518 \mathrm{Km}$ e deságua no Oceano Atlântico. A pesca figura entre as principais atividades econômicas da região (DIEGUES, 2002).

Distribuída pelos estados do Pará, Maranhão, Tocantins, Goiás e Mato Grosso, a Bacia do Tocantins-Araguaia ocupa uma área de $803.250 \mathrm{Km}^{2}$, cerca de $9 \%$ do território nacional, destacando os Rios Tocantins e Araguaia. A pesca também é uma importante atividade econômica da região (DIEGUES, 2002).

A Bacia do São Francisco drena uma área de $631.133 \mathrm{Km}^{2}$, tendo como principal coletor o Rio São Francisco, distribuída entre os estados do Sergipe, Alagoas, Pernambuco e parte dos territórios da Bahia, Goiás, Minas Gerais e o Distrito Federal (DIEGUES, 2002).

Sendo subdividida em três bacias menores, a Bacia Platina apresenta a atividade pesqueira como importante atividade da região do Pantanal (DIEGUES, 2002).

A Bacia do Rio Uruguai, uma das divisões da Bacia Platina, apresenta como principal coletor o Rio Uruguai, que marca o limite territorial entre o Brasil e Argentina e o Brasil e Uruguai. Sua porção brasileira ocupa cerca de $178.235 \mathrm{Km}^{2}$ (DIEGUES, 2002).

Ocupando os estados de Goiás, Mato Grosso do Sul, Minas Gerais, Paraná e São Paulo, a Bacia do Paraná, outra divisão da Bacia Platina, totaliza $891.309 \mathrm{Km}^{2}$, tendo como principal coletor o Rio Paraná (DIEGUES, 2002).

A terceira divisão da Bacia Platina, a Bacia do Paraguai drena uma área de 345.701 $\mathrm{Km}^{2}$ dos estados de Mato Grosso e Mato Grosso do Sul, tendo como principal coletor o rio Paraguai (DIEGUES, 2002).

A Bacia do Nordeste, uma das três Bacias Secundárias Brasileiras, ocupa uma área de $884.835 \mathrm{Km}^{2}$, ocupando os estados do Piauí, Ceará, Rio Grande do Norte e parcialmente os estados do Maranhão, Paraíba, Pernambuco e Alagoas. A pesca, 
principalmente a estuarina e costeira, é ocupa um papel de destaque na economia da região (DIEGUES, 2002).

Ocupando parte dos estados de Sergipe, Bahia, Minas Gerais, Espírito Santo, Rio de Janeiro e o litoral norte de São Paulo, a Bacia do Leste ocupa uma região de $569.310 \mathrm{Km}^{2}$, tendo a atividade pesqueira como uma importante atividade econômica da região (DIEGUES, 2002).

A Bacia do Sul, a terceira Bacia Secundária Brasileira, ocupa uma região de 223.688 $\mathrm{Km}^{2}$, ocupando parte dos estados de São Paulo, Paraná, Santa Catarina e Rio Grande do Sul. Nas regiões costeiras e estuarinas, a atividade pesqueira merece destaque econômico na região (DIEGUES, 2002).

A região Norte e Centro-oeste do Brasil, ocupadas pelas Bacias Amazônica, do Tocantins-Araguaia e do Paraguai, detêm a maior disponibilidade de corpos de água, concentrando cerca de $89 \%$ do potencial de águas superficiais do país. A região Centro-oeste ainda apresenta o Pantanal, uma das maiores regiões úmidas do mundo, com cerca de $140.000 \mathrm{Km}^{2}$. A região Nordeste, ocupada pela Bacia do Nordeste e parte das Bacias do São Francisco e do Leste, apresenta um grande número de açudes particulares, armazenando cerca de 1,5 bilhões $\mathrm{m}^{3}$ de água (OSTRENSKY; BOEGER; CHAMMAS, 2008).

As áreas de projetos de irrigação espalhadas pelo Brasil são consideradas um grande potencial para a expansão da aquicultura, por poder consorciar a produção agrícola e aquícola. Em 2001, havia 3.113 milhões de hectares de áreas irrigadas para a agricultura e um potencial de 14,6 milhões de hectares disponíveis para a agricultura irrigada (DIEGUES, 2006).

De acordo com o Departamento de Pesca e Aquicultura ${ }^{2}$ da FAO, toda esta área ocupada pelas bacias e lagos brasileiros é estimada em 8 milhões de quilômetros quadrados, tendo um potencial produtivo de aproximadamente 600 mil toneladas por ano.

\footnotetext{
${ }^{2}$ Fisheries and Aquaculture Department.
} 
Já em relação ao potencial costeiro, é importante conhecer as características das correntes que banham o litoral brasileiro. A Corrente Sul-Equatorial, que atravessa o Oceano Atlântico desde a costa Africana, atinge o Brasil na altura de João PessoaPB, bifurcando-se em duas direções: uma que flui para o sul, formando a Corrente do Brasil, e outra que flui para noroeste, formando a Corrente Norte do Brasil (Figura 2). Ambas apresentam como características comuns a elevada salinidade e temperatura e as baixas quantidades de sais nutrientes. Isso leva a uma baixa produtividade das regiões banhadas por tais correntes, uma vez que a elevada profundidade da termoclina (camada intermediária do oceano, caracterizada por uma elevada taxa de queda de temperatura conforme o aumento da profundidade do mar) dificulta a distribuição destes sais nutrientes até a zona eufótica (zona da superfície até $80 \mathrm{~m}$ de profundidade, onde ocorre a produção primária pesqueira) (BRASIL, 1996). 


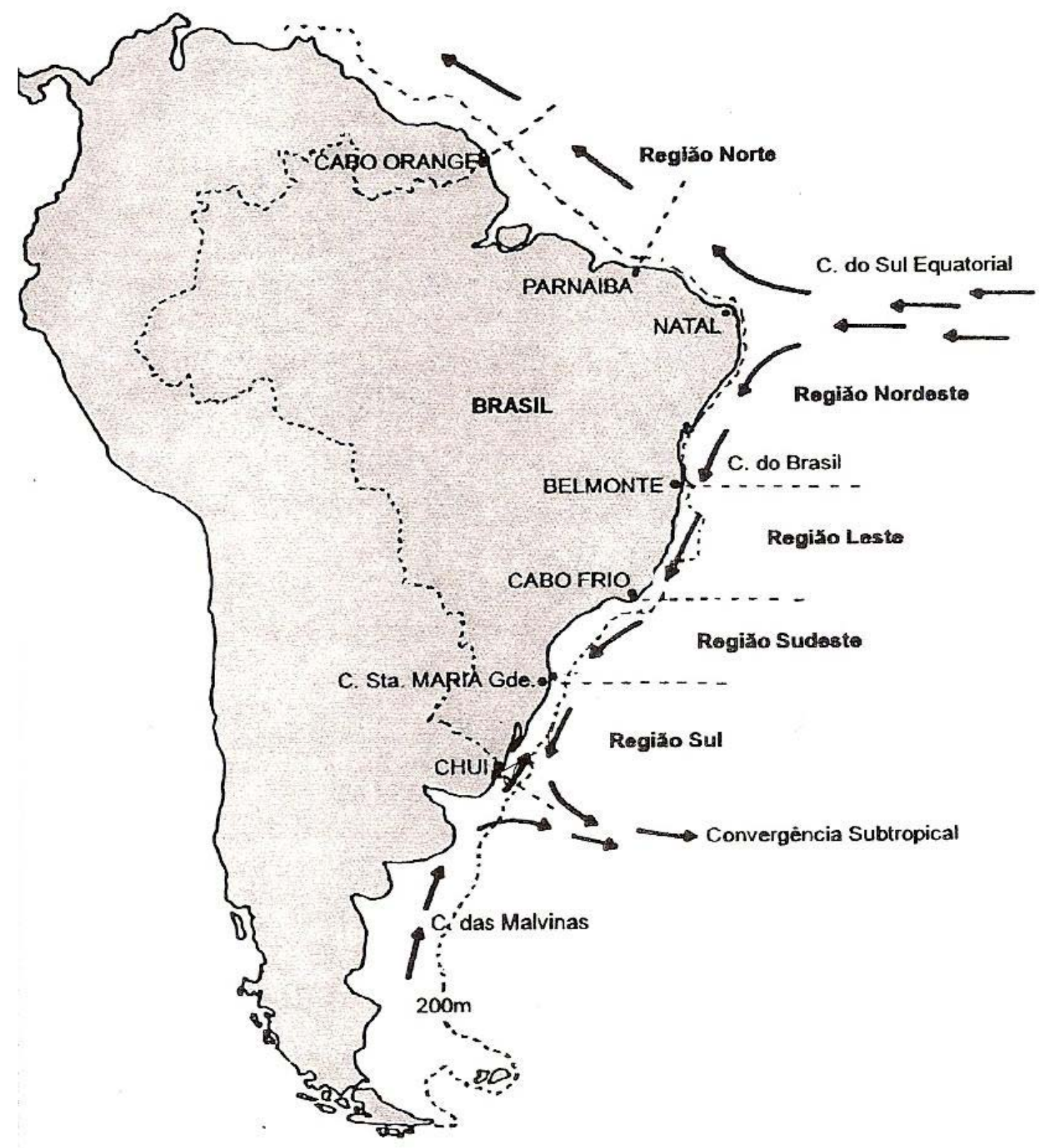

Fonte: BRASIL, 1996.

Figura 2 - Correntes marítimas do Brasil

Duas outras características do litoral brasileiro devem ser conhecidas, pois explicam a produtividade de regiões importantes para o setor pesqueiro. A primeira é o grande volume de água doce despejado pelo Rio Amazonas, que devido à grande quantidade de material em suspensão, fluindo em direção ao Noroeste, faz com que as costas dos estados do Pará e Amapá apresentem elevada produtividade. A segunda característica é a mudança da direção para Sudoeste da Corrente do Brasil, na altura de Cabo Frio-RJ, devido à mudança da linha da costa. Na altura dos 
paralelos $34-36^{\circ}$, essa se encontra com a Corrente das Malvinas, mudando de direção para Leste, formando a Convergência Subtropical. Uma parte da massa de água da Corrente das Malvinas afunda-se na Convergência Subtropical, ocupando a camada inferior da Corrente do Brasil, formando uma massa de água chamada de Água Central do Atlântico Sul, caracterizada por baixa temperatura e salinidade, mas com elevadaconcentração de sais e nutrientes. As regiões Sul e Sudeste são influenciadas direta ou indiretamente por essa massa de água, elevando a produtividade dessas regiões (BRASIL, 1996).

Uma última característica importante sobre a costa brasileira é a ocorrência pouco marcante do fenômeno da ressurgência, tal qual ocorre em outros países, quando as águas oceânicas movem-se do fundo para a superfície, carregando nutrientes importantes que favorecem o desenvolvimento das diversas formas de vida marinha. Tal fenômeno é expressivo, por exemplo, na costa Oeste dos estados Unidos, no Chile e ao longo da região Equatorial (Figura 3) (ISAACS, 1971).

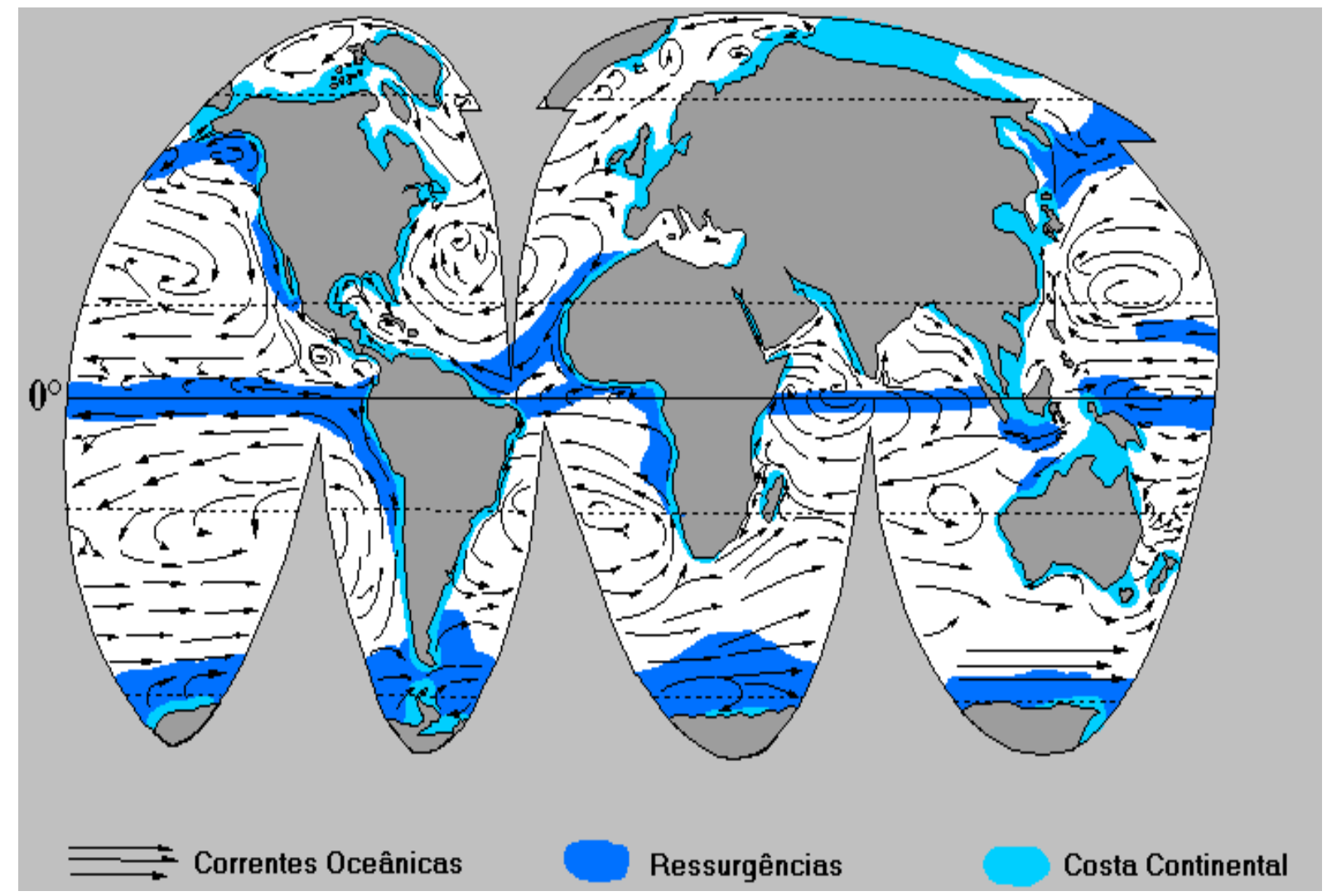

Fonte: ESPENSADE (1950) apud ODUM et al. (1987).

Figura 3 - Áreas de ressurgência importantes para a pesca e aquicultura 
De acordo com o Departamento de Pesca e Aquicultura da FAO, um perfil das regiões marítimas brasileiras pode ser traçado, conforme a Tabela 1 (FAO, 2001).

Tabela 1 - Perfil das regiões brasileiras para a pesca marinha

\begin{tabular}{|c|c|c|c|c|}
\hline Região & Perfil & $\begin{array}{c}\text { Potencial de } \\
\text { pesca (mil } \\
\text { toneladas/ano) }\end{array}$ & $\begin{array}{l}\text { Espécies pelágicas } \\
\text { (mil toneladas/ano) }\end{array}$ & $\begin{array}{c}\text { Espécies } \\
\text { demersais (mil } \\
\text { toneladas/ano) }\end{array}$ \\
\hline Norte & $\begin{array}{l}\text { Abundância de peixes } \\
\text { e crustáceos, } \\
\text { beneficiada pela } \\
\text { riqueza de nutrientes } \\
\text { do rio Amazonas e pela } \\
\text { extensão da costa com } \\
\text { grande proporção de } \\
\text { fundo regular }\end{array}$ & $385-485$ & 235 & $150-240$ \\
\hline Nordeste & $\begin{array}{l}\text { Apesar da grande } \\
\text { extensão costeira, a } \\
\text { produção é menos } \\
\text { favorecida pela } \\
\text { salinidade e } \\
\text { temperatura das águas } \\
\text { e pela pequena largura } \\
\text { da plataforma } \\
\text { continental }\end{array}$ & $200-275$ & 100 & $100-175$ \\
\hline Sudeste & $\begin{array}{c}\text { Significante produção } \\
\text { entre Cabo Frio e Ilha } \\
\text { Grande (Rio de } \\
\text { Janeiro), devido à } \\
\text { ressurgência das águas } \\
\text { frias, que favorecem a } \\
\text { disponibilidade de } \\
\text { recursos }\end{array}$ & $265-290$ & 195 & $70-95$ \\
\hline Sul & $\begin{array}{c}\text { Favorecida pela } \\
\text { convergência da } \\
\text { Corrente das Malvinas } \\
\text { e da Corrente do Brasil }\end{array}$ & $550-660$ & 370 & $180-290$ \\
\hline
\end{tabular}

Fonte: FAO, 2001.

Além das características hidrográficas, o Brasil apresenta outras vantagens quando comparado a outros países. Uma delas é a proximidade dos estoques em áreas oceânicas para explotação, como o estoque do atum. Enquanto as embarcações operantes nos portos brasileiros levam algumas poucas horas para chegar nesses estoques, as embarcações de países com grande tradição pesqueira devem navegar mais de 20 mil quilômetros para alcançar as mesmas áreas. Além disso, o país dispõe de muitos portos para a atividade da frota pesqueira e está próximo dos três maiores blocos econômicos e mercados consumidores do mundo. Por fim, existe ainda um grande potencial interno para aumentar a demanda por pescado e 
produtos derivados, uma vez que o país é caracterizado por baixo consumo per capita (FAO, 2001).

Os estudos realizados para o Programa de Avaliação Sustentável dos Recursos Vivos da Zona Econômica Exclusiva Brasileira (REVIZEE) mostraram que o país dispõe de diversos estoques pesqueiros com potencial de explotação. Dos 153 estoques estudados para o programa, 15,7\% poderiam ter sua produção elevada por estarem sub ou não-explotados (4,6\% e 11,1\%, respectivamente), como o ariocó (Lutjanus synaguis) e a cabeçuda (Ctenosciaena gracilicirrhus) no Norte, o cherne (Epinephelus niveatus) e o caçonete (Mustelus canis) no Nordeste, o espadarte (Xiphias gladius) e a chicharra (Decapterus tabl) na região Central, a sardinha-laje (Opisthonema oglinum) e a anchoíta (Engraulis anchoita) no Sudeste e Sul do Brasil, entre outras espécies. Ressalta-se também a importância da realização de estudos prévios à explotação dessas espécies, desenvolvendo o conhecimento relacionado à dinâmica populacional, viabilidade dos estoques à exploração, aos limites sustentáveis e outros pontos de interesse peculiares a cada espécie, de modo a evitar um futuro estado de sobrepesca ou de extinção das mesmas (BRASIL, 2006).

\subsection{SISTEMA AGROALIMENTAR}

Em 1957, Davis e Goldberg ${ }^{3}$ (1957) (apud BATALHA, 1997, p. 25) definiram agribusiness como sendo "a soma das operações de produção e distribuição de suprimentos agrícolas, das operações de produção nas unidades agrícolas, do armazenamento, processamento e distribuição dos produtos agrícolas e itens produzidos a partir deles." Com base nesse trabalho e na publicação de Goldberg (1968), as relações de dependência entre as indústrias de insumos, de produção agropecuária, indústrias de alimentos e o sistema de distribuição não puderam mais ser ignoradas (ZYLBERSZTAJN, 2000b).

\footnotetext{
${ }^{3}$ DAVIS, J. H.; GOLDBERG, R. A. A concept of agribusiness. Boston: Division of Research, Graduate School of Business Administration, Harvard University, 1957. 136 p.
} 
No Brasil, a partir da década de 60, as relações entre as indústrias e a agropecuária passaram por mudanças notáveis. As chamadas agroindústrias cresceram como grandes consumidoras dos produtos agropecuários. Surgiram nessa época, novas agroindústrias de grande porte ligadas ao exigente mercado interno. De modo veloz, o aspecto artesanal-manufatureiro das indústrias deu espaço às indústrias com caráter de processamento, beneficiamento e distribuição internacionais. Isso teve um grande impacto na agropecuária, principalmente no seu modo de produzir, organizar e comercializar, o que acelerou a transformação da forma predominantemente atrasada de produzir por outra que cada vez mais consome insumos industriais (MÜLLER, 1989).

Até o final da década de 70 as relações entre as indústrias e a agropecuária apresentavam um elevado grau de integração, com praticamente todos os ramos setoriais instalados no país. Este processo de integração ocorreu devido às relações entre as grandes empresas, os grupos econômicos e o estado. Este último atuava, sobretudo, fornecendo subsídios creditícios, incentivos fiscais e através de toda uma política de estímulo à exportação, permitindo o crescimento e expansão das empresas e dos grupos econômicos industriais. A este processo de integração entre as indústrias e a agropecuária é atribuída a denominação de complexo agroindustrial (MÜLLER, 1989).

No início da década de 90, o conceito de cadeia do agronegócio era difundido no Brasil. O setor agropecuário passava a não mais ser visto isoladamente, mas sim junto ao suprimento e à distribuição, tanto para a definição de novas políticas agroindustriais, quanto para a definição de estratégias do setor privado (ZYLBERSZTAJN, 2005).

Os termos sistema agroindustrial, complexo agroindustrial e cadeia de produção agroindustrial, por serem muito próximos, geram confusão e, por vezes, são utilizados de maneira errônea. Batalha (1997) define cada um desses termos como níveis de análise, do mais amplo ao mais restrito:

I) Sistema agroindustrial: é o conjunto das atividades que concorrem para a produção de produtos agroindustriais, desde a produção de insumos até a 
chegada do produto final ao consumidor, não sendo associado a nenhuma matéria-prima pura ou produto final específico. É o termo mais amplo, sendo muito próximo do conceito de agribusiness. De acordo com Malassis ${ }^{4}$ (1979) (apud BATALHA, 1997, p. 30), é composto por seis conjuntos de agentes agricultura, pecuária e pesca; indústrias agroalimentares; distribuição agrícola e alimentar; comercio internacional; consumidor; indústrias e serviços de apoio;

II) Complexo agroindustrial: apresenta como ponto de partida uma determinada matéria-prima de base, sendo sua arquitetura ditada pelos diferentes caminhos que a matéria prima pode tomar, segundo os diferentes processos industriais e comerciais que ela pode sofrer até sua transformação em diferentes produtos finais;

III) Cadeia de produção agroindustrial: é definida a partir da identificação de determinado produto final, sendo a sequência de operações técnicas, comerciais e logísticas necessárias para a sua produção.

Portanto, a economia agroalimentar é fundamentada na análise integrada da produção, indústria e distribuição e comercialização, devido às suas estreitas ligações, e com o conjunto da economia, sem restringir-se ao estudo isolado de um destes setores (ABIA, 1993). O conhecimento das complexas relações de interdependência inerentes ao sistema agroalimentar é de suma importância tanto para o setor público, quanto para o setor privado (ABIA, 1993; BATALHA, 1997; ZYLBERSZTAJN, 2000b). Batalha (1997) afirma que tal conhecimento pode auxiliar na estratégia e marketing das empresas, na formulação da política industrial, na gestão tecnológica, na descrição técnico-econômica do setor e serve como modelo de delimitação de espaços de análise dentro do sistema produtivo, conforme exemplificado a seguir:

a) Metodologia de análise da estratégia das firmas: uma análise da cadeia produtiva pode ser utilizada como ferramenta para a observação de concorrência;

\footnotetext{
${ }^{4}$ MALASSIS, L. Economie agro-alimentaire. Paris: Cujas, 1979.
} 
b) Ferramenta de análise e formulação de políticas públicas e privadas: o estudo da cadeia de produção pode auxiliar na identificação de elos fracos, facilitando as ações públicas ou privadas para o incentivo a tal setor;

c) Análise das inovações tecnológicas: o conhecimento da cadeia permite avaliar o impacto das inovações tecnológicas sobre suas atividades e as da concorrência;

d) Ferramenta de descrição técnico-econômica: sendo a cadeia produtiva um conjunto de operações técnicas e de operações comerciais, o seu estudo pode ser utilizado para descrição das operações de produção durante a transformação da matéria-prima em produto acabado, além das relações econômicas entre os agentes da cadeia.

Considerando uma estrutura de cadeia produtiva que fundamenta um sistema agroalimentar, este, por natureza, apresenta três grandes segmentos principais (Figura 4) (ABIA, 1993; BATALHA, 1997; ZYLBERSZTAJN, 2000b):

I) Segmento agropecuário: é composto por atividades econômicas que têm como resultado final os produtos que servem como insumo para as indústrias de alimentos, como os produtos agrícolas, pecuários, da pesca e florestais;

II) Segmento da indústria agroalimentar: é o setor que agrupa o conjunto de operações para o beneficiamento, transformação, conservação, preparação e acondicionamento dos produtos agrícolas ou de consumo intermediário de insumos agrícolas. Podem ser classificados em indústrias de transformação primária (quando os insumos provêm diretamente do setor primário) ou indústrias de transformação secundária (quando os insumos provêm de outras indústrias agroalimentares); 
III) Segmento de distribuição e comercialização alimentar: é o setor que compreende as atividades comerciais que são realizadas entre as funções de produção de bens agropecuários e a fabricação de bens alimentícios e o consumidor final, permitindo o acesso deste último ao alimento. Pode ser classificado como comércio atacadista (é o local de concentração física dos produtos, como as centrais de recepção e os entrepostos) e o comercio varejista (é o local de distribuição dos produtos, como os hipermercados, supermercados, armazéns, lojas de conveniência e auto-serviços). As atividades comerciais existentes entre o segmento agropecuário e o setor da indústria agroalimentar também fazem parte deste grupo (como os compradores intermediários e atravessadores).

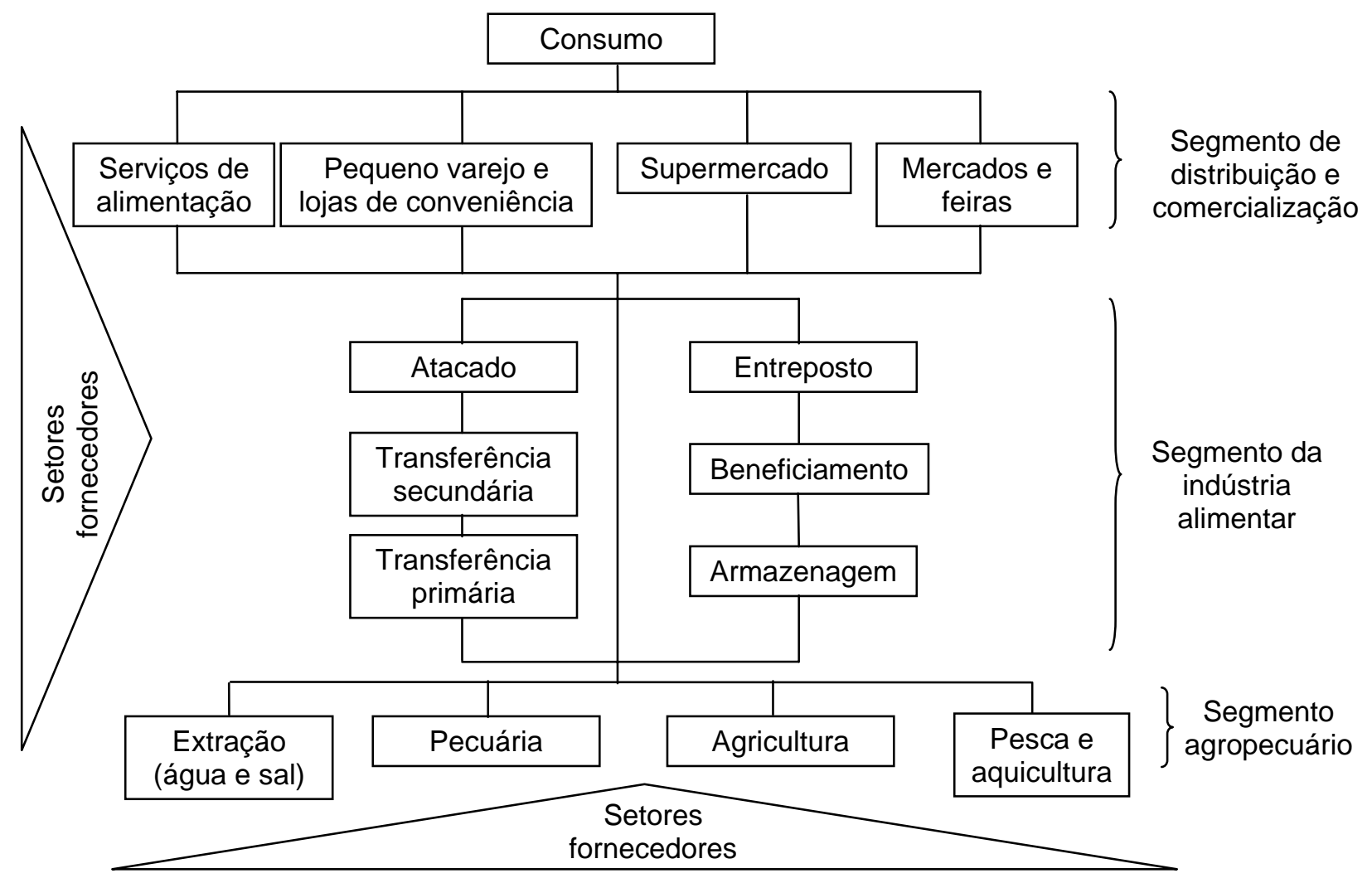

Fonte: ABIA, 1993.

Figura 4 - Fluxo do sistema agroalimentar 
Ainda, atuando no sistema agroalimentar, existem outros segmentos e setores de outros sistemas, como os setores fornecedores e os para-agroalimentares. Este é representado por empresas transportadoras, consultoria, marketing, sociedades de gestão, oficinas de engenharia e manutenção, instituições de crédito, entre outras; enquanto que aquele é representado por fornecedores de sementes, fertilizantes, defensivos agrícolas, indústria de produtos veterinários, indústria de tratores, indústria de implementos agrícolas, entre outros (ABIA, 1993).

Os sistemas agroindustriais são dinâmicos e sofrem mudanças ao longo do tempo conforme as relações entre os agentes são modificadas, seja por inovações tecnológicas, alterações externas ou concorrência. Para a realização de uma análise descritiva de um sistema agroindustrial, os agentes envolvidos, as relações entre eles, os setores envolvidos, as organizações de apoio e o ambiente institucional devem ser conhecidos (ZYLBERSZTAJN, 2000b).

Os agentes envolvidos no sistema agroindustrial, que necessariamente devem ser caracterizados, podem ser resumidos pela produção primária, indústria e distribuição (BATALHA, 1997; ZYLBERSZTAJN, 2000b). A caracterização detalhada das transações existentes entre esses agentes é de grande importância para uma eficiente coordenação do sistema, de modo que possibilita a redução dos custos de transação das formas contratuais e possibilita o desenho de contratos mais eficientes (ZYLBERSZTAJN, 2000a).

Por fim, o conhecimento sobre o ambiente institucional e organizacional é de fundamental importância. O ambiente institucional é o conjunto de regras, sejam elas formais (explícitas por algum poder legítimo) ou informais (culturais), pois estabelecem o ambiente no qual as transações ocorrem. Já o ambiente organizacional é representado pelo comportamento cooperativo, no qual um grupo de indivíduos se une em busca de determinada finalidade, unidos por determinado interesse comum, cujo objetivo final é a maximização dos lucros (SAES, 2000). 


\subsection{ESTUDOS SOBRE O COMPLEXO AGROINDUSTRIAL DO PESCADO}

Conforme visto anteriormente, os estudos sobre os sistemas agroalimentares são de grande importância para o desenvolvimento dos diversos setores produtivos. No Brasil e em outros países, diversas cadeias produtivas e complexos agroindustriais são estudados com diferentes enfoques, conforme exemplificado a seguir.

Schulze, Spiller e Theuvesen (2007) discutiram a questão da coordenação vertical na cadeia produtiva da carne suína na Alemanha. Apesar da grande importância atribuída à formulação de contratos e à integração vertical para o futuro da competitividade das cadeias produtivas de carnes, foi concluída a viabilidade de longo prazo do mercado de abate suíno com baixo grau de coordenação vertical, tendo em vista o grande número de produtores de suínos que rejeitam a idéia das obrigações contratuais. Foi recomendada a gestão do fator confiança como instrumento para ganhar vantagens que são geralmente atribuídas aos contratos.

A partir da determinação completa do complexo agroindustrial do salmão cultivado, Senneset, Foras e Fremme (2007) avaliaram os desafios da implementação de rastreabilidade eletrônica na Noruega. Concluíram que o sistema TraceFish, padronizado pelo Comitê Europeu de Padronização (CEN, 2003), pode ser utilizado como base para a implantação da rastreabilidade eletrônica. A falta de atenção ao sistema de rastreabilidade interno das empresas, foi identificado como dos maiores obstáculos à implementação.

Hendrickson et al. (2001), utilizando como caso de estudo o complexo agroindustrial do leite nos estados Unidos, discutiram o processo de reestruturação dos segmentos comercial e industrial, descrevendo os diferentes processos de integração que ocorreram nas cadeias produtivas. Foi identificado que com o crescimento das grandes redes de supermercados, através das aquisições e fusões, foi desenvolvida uma integração entre essas empresas, os setores industrial e produtor, dificultando a situação dos pequenos comércios e pequenas indústrias. São apresentados alguns casos de criação de cooperativas entre os produtores de leite, que criaram produtos 
de marca própria como uma forma de superar as dificuldades da verticalização causada pelas grandes redes varejistas.

Tendo em vista as novas preocupações dos consumidores relacionadas à qualidade dos alimentos, bem-estar animal e meio ambiente, Lindgreen e Hingley (2003) discutiram através do estudo de caso da rede varejista Tesco, a maior do Reino Unido, as medidas adotadas para a garantia dos produtos comercializados perante os consumidores. Foi concluída que a integração do varejo com os segmentos industrial e produtor apresentou resultado positivo, uma vez que permitiu a comunicação entre os agentes do sistema, principalmente a divulgação das percepções do varejo em relação às preocupações dos consumidores, fazendo com que tais tópicos fossem trabalhados ao longo da cadeia.

No Brasil, a partir da descrição do complexo agroindustrial do trigo e da realização de um workshop com representantes dos diversos segmentos do setor, Rossi e Neves (2004) formularam projeções do aumento de produção e custo para suprir as necessidades do consumo para o ano de 2030, bem como fizeram recomendações para o desenvolvimento do setor, dentre elas o desenvolvimento de uma estrutura organizacional, permitindo a integração entre os diferentes agentes para a elaboração de ações conjuntas; estimular o aumento do consumo dos derivados do trigo; o aumento da produção rural para diminuir a dependência externa; o incentivo à pesquisa para aumentar a qualidade e a produtividade do cultivo; o combate à informalidade; a qualificação da mão-de-obra visando ganhos de produtividade e qualidade; o investimento na atualização tecnológica para superar a defasagem de alguns agentes.

De forma semelhante, Cônsoli e Neves (2006) estudaram o complexo agroindustrial do leite no Brasil. Com o conhecimento do setor e suas dificuldades, adquiridos através da descrição do complexo agroindustrial e da realização de um workshop com representantes de diversos segmentos do setor, foram idealizados alguns projetos para o desenvolvimento e viabilidade do setor leiteiro. São eles: projeto de competitividade das fazendas, para caracterizar os diferentes produtores e planejar estratégias para o segmento produtor; o planejamento para as cooperativas de leite, visando avaliar a situação das cooperativas e analisar a viabilidade de parcerias e 
fusões; o projeto de análise legal e tributária, cujo objetivo é controlar a fraude fiscal e de produtos, além de promover ações referentes à classificação dos produtos lácteos; o programa de capacitação das unidades produtoras, para a qualificação técnico-administrativa dos produtores; o projeto de desenvolvimento de organizações verticais e ações coletivas, de modo a reestruturar as organizações existentes ou criar novas organizações verticais; o projeto de qualidade do leite na cadeia, com a pretensão de avaliar e definir os processos críticos que garantem a qualidade do leite e pontos críticos de controle em todo o complexo; a exploração de nichos de mercado, que intenta verificar as tendências de produtos e determinar estratégias de entrada e exploração; o plano de exportação, para avaliar as dificuldades e o monitoramento de barreiras aos produtos brasileiros; o plano de competitividade industrial, com o objetivo de estudar a possibilidade de parcerias no setor e o projeto do centro de informações do leite, para o compartilhamento de informações; entre outros.

Sendo considerado um caso de sucesso brasileiro, uma vez que o produto detém $80 \%$ do mercado mundial, Neves e Lopes (2005) estudaram o complexo agroindustrial da laranja no Brasil. Após a descrição do setor e realização de um workshop com representantes de diversos segmentos do complexo agroindustrial, o que permitiu conhecer o segmento, suas potencialidades e seus principais entraves, foram propostas algumas ações para o seu desenvolvimento, como a reestruturação da rede de extensão e pesquisa, cuja falha de comunicação prejudica a modernização e desenvolvimento do setor; o incentivo ao consumo da laranja e produtos derivados, que proporciona estabilidade e crescimento da citricultura; o incentivo à pesquisa relacionada às questões fitossanitárias e divulgação de resultados, que servem como barreiras às exportações e ao consumo interno; a redução da carga tributária, que eleva o custo de produção, diminuindo a competitividade dos produtos; a criação da associação de exportadores de frutas frescas, para aumentar as exportações e a força de lobby do grupo; o fortalecimento do associativismo, de modo a diminuir os interesses conflitantes; a geração e divulgação de informações de mercado confiáveis, que servem para a definição de estratégias mais eficientes e coerentes; o treinamento e capacitação técnicoadministrativa dos produtores, que são prejudicados pela limitação técnica e administrativa; o marketing institucional e os acordos bilaterais para o mercado 
exterior, proporcionando melhores condições comerciais e maior competitividade; a regulamentação do uso de defensivos; entre outros.

Em relação ao pescado, o número de publicações sobre o sistema agroindustrial aparenta ser um pouco mais reduzido, quando comparado aos trabalhos sobre outras cadeias e complexos agroindustriais. No âmbito internacional, foram encontrados trabalhos como o de Tilburg et al. (2007), que discutem sobre a organização e performance de cadeias produtivas de produtos tropicais, como 0 caso da criação de Perca do Nilo no Quênia. São relatadas as ações de gestão de qualidade, com a finalidade de adequar o produto à demanda externa, e as ações de governança, para melhorar a coordenação e o fator confiança entre os agentes do sistema, bem como a redução de custos.

Grunert et al. (2005) estudaram quatro cadeias produtivas, dentre elas a cadeia do bacalhau congelado da Noruega, em relação à estrutura para a tomada de decisões voltadas ao mercado. São discutidos tópicos como a demanda no Reino Unido por produtos derivados do bacalhau, que foi caracterizada como de elevado grau de heterogeneidade; as peculiaridades da pesca, que apresentam oscilações de tamanho, qualidade e quantidade durante o ano; as relações comerciais entre os segmentos da cadeia, caracterizado por baixo-moderado grau de confiança e de comprometimento entre os pescadores e a indústria, e moderado grau de confiança entre a indústria e o comércio; a regulamentação da pesca e do comércio do bacalhau, que é fortemente presente nesses segmentos e o nível das ações voltadas para o mercado. Foi constatado que, baseado em dados de venda, o setor comercial possui informações valiosas sobre os consumidores. Contudo, tal conhecimento não é disseminado ao longo da cadeia produtiva, sendo pouco transmitido ao segmento industrial, principalmente para aquelas indústrias fornecedoras dos produtos com a marca do comércio. Em virtude do elevado grau de fragmentação e da forte regulamentação do setor, associações comerciais e órgãos semi-governamentais atuam na criação e disseminação das percepções dos consumidores pelos segmentos iniciais da cadeia produtiva. Foi concluído que o grau das ações voltadas ao mercado está relacionado à heterogeneidade e dinamismo dos consumidores finais, à natureza das relações entre os segmentos da 
cadeia, à regulamentação do setor e à existência de modelos que auxiliem a tomada de decisões.

O complexo agroindustrial do salmão cultivado, com foco no mercado e nos consumidores holandeses, foi estudado por Roest et al. (2007), tendo em vista a identificação de riscos potenciais à saúde dos consumidores ao longo das cadeias produtivas. São discutidos os métodos de produção, industrialização e comercialização do salmão, bem como os possíveis riscos em cada etapa de processamento e recomendação de métodos para a identificação e prevenção de tais riscos.

De forma semelhante no Brasil, foram poucos os trabalhos encontrados classificados como estudos sobre o sistema agroindustrial do pescado. O projeto regional da FAO intitulado Mejoramiento de mercados domesticos de pescado $y$ productos pesqueiros en America Latina y El Caribe, com início em 2007, resultou, no Brasil, no trabalho de Soares (2007). Através de uma pesquisa documental e bibliográfica, o estudo caracterizou o mercado interno para os produtos derivados do pescado, identificando as potencialidades para o aumento da oferta de produtos de qualidade, sendo esse o único trabalho encontrado em nível nacional. Após caracterizar o mercado interno, Soares (2007) identificou as principais restrições à ampliação do mercado brasileiro de pescado de qualidade, que seguem a seguir:

a) Limitação na expansão de oferta dos recursos pesqueiros marinhos, cujos estoques se encontram em plena explotação e sobre-explotados;

b) Número representativo de micro empresas na indústria pesqueira;

c) Presença restrita de profissionais aptos ao controle de qualidade e segurança na indústria pesqueira;

d) Heterogeneidade e assimetrias tecnológicas na cadeia produtiva de pescado;

e) Concentração da aquisição de pescado numa pequena parcela da população;

f) Gastos irrisórios para a aquisição de pescado; 
g) Aquisição de pescado mais representativa em locais que comercializam-no fresco;

h) Indisponibilidade de tecnologia e infraestrutura para armazenamento de produtos aquícolas;

i) Presença de grande número de intermediários na distribuição e comercialização de pescado proveniente da pesca artesanal;

j) Deficiências tecnológicas na conservação e armazenagem na pesca artesanal.

De forma semelhante, Soares (2007) identificou as principais potencialidades à ampliação do mercado brasileiro de produtos pesqueiros de qualidade, que seguem a seguir:

a) Potencial de fornecimento de pescado através da pesca oceânica de atun e afins, com estoques de tunídeos do Atlântico Sul ainda subexplotados, e da atividade aquícola;

b) Desenvolvimento de novas pescarias voltadas a recursos subexplotados e com potencial de explotação;

c) Tendência a verticalização da indústria pesqueira, o que reduz o número de intermediários envolvidos na produção, além de permitir um maior controle organizacional sobre os processos e produtos;

d) O aumento da participação da indústria pesqueira brasileira no mercado externo, que faz com essas se adequem às exigências mais rigorosas quanto à qualidade do produto.

Alguns poucos trabalhos direcionados a determinadas regiões foram publicados, como o trabalho de Martins e Martins (1999), que através de pesquisa de campo levantaram informações sobre o complexo agroindustrial do pescado na região do Reservatório de Itaipu, estado do Paraná, e seus principais pontos de estrangulamento. Após a caracterização da cadeia, foram identificados alguns 
entraves, como o baixo nível tecnológico utilizado na atividade de captura, que diminui o desempenho dos pescadores; o baixo nível tecnológico das embarcações, o qual não permite conservação adequada do produto; e a quase inexistência de estratégias para alcançar o mercado consumidor, que dificulta a saída do produto para outros estados. Os autores recomendaram a reorganização da cadeia, o treinamento dos pescadores nas áreas de gerenciamento, contratos e princípios de economia; apoio dos órgãos do estado através de incentivos financeiros e linhas de crédito e a oferta de cursos e treinamento aos pescadores pelas universidades e pela Itaipu Binacional.

Chaves, Pichler e Robert (2002), através de uma pesquisa documental, bibliográfica e de campo, descreveram a situação da atividade pesqueira na Baía de Guaratuba, estado do Paraná, levando em consideração os entraves técnicos, biológicos e socioeconômicos. Os fatores técnicos, como a pequena variedade de técnicas de pesca associada às condições econômicas da população, e os fatores ictiofaunísticos, como a ocorrência ocasional das espécies explotadas e o tamanho reduzido dos indivíduos obtidos, foram considerados fatores limitantes para o sucesso da atividade. Os autores ressaltam o potencial da aquicultura para o desenvolvimento econômico da comunidade.

Castro et al. (2005), através de uma pesquisa documental e bibliográfica, descreveram o setor primário do complexo agroindustrial do pescado no litoral do estado de São Paulo e os entraves existentes na carcinicultura, psicultura e malacocultura, como a falta de investimentos para agregação de valor ao produto, quadro de especialistas insuficiente para atender à demanda, infraestrutura de apoio insuficiente, falta de organização comunitária, falta de linhas de crédito, inexistência de projetos municipais, exigências intransponíveis e incontestáveis da legislação ambiental, alto custo dos insumos, falta de regulamentação para legitimar a criação de moluscos, entre outros. Os autores destacam a importância das instituições de pesquisa no desenvolvimento da atividade aquícola.

Santos (2005) analisou o complexo agroindustrial do pescado oriundo da pesca artesanal no Nordeste do estado do Pará através de uma pesquisa documental, bibliográfica e de campo. Foram analisadas informações referentes aos aspectos 
sócioeconômicos dos trabalhadores, aspectos tecnológicos e produtivos da atividade, custos operacionais, comercialização e os ambientes institucional e organizacional. Foi identificado que, de forma geral, esses trabalhadores apresentam baixo grau de instrução, idade acima de 35 anos, baixo acesso aos bens de consumo duráveis modernos, residem em habitações rústicas e com baixo nível de saneamento básico. Na atividade são empregados métodos tradiconais e equipamentos rudimentares, geralmente confeccionados pelos próprios pescadores. A maior parte da produção é destinada à comercialização, atrelada à figura dos agentes intermediários que compram o pescado dos pescadores e vendem em outras comunidades, pequenos comerciantes ou outras cidades e estados. O nível organizacional dos trabalhadores é baixo, estando associados, principalmente, em colônias de pescadores de baixa representatividade. Foi detectada carência da prestação de assistência técnica rural, que deve ser voltata também para as questões ambientais, sociais e econômicas. A oferta de recursos financeiros também foi discutida, tendo como foco a inadequação das exigências para a aquisição de crédito perante a realidade do setor.

Dutra, Azevedo e Elias (2008), através de um estudo de caso, discutem as mudanças sofridas por uma propriedade de engorda de alevinos, no estado do Rio Grande do Sul, após a inclusão de outros processos produtivos em sua planta agroindustrial. Tendo em vista a necessidade de um maior grau de independência dos fornecedores de alevinos, a criação de uma nova fonte de renda com a comercialização de alevinos e a agregação de valor aos produtos, com auxílio da Associação Riograndense de Empreendimentos de Assistência Técnica e Extensão Rural (EMATER-RS), o produtor inseriu em sua propriedade a produção de alevinos e uma indústria processadora. Essa transformação permitiu uma maior coordenação e controle, por parte do proprietário, entre os segmentos do complexo, tanto dentro da sua propriedade, quanto junto às parcerias criadas para garantir o suprimento necessário para sua agroindústria. Contudo, algumas deficiências foram identificadas: entre elas a inexistência de um contrato formal junto aos seus clientes finais, como os restaurantes, lanchonetes, mercados e supermercados, que representam seus principais clientes em relação à quantidade de vendas, implicando em uma atual relação confiança e necessidade. 
Comparativamente com os outros setores produtivos citados anteriormente, a escassez de trabalhos relacionados ao sistema agroindustrial do pescado reforça a importância deste trabalho para o desenvolvimento do setor.

\subsection{A GESTÃO DO COMPLEXO AGROINDUSTRIAL DO PESCADO NO BRASIL}

No Brasil, o complexo agroindustrial do pescado sofre por ter uma governança indefinida. Diversos órgãos oficiais estão diretamente ou indiretamente envolvidos com o setor, da produção primária à comercialização com o consumidor final. A deficiência administrativa no segmento torna o cenário instiucional lento, burocrático e ineficiente (GREENPEACE, 2008).

A gestão governamental da pesca e da aquicultura no Brasil teve início em 1910, com a criação da Inspetoria de Pesca, que atuava no levantamento das espécies marinhas. Com a extinção desse órgão, foi criado o Serviço de Pesca e Saneamento do Litoral, em 1923, que focou em ações voltadas para a pesca artesanal. No início da década de 30, o serviço anterior deu lugar à Divisão de Caça e Pesca, direcionando ações voltadas para a capacitação dos trabalhadores e ao desenvolvimento da produção pesqueira. É nesse contexto que foi criada a Caixa de Créditos da Pesca, que tinha por objetivo financiar o setor privado (BRASIL, [2008?a]).

Em 1961, surgiu o Conselho de Desenvolvimento da Pesca, voltado exclusivamente à normatização e orientação da política de desenvolvimento do setor pesqueiro, em contraposição à disseminada atribuição de competências que existia anteriormente. Em 1962, foi criada a Superintendência do Desenvolvimento da Pesca (SUDEPE), extinguindo e centralizando todas as funções políticas e econômicas da Divisão de Caça e Pesca, Caixa de Crédito da Pesca e do Conselho de Desenvolvimento da Pesca. Esse novo órgão utilizou um modelo de desenvolvimento do setor pesqueiro atrelado a uma concepção de crescimento da produção a qualquer custo. Com a extinção da SUDEPE e a criação do Instituto Brasileiro do Meio Ambiente e dos 
Recursos Naturais renováveis (IBAMA), em 1989, este recebeu a gestão da pesca e da aquicultura. A administração da pesca sofreu uma mudança significativa, à medida que as questões ambientais ganharam um peso maior na gestão dos recursos. Enquanto que no período anterior a atividade pesqueira foi administrada com foco no desenvolvimento produtivo, nessa nova fase a atividade foi vinculada quase que exclusivamente à dimensão ambiental (BRASIL, [2008?a]).

Com a reestruturação organizacional da Presidência da República e dos Ministérios, em 1998, a competência relacionada ao apoio da produção e o fomento da atividade pesqueira foi transferida para o Ministério da Agricultura, Pecuária e Abastecimento (MAPA), criando o Departamento de Pesca e Aquicultura. As resposabilidades relaiconadas com a política de preservação, conservação e uso sustentável dos recursos naturais permaneceram a cargo do Ministério do Meio Ambiente (MMA) e do IBAMA (BRASIL, [2008?a]).

Em 2003, foi criada a Secretaria Especial de Aquicultura e Pesca (SEAP), órgão ligado à Presidência da República com status de Ministério, cujas atribuções abrangem a formulação de política de fomento e desenvolvimento para a pesca e aquicultura, permanecendo a gestão compatilhada do uso dos recursos com o MMA (BRASIL, [2008?a]). Atualmente, compete à SEAP assessorar a formulação das políticas e diretrizes para o desenvolvimento e o fomento da produção pesqueira e aquícola; promover a execução e a avaliação das medidas, programas e projetos de apoio ao desenvolvimento da pesca artesanal e industrial, bem como de ações voltadas à implantação de infraestrutura de apoio à produção e comercialização do pescado e de fomento à pesca e aquicultura; organizar e manter o Registro Geral da Pesca previsto no artigo 93 do Decreto-Lei no 221, de 28/02/1967; normatizar e estabelecer medidas que permitam o aproveitamento sustentável dos recursos pesqueiros altamente migratórios e dos que estejam sub ou não-explotados; supervisionar, coordenar e orientar as atividades referentes às infraestruturas de apoio à produção e circulação do pescado e das estações e postos de aquicultura; manter, em articulação com o Distrito Federal, estados e Municípios, programas racionais de exploração da aquicultura em águas públicas e privadas (BRASIL, 2003a). 
Enquanto a SEAP atua na política de desenvolvimento da aquicultura e pesca, o MMA e o IBAMA atuam na política de preservação, conservação e uso sustentável dos recursos naturais (BRASIL, [2008?a]). Em relação à produção de pescado, compete ao MMA a política nacional do meio ambiente e dos recursos hídricos; as políticas de preservação, conservação e utilização sustentável de ecossistemas e biodiversidades; a proposição de estratégias, mecanismos e instrumentos econômicos e sociais para a melhoria da qualidade ambiental e do uso sustentável dos recursos naturais e as políticas para integração do meio ambiente e produção (BRASIL, 2003a). Já o IBAMA, tendo em vista a produção de pescado, tem como função o exercício do poder de polícia ambiental; a execução de ações de políticas nacionais de meio ambiente, relativas ao licenciamento ambiental, ao controle da qualidade ambiental, à autorização de uso dos recursos naturais e à fiscalização, monitoramento e controle ambiental (BRASIL, 1989).

O MAPA também desempenha importante papel no complexo agroindustrial do pescado, atuando sobre o setor primário e a indústria. Dentre suas competências, estão relacionadas ao pescado a defesa sanitária animal, a fiscalização dos insumos e a classificação e inspeção sanitária dos produtos derivados (BRASIL, 2003a).

Sendo competência do Ministério da Saúde (MS) e da Agência Nacional de Vigilância Sanitária (Anvisa), a questão da saúde pública também está diretamente relacionada ao pescado. De acordo com o artigo 196 da Constituição Brasileira de 1988 (BRASIL, 1988a):

A saúde é um direito de todos os cidadãos e um dever do estado, garantido mediante políticas sociais e econômicas que visem à redução do risco de doença e de outros agravos e ao acesso universal e igualitário às ações e serviços para sua promoção, proteção e recuperação.

Compete ao sistema único de saúde, dentre outras atribuições, o controle e fiscalização de produtos e substâncias de interesse para a saúde, a execução das ações de vigilância sanitária e epidemiológica e a fiscalização e inspeção de alimentos. As ações e os serviços públicos de saúde devem integrar uma rede regionalizada e hierarquizada, constituindo um sistema único e descentralizado, com direção única em cada esfera de governo (BRASIL, 1988a). Assim, a direção é 
exercida pelo MS no âmbito da Federal, pela Secretaria de Saúde ou órgão equivalente no âmbito Estadual, e pela Secretaria de Saúde ou órgão equivalente no âmbito Municipal (BRASIL, 1990).

A Anvisa, criada em 1999 pela lei n. 9.782 (BRASIL, 1999), é uma autarquia vinculada ao MS, que tem como finalidade

[...] promover a proteção da saúde da população, por intermédio do controle sanitário da produção e da comercialização de produtos e serviços submetidos à vigilância sanitária, inclusive dos ambientes, dos processos, dos insumos e das tecnologias a eles relacionados, bem como o controle de portos, aeroportos e de fronteiras.

Dentre outras atribuições, compete à Anvisa proceder à implementação e à execução do Sistema Nacional de Vigilância Sanitária; normatizar, controlar e fiscalizar produtos, substâncias e serviços de interesse para a saúde; acompanhar e coordenar as ações estaduais, distrital e municipais de vigilância sanitária; prestar cooperação técnica e financeira aos estados, ao Distrito Federal e aos Municípios e atuar em circunstâncias especiais de risco à saúde (BRASIL, 1999).

O Sistema Nacional de Vigilância Sanitária compreende diversas ações para a promoção, proteção e recuperação da saúde (BRASIL, 1999), descritas pela lei n. 8.080, de 19/09/1990 (BRASIL, 1990), dentre elas a vigilância sanitária, que é definida pela mesma lei como sendo

[...] um conjunto de ações capaz de eliminar, diminuir ou prevenir riscos à saúde e de intervir nos problemas sanitários decorrentes do meio ambiente, da produção e circulação de bens e da prestação de serviços de interesse da saúde, abrangendo:

I - o controle de bens de consumo que, direta ou indiretamente, se relacionem com a saúde, compreendidas todas as etapas e processos, da produção ao consumo; e

II - o controle da prestação de serviços que se relacionem direta ou indiretamente com a saúde.

Os alimentos, inclusive bebidas, águas envasadas, seus insumos e embalagens, aditivos alimentares, limites de contaminantes orgânicos, resíduos de agrotóxicos e de medicamentos veterinários, são alguns dos produtos submetidos ao controle e 
fiscalização sanitária pela Anvisa (BRASIL, 1999). O não cumprimento da legislação sanitária federal acarreta em punições previstas em lei, que podem variar desde advertência e multa à apreensão, interdição, suspensão de vendas/fabricação de produtos, interdição total ou parcial do estabelecimento e cancelamento de autorização para o funcionamento da empresa (BRASIL, 1977, alterada por BRASIL, 1998c).

Tendo em vista a fiscalização sanitária de alimentos como base das ações de vigilância sanitária dos mesmos e a utilização da inspeção como instrumento de fiscalização sanitária, abrangendo todas as etapas da cadeia alimentar, o MS aprovou em 1993 o Regulamento Técnico para Inspeção Sanitária de Alimentos, as Diretrizes para o Estabelecimento de Boas Práticas de Produção e Prestação de Serviços na Área de Alimentos e o Regulamento Técnico para o Estabelecimento de Padrão de Identidade e Qualidade para Serviços e Produtos na Área de Alimentos, objetivando a proteção e defesa da saúde do consumidor. Dessa forma, foram estabelecidas as orientações para a execução das atividades de inspeção sanitária por parte dos órgãos de vigilância nos níveis federal, estadual e municipal, bem como as diretrizes para a elaboração das boas práticas de produção e prestação de serviços por parte dos estabelecimentos produtores e/ou prestadores de serviços na área de alimentos (BRASIL, 1993).

Diversas outras instituições estão envolvidas com o complexo agroindustrial do pescado, como o Ministério do Trabalho e Emprego (MTE) (política salarial, segurança e saúde no trabalho, política e diretrizes para a geração de emprego e renda); o Ministério da Previdência Social (previdência social); Ministério do Desenvolvimento, Indústria e Comércio Exterior (MDIC) (política de desenvolvimento da indústria e de comércio exterior); Ministério do Desenvolvimento Agrário (promoção do desenvolvimento sustentável do segmento rural); Ministério da Defesa (política marítima nacional, segurança do tráfego aquaviário); entre outros (BRASIL, 2003a). 


\section{MATERIAL E MÉTODO}

O presente trabalho tem como finalidade descrever o complexo agroindustrial do pescado no Brasil, identificar os principais entraves do setor e analisar a atuação dos órgãos públicos perante tais problemas. Valendo-se das diferentes descrições metodológicas citadas por Tobar e Yalour (2001) e tendo em vista o objetivo desta dissertação, este estudo é classificado como uma pesquisa descritiva.

Já em relação aos meio empregados para a condução da pesquisa, tendo em vista a utilização de documentos emitidos por órgãos públicos, publicações técnicocientíficas e pesquisa junto à pessoas relacionadas à área de interesse, valendo-se das descrições metodológicas citadas por Tobar e Yalour (2001), o presente trabalho é classificado como uma pesquisa de campo, documental e bibliográfica.

\subsection{MÉTODO}

Embasado no conhecimento teórico descrito anteriormente sobre os sistemas agroalimentares e nas publicações de Zylbersztajn e Neves (2000) e Neves et al. (2004), sobre caracterização e quantificação dos sistemas agroindustrias, o presente trabalho buscou identificar e caracterizar através do número de trabalhadores, número de estabelecimentos e da quantificação da produção, cada segmento do complexo agroindustrial do pescado brasileiro.

De acordo com Neves et al. (2004), para uma quantificação de valores das cadeias produtivas, cinco passos devem ser seguidos:

I) Descrição da cadeia vertical do setor de interesse: um esquema simples contendo os tradicionais segmentos do fluxo de mercado;

II) Submissão do esquema ao setor privado e especialistas e melhoramento: após a descrição no esquema inicial, algumas entrevistas com empresas e 
especialistas envolvidos com o setor devem ser realizadas com a finalidade de melhorar a descrição inicial;

III) Pesquisa por dados de vendas em associações, instituições de pesquisa e publicações;

IV) Entrevistas com empresas: entrevistas com gerentes de vendas para descobrir quanto as empresas vendem para o mercado;

V) Quantificação: processamento dos dados e inserção na descrição inicial;

VI) Workshop: realização de um workshop para apresentação dos resultados e discussão com grupos de interesse, com a finalidade de discutir ações coletivas.

Após a identificação de dificuldades para a obtenção de dados numéricos relacionados à produção e volume de vendas observada em pesquisa inicial (projeto-piloto, entre março/2008 e junho/2008) junto às empresas do setor, que serão discutidas no capítulo seguinte, foi realizada uma adaptação da metodologia proposta por Neves et al. (2004), com o intuito de caracterizar o setor produtivo de pescado.

Para a realização deste trabalho, foram seguidos os seguintes passos:

I) Descrição simples do complexo agroindustrial do pescado: confecção de um esquema simples contendo os tradicionais segmentos do fluxo de mercado, ou seja, produção primária, indústria, comércio e consumidor;

II) Comparação da descrição simples com dados de publicações e ajustes: após consultar publicações relacionadas ao tema, o esquema anteriormente elaborado foi corrigido, tendo seus agentes identificados;

III) Pesquisa de dados relacionados aos segmentos em associações, órgãos governamentais, instituições de pesquisa e publicações: após a identificação dos agentes, os diferentes segmentos do complexo agroindustrial são caracterizados através da busca por informações relacionadas;

IV) Processamento dos dados e inserção na descrição inicial: cada segmento é descrito de acordo com as informações obtidas. 
Durante o processo de descrição do complexo agroindustrial do pescado, algumas dificuldades e entraves vivenciados pelos agentes do setor foram detectados, bem como foram encontradas publicações relacionadas a estes problemas. Com a finalidade de identificar a atuação dos órgãos governamentais junto às dificuldades e entraves, uma nova pesquisa em busca de maiores informações foi realizada:

a) Identificação das dificuldades e entraves: listagem de alguns problemas observados em publicações ou identificados durante o processo de descrição do setor;

b) Pesquisa por maiores informações relacionadas a tais dificuldades e entraves em publicações e junto aos órgãos oficiais: obtenção de dados pertinentes, relacionando a importância das dificuldades e entraves, bem como a atuação dos órgãos governamentais junto à estes problemas;

c) Processamento das informações: análise crítica das informações sobre a problemática estudada, determinando a atuação dos órgãos oficiais e sugerindo possíveis soluções.

\subsection{MATERIAL}

Definidos os métodos, o material utilizado neste trabalho foi constituído de publicações e bancos de dados relacionados ao setor do pescado:

a) Publicações: pesquisadas em diversas bases de dados, dentre elas a Biblioteca Nacional de Agricultura, pertencente ao Ministério da Agricultura, Pecuária e Abastecimento; a Base de Dados de Pesquisa Agropecuária, pertencente à Empresa Brasileira de Pesquisa Agropecuária; Animal Health \& Production Compendium; Aquaculture Compendium; Aquatic Sciences and Fishery Abstracts (ASFA); Centre for Agriculture Bioscience International (CABI); EMBASE; Electronic Reference Library; Industrial and Applied Microbiology Abstracts; JSTOR; Oceanic Abstracts e Scopus;

b) Órgãos governamentais: baseou-se principalmente na busca por informações no endereço eletrônico das instituições, mas também foram consultados os 
bancos de dados e funcionários das mesmos (através de contato telefônico ou do endereço eletrônico). Dos órgãos pesquisados, pode-se citar a Agência Nacional de Vigilância Sanitária (Anvisa); Conselho Nacional de Pesca e Aquicultura (CONEPE); Departamento de Inspeção de Produtos de Origem Animal (DIPOA); Divisão de Inspeção de Pescados e Derivados do DIPOA (DIPES); Food and Agriculture Organization of the United Nations (FAO); Instituto Brasileiro de Geografia e Estatística (IBGE); Instituto Brasileiro do Meio Ambiente e dos Recursos Naturais Renováveis (IBAMA); Instituto da Pesca (IP); Instituto de Economia Agrícola (IEA); Ministério da Agricultura, Pecuária e Abastecimento (MAPA); Ministério da Saúde (MS); Ministério do Desenvolvimento, Indústria e Comércio Exterior (MDIC); Ministério do Trabalho e Emprego (MTE); Secretaria Especial da Aquicultura e Pesca (SEAP); Secretaria Estadual de Agricultura e Abastecimento de São Paulo; Secretaria de estado da Agricultura do Pará; Secretaria de Agricultura, Pesca, Pecuária e Agronegócio do Rio Grande do Sul; Secretaria de Agricultura, Pecuária, Pesca e Abastecimento do Rio de Janeiro; Secretaria de estado da Agricultura e Desenvolvimento Rural de Santa Catarina; Secretaria de estado da Agricultura e do Desenvolvimento Agrário de Alagoas; Secretaria de estado da Produção Agropecuária, Pesca e Desenvolvimento Rural Integrado do Amazonas; Secretaria de estado de Agricultura, Pecuária e Abastecimento de Minas Gerais; Secretaria de estado de Agropecuária do Acre; Secretaria do Desenvolvimento Agrário do Ceará;

c) Associações e sindicatos: baseou-se na busca por informações no endereço eletrônico das entidades e através de contato com funcionários das mesmas (através de contato telefônico ou do endereço eletrônico). Das instituições pesquisadas, pode-se citar a Associação Bahiana de Supermercados (ABASE); Associação Brasileira das Indústrias da Alimentação (ABIA); Associação Brasileira dos Supermercados (ABRAS); Associação Capixaba de Supermercados (ACAPS); Associação Catarinense de Supermercados (ACATS); Associação de Supermercados da Paraíba (ASPB); Associação de Supermercados de Mato Grosso (ASMAT); Associação de Supermercados do estado do Rio de Janeiro (ASSERJ); Associação Gaúcha de Supermercados (AGAS); Associação Mineira de Supermercados (AMIS); Associação Paraense de Supermercados (ASPAS); Associação Paranaense de Supermercados 
(APRAS); Associação Paulista dos Supermercados (APAS); Associação Pernambucana de Supermercados (APES); Associação Sul-Matogrossense de Supermercados (AMAS); Sindicato da Indústria da Pesca dos estados do Pará e Amapá (SIPESCA) e Sindicato das Indústrias da Pesca de Itajaí e Região (SINDIPI).

Dentre os bancos de dados, merece destaque a Relação Anual de Informações Sociais (RAIS) do MTE. Este banco foi utilizado para a quantificação do número de estabelecimentos e de trabalhadores, bem como suas funções no setor produtivo de pescado. A RAIS é um instrumento de coleta de dados, cujo objetivo é suprir as necessidades de controle da atividade trabalhista no Brasil, além do provimento de dados para a elaboração de controle de estatísticas do trabalho e a disponibilização de informações do mercado de trabalho às entidades governamentais. O MTE aponta uma extensa relação de quem deve e quem não deve entregar a declaração da RAIS, mas de forma geral, anualmente todos os empregadores devem entregála, declarando todos os empregados, trabalhadores avulsos, temporários e aprendizes (BRASIL, [2008?b]). 


\section{RESULTADOS E DISCUSSÃO}

Para melhor entendimento dos resultados obtidos, este capítulo está dividido em duas partes. A primeira caracteriza o complexo agroindustrial do pescado, dividido nos setores de produção (pesca e aquicultura), industrialização e comercialização. Em seguida, os principais entraves identificados são estudados, apontando causas e possíveis alternativas para a ordenação do sistema.

\subsection{CARACTERIZAÇÃO DO COMPLEXO AGROINDUSTRIAL DO PESCADO}

Fundamentado nos estudos de Batalha (1997) e Zylbersztajn (2000b) sobre a segmentação dos sistemas agroalimentares, a Figura 5 foi elaborada para esquematizar de forma simples o complexo agroindsutrial do pescado, servindo como base inicial para a pesquisa.

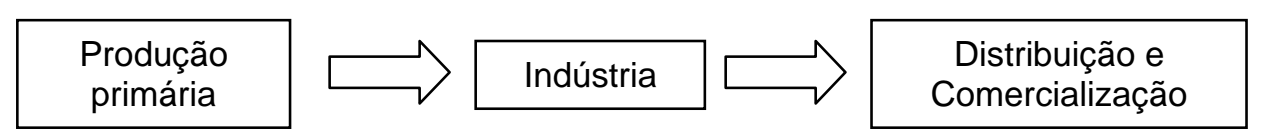

Figura 5 - Esquema inicial do complexo agroindustrial do pescado no Brasil

A Comissão Nacional de Classificação (CONCLA) do IBGE, utilizando a classificação das atividades econômicas da Comissão Nacional de Atividades Econômicas (CNAE 1.0, revisada em 2002), denomina as seguintes atividades envolvendo exclusivamente o pescado (BRASIL, [2002?]):

I) Pesca e serviços relacionados (Classe 0511-8): compreende a pesca em águas marítimas e em águas interiores; captura de peixes vivos para reprodução ou para outras finalidades; a captura de crustáceos, ostras e moluscos de águas marinhas ou de águas interiores; os serviços relacionados com a pesca; a preparação e conservação do peixe no próprio barco e a coleta de outros produtos marinhos ou de águas interiores, como esponjas, corais, pérolas, algas, outros produtos e seres vivos aquáticos. Não compreende a 
preparação do pescado, crustáceos e moluscos (frigorificados, congelados, salgados, secos) e a fabricação de conservas em estabelecimentos fabris, inclusive em barcos-fábrica; a preparação de qualquer tipo de farinha do pescado; a criação de peixes, crustáceos, moluscos, e de outros animais aquáticos; a pesca esportiva e de lazer e os serviços afins;

II) Aquicultura e serviços relacionados (Classe 0512-6): abrange a realização de cultivos e semicultivos, em águas continentais ou marinhas, de espécies de hábito aquático, como vegetais (plantas aquáticas e algas) e animais (espécies cujas fases reprodutivas de seu ciclo vital se processam, no todo ou em parte, na água); a criação de peixes, camarões e de outros crustáceos; o cultivo de ostras e outros moluscos; a criação de peixes ornamentais; a criação de rãs; o cultivo de algas; o cultivo de pérolas; a produção de alevinos e os serviços relacionados com a aquicultura. Não compreende a pesca em águas marinhas ou em águas interiores; a criação de escargô e a exploração da pesca desportiva e de lazer;

III) Preparação e preservação do pescado e fabricação de conservas de peixes, crustáceos e moluscos (Classe 01514-8): envolve a preparação de peixes, crustáceos e moluscos (frigorificados, congelados, salgados e secos) e a fabricação de conservas, mesmo quando efetuada em barcos-fábricas; a produção de qualquer tipo de farinha derivada e a produção de alimentos para animais à base de pescado. Não inclui a pesca e elaboração de produtos nos próprios barcos pesqueiros, a produção de óleos e gorduras e a fabricação de sopas que contenham pescado;

IV) Comércio atacadista de pescado e frutos do mar (Classe 5135-7): compreende o comércio atacadista de peixes e outros frutos do mar frescos, frigorificados, congelados, preparados, secos e salgados.

Porém, diversas outras atividades previstas pela CONCLA podem estar relacionadas ao complexo agroindustrial do pescado, embora este não esteja implícito na descrição dessas atividades. Na Pesquisa de Orçamentos Familiares 2002-2003 (IBGE ${ }^{5}, 2004$ b apud SONODA, 2006, p. 71), por exemplo, podem-se observar outras atividades relacionadas ao comércio de produtos derivados do pescado que não o

5 IBGE. INSTITUTO BRASILEIRO DE GEOGRAFIA E ESTATíSTICA. Pesquisa de Orçamentos Familiares 2002-2003: microdados. Rio de Janeiro: IBGE, 2004b. 1 CD-ROM. 
comércio atacadista descrito pela CONCLA, como o comércio varejista, feiras e mercados, peixarias, vendedores ambulantes e mercearias e armazéns. A seguir, são citadas outras atividades previstas pela CONCLA, as quais não apresentam o termo pescado em sua descrição, porém podem apresentar tal produto como parte de sua atividade:

a) Atividades desportivas (Classe 9261-4): envolve uma série de atividades recreativas, dentre elas a pesca desportiva e de lazer;

b) Transporte ferroviário interurbano (Classe 6010-0): compreende o transporte ferroviário interurbano, intermunicipal e interestadual de cargas e passageiros;

c) Transporte rodoviário de cargas, em geral (Classe 6026-7): inclui o transporte rodoviário urbano, interurbano e internacional de cargas em geral, exceto o de produtos perigosos;

d) Transporte marítimo de cabotagem (Classe 6111-5): abrange o transporte de passageiro e cargas, regular e não-regular, realizado entre portos ou pontos do território brasileiro, utilizando a via marítima ou esta e as vias navegáveis interiores;

e) Transporte marítimo de longo curso (Classe 6112-3): refere-se ao transporte marítimo internacional de passageiro e cargas, regular e não-regular, realizado entre portos brasileiros e estrangeiros;

f) Transporte por navegação interior de carga (Classe 6122-0): trata-se do transporte de cargas não-urbano, regular e não-regular, por rios, lagos, lagoas e outras vias de navegação interior, em percurso nacional ou internacional;

g) Transporte aquaviário intermunicipal urbano (Classe 6123-9): compreende o transporte aquaviário de passageiro e cargas, em uma mesma embarcação ou não, realizado no meio urbano ou em seu entorno, como as travessias de rios, lagos, lagoas, canais, baías, etc.;

h) Transporte aéreo regular (Classe 6210-3): abange o transporte aéreo de passageiro e cargas em linhas domésticas e internacionais, com itinerários e horários estabelecidos;

i) Transporte aéreo não-regular (Classe 6220-0): envolve o transporte aéreo de passageiro e cargas, não-regular; 
j) Carga e descarga (Classe 6311-8): inclui as atividades de carga e descarga, por manuseio ou não, de mercadorias ou bagagens, independentemente do meio de transporte utilizado;

k) Armazenamento e depósito de cargas (Classe 6312-6): refere-se ao transporte aéreo de passageiro e cargas em linhas domésticas e internacionais, com itinerários e horários estabelecidos;

l) Comércio varejista de mercadorias em geral, com predominância de produtos alimentícios, com área de venda superior a $5000 \mathrm{~m}^{2}$ - hipermercado (Classe 5211-6): compreende as atividades dos estabelecimentos comerciais com venda predominante de produtos alimentícios variados, além de oferecer uma gama de outras mercadorias, tais como utensílios domésticos, roupas, ferragens, entre outros, com área de venda superior a $5000 \mathrm{~m}^{2}$;

m) Comércio varejista de mercadorias em geral, com predominância de produtos alimentícios, com área de venda entre 300 e $5000 \mathrm{~m}^{2}$ - supermercado (Classe 5212-4): inclui as atividades dos estabelecimentos comerciais com venda predominante de produtos alimentícios variados, além de oferecer variedade de outras mercadorias, tais como utensílios domésticos, roupas, ferragens, entre outros, com área de venda entre 300 e $5000 \mathrm{~m}^{2}$;

n) Comércio varejista de mercadorias em geral, com predominância de produtos alimentícios, com área de venda inferior a $300 \mathrm{~m}^{2}$ - exceto lojas de conveniência (Classe 5213-2): abrange as atividades dos estabelecimentos comerciais com venda predominante de produtos alimentícios variados, em mercados com sortimento limitado, armazéns, empórios e mercearias, com área de venda inferior a $300 \mathrm{~m}^{2}$;

o) Comércio varejista de mercadorias em geral, com predominância de produtos alimentícios industrializados - lojas de conveniência (Classe 5214-0): tratase das atividades dos estabelecimentos comerciais com venda predominante de produtos alimentícios industrializados, além de outros não-alimentícios, usualmente associadas a outra atividade, com horário de funcionamento normalmente de 24 horas por dia;

p) Comércio varejista não especializado, sem predominância de produtos alimentícios (Classe 5215-9): compreende o comércio varejista nãoespecializado sem predominância de gêneros alimentícios, em estabelecimentos que oferecem uma variedade de linhas de mercadorias, 
como roupas, móveis, eletrodomésticos, ferragens, cosméticos, bijuterias, jogos, artigos de esporte, entre outros, além do comércio varejista realizado em lojas de departamentos e o comércio fora de loja ou não-tradicional e nãoespecializado, como o eletrônico;

q) Comércio varejista de outros produtos alimentícios não especificados anteriormente e de produtos do fumo (Classe 5229-9): refere-se ao comércio varejista em lojas especializadas de hortifrutigranjeiros, pescado fresco, congelado ou frigorificado, aves vivas e ovos, outros pequenos animais vivos para alimentação (coelhos, cabritos e similares), fumo em rolo ou em corda, cigarros, cigarrilhas, charutos, fumo desfiado, isqueiros, piteiras e cachimbos.

r) Comércio em vias públicas, exceto em quiosques fixos (Classe 5262-0): compreende o comércio varejista de qualquer tipo de produto realizado em vias públicas, através de vendedores ambulantes e vendedores em domicílio;

s) Restaurantes e estabelecimentos de bebidas, com serviço completo (Classe 5521-2): aborda as atividades de vender e servir comida preparada, com ou sem bebidas alcoólicas, com ou sem entretenimento, ao público em geral, com serviço completo;

t) Lanchonetes, casas de chá, de sucos e similares (Classe 5522-0): abrange os serviços de alimentação para consumo no local, com venda ou não de bebidas, em estabelecimentos que não oferecem serviço completo, tais como lanchonetes, fast-food, pastelarias, casas de sucos, sorveterias, botequins e similares;

u) Cantinas (Classe 5523-9): inclui os serviços de alimentação e a venda de bebidas de caráter privativo (exploração própria ou por terceiros) para grupos de pessoas em fábricas, universidades, colégios, associações, casernas, órgãos públicos, etc.;

v) Fornecimento de comida preparada (Classe 5524-7): refere-se à preparação de refeições em cozinha central por conta de terceiros para fornecimento a empresas de linhas aéreas e outras empresas de transporte, cantinas, restaurantes de empresas e outros serviços de alimentação privativos, restaurantes, hospitais, penitenciárias, domicílio, bufês, coquetéis, recepções, etc.;

w) Outros serviços de alimentação (Classe 5529-8): compreende os serviços de alimentação de comida preparada, para o público em geral, em locais abertos, 
permanentes ou não, tais como trailers, quiosques, carrocinhas e outros tipos de ambulantes de alimentação preparada para consumo imediato.

Valendo-se dos trabalhos relacionados ao estudo do complexo agroindustrial do pescado no Brasil, citados na quinta parte da Revisão de Literatura, e tendo em vista as atividades classificadas pela CONCLA descritas anteriormente, o esquema inicial da Figura 5 foi ajustado para melhor retratar o setor, conforme exposto na Figura 6.

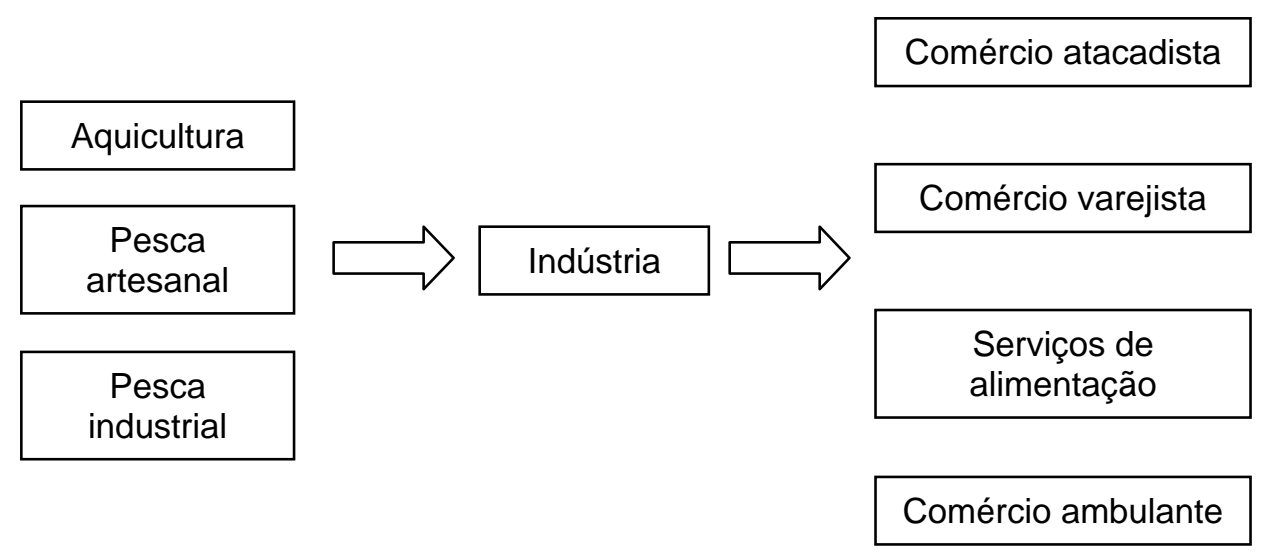

Figura 6 - Complexo agroindustrial do pescado após ajustes e correções

Tais modificações se deram pela identificação de diferentes atividades de comercialização existentes (CONCLA; SOARES, 2007) e de diferentes modalidades de produção primária (CONCLA; SOARES, 2007; CASTRO et al., 2005; MARTINS; MARTINS, 1999; CHAVES; PICHLER; ROBERT, 2002). A partir da elaboração desse novo esquema, cada segmento do complexo agroindustrial do pescado no Brasil foi estudado e descrito durante o período compreendido entre junho e novembro de 2008.

Para a quantificação dos estabelecimentos e trabalhadores em cada segmento, foram utilizadas as informações do banco de dados do MTE (Relação Anual de Informações Sociais - RAIS), compreendidas entre 1995 e 2005. A escolha deste período se deu pela utilização da primeira versão da classificação das atividades econômicas feita pela CNAE, a qual apresenta o termo pescado em quatro atividades econômicas (Pesca e serviços relacionados; Aquicultura e serviços relacionados; Preparação e preservação do pescado e fabricação de conservas de peixes, crustáceos e moluscos; e Comércio atacadista de pescado e frutos do mar). 
As demais classificações utilizadas em outros períodos apresentaram uma menor quantidade de atividades relacionadas exclusivamente ao pescado, como a segunda versão da classificação das atividades econômicas feita pela CNAE, utilizada para os dados de 2006 e 2007, a qual não apresenta uma atividade de comércio exclusiva para o pescado, e a classificação dos subsetores de atividade econômica feita pelo IBGE, utilizada entre 1985 e 1994, que não apresenta nenhuma atividade relacionada exclusivamente ao pescado.

Tendo em vista o foco do trabalho sobre o complexo agroindustrial do pescado, a quantificação foi prejudicada por três fatores:

I) Ficou impossibilitada a utilização de informações mais recentes e de uma série histórica maior, uma vez que a RAIS utilizou três diferentes classificações de atividades econômicas desde 1985, implicando em diferentes nomenclaturas e agrupamento ou separação de atividades próximas;

II) A quantificação do segmento comercial do pescado ficou subestimada, sendo considerada apenas a participação do comércio atacadista de pescado, uma vez que é impossível garantir que todas as demais atividades comerciais descritas pela primeira versão da CNAE praticam a comercialização de pescado. Caso essas outras catividades comerciais fossem contabilizadas nesse trabalho, certamente resultaria em uma falsa estimativa do segmento comercial, pois nem todas as atividades comerciais, necessariamente, comercializam pescado.

III) A quantificação de todos os segmentos pode ter sido subestimada, uma vez que devem existir trabalhadores autônomos e sem registro em carteira de trabalho, como pescadores e vendedores ambulantes, bem como de estabelecimentos beneficiadores clandestinos, conforme alertado por Barroso e Freitas (2008). 


\subsubsection{Setor produtivo pesqueiro e aquícola}

Segundo Silva (2008), o "Brasil continua sem um inventário confiável de seus recursos pesqueiros, o que dificulta uma estimativa exata da produção ${ }^{6}$." Dados oficiais de produção são divulgados pelo IBAMA e pela SEAP e as informações mais recentes são relacionadas à produção do ano de 2006, publicadas em 2008. Essa falta de atualização constante dos dados aliada à falta de confiabilidade das informações são prejudiciais ao desenvolvimento do setor, uma vez que dificultam, por exemplo, a análise e formulação de estratégias empresariais e políticas públicas.

O setor produtivo de pescado do Brasil está em plena expansão, apresentando nos últimos anos os maiores índices de produção da história do setor (Gráfico 4). Entre 1997 e 2006, o setor apresentou crescimento de 51,59\%. O recorde brasileiro de produção de pescado ocorreu em 2006, com produção total de 1.050 .808 toneladas (R\$3.294.604.130,05) (IBAMA, 2008).

\footnotetext{
6 "Brazil remains without a reliable inventory of its fisheries resources, which makes it difficult to estimate exact production."
} 


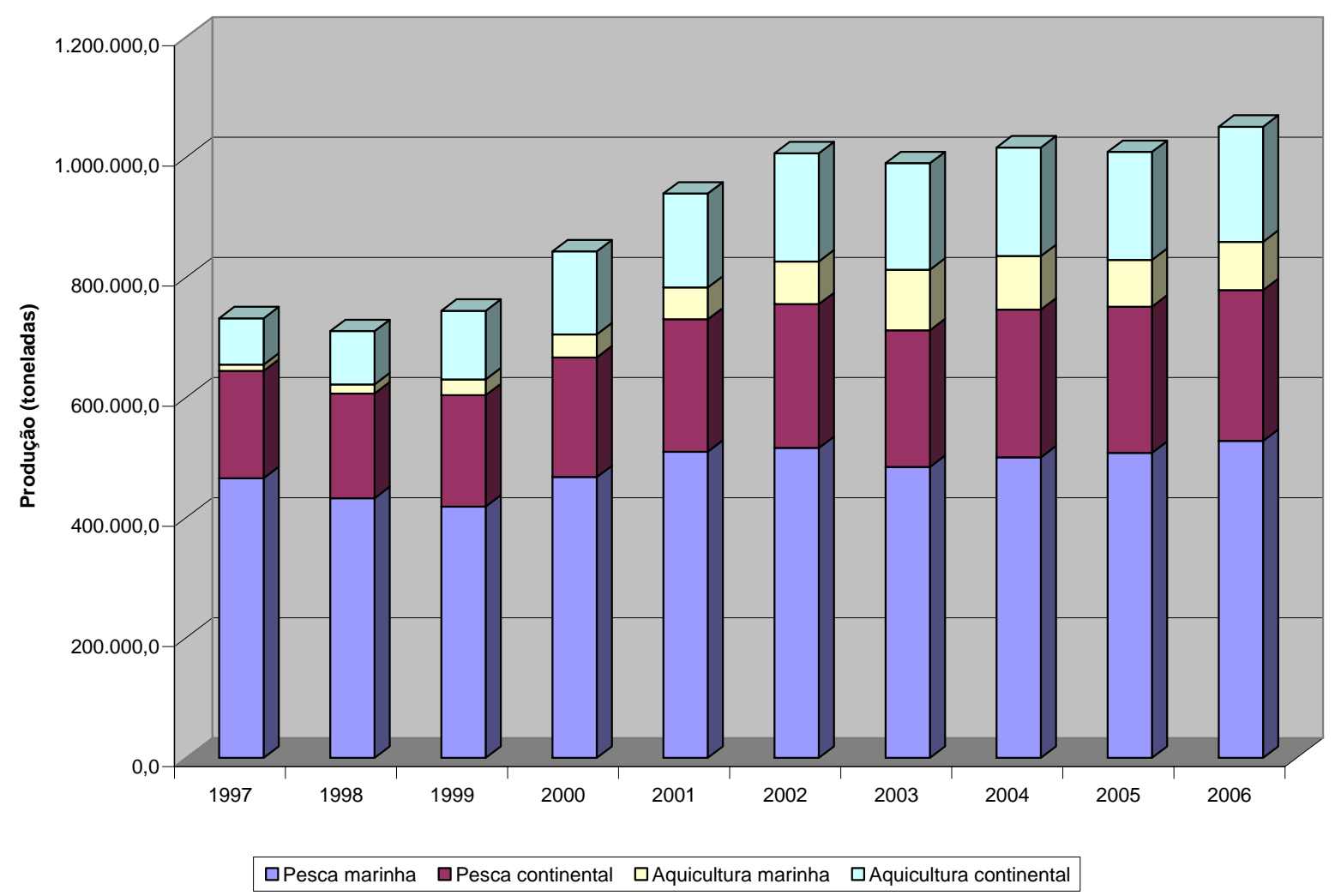

Fonte: IBAMA, 2008.

Gráfico 4 - Produção de pescado no Brasil - 1997-2006

No Gráfico 4 é possível observar que até o ano de 2001, a atividade extrativa marinha era a mais representativa para a produção total de pescado no Brasil, respondendo por aproximadamente 64\% do total produzido em 1997. A partir de 2001, com o menor crescimento da produção extrativa marinha e o maior crescimento da produção da atividade aquícola e da pesca continental, a pesca marinha teve sua representatividade reduzida para quase $50 \%$ da produção total do setor, como em 2003 e 2004, quando representou aproximadamente $49 \%$ do total (IBAMA, 2008).

No período entre 1997 e 2006, a aquicultura marinha foi o setor produtivo que apresentou um incremento na produção mais expressivo (690,88\%), seguida da aquicultura continental (146,71\%), pesca continental $(40,46 \%)$ e pesca marinha (13,35\%) (IBAMA, 2008).

O número de estabelecimentos e de trabalhadores do setor também apresentou um expressivo crescimento. Entre 1995 e 2005, tanto o setor extrativista quanto o setor 
aquícola apresentaram um aumento do número de estabelecimentos e seus trabalhadores, sendo o incremento do setor aquícola (284,45\% para estabelecimentos e $612,27 \%$ para trabalhadores) mais expressivo do que o do setor extrativista (37,30\% para estabelecimentos e 9,95\% para trabalhadores) (MTE). No ano de 2005, o setor produtivo registrou um total de 2.564 estabelecimentos, empregando 23.176 trabalhadores (Gráfico 5) (BRASIL, 2008?c).

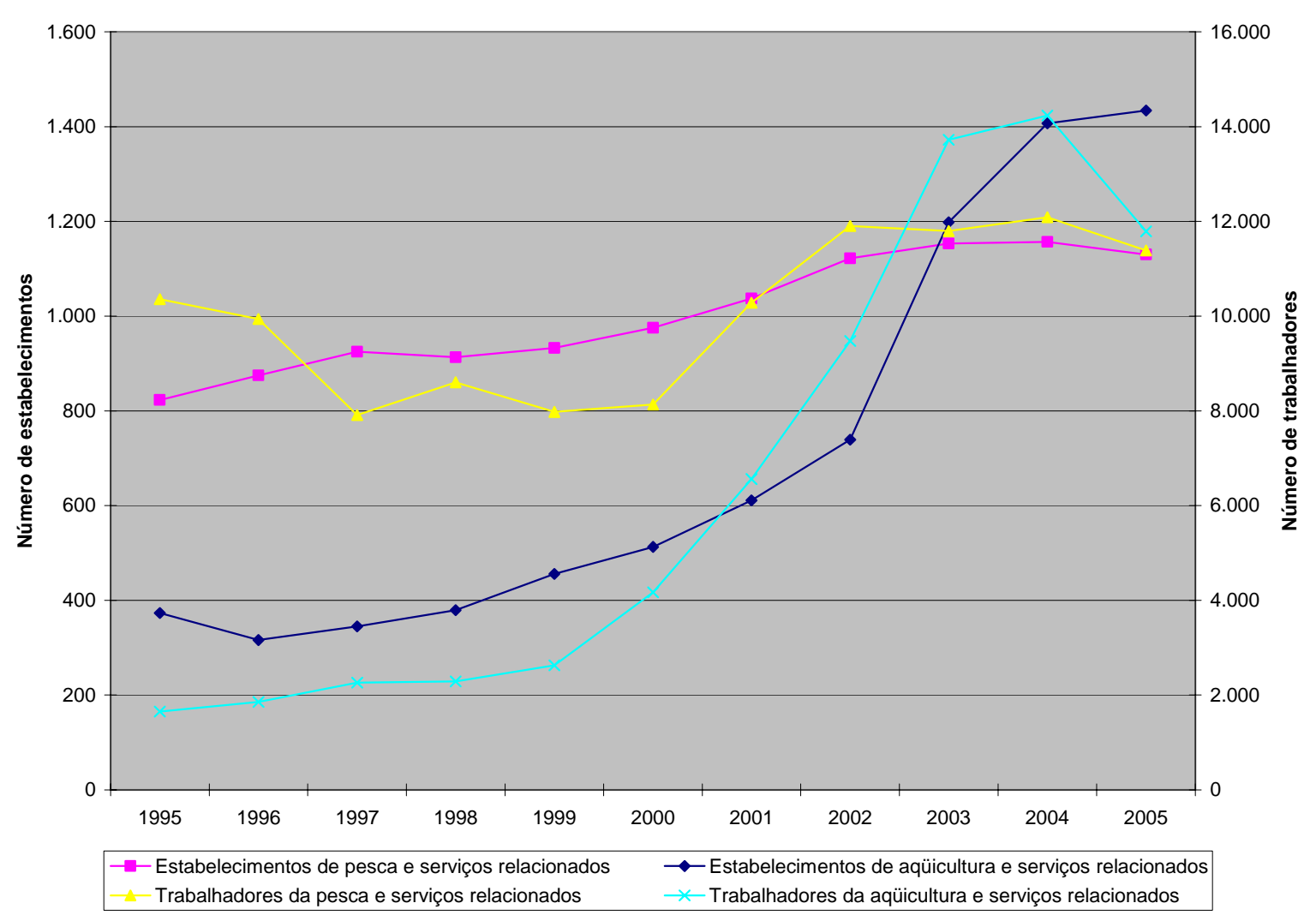

Fonte: BRASIL, [2008?c].

Gráfico 5 - Evolução do número de estabelecimentos e de trabalhadores do setor primário de pescado no Brasil - 1995-2005

É possível que esse aumento da produção e do número de estabelecimentos e trabalhadores do segmento produtivo primário do pescado esteja relacionado com as políticas públicas do final da década de 90 e do início da primeira década de 2000, uma vez que, segundo Boeger e Borghetti (2008), a partir da criação do IBAMA, em 1989, houve uma progressiva estagnação do desenvolvimento dos setores aquícola e pesqueiro, que perdurou por cerca de 10 anos. Dentre as principais políticas públicas voltadas à estruturação de serviços oficiais para o desenvolvimento do setor, destacam-se a lei $n^{\circ}$ 9.649, de 27 de maio de 1998, que transferiu a competência da produção e do fomento da atividade pesqueira do 
IBAMA e MMA ao Ministério da Agricultura e do Abastecimento (BRASIL, 1998a); o decreto $\mathrm{n}^{\circ}$ 2.681, de 21 de junho de1998, que criou o Departamento de Pesca e Aquicultura na estrutura do Ministério da Agricultura e do Abastecimento (BRASIL, 1998b); e a lei $n^{\circ} 10.683$, de 28 de maio de 2003, que criou a Secretaria Especial de Aquicultura e Pesca (BRASIL, 2003). Boeger e Borghetti (2008) citam outras ações que instituições governamentais tomaram em prol da aquicultura, o setor produtivo de pescado que mais cresceu desde 1997, como o diagnóstico do setor aquícola apoiado pelo Conselho Nacional de Desenvolvimento Científico e Tecnológico (CNPq), em 1994; a criação do Comitê Acessor de Aquicultura do CNPq, que apoiava pesquisas aplicadas; o apoio do Serviço Brasileiro de Apoio às Micro e Pequenas Empresas (SEBRAE) ao primeiro projeto de aquicultura na área da carcinicultura de água doce, em 1996; a criação de grupos de trabalho para a realização de um levantamento do setor no âmbito nacional, em 1997; o desenvolvimento do Programa de Aquicultura Polarizada, a fim de diagnosticar a situação do setor, a partir de 1997; entre outros. Os autores ainda destacam este último projeto como o de maior importância para o desenvolvimento da atividade aquícola desde então.

Com exceção do número de trabalhadores da pesca e atividades relacionadas da região Sudeste, que sofreu diminuição de 31,12\%, tanto o número de estabelecimentos quanto o de trabalhadores da pesca, aquicultura e serviços relacionados, em todas as regiões do Brasil, tiveram um incremento entre 1995 e 2005. Nas regiões Norte, Nordeste e Sudeste, o crescimento do setor aquícola foi mais expressivo do que o crescimento do setor extrativista, principalmente na região Nordeste. Já as regiões Sul e Centro-oeste apresentaram crescimentos percentuais maiores para o número de estabelecimentos extrativistas e de trabalhadores da aquicultura (MTE). Na literatura pesquisada não foram encontradas informações que permitissem explicar essas variações regionais. A evolução do número de estabelecimento e de trabalhadores das regiões Norte, Nordeste, Sudese, Sul e Centro-oeste é apresentada no Apêndice A pelos gráficos 41 a 45, respectivamente.

Apesar de ser historicamente a região com a menor produção pesqueira, a região Centro-oeste apresentou o maior crescimento da produção entre 1996 e 2006 
(107,75\%), seguida das regiões Nordeste $(75,21 \%)$, Norte $(74,83 \%)$, Sul $(27,65 \%)$ e Sudeste (22,37\%) (Gráfico 6) (IBAMA, 2007, 2008).

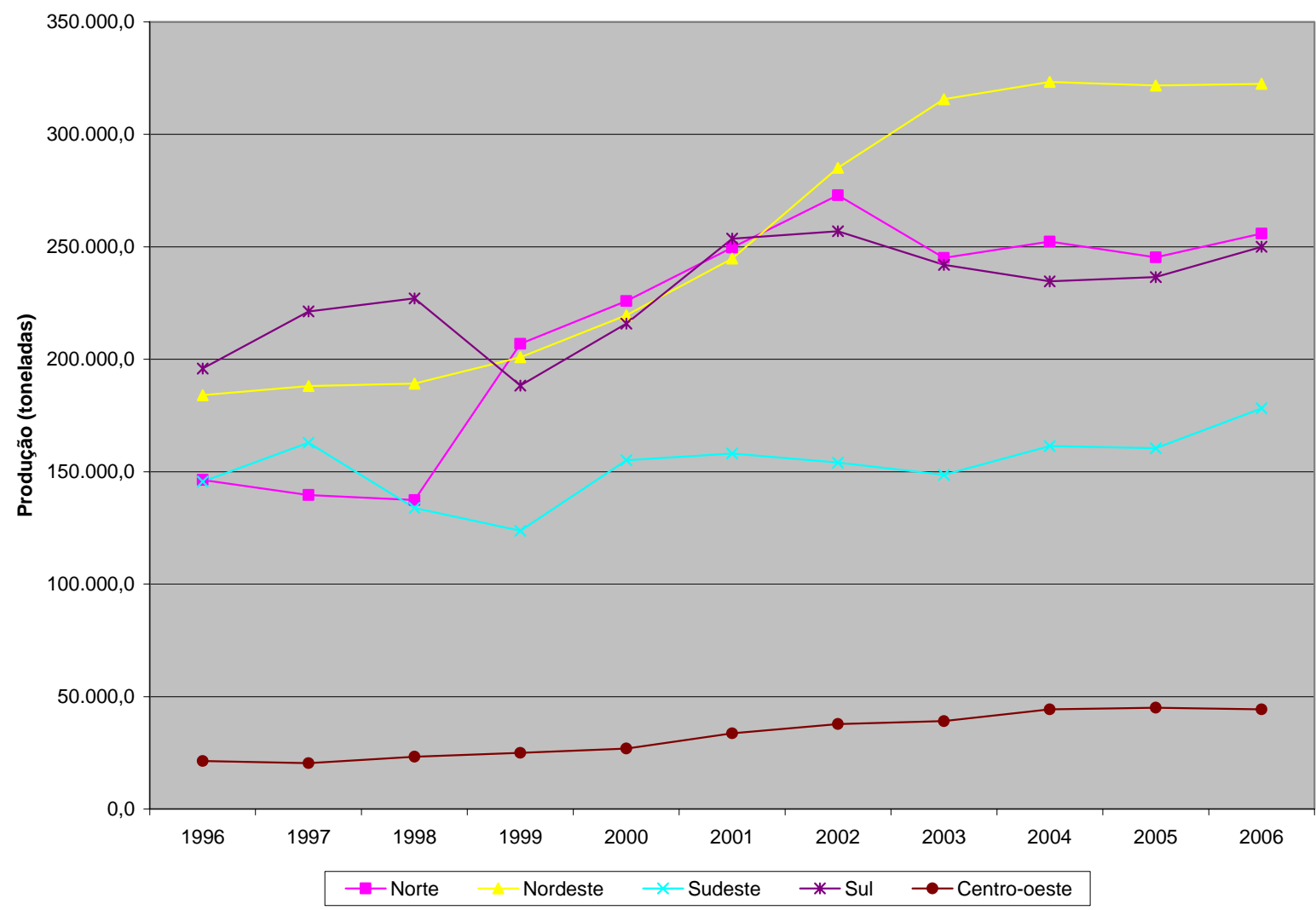

Fonte: IBAMA, 2007, e IBAMA, 2008.

Gráfico 6 - Produção de pescado por regiões do Brasil - 1996-2006

Em 2006, a região Nordeste apresentou a maior produção de pescado do Brasil (30,69\% da produção total), seguida pelas regiões Norte, Sul, Sudeste e Centrooeste $(24,35, \% ; 23,79 \% ; 16,96 \%$ e $4,21 \%$ da produção total, respectivamente). No entanto, os estados de maior representatividade foram Santa Catarina e Pará (15,69\% e 14,54\% da produção total, respectivamente) (Gráfico 7) (IBAMA, 2008). 


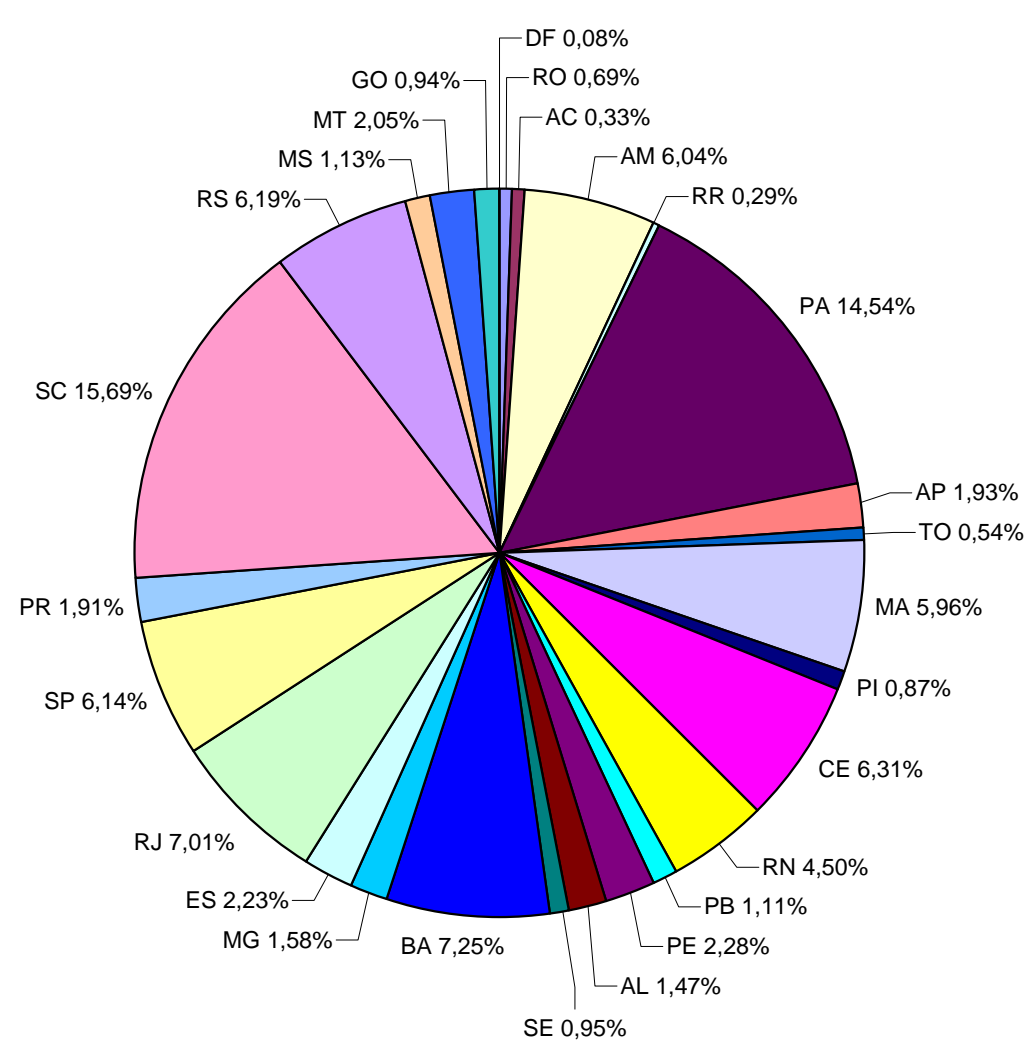

Fonte: IBAMA, 2008.

Gráfico 7 - Distribuição da produção de pescado por unidade federativa no Brasil - 2006

A maior produção por parte da região Nordeste pode ser explicada pelo seu excelente desempenho em todas as modalidades produtivas de pescado, figurando sempre entre as duas regiões de maior produção, tanto no setor extrativista marinho e continental quanto na maricultura (no ano de 2006, a região Nordeste teve a terceira maior produção na modalidade aquicultura continental, com volume muito próximo ao da região Sudeste, segunda maior produção nesse quesito). Contudo, esse excelente desempenho da região na produção de pescado é de difícil explicação, uma vez que, segundo o MMA (1996), o potencial produtivo extrativista marítimo é reduzido devido à elevada salinidade e temperatura e às baixas quantidades de sais nutrientes da Corrente do Brasil. Essas características fazem com que o potencial extrativo marítimo da região seja o menor do Brasil, de acordo com o Departamento de Pesca e Aquicultura da FAO (FAO, 2001).

Já a região Norte figura como a segunda maior produtora devido à grande exploração extrativista continental, justificada pela presença da Bacia Amazônica, que detém grande parte do potencial de águas superficiais do país (OSTRENSKY; 
BOEGER; CHAMMAS, 2008). Apesar de possuir a menor produção extrativa marinha, a atividade na região Norte é beneficiada pela desembocadura do Rio Amazonas, que fornece nutrientes às costas dos estados do Pará (segundo maior produtor de pescado do Brasil) e Amapá (sétimo maior produtor) (BRASIL, 1996), fazendo com que essa região tenha o segundo maior potencial extrativo marinho do país (FAO, 2001).

De modo semelhante à região Nordeste, a região Sul também figura entre as duas regiões de maior produção em quase todas as modalidades produtivas, com exceção da pesca continental. A região apresenta a maior produção aquícola continental e a segunda maior produção aquícola marinha, além de ser beneficiada pelas características de baixa temperatura e salinidade e elevada concentração de sais e nutrientes da Água Central do Atlântico Sul (BRASIL, 1996), fazendo com que a região tenha o segundo maior potencial produtivo marinho (FAO, 2001). Nesse contexto se encontra o estado de Santa Catarina, o maior produtor de pescado do Brasil.

A representatividade da produção pesqueira vem diminuindo, paralelamente ao aumento da produção aquícola, embora ainda seja responsável pela maior parte da produção nacional (Gráfico 4). No ano de 2006, a pesca extrativa marinha foi responsável por pouco mais da metade da produção total $(50,23 \%)$, seguida da pesca extrativa continental, aquicultura continental e maricultura (23,91\%; 18,19\% e $7,66 \%$ da produção total, respectivamente) (Gráfico 8), o que mostra a dependência do Brasil em relação aos estoques naturais e a subutilização do seu potencial para o setor de cultivo (IBAMA, 2008). 


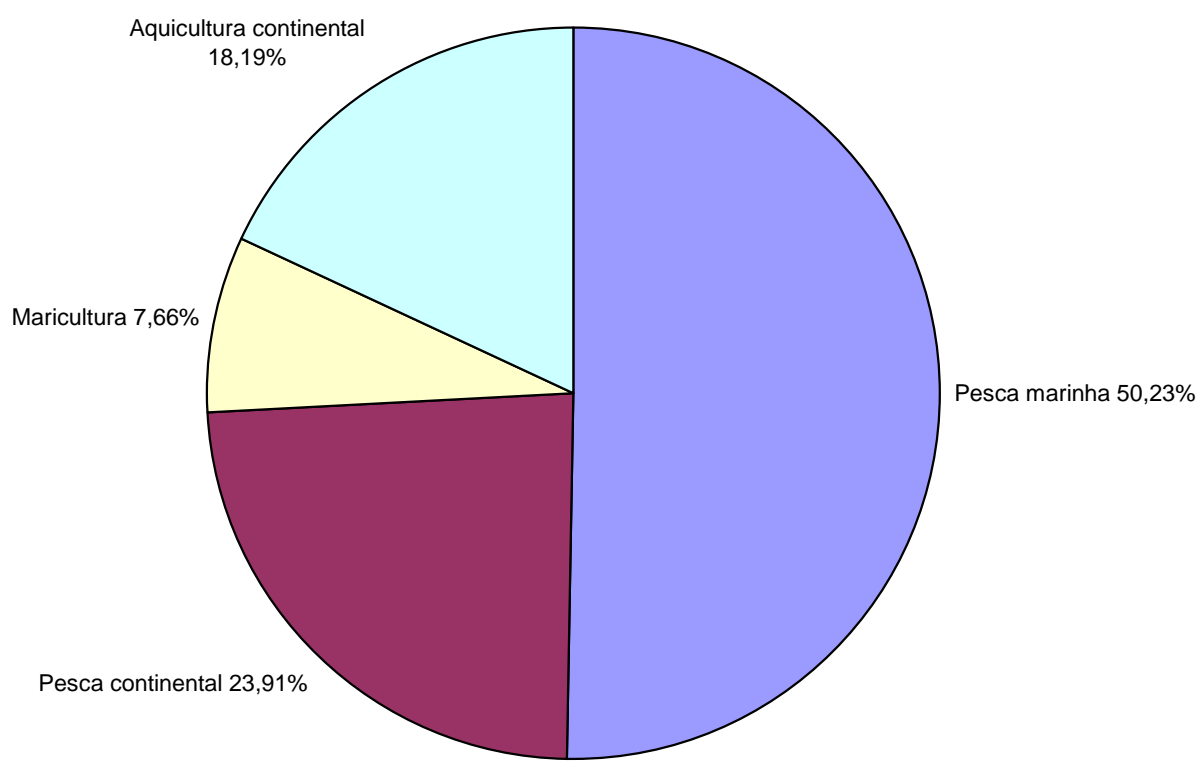

Fonte: IBAMA, 2008.

Gráfico 8 - Distribuição da produção pesqueira brasileira por tipo de produção - 2006

Conforme o Departamento de Pesca e Aquicultura da FAO, a maior parte da produção brasileira de pescado é destinada ao mercado externo, enquanto uma menor parte é destinada ao mercado interno, na forma de produto fresco ou processado. De modo geral, a produção pesqueira artesanal é voltada principalmente para o abastecimento do mercado interno, na forma fresca ou refrigerada. A produção da frota costeira fornece, principalmente, insumos para as indústrias de enlatados, de refrigeração e de congelamento, produzindo diferentes tipos de produtos para exportação e, em menor parte, para o mercado interno. Por sua vez, a produção oceânica é voltada para a exportação de produtos frescos, refrigerados e congelados e, em menor parte, para o mercado interno (FAO, 2001).

Em relação à remuneração, no ano de 2005, aproximadamente $73 \%$ dos trabalhadores da pesca estavam na faixa salarial entre 1,01 e 3,00 salários mínimos $^{7}$, enquanto que na aquicultura aproximadamente $85 \%$ dos trabalhadores

\footnotetext{
${ }^{7}$ De acordo com BRASIL (2005a), a partir de $1^{\circ}$ de maio de 2005, o valor do salário mínimo passou a ser de $\mathrm{R} \$ 300,00$ (trezentos reais), sendo esta lei posteriormente revogada pela Lei $\mathrm{n}^{\circ} 11.321$, de 07/07/2006.
} 
encontravam-se na faixa entre 0,51 e 2,00 salários mínimos (Gráfico 9) (BRASIL, [2008?c]).

Conforme dito anteriormente, além da falta de confiabilidade das informações a respeito da produção de pescado no Brasil, é provável que a quantificação dos estabelecimentos e dos trabalhadores também esteja sujeita a erros, uma vez que devem existir trabalhadores autônomos e sem registro atuando na atividade pesqueira, não sendo incluídos na RAIS e subestimando a quantificação.

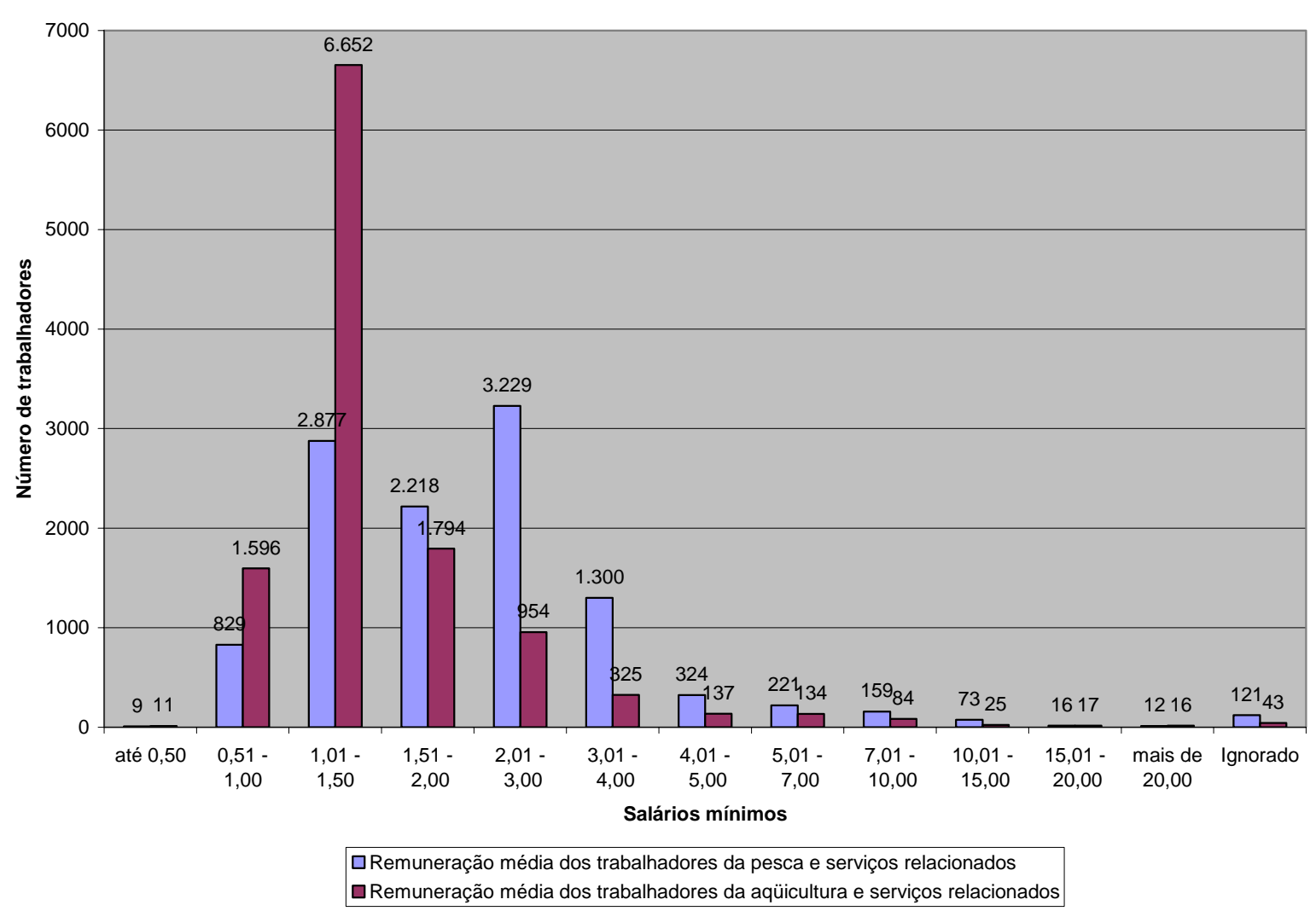

Fonte: BRASIL, [2008?c].

Gráfico 9 - Remuneração média dos trabalhadores brasileiros da pesca, aquicultura e serviços relacionados -2005

\subsubsection{Setor pesqueiro}

De acordo com Dias-Neto e Dornelles (1996), no Brasil, os sistemas de pesca são classificados em cinco modalidades, sendo três delas relacionadas à atividade produtiva comercial: 
a) Pesca amadora: é a atividade praticada ao longo do litoral, com finalidade de turismo, lazer ou desporto, não podendo o produto ser industrializado e/ou comercializado;

b) Pesca de subsistência: modalidade cujo objetivo é a obtenção de alimento para consumo próprio, praticada com técnicas rudimentares e sem finalidade comercial;

c) Pesca artesanal ou de pequena escala: abrange a atividade pesqueira cujo objetivo é a obtenção de alimento para a família e a comercialização de produtos ou exclusivamente de caráter comercial. Esta, em geral, é praticada como alternativa sazonal à agricultura, utilizando equipamentos básicos de navegação, embarcações de médio porte com propulsão motorizada ou não, adquiridas de estaleiros, e materiais de pesca também adquiridos no comércio local e em áreas de atuação próxima da costa. Já aquela utiliza material de pesca e embarcação construídos pelos próprios pescadores. Ambas apresentam tecnologia de captura capaz de produzir pequenos e médios volumes de pescado. Representa a maior parte da frota brasileira;

d) Pesca industrial costeira: é realizada por embarcações de maior autonomia, capazes de atuar em áreas mais distantes da costa. Apresenta propulsão motorizada à diesel, equipamento eletrônico de navegação e detecção, podendo o casco da embarcação ser de madeira ou aço. Está concentrado na captura dos principais recursos em volume ou valor da produção nacional;

e) Pesca industrial oceânica: atividade ainda incipiente no Brasil, que envolve embarcações capazes de atuar em toda a ZEE, incluindo áreas oceânicas mais distantes e mesmo outros países. São embarcações amplamente mecanizadas, de grande autonomia, podendo até industrializar o pescado a bordo, apresentando sofisticado equipamento de navegação e detecção.

De acordo com o Departamento de Pesca e Aquicultura da FAO, a frota pesqueira brasileira marítima é dividida em três categorias: 1.630 embarcações para a pesca costeira; 100 embarcações para a pesca oceânica, das quais 60 são embarcações estrangeiras arrendadas; e 23.000 embarcações para a pesca artesanal (FAO, 2001). 
Das 779.112,5 toneladas $(\mathrm{R} \$ 2.276 .762 .230,05)$ de pescado produzidas pela pesca em 2006, 527.871,5 toneladas ( $R$ 1.690.364.770,00) foram de origem da pesca marinha e $251.241,0$ toneladas $(R \$ 586.397 .460,05)$ foram de origem da pesca continental, fazendo com que o setor extrativista correspondesse a $74,14 \%$ da produção total de pescado (IBAMA, 2008). Isso mostra o elevado grau de dependência do Brasil em relação à situação dos estoques naturais explotados e a necessidade do uso sustentável dos recursos disponíveis.

No ano de 2006, os estados de maior representatividade para a pesca marinha foram Santa Catarina $(24,09 \%$, tendo como principais espécies a abrótea Urophycis spp; o bonito-listrado - Katsuwonus pelamis; a cabra - Prionotus spp; a castanha - Umbrina canosai; a corvina - Micropogonias furnieri; a sardinhaverdadeira - Sardinella brasiliensis; a tainha - Mugil spp; o camarão-barba-ruça Artemesia longinaris; e a lula - várias espécies das famílias Loliginidae e Ommastrephidae), o Pará (14,86\%, tendo como principais espécies o bagre - Bagre spp; a corvina - Micropogonias furnieri; a gurijuba - Arius sp; o pargo - Lutjanus purpureus; a pescada-amarela - Cynoscion acoupa; a serra - Scomberomorus spp, Auxis thazard thazard, Sarda sarda e Pristis perotteti; os tubarões - diversas espécies; a uritinga - Sciades proops; o camarão-rosa - Farfantepenaeus spp; e o caranguejo - diversas espécies) e o Rio de Janeiro (12,68\%, tendo como principais espécies o bonito-listrado - Katsuwonus pelamis; a corvina - Micropogonias furnieri; o peixe-porco - diversas espécies da família Balistidae; a sardinha-boca-torta Anchovia clupeoides; e a sardinha-verdadeira - Sardinella brasiliensis). A região Sul apresentou a maior produção nessa modalidade, seguida pelas regiões Nordeste, Sudeste e Norte (31,87\%; 29,39\%; 22,51\% e 16,21\% da produção extrativista marinha, respectivamente) (Gráfico 10) (IBAMA, 2008). 


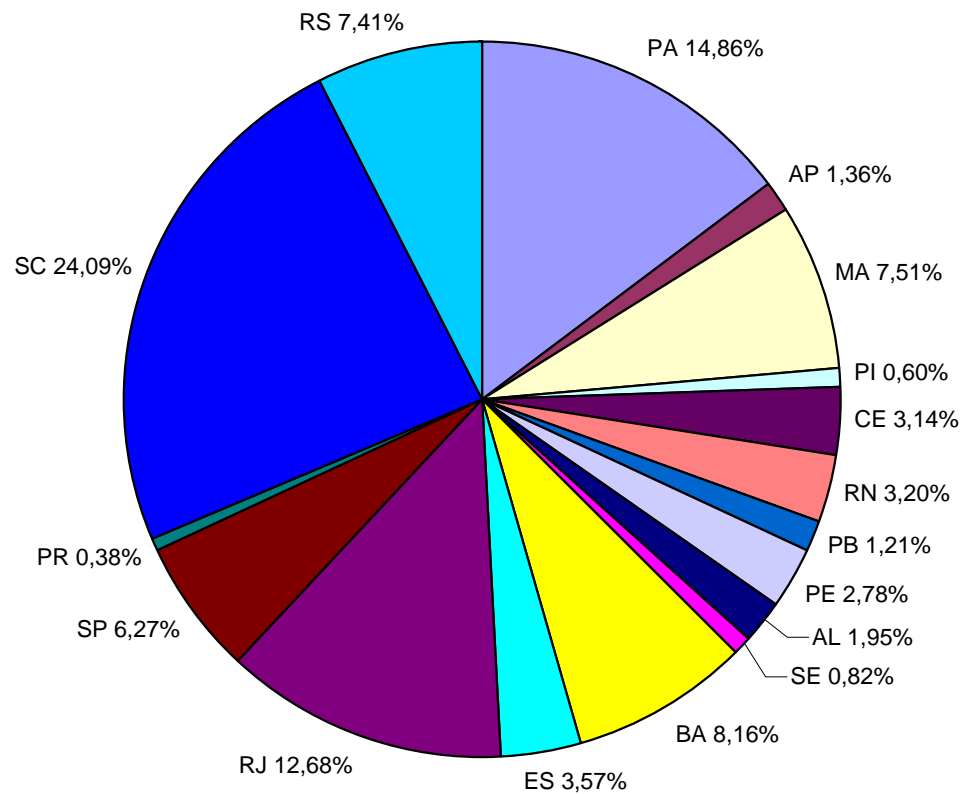

Fonte: BRASIL, [2008?c].

Gráfico 10 - Distribuição da produção da pesca marinha brasileira por unidade federativa - 2006

A maior produção marinha por parte da região Sul, em especial de Santa Catarina, bem como a elevada produção do estado do Rio de Janeiro, podem ser explicadas pelas características da Água Central do Atlântico Sul de baixa temperatura e salinidade e elevada concentração de sais e nutrientes (BRASIL, 1996). Já a elevada produção do estado do Pará é explicada pela desembocadura do Rio Amazonas, que fornece nutrientes à região costeira desse estado (BRASIL, 1996).

Já para a pesca continental, no ano de 2006, os estados de maior representatividade foram o Pará $(28,64 \%$, tendo principais espécies a dourada Brachyplatystoma rousseauxii; a mapará - Hipophthalmus marginatus; a pescada Plagioscon spp; e a piramutaba - Brachyplatystoma vaillant) e o Amazonas (22,81\%, tendo como principais espécies a curimatã - Prochilodus spp; o jaraqui Semaprochilodus spp; o pacu - Metynnis spp; e a piramutaba - Brachyplatystoma vaillant). A região Norte apresentou a maior produção nessa modalidade, seguida pelas regiões Nordeste, Sudeste, Centro-oeste e Sul (58,88\%; 26,87\%; 8,92\%; 
$4,11 \%$ e 1,21\% da produção extrativista continental, respectivamente) (Gráfico 11) (IBAMA, 2008).

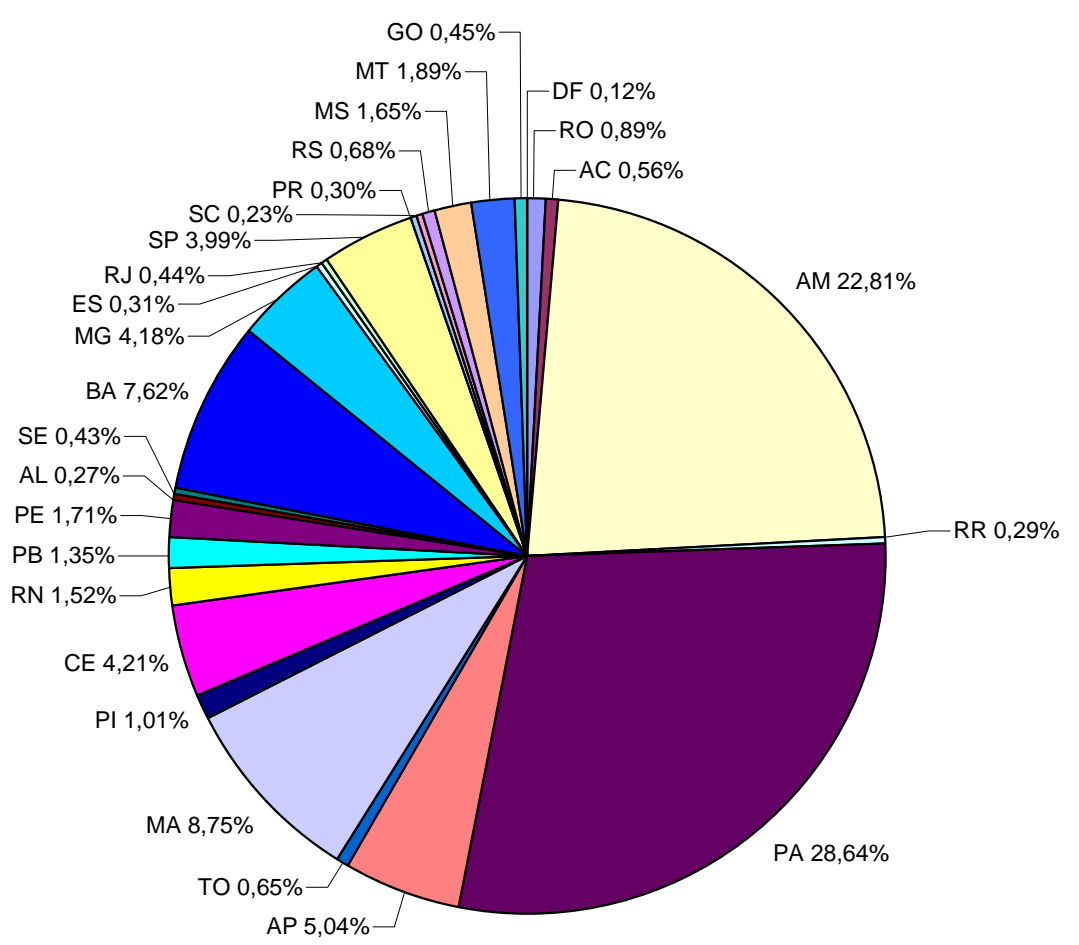

Fonte: BRASIL, [2008?c].

Gráfico 11 - Distribuição da produção da pesca continental brasileira por unidade federativa - 2006

A maior produção extrativista em águas continentais por parte dos estados da região Norte é explicada pela presença da Bacia Amazônica, que detém grande parte do potencial de águas superficiais do país (OSTRENSKY; BOEGER; CHAMMAS, 2008).

A última publicação do IBAMA sobre os recursos pesqueiros, datada de 2008, dispõe de uma variedade de dados, incluindo informações sobre o volume produzido de cada espécie de pescado por Unidade Federativa. Neste trabalho, como forma de caracterização do setor, o Anexo A mostra as principais espécies da pesca brasileira, segundo o IBAMA (2008).

De acordo com os dados de 2005 da RAIS, o Brasil apresentou um total de 1.130 estabelecimentos relacionados à pesca. Os estados de Santa Catarina, São Paulo e 
Rio de Janeiro foram os mais expressivos em termos de quantidade de estabelecimentos (297, 244 e 207 respectivamente), fazendo com que a região Sudeste concentrasse a maioria, seguida pelas regiões Sul, Nordeste, Norte e Centro-oeste $(45,13 \% ; 31,94 \% ; 12,66 \% ; 6,82 \%$ e 3,45\% do total, respectivamente) (Gráfico 12) (BRASIL, [2008?c]).

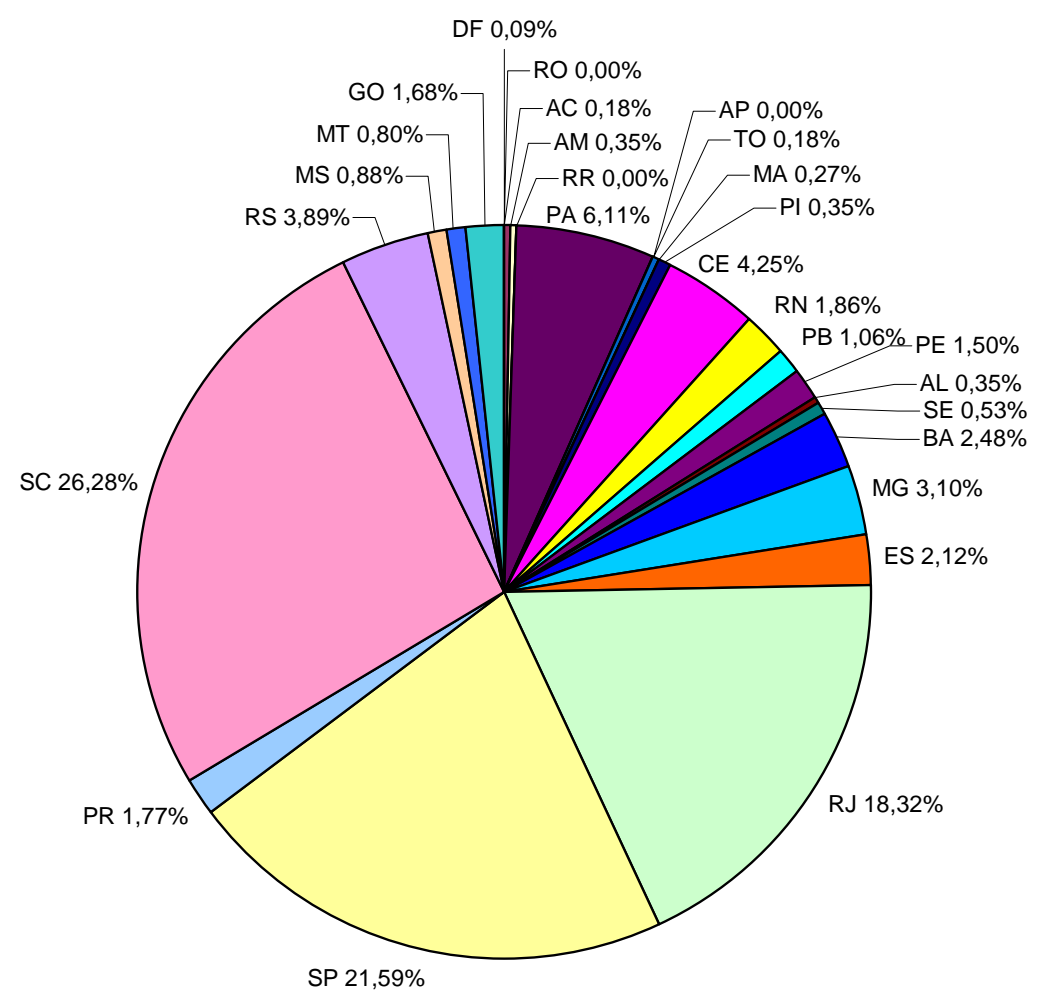

Fonte: BRASIL, [2008?c].

Gráfico 12 - Distribuição dos estabelecimentos de pesca e serviços relacionados por unidade federativa - 2005

Sendo as regiões Norte e Nordeste as maiores produtoras de pescado no segmento extrativista, pode-se observar uma maior concentração da produção em um menor número de estabelecimentos, enquanto que nas regiões Sul e Sudeste, de menor produção extrativista, observa-se uma distribuição da produção em uma maior quantidade de estabelecimentos. Na literatura pesquisada, não foram encontradas justificativas e consequências para essa observação.

No ano de 2005, o setor de pesca e serviços relacionados empregou um total de 11.388 trabalhadores. Das 584 famílias ocupacionais relacionadas na RAIS, a família "Pescador de água costeira e alto mar" foi a que apresentou maior número de 
trabalhadores, empregando um total de 3.807. Para a correta interpretação do Gráfico 13, é importante salientar que na denominação "Outros" ocorrem diversas ocupações cujas porcentagens individuais foram inferiores a 1,55\% como, por exemplo, "Trabalhadores agropecuários em geral" (0,5\%), "Tratadores polivalentes de animais" (0,04\%) e "Diretores Gerais" (0,02\%) (Gráfico 18) (BRASIL, [2008?c]).
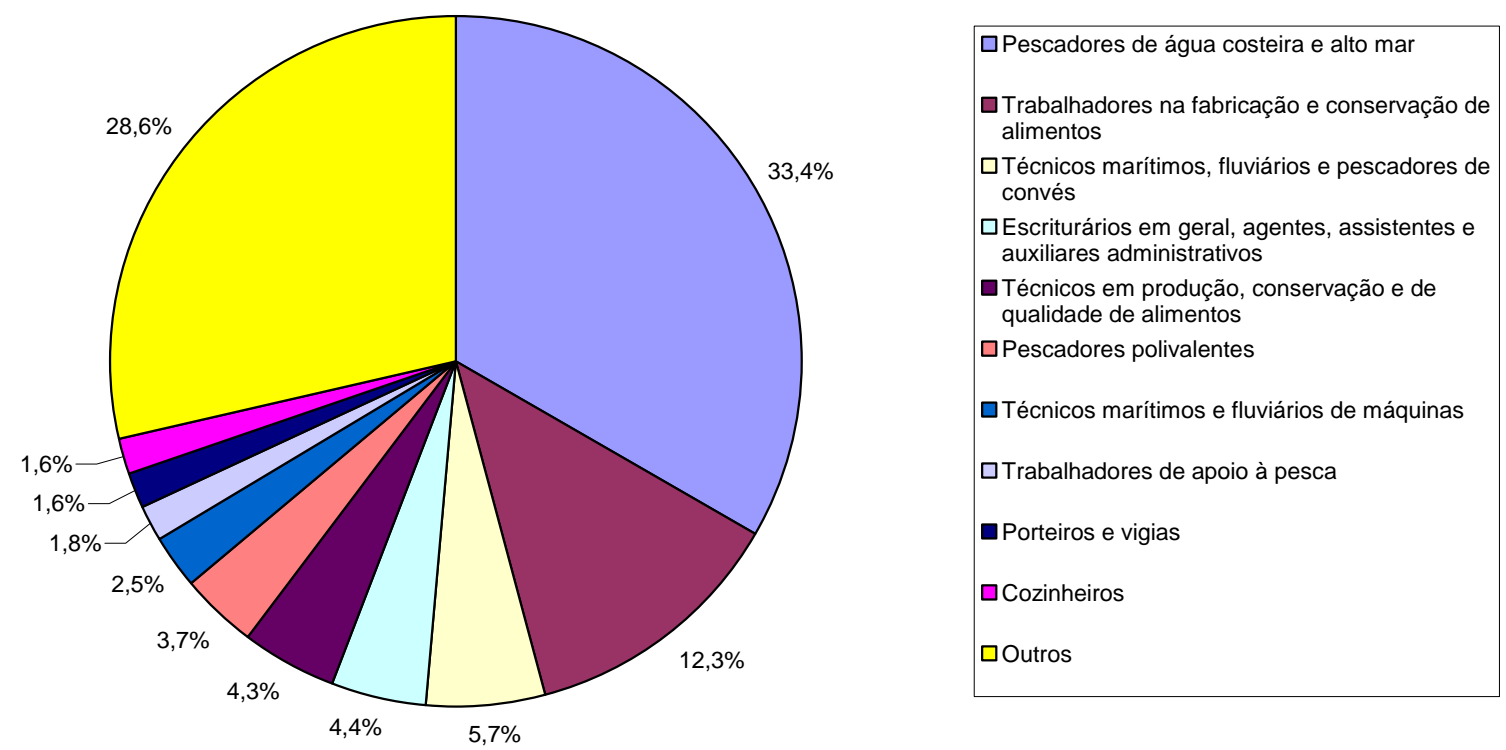

Fonte: BRASIL, [2008?c].

Gráfico 13 - Principais ocupações da pesca e serviços relacionados - 2005

\subsubsection{Setor aquícola}

De acordo com Lucas e Southgate (2003), os sistemas de produção aquícola são classificados de acordo com três critérios principais: as estruturas utilizadas, a intensidade de produção e as trocas de água. Em relação às estruturas, dificilmente ocorre a utilização de uma única estrutura durante todo o processo de desenvolvimento do pescado, com exceção da produção de algumas espécies em particular. As estruturas são classificadas em: 
a) Lagoa: é a estrutura mais simples, requer um suprimento de água de boa qualidade, um terreno impermeável com adequada quantidade de matéria orgânica no solo e, preferencialmente, com certo grau de declividade. Pode ser do tipo escavado, barragem ou represado. Normalmente é utilizado para o cultivo de peixes e crustáceos. É a estrutura de menor custo, tanto para a construção quanto para a manutenção, porém, permite a produção em pequenas densidades. Apresenta diversos esquemas de construção, cada qual com vantagens e desvantagens diferentes: em série (vantajoso pela facilidade de movimentação entre as unidades, e desvantajoso por apresentar isolamento entre as unidades e diminuição do controle da qualidade da água e de doenças), em paralelo (apresenta maior dificuldade na movimentação entre as unidades e um maior custo com a maior utilização de água, porém, a qualidade desta é superior, além da simplificação da gestão da qualidade da água), radial (é utilizada em casos específicos, quando da entrada constante de formas jovens, com necessidade de maior espaço durante o desenvolvimento) e compartilhado (onde dentro de uma unidade maior, que comporta o desenvolvimento dos organismos em estágios avançados, existe uma unidade menor, para o berçário);

b) Tanques: são estruturas amplamente utilizadas depois das lagoas, geralmente com construção em alvenaria. Podem ser utilizados em locais onde o terreno não é adequado para a construção de lagoa, uma vez que nesse tipo de construção a água não entra em contato com o solo. São mais utilizados para o desenvolvimento de estágios iniciais de peixes, bivalves, crustáceos e cultivos de peixes de alto valor;

c) Raceways: são muito semelhantes aos tanques, mas apresentam entrada e saída de água em lados opostos da construção permitindo certo grau de correnteza da água. São mais utilizados para o cultivo de peixes de alto valor comercial;

d) Gaiolas: são estruturas quadradas, retangulares ou circulares, de tamanhos variados e recobertas com redes. São mais utilizadas para a produção de peixes na fase de terminação. Apresentam preço de custo intermediário, baixo custo de operação, necessidade de manutenção e não requer bombeamento de água. Não permite controle da qualidade de água, predadores, parasitas e 
desenvolvimento de organismos indesejáveis. É necessário o suprimento de água de boa qualidade;

e) Cercado: utilizado em locais de água rasa, principalmente na criação de moluscos gastrópodes;

f) Substratos, racks e cultivos suspensos: utilizados para cultura de bivalves.

Já em relação à Intensidade de cultivo, leva-se em consideração a densidade de organismos criados por unidade de volume ou de área. Quanto maior a densidade, maiores são os requerimentos de entrada do sistema produtivo. Os sistemas são classificados em:

a) Ecossistema natural: necessita da presença de energia disponível aos animais no ambiente para suprir as perdas metabólicas;

b) Intensivo: toda a nutrição é introduzida pela alimentação, sem utilização de dietas naturais que podem estar presentes no meio. Pode ocorrer em estruturas do tipo lagoas, gaiolas, tanques e raceways. A densidade máxima é dependente da manutenção da qualidade da água. O sistema utiliza grande volume de troca de água, podendo ser até mecânico. Mecanismos para aeração da água podem estar presentes;

c) Extensivo: caracterizado pelo baixo custo de produção, o sistema é utilizado para a criação de peixes de baixo valor. Apresenta pouco controle sobre 0 ambiente, baixa produtividade, alimentação to tipo natural e baixa densidade de produção;

d) Semi-intensivo: meio termo entre extensivo e intensivo, pode apresentar mecanismos de aeração, fertilização e suplementação alimentar;

e) Policultura: ocorre em sistemas semi-intensivos e extensivos, com criação de diferentes espécies no mesmo local, aumentando a produção por maximizar a utilização dos nichos nutricionais;

f) Integração agropecuária-aquicultura: ocorre o desenvolvimento de diversas espécies no mesmo local, reutilizando a água de maneira sucessiva e com integração com outros sistemas produtivos. É mais frequente em pequenas produções familiares.

Por fim, em relação aos sistemas de troca de água, podem ser classificados como: 
a) Sistema estático: não ocorre troca de água durante o período de cultivo. Geralmente ocorre em sistemas extensivos;

b) Sistema aberto: o próprio meio ambiente é o local de produção, através de isolamento em grandes áreas de água. A qualidade da água é mantida por meios naturais, sem circulação artificial. Apresenta baixos custos operacionais, porém ocorre a perda do controle da qualidade da água, predadores e doenças;

c) Sistema semi-fechado: ocorre em estruturas do tipo lagoas, tanques e raceways, com confinamento dos animais em unidades. Apresenta troca de água maior do que o sistema fechado;

d) Sistema de recirculação: caracterizado pelo mínimo contato com o meio ambiente e com a fonte de água original. Durante o ciclo de produção, ocorre mínima troca de água, havendo adição para suprir as perdas (acidentais ou por evaporação) e para garantir a qualidade da água.

A aquicultura brasileira é baseada principalmente em regimes semi-intensivos de produção e, com exceção da carcinicultura, é sustentada principalmente por pequenos produtores. Tal fato deve ser encarado como positivo, uma vez que os grandes produtores mundiais de organismos aquáticos cultivados são países cuja produção está baseada em pequenas propriedades (VALENTI et al., 2000). Como exemplos dos regimes de produção no Brasil, Borghetti e Silva (2008) citam:

a) Semi-intensivo: a carcinicultura marinha e a maioria dos cultivos de peixes realizados em viveiros escavados;

b) Extensivo: os cultivos de peixes realizados por pequenos produtores em Santa Catarina e no Rio Grande do Sul que utilizam subprodutos agrícolas ou dejetos animais na alimentação dos peixes; a produção de tambaqui (Colossoma macropomum), curimbatás (Prochilodus argenteus e P. brevis), tilápia (Oreochromis spp) e carpas (comum e Chinesa) em açudes particulares; e a malacocultura;

c) Intensivo: os cultivos de tilápia em tanques-rede nos grandes reservatórios da União, como os reservatórios do Rio São Francisco e do Rio Tietê; a 
carcinicultura marinha; e a integração de ostras (Crassostrea rhizophorae) e macroalgas (Gracillaria sp).

Segundo Borghetti e Silva (2008), os principais sistemas de cultivo empregados na aquicultura continental do Brasil são:

a) Cultivos em viveiros: sendo diferenciados em viveiros adubados (capacidade de suporte entre 1.000 e $3.700 \mathrm{Kg} / \mathrm{ha}$ ), viveiros adubados com suplementação alimentar (capacidade de suporte entre 2.500 e $5.00 \mathrm{Kg} / \mathrm{ha}$ ), viveiros com baixa renovação de água e ração completa (capacidade de suporte entre $6.000 \mathrm{e}$ $10.000 \mathrm{Kg} / \mathrm{ha}$ ) e viveiros com renovação de água e aeração (capacidade de suporte pode chegar a $40.000 \mathrm{Kg} / \mathrm{ha}$ ). São exemplos de espécies cultivadas: a carpa (Cypinnus carpio, Ctenopharyngodon idella, Hipophtalmichys molitrix, Aristichthys nobilis), a tilápia (Oreochromis niloticus, O. hornorum), o catfish (Ictalurus punctatus), o tambaqui (Colossoma macropomum), o curimbatá (Prochilodus scrofa), o jundiá (Rhandia sp), a rã (Rana catesbeiana) e o camarão de água doce (Macrobrachium rosenbergii);

b) Cultivos consorciados: ocorre principalmente no estado de Santa Catarina, com a integração entre a piscicultura e a suinocultura, são baseados na utilização de subprodutos agrícolas na alimentação dos peixes, no policultivo, abastecimento controlado e renovação mínima de água, e na baixa densidade de povoamento. A carpa (Cypinnus carpio, Ctenopharyngodon idella, Hipophtalmichys molitrix, Aristichthys nobilis) é um exemplo de espécie cultivada;

c) Cultivos em tanques-rede: implantado em barragens, açudes, lagoas e reservatórios da União. São exemplos de espécies cultivadas a tilápia (Oreochromis niloticus, O. hornorum), o tambaqui (Colossoma macropomum), o jundiá (Rhandia sp) e o camarão de água doce (Macrobrachium rosenbergii);

d) Cultivos em canais de irrigação: apesar da grande ocorrência na região Nordeste, os cultivos ainda são raros, pois o bombeamento de água não é contínuo, podendo baixar a concentração de oxigênio dissolvido na água para níveis críticos. 
Já em relação à aquicultura marinha, Borghetti e Silva (2008) citam os seguintes principais sistemas de cultivo empregados no Brasil:

a) Carcinicultura (Litopenaus vannamei, Farfantepenaus paulensis): cultivo em viveiros em regime extensivo ou semi-intensivo. No estado do Rio Grande do Sul, o cultivo em cercados está em desenvolvimento. Nos estados da Bahia, Paraná e São Paulo, o cultivo em tanques-rede existe em escala experimental;

b) Malacocultura (ostra do Pacífico - Crassostrea gigas, ostra-do-mangue - $C$. rizophorae, mexilhão - Perna perna): cultivo em águas da União utilizando um sistema suspenso fixo ou flutuante.

De acordo com o Departamento de Pesca e Aquicultura da FAO, a aquicultura brasileira é representada por três grandes grupos: peixes, crustáceos e moluscos. A piscicultura é um importante setor, explorando uma área de aproximadamente 40.000 hectares, tendo como principais espécies cultivadas a tilápia (Oreochromis spp), as carpas comum e Chinesa (Cyprinus carpio, C. idello, Nobilis molitrix e Hypophthalmichthys molitrix), o pacu (Piaractus mesopotamicus) e o tambaqui (Colossoma macropomum). Em relação à carcinicultura, o Brasil apresenta dois diferentes setores: o primeiro é a cultura de camarões marinhos, ocupando uma área de 6.500 hectares, com produção de 25.000 toneladas em 2000 , com cultivo da espécie Litopenaeus vannamei em 95\% dos criadouros; e o segundo é a cultura de camarões em água doce, ocupando uma área de aproximadamente 200 hectares, com produção anual de 500 toneladas (FAO, 2001).

Das 271.695,5 toneladas $(\mathrm{R} \$ 1.017 .841 .900,00)$ de pescado produzidas pela aquicultura em 2006, 80.512 toneladas $(R \$ 302.614 .500,00)$ foram de origem da maricultura e 191.183,5 toneladas $(\mathrm{R} \$ 715.227 .400,00)$ da aquicultura continental, fazendo com que o setor de cultivo correspondesse a $25,85 \%$ da produção total de pescado (IBAMA, 2008).

No ano de 2006, os estados com maior representatividade para aquicultura marinha foram o Rio Grande do Norte (32,79\%, tendo como principal cultivo o camarão Litopenaus vannamei), o Ceará (27,33\%, tendo como principal cultivo o camarão Litopenaus vannamei) e Santa Catarina (18,93\%, tendo como principais cultivos os 
mexilhões - Perna perna; ostras - Crassostrea gigas e C. rizophorae; e camarão Litopenaus vannamei). A região Nordeste apresentou a maior produção nessa modalidade, seguida pelas regiões Sul, Sudeste e Norte (79,18\%; 19,71\%; 0,79\% e 0,31\%, respectivamente) (Gráfico 14). A carcincicultura, atividade marcante na região Nordeste (BORGHETTI; SILVA, 2008), produziu 65.000 toneladas, representando $80,73 \%$ da produção oriunda da maricultura; enquanto que a malacocultura, atividade marcante em Santa Catarina (BORGHETTI; SILVA, 2008), produziu 14.757 toneladas, representando $18,32 \%$ da produção oriunda da maricultura (IBAMA, 2008).

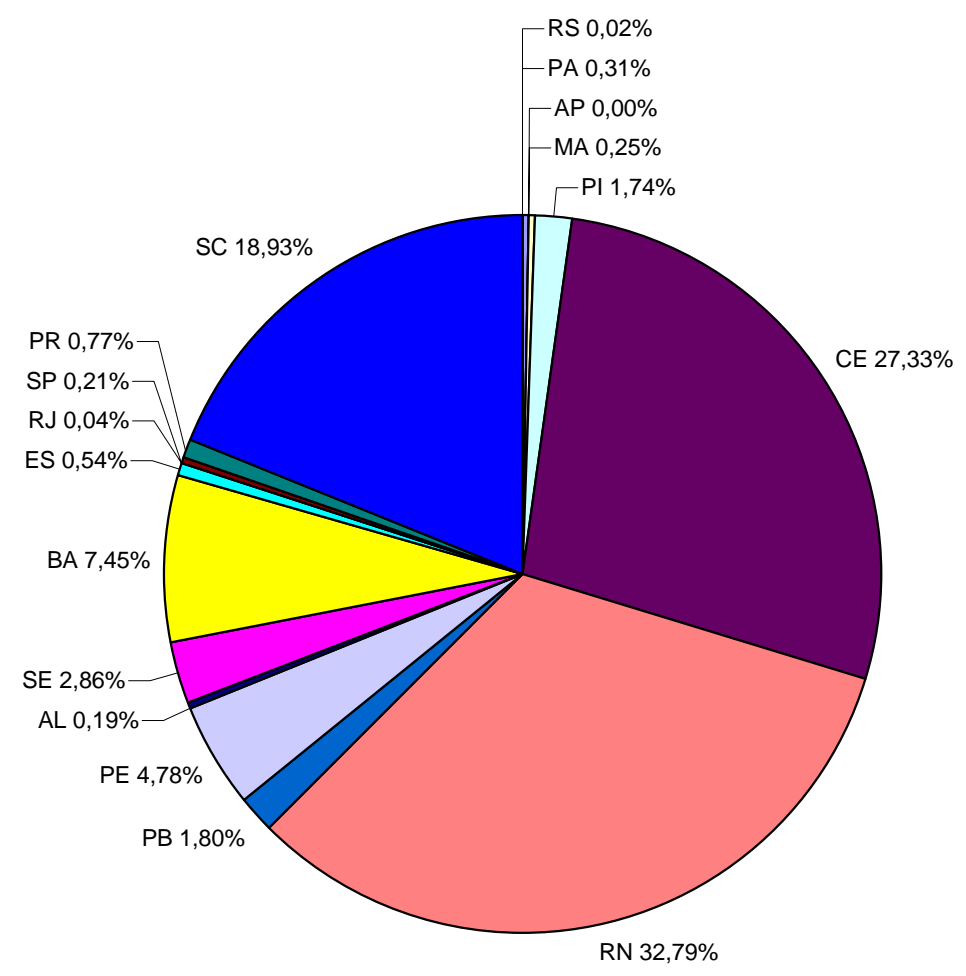

Fonte: IBAMA, 2008.

Gráfico 14 - Distribuição da produção da maricultura brasileira por unidade federativa - 2006

Já em relação à aquicultura continental, no ano de 2006, os estados de maior representatividade foram o Rio Grande do Sul (12,68\%, tendo como principal cultivo a carpa - Cyprinus carpio, C. idello, Nobilis molitrix e Hypophthalmichthys molitrix), Santa Catarina $(11,45 \%$, tendo como principais cultivos a carpa - Cyprinus carpio, C. idello, Nobilis molitrix e Hypophthalmichthys molitrix e a tilápia - Oreochromis spp), São Paulo (11,11\%, tendo como principais cultivos a carpa - Cyprinus carpio, 
C. idello, Nobilis molitrix e Hypophthalmichthys molitrix e a tilápia - Oreochromis spp), Ceará (8,99\%, tendo como principal cultivo a tilápia - Oreochromis spp), Mato Grosso (8,80\%, tendo como principais cultivos o pacu - Piaractus mesopotamicus; tambacu - híbrido entre Piaractus mesopotamicus e Colossoma macropomum; e tambaqui - Colossoma macropomum) e o Paraná (8,73\%, tendo como principal cultivo a tilápia - Oreochromis spp). A região Sul apresentou a maior produção nessa modalidade, seguida pelas regiões Sudeste, Nordeste, Centro-oeste e Norte $(32,86 \% ; 18,97 \% ; 18,85 \% ; 17,74 \%$ e 11,55\%, respectivamente) (Gráfico 15) (IBAMA, 2008).

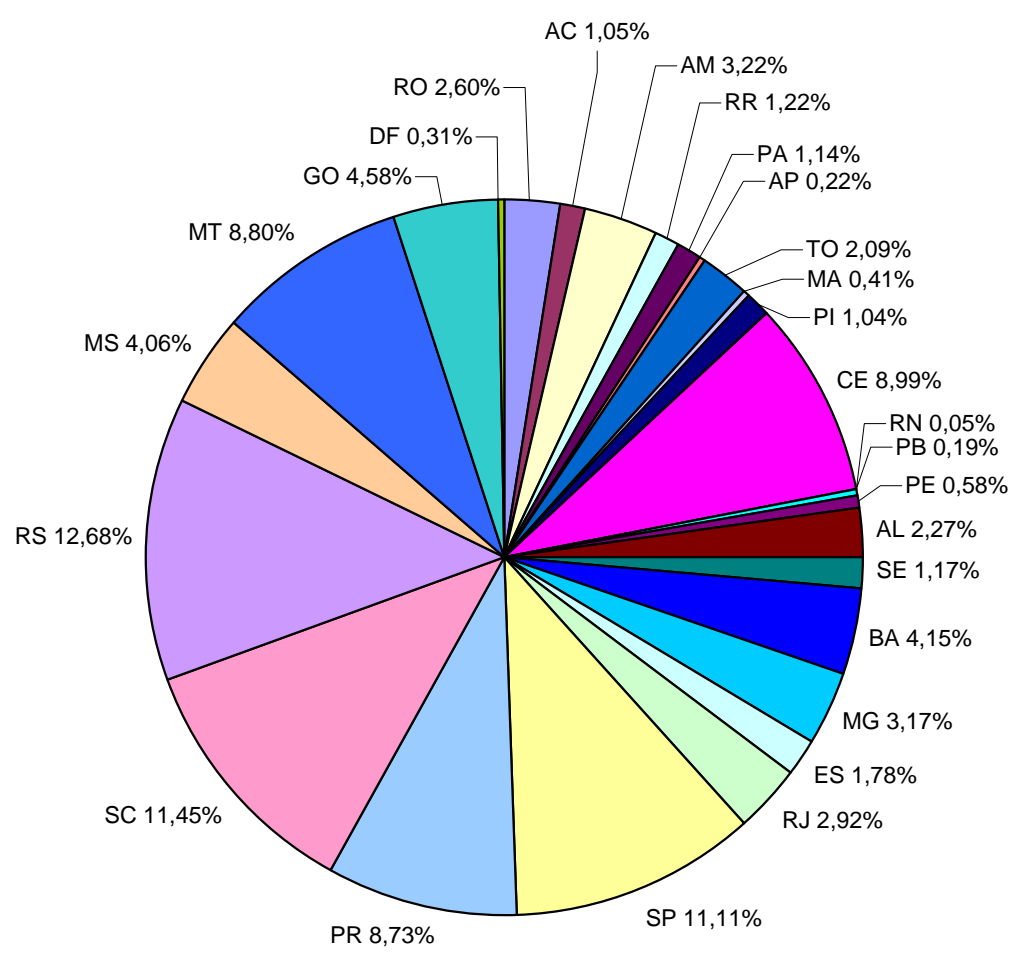

Fonte: IBAMA, 2008.

Gráfico 15 - Distribuição da produção da aquicultura continental brasileira por unidade federativa 2006

No Gráfico 15, ainda é possível observar a subutilização do potencial existente nas regiões Norte e Centro-oeste, as quais, segundo Ostrensky, Boeger e Chammas (2008), detém a maior disponibilidade de corpos de água do país, concentrando cerca de $89 \%$ do potencial de águas superficiais. 
De forma semelhante ao realizado na parte referente à pesca, como forma de caracterização do setor, o Anexo B mostra as principais espécies da aquicultura brasileira, segundo o IBAMA (2008).

Em relação ao número de estabelecimentos, no ano de 2005 o Brasil apresentou um total de 1.434 estabelecimentos relacionados à aquicultura. Os estados de Minas Gerais, Rio Grande do Norte e São Paulo (276, 197 e 174 estabelecimentos respectivamente) foram os mais expressivos em relação à quantidade desses. A região Nordeste concentrou a maioria, seguida pelas regiões Sudeste, Sul, Centrooeste e Norte $(38,07 \% ; 36,89 \% ; 16,53 \% ; 5,71 \%$ e 2,8\%, respectivamente) (Gráfico 16) (BRASIL, [2008?c]).

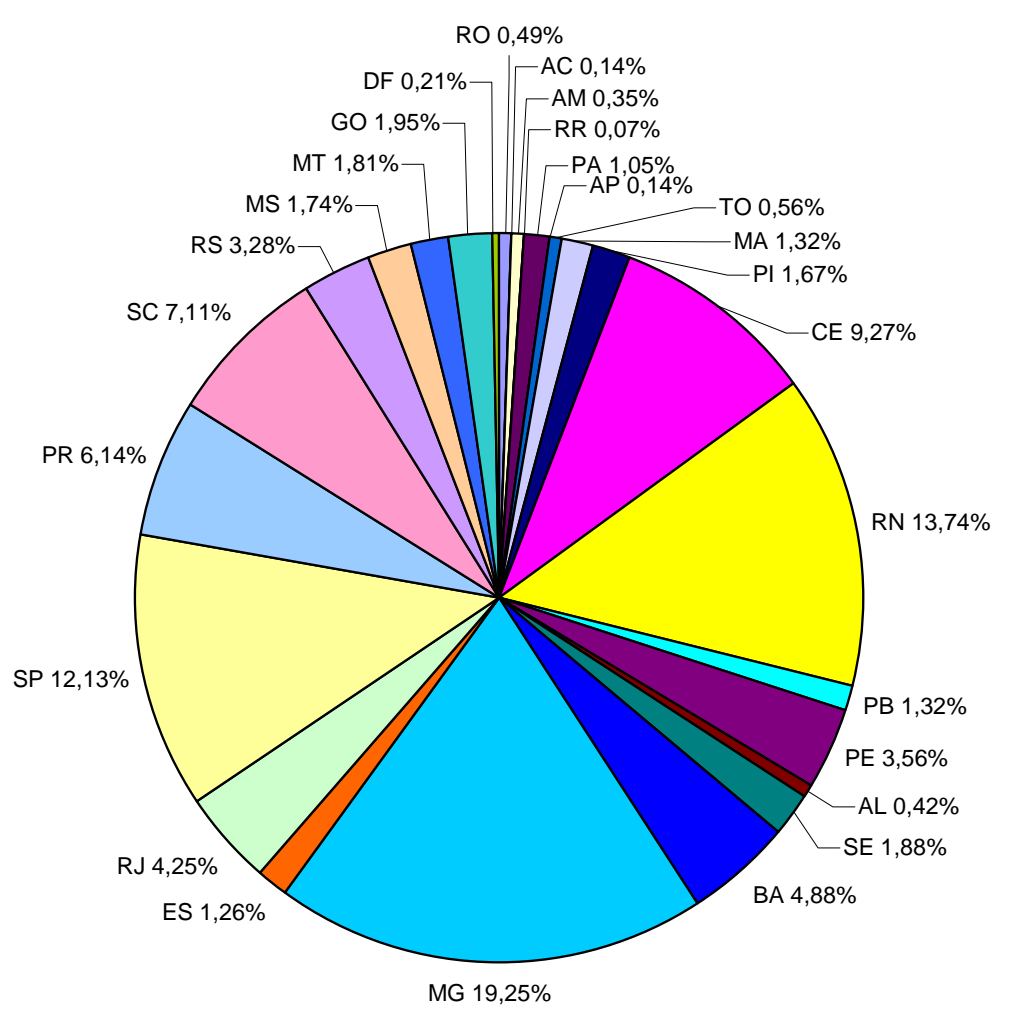

Fonte: BRASIL, [2008?c].

Gráfico 16 - Distribuição dos estabelecimentos de aquicultura e serviços relacionados por unidade federativa - 2005

No ano de 2005, o setor de aquicultura e serviços relacionados empregou um total de 11.788 trabalhadores. Das 584 famílias ocupacionais relacionadas na RAIS, a família "Trabalhadores agropecuários em geral" foi a que apresentou maior número de trabalhadores, empregando um total de 2.139. Para a correta interpretação do 
Gráfico 17, é importante salientar que na denominação "Outros" ocorrem diversas ocupações cujas porcentagens individuais foram inferiores a 3,16\% como, por exemplo, "Motoristas de veículos de cargas em geral" (1,15\%), "Supervisores na exploração agropecuária" (0,33\%) e "Diretores Gerais" (0,02\%) (Gráfico 17) (MTE).

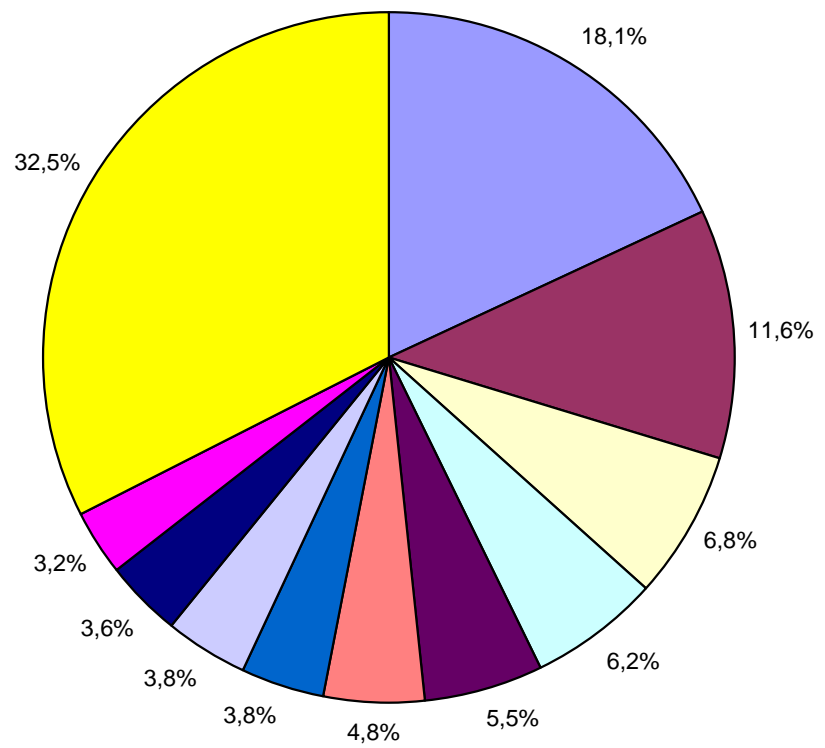

$\square$ Trabalhadores agropecuários em geral

$\square$ Criadores de animais aquáticos

口Trabalhadores na fabricação e conservação de alimentos

$\square$ Mantenedores de edificações

Porteiros e vigias

$\square$ Técnicos em aqüicultura

口Escriturários em geral, agentes, assistentes e auxiliares administrativos

口Trabalhadores nos serviços de manutenção e

conservação de edifícios e logradouros

- Pescadores polivalentes

$\square$ Trabalhadores de apoio à agricultura

$\square$ Outros

Fonte: MTE.

Gráfico 17 - Principais ocupações da aquicultura e serviços relacionados - 2005

\subsubsection{Setor industrial do pescado}

Durante a pesquisa por informações relacionadas ao segmento industrial do pescado, não foram encontrados dados oficiais publicados sobre a produção industrial e valores financeiros. Assim como ocorre no segmento produtor de pescado, a escassez de informações sobre o setor industrial é prejudicial ao seu desenvolvimento, dificultando, por exemplo, a análise e formulação de estratégias empresariais e políticas públicas. 
Todas as instituições consultadas, dentre elas a SEAP, o MAPA, o Departamento de Inspeção de Produtos de Origem Animal (DIPOA), a Divisão de Inspeção de Pescados e Derivados do DIPOA (DIPES), o Sindicato das Indústrias da Pesca de Itajaí e Região (SINDIPI), o Sindicato da Indústria da Pesca dos estados do Pará e Amapá (SIPESCA) e a Associação Brasileira das Indústrias da Alimentação (ABIA), não atenderam à solicitação de informações, negaram o conhecimento de tais informações ou indicaram a pesquisa junto à SEAP ou junto aos dois sindicatos das indústrias de Itajaí e do Pará (informação verbal ${ }^{8}$ ). Em virtude disso, não foi possível caracterizar o setor industrial através da produção e de valores financeiros.

Aparentemente, os dados relacionados à produção das indústrias registradas no Serviço de Inspeção Federal (SIF), bem como de informações sobre dificuldades técnicas nestes estabelecimentos e de problemas sanitários, são centralizados pela DIPES do DIPOA/MAPA (informação pessoal ${ }^{9}$ ). Porém, após diversas tentativas de contatar a divisão, através de contato telefônico e correio eletrônico (três e cinco tentativas, respectivamante), as solicitações não foram atendidas. Assim, a caracterização do segmento industrial de pescado ficou prejudicada pela impossibilidade de obter informações precisas sobre a produção da indústria brasileira.

IBGE (2006a), através da Pesquisa Industrial Anual sobre Produtos, apontou valores sobre as quantidades e valores financeiros de produção e de venda de diversos produtos produzidos pelas indústrias brasileiras, definidos de acordo com a CNAE (1.0, revisada em 2002) e com a Nomenclatura Comum do Mercosul (NCM). A pesquisa junto às indústrias de "Preparação e preservação do pescado e fabricação de conservas de peixes, crustáceos e moluscos" resultou em 144 estabelecimentos entrevistados no ano de 2006, gerando os resultados apresentados na Tabela 2. Esse foi o único trabalho identificado contendo dados numéricos sobre a indústria de pescado no Brasil.

\footnotetext{
${ }^{8}$ Informação fornecida por contato telefônico, correio eletrônico ou mensagens através da sessão Fale Conosco dos respectivos endereços eletrônicos, no período entre setembro e novembro de 2008.

9 Informação fornecida por contato telefônico no número (61) 3218-2775 e contato por correio eletrônico com Lúcio Akio Kikuchi, Diretor da DIPES, através do correio eletrônico lucio.kikuchi@agricultura.gov, entre outubro e novembro de 2008.
} 
Tabela 2 - Produção e vendas dos produtos industriais derivados do pescado no Brasil no ano de 2006

(continua)

\begin{tabular}{|c|c|c|c|c|c|}
\hline \multirow[b]{2}{*}{ Produto } & \multirow[b]{2}{*}{$\begin{array}{l}\text { Número de } \\
\text { informações }\end{array}$} & \multicolumn{2}{|c|}{ Produção } & \multicolumn{2}{|c|}{ Venda } \\
\hline & & Quantidade & $\begin{array}{c}\text { Valor } \\
\text { (R\$1.000) }\end{array}$ & Quantidade & $\begin{array}{c}\text { Valor } \\
(\mathrm{R} \$ 1.000)\end{array}$ \\
\hline $\begin{array}{l}\text { Crustáceos } \\
\text { congelados }\end{array}$ & 20 & $60.811,00 \mathrm{t}$ & $326.358,00$ & $44.608,00 \mathrm{t}$ & $224.018,00$ \\
\hline $\begin{array}{l}\text { Extratos ou sucos de } \\
\text { peixes, crustáceos, } \\
\text { etc. }\end{array}$ & 0 & 0 & 0 & 0 & 0 \\
\hline $\begin{array}{c}\text { Farinhas, pós e pellets } \\
\text { de peixes, próprios } \\
\text { para alimentação } \\
\text { humana }\end{array}$ & 4 & $\begin{array}{c}3.629 .132,00 \\
\mathrm{Kg}\end{array}$ & Omitido & $\begin{array}{c}1.286 .106,00 \\
\mathrm{Kg}\end{array}$ & Omitido \\
\hline $\begin{array}{c}\text { Farinhas, pós e pellets } \\
\text { de peixes, crustáceos } \\
\text { e moluscos, } \\
\text { impróprios para } \\
\text { alimentação humana }\end{array}$ & 5 & $29.945,00 t$ & $8.967,00$ & $29.981,00 \mathrm{t}$ & $8.819,00$ \\
\hline $\begin{array}{l}\text { Fígados ou ovas de } \\
\text { peixes refrigerados, } \\
\text { secos, salgados ou } \\
\text { defumados }\end{array}$ & 1 & Omitido & Omitido & Omitido & Omitido \\
\hline $\begin{array}{c}\text { Moluscos ou outros } \\
\text { invertebrados } \\
\text { aquáticos } \\
\text { refrigerados, } \\
\text { congelados, secos ou } \\
\text { salgados }\end{array}$ & 11 & $\begin{array}{c}2.758 .020,00 \\
\mathrm{Kg}\end{array}$ & $17.404,00$ & $\begin{array}{c}2.471 .955,00 \\
\mathrm{Kg}\end{array}$ & $15.401,00$ \\
\hline $\begin{array}{l}\text { Peixes, filés e outras } \\
\text { carnes de peixes, } \\
\text { frescos ou } \\
\text { refrigerados }\end{array}$ & 41 & $66.975,00 \mathrm{t}$ & $309.356,00$ & $58.165,00 \mathrm{t}$ & $263.959,00$ \\
\hline $\begin{array}{c}\text { Peixes, filés e outras } \\
\text { carnes de peixes } \\
\text { secos, salgados ou } \\
\text { defumados }\end{array}$ & 4 & $2.240,00 \mathrm{t}$ & $6.707,00$ & $2.101,00 \mathrm{t}$ & $6.313,00$ \\
\hline $\begin{array}{l}\text { Peixes, filés e outras } \\
\text { carnes de peixes; } \\
\text { fígados ou ovas de } \\
\text { peixes, congelados }\end{array}$ & 19 & $78.826,00 t$ & $240.310,00$ & $52.506,00 \mathrm{t}$ & $171.202,00$ \\
\hline $\begin{array}{l}\text { Preparações e } \\
\text { conservas de } \\
\text { crustáceos e } \\
\text { moluscos, exceto } \\
\text { pratos prontos } \\
\text { congelados }\end{array}$ & 7 & $110.697,00 \mathrm{t}$ & $46.695,00$ & $114.327,00 \mathrm{t}$ & $81.116,00$ \\
\hline $\begin{array}{c}\text { Preparações e } \\
\text { conservas de peixes, } \\
\text { exceto pratos prontos } \\
\text { congelados }\end{array}$ & 19 & $97.362,00 \mathrm{t}$ & $561.446,00$ & $48.914,00 \mathrm{t}$ & $337.404,00$ \\
\hline $\begin{array}{l}\text { Produtos da pesca } \\
\text { impróprios para a } \\
\text { alimentação humana } \\
\text { (beixiga natatórias, } \\
\text { tripas e outros } \\
\text { desperdícios não } \\
\text { comestíveis) }\end{array}$ & 1 & Omitido & Omitido & Omitido & Omitido \\
\hline
\end{tabular}


(conclusão)

\begin{tabular}{ccccccc}
\hline & Número de & \multicolumn{2}{c}{ Produção } & \multicolumn{2}{c}{ Venda } \\
Produto & $\begin{array}{c}\text { Valor } \\
\text { informações }\end{array}$ & Quantidade & (R\$1.00) & Quantidade & (R\$1.000) \\
\hline $\begin{array}{c}\text { Serviços de } \\
\text { preparação de }\end{array}$ & & & & & & \\
conservas do pescado & 12 & 0 & $24.961,00$ & 0 & $24.961,00$ \\
Outros & 6 & 0 & $84.875,00$ & 0 & $32.126,00$ \\
\hline
\end{tabular}

Por não haver uma descrição metodológica na Pesquisa Industrial Anual sobre Produtos do IBGE (2006a), e como o setor industrial contava com aproximadamente 300 estabelecimentos beneficiadores de pescado em 2006, entende-se aqui que os valore obtidos pelo IBGE refletem apenas os resultados de algumas empresas que colaboraram com a pesquisa, representando aproximadamente $50 \%$ do segmento. Tal fato pode ser justificado pela omissão dos resultados de produção e de valores financeiros para alguns produtos, a fim de evitar a individualização da informação e divulgação de posições estratégicas de algumas empresas.

Outro ponto observado na Tabela 2 é a não concordância entre os valores de produção e de venda para alguns produtos, como as "Preparações e conservas de crustáceos e moluscos", uma vez que os valores de venda representam a comercialização de produtos em 2006 que não necessariamente foram produzidos nesse ano.

Segundo o Departamento de Pesca e Aquicultura da FAO, o parque industrial do pescado brasileiro é constituído por aproximadamente 300 estabelecimentos com linhas de produção diferentes e de alta produtividade. Esse parque industrial é considerado relativamente novo, tendo aproximadamente 20 anos de funcionamento, com nível tecnológico comparado aos melhores do mundo além de apresentar o programa de Análise de Perigos e Pontos Críticos de Controle (APPCC) (FAO, 2001).

Apesar do aumento da produção e do número de estabelecimentos e trabalhadores do setor primário de pescado entre 1995 e 2005, de forma geral, o número de estabelecimentos e trabalhadores do setor industrial apresentou queda nesse mesmo período $(-6,47 \%$ e $-17,56 \%$ respectivamente) (Gráfico 18) (BRASIL, 
[2008?c]). Na literatura pesquisada, não foram encontradas justificativas para tal ocorrência.

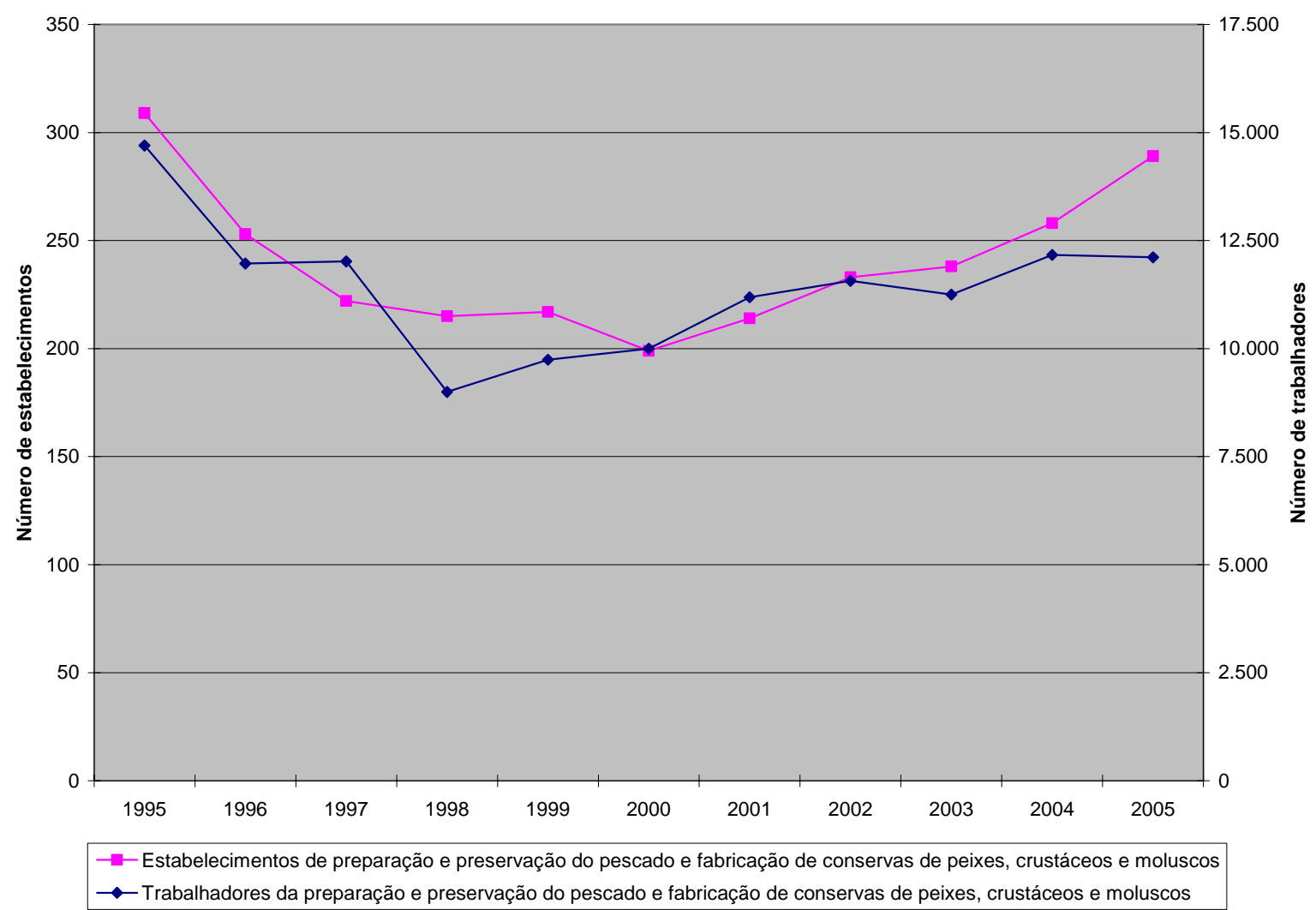

Fonte: MTE.

Gráfico 18 - Evolução do número de estabelecimentos e de trabalhadores do setor industrial de pescado brasileiro - 1995-2005

Entre 1995 e 2005, enquanto as regiões Norte, Nordeste, Sul e Centro-oeste apresentaram um aumento tanto do número de estabelecimentos quanto de trabalhadores, a região Sudeste apresentou uma expressiva queda em ambos, fazendo com que no âmbito nacional o Brasil também apresentasse essa diminuição (MTE). A evolução do número de indústrias e de trabalhadores das regiões Norte, Nordeste, Sudese, Sul e Centro-oeste é apresentada no Apêndice B pelos gráficos 46 a 50 , respectivamente.

Essa queda dos números de indústrias e trabalhadores da região Sudeste e aumento nas demais regiões podem estar relacionados à saída de empresas da região Sudeste para outras regiões do Brasil, que ocorreu no setor fabril brasileiro entre 1996 e 2006. Nesse período, houve uma redução da participação das regiões Sudeste e Sul no valor da transformação industrial (diferença entre o valor bruto da 
produção e os custos das operações industriais) de 71,6\% para 64,4\% no Sudeste e de $15,5 \%$ para $14,7 \%$ no Sul, enquanto que as demais regiões apresentaram ganhos de participação, de 1,2\% para 3,3\% no Centro-Oeste, de 7,1\% para 11,3\% no Nordeste, e de $4,5 \%$ para $6,3 \%$ no Norte (IBGE, 2006b). Segundo Isabela Nunes (apud GANDRA, 2008), Gerente do Grupo de Análise do IBGE, "a expansão agrícola e maiores incentivos fiscais são alguns dos fatores que explicam a atração exercida por outros estados fora do Sudeste para as grandes indústrias brasileiras [...]".

No ano de 2005, o Brasil apresentou um total de 289 indústrias de pescado. Os estados de Santa Catarina, São Paulo, Rio Grande do Sul e Pará apresentaram mais estabelecimentos beneficiadores de pescado (62, 35, 32 e 26 estabelecimentos respectivamente), fazendo com que a região Sul concentrasse a maioria, seguida pelas regiões Sudeste, Nordeste, Norte e Centro-oeste (37,37\%; 23,88\%; 20,07\%; 15,22\% e 3,46\%) (Gráfico 19) (BRASIL, [2008?c]). Embora as regiões Nordeste e Norte sejam as maiores produtoras de pescado, contraditoriamente, as indústrias processadoras estão mais concentradas nas regiões Sul e Sudeste. O fato dos estados de Santa Catarina e Pará possuírem uma grande quantidade de estabelecimentos beneficiadores pode ser explicado pela maior produção brasileira de pescado por esses dois estados, necessitando de um maior número de indústrias. 


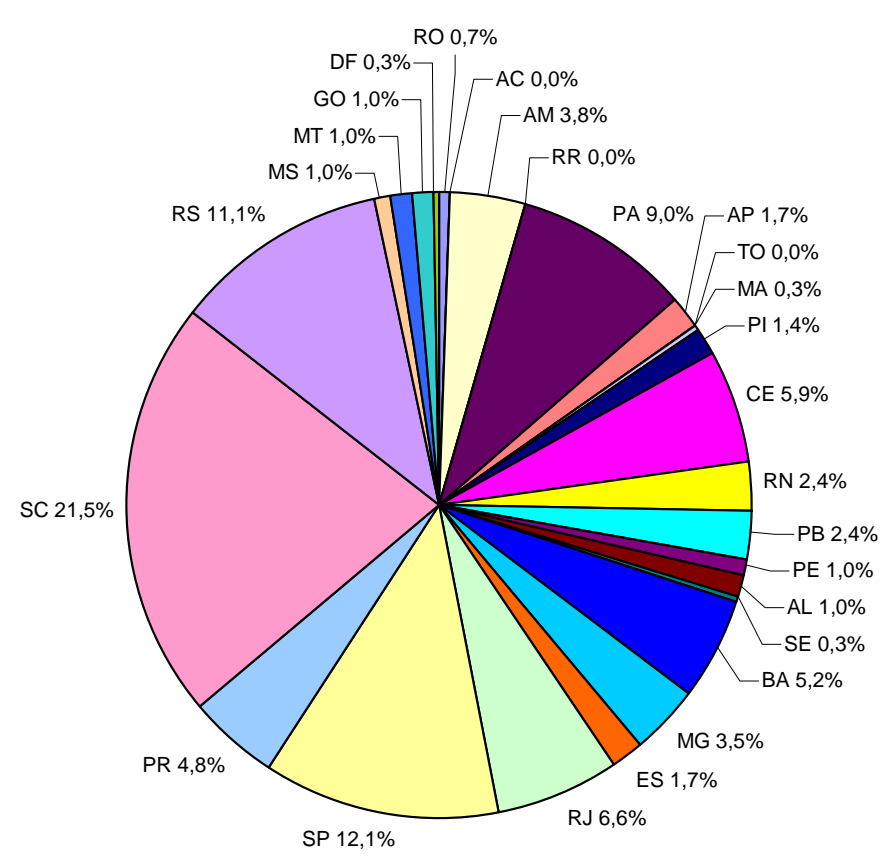

Fonte: MTE.

Gráfico 19 - Distribuição dos estabelecimentos da indústria de pescado por unidade federativa 2005

Vale ressaltar que, desse total de estabelecimentos no Brasil, apenas cinco indústrias $(1,73 \%)$ foram classificadas como estabelecimentos de grande porte (com número de trabalhadores superior a 500$)$, enquanto que 22 indústrias $(7,61 \%)$ foram classificadas como médias empresas (entre 100 e 499 trabalhadores), 65 indústrias $(22,49 \%)$ foram classificadas como pequenas empresas (entre 20 a 99 trabalhadores), e 197 indústrias (68,17\%) foram classificadas como micro empresas (até 19 trabalhadores) (informação verbal ${ }^{10}$ ). Conciliando essas informações com os dados disponíveis na RAIS, das 5 indústrias de grande porte, 3 estavam em Santa Catarina (estado com a maior produção de pescado do Brasil), uma no Rio de Janeiro (quarto estado com maior produção) e uma no Rio Grande do Sul (sexto estado com a maior produção).

Assim, como pouco mais de $90 \%$ das indústrias de pescado brasileiras são classificadas como micro ou pequena empresa, presume-se a baixa capacidade de processar grandes volumes de pescado, visto que em $68,17 \%$ dessas empresas, o

\footnotetext{
10 Informação fornecida por Maria Aparecida Rodrigues Leal da Secretaria do Desenvolvimento da Produção do Ministério do Desenvolvimento, Indústria e Comércio Exterior, através do Fale Conosco do endereço eletrônico <www.desenvolvimento.gov.br> em outubro de 2008.
} 
quadro de funcionários é inferior a 20 trabalhadores. Essa baixa capacidade de processamento da indústria de pescado é vista como um empecilho ao desenvolvimento da aquicultura nacional (OSTRENSKY; BOEGER, 2008) e talvez a todo esse complexo agroindustrial, por gerar um baixo volume e diversidade de produtos à base de pescado, levando a uma menor demanda por tais produtos.

De acordo com o Departamento de Pesca e Aquicultura da FAO, nas regiões Norte e Nordeste predominam as indústrias de congelamento, destinadas à produção para o mercado externo. Já nas regiões Sudeste e Sul, as indústrias são direcionadas para o processo de enlatamento de sardinhas e atuns e refrigeração e congelamento de filés, predominantemente para o abastecimento do mercado interno (FAO, 2001).

É possível que a atual situação sanitária das indústrias brasileiras de pescado tenha relação direta com as exigências do comércio internacional. Donovan, Caswell e Salay (2001) avaliaram o impacto das regulamentações mais rigorosas dos países desenvolvidos sobre a segurança alimentar na indústria processadora de pescado no Brasil. Foi observado que em 1993, o Estado impôs a implantação de programas de APPCC em estabelecimentos processadores que exportavam pescado, tendo em vista não perder espaço junto aos principais mercados para seus produtos: o camarão congelado para os Estados Unidos, Japão e União Européia, e a lagosta para os Estados Unidos, correspondendo juntos por 74\% das exportações em 1995. Porém, a obrigatoriedade da implantação desses programas atingiu apenas as indústrias exportadoras, ficando de fora as indústrias que objetivavam o mercado interno. Para estas empresas, existe uma visão de que os custos são muito superiores aos benefícios da implantação.

Através de uma pesquisa realizada por busca em endereços eletrônicos ou de contato por correio eletrônico, junto às 19 empresas relacionadas no caderno índice de Fornecedores do Anuário Brasileiro das Indústrias da Alimentação (ABIA, 2007a) e junto à 96 das 364 empresas registradas no SIF (informação verbal ${ }^{11}$ ), foi

\footnotetext{
${ }^{11}$ Informação fornecida por Guilherme Crispim Hundley, Coordenador Geral de Comercialização e Promoção Comercial da Secretaria Especial de Aquicultura e Pesca, através do correio eletrônico guilhermecrispim@seap.gov.br em novembro de 2008.
} 
elaborada uma lista contendo os principais produtos produzidos pelas indústrias processadoras de pescado no Brasil (Apêndice C).

Em relação à remuneração, no ano de 2005, aproximadamente 79,52\% dos trabalhadores da indústria de pescado estavam na faixa salarial entre 0,51 e 3,00 salários mínimos ${ }^{12}$ (Gráfico 20) (BRASIL, [2008?c]).

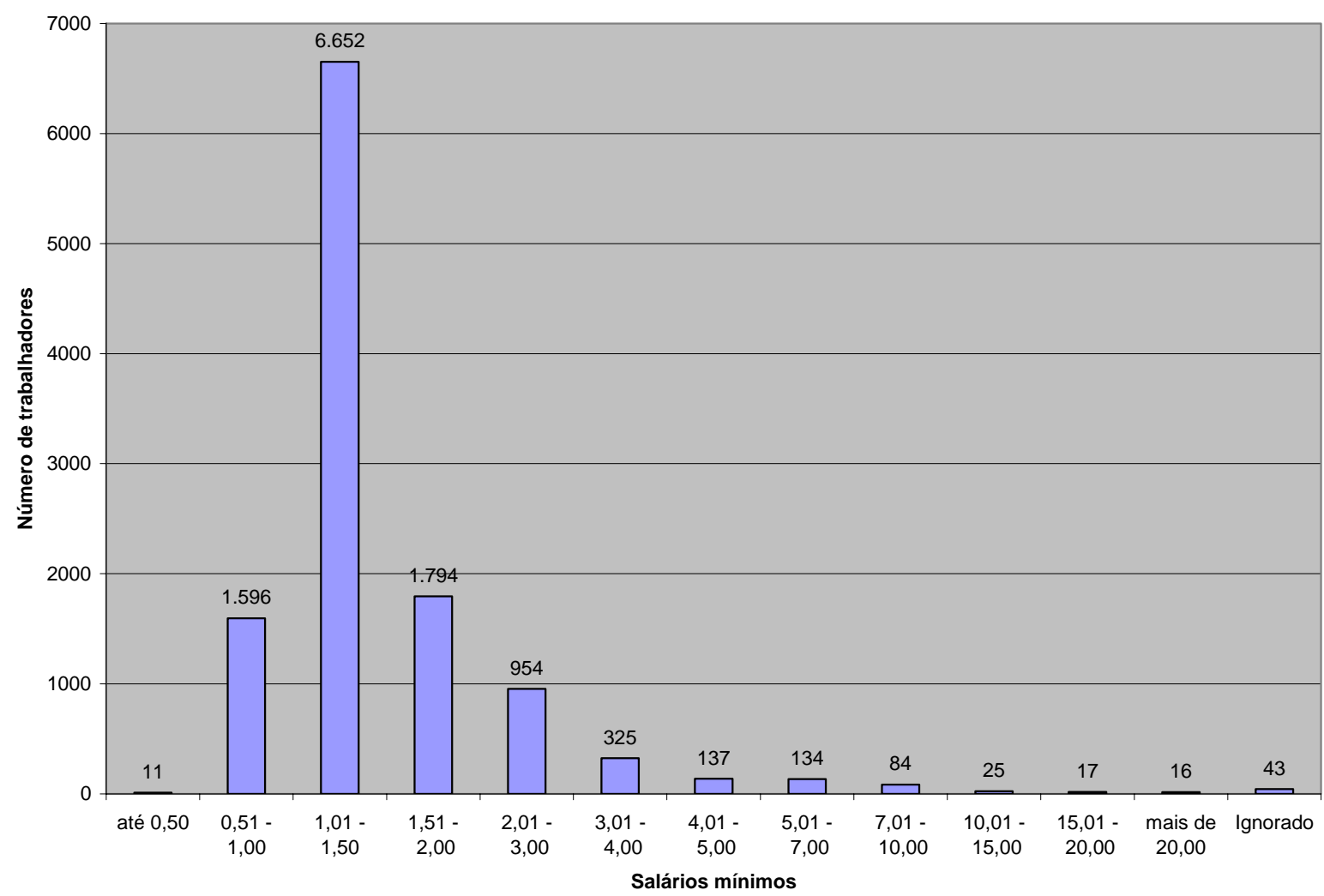

Fonte: MTE.

Gráfico 20 - Remuneração média dos trabalhadores brasileiros da indústria de pescado - 2005

No ano de 2005, o setor beneficiador de pescado empregou um total de 12.114 trabalhadores. Das 584 famílias ocupacionais relacionadas na RAIS, a família "Trabalhadores na fabricação e conservação de alimentos" foi a que apresentou maior número de trabalhadores, empregando um total de 5.554. Para a correta interpretação do Gráfico 9, é importante salientar que na denominação "Outros" ocorrem diversas ocupações cujas porcentagens individuais foram inferiores à 1,52\%, como por exemplo "Trabalhadores de embalagem e etiquetagem" (1\%),

\footnotetext{
${ }^{12}$ De acordo com BRASIL (2005a), a partir de $1^{\circ}$ de maio de 2005, o valor do salário mínimo passou a ser de $R \$ 300,00$ (trezentos reais), sendo posteriormente revogada pela Lei $n^{\circ} 11.321$, de 07/07/2006.
} 
"Operadores de instalações de refrigeração e ar-condicionado" (0,52\%) e "Operadores de rede de teleprocessamento e afins" (0,1\%) (Gráfico 21) (BRASIL, [2008?c]).

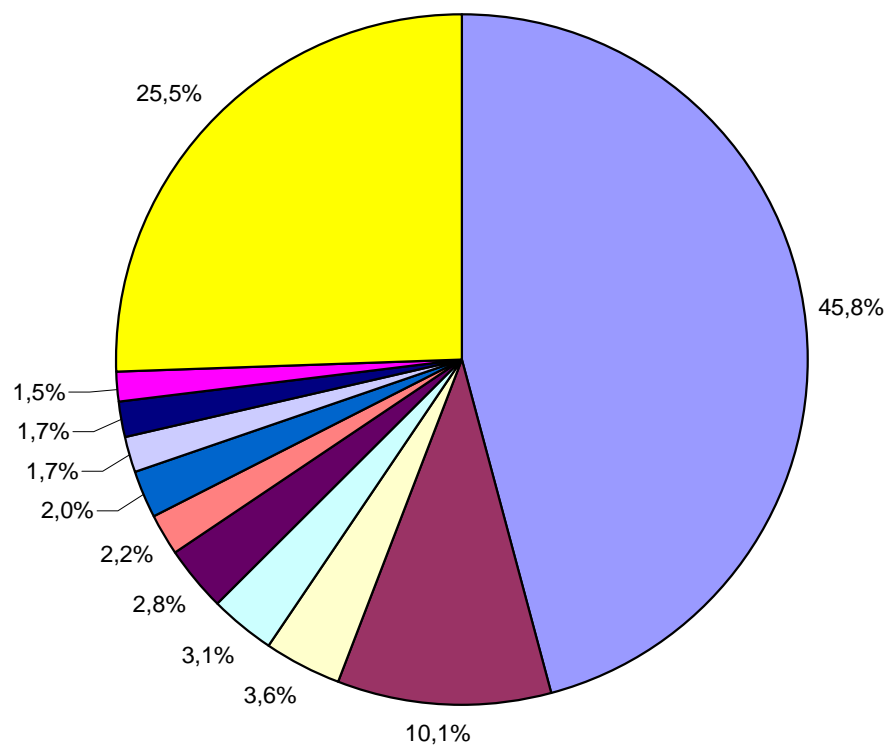

Trabalhadores na fabricação e conservação de alimentos

$\square$ Alimentadores de linhas de produção

口Escriturários em geral, agentes, assistentes e auxiliares administrativos

$\square$ Pescadores de água costeira e alto mar

—operadores de máquinas a vapor e utilidades

$\square$ Motoristas de veículos de cargas em geral

$\square$ Mantenedores de edificações

口Trabalhadores nos serviços de manutenção e conservação de edifícios e logradouros

- Operadores do comércio em lojas e mercados

$\square$ Porteiros e vigias

$\square$ Outros

Fonte: MTE.

Gráfico 21 - Principais ocupações da indústria de pescado - 2005

A associação Brasileira das Indústrias da Alimentação (ABIA) (2007b) aponta a indústria de conservas de pescado na última colocação dentre os dez principais setores da indústria alimentícia em 2006. Em seu balanço anual das indústrias alimentícias desse mesmo ano, esse é o único segmento industrial de pescado referido, o qual teve um faturamento de $\mathrm{R} \$ 1,64$ bilhões, apresentando sensível crescimento desde 2003, quando faturava $R \$ 1,4$ bilhões. Tal crescimento é justificado pelo aumento da demanda no mercado interno, em função de ser um substituto proteico cujo valor unitário é menor que os demais produtos proteicos. 


\subsubsection{Setor comercial do pescado}

Aparentemente, não existem dados oficiais relacionados à comercialização interna de pescado, já que vários dos órgãos governamentais pesquisados, como a SEAP; o MAPA; o MDIC; o MS; o Ministério da Fazenda (MF); a Secretaria Estadual de Agricultura e Abastecimento de São Paulo; a Secretaria de Agricultura, Pecuária, Pesca e Abastecimento do Rio de Janeiro; a Secretaria de Estado de Agricultura, Pecuária e Abastecimento de Minas Gerais; a Secretaria de Agricultura, Pesca, Pecuária e Agronegócio do Rio Grande do Sul; a Secretaria de Estado da Agricultura e Desenvolvimento Rural de Santa Catarina; a Secretaria do Desenvolvimento Agrário do Ceará; a Secretaria de Estado da Agricultura e do Desenvolvimento Agrário de Alagoas; a Secretaria de Estado da Produção Agropecuária, Pesca e Desenvolvimento Rural Integrado do Amazonas; a Secretaria de Estado da Agricultura do Pará e a Secretaria de Estado de Agropecuária do Acre (informação verbal ${ }^{13}$ ), não responderam, negaram o conhecimento de tais informações ou indicaram a pesquisa junto à SEAP. Atualmente, esta utiliza os dados da Pesquisa de Orçamentos Familiares 2002-2003, fornecidos pelo IBGE, para relacionar o consumo interno de pescado (informação verbal ${ }^{14}$ ).

Também foram consultadas as associações de supermercados, como a Associação Brasileira dos Supermercados (ABRAS), a Associação Paulista dos Supermercados (APAS), a Associação de Supermercados do estado do Rio de Janeiro (ASSERJ), a Associação Catarinense de Supermercados (ACATS), a Associação Bahiana de Supermercados (ABASE), a Associação Paraense de Supermercados (ASPAS), a Associação Mineira de Supermercados (AMIS), a Associação de Supermercados da Paraíba (ASPB), a Associação de Supermercados de Mato Grosso (ASMAT), a Associação Paranaense de Supermercados (APRAS), a Associação Capixaba de Supermercados (ACAPS), a Associação Gaúcha de Supermercados (AGAS), a Associação Sul-Matogrossense de Supermercados (AMAS) e a Associação

\footnotetext{
${ }^{13}$ Informação fornecida por contato por correio eletrônico e mensagens através da sessão Fale Conosco dos respectivos endereços eletrônicos em setembro, outubro e novembro de 2008.

${ }^{14}$ Informação fornecida por Guilherme Crispim Hundley, Coordenador Geral de Comercialização e Promoção Comercial da Secretaria Especial de Aquicultura e Pesca, através do correio eletrônico guilhermecrispim@seap.gov.br em outubro de 2008.
} 
Pernambucana de Supermercados (APES) (informação verbal ${ }^{15}$ ), que negaram a existência de tais informações ou sugeriram a pesquisa junto à ABRAS ou junto à SEAP. Apesar de ser um projeto regional da FAO, o trabalho de Soares (2007), que caracterizou o mercado interno para os produtos derivados do pescado, também não apresentou informações sobre a comercialização do mesmo. Em virtude disso, não foi possível caracterizar o setor comercial através do volume de vendas e de valores financeiros.

Assim como nos segmentos anteriormente descritos do complexo agroindustrial do pescado, a falta de informações sobre a comercialização é prejudicial para o desenvolvimento do setor, dificultando, por exemplo, a análise e formulação de estratégias empresariais e políticas públicas.

O consumo brasileiro de pescado é relativamente baixo se comparado a países com menor potencial para o setor. De acordo com a SEAP (BRASIL, [2008?a]), o consumo brasileiro médio anual per capita é de 6,8Kg. Em termos comparativos, países industrializados apresentavam, em 2003, um consumo médio anual per capita de 29,7Kg (FAO, 2007).

De acordo com a Pesquisa de Orçamentos Familiares 2002-2003, realizada pelo IBGE, a aquisição domiciliar per capita anual de pescado no Brasil, em 2003, foi de $4,587 \mathrm{Kg}$, sendo a região Norte a maior consumidora, adquirindo 24,667 Kg/hab/ano (Tabela 3) (IBGE, 2004a).

Tabela 3 - Aquisição domiciliar per capita anual de pescado, em Kg/hab/ano - 2002-2003

\begin{tabular}{cccccccc}
\hline & \multicolumn{6}{c}{ Aquisição domiciliar per capita anual (Kg/hab/ano) } \\
Produtos & Brasil & Norte & Nordeste & Sudeste & Sul & Centro-oeste \\
\hline Pescado & 4,587 & 24,667 & 4,973 & 2,171 & 1,783 & 1,36 \\
\hline Pescado de água salgada & 1,824 & 5,515 & 2,234 & 1,459 & 0,824 & 0,404 \\
Pescado de água doce & 2,124 & 17,759 & 1,778 & 0,336 & 0,463 & 0,526 \\
Pescado não especificado & 0,64 & 1,393 & 0,96 & 0,376 & 0,497 & 0,43 \\
\hline
\end{tabular}
Fonte: IBGE, 2004a.

15 Informação fornecida por contato telefônico, por correio eletrônico ou mensagens através da sessão Fale Conosco dos respectivos endereços eletrônicos em setembro e outubro de 2008. 
No ano de 2003, o estado do Amazonas foi o maior consumidor de pescado do Brasil (50,192Kg/hab/ano), bem como o maior consumidor de pescado de água doce $(45,896 \mathrm{Kg} / \mathrm{hab} / \mathrm{ano})$. O estado do Pará foi o segundo maior consumidor de pescado $(24,114 \mathrm{Kg} / \mathrm{hab} / \mathrm{ano})$, o segundo maior consumidor de pescado de água doce $(14,346 \mathrm{Kg} / \mathrm{hab} / \mathrm{ano})$ e maior consumidor de pescado de água salgada (9,542Kg/hab/ano) (Gráfico 22) (IBGE, 2004a).

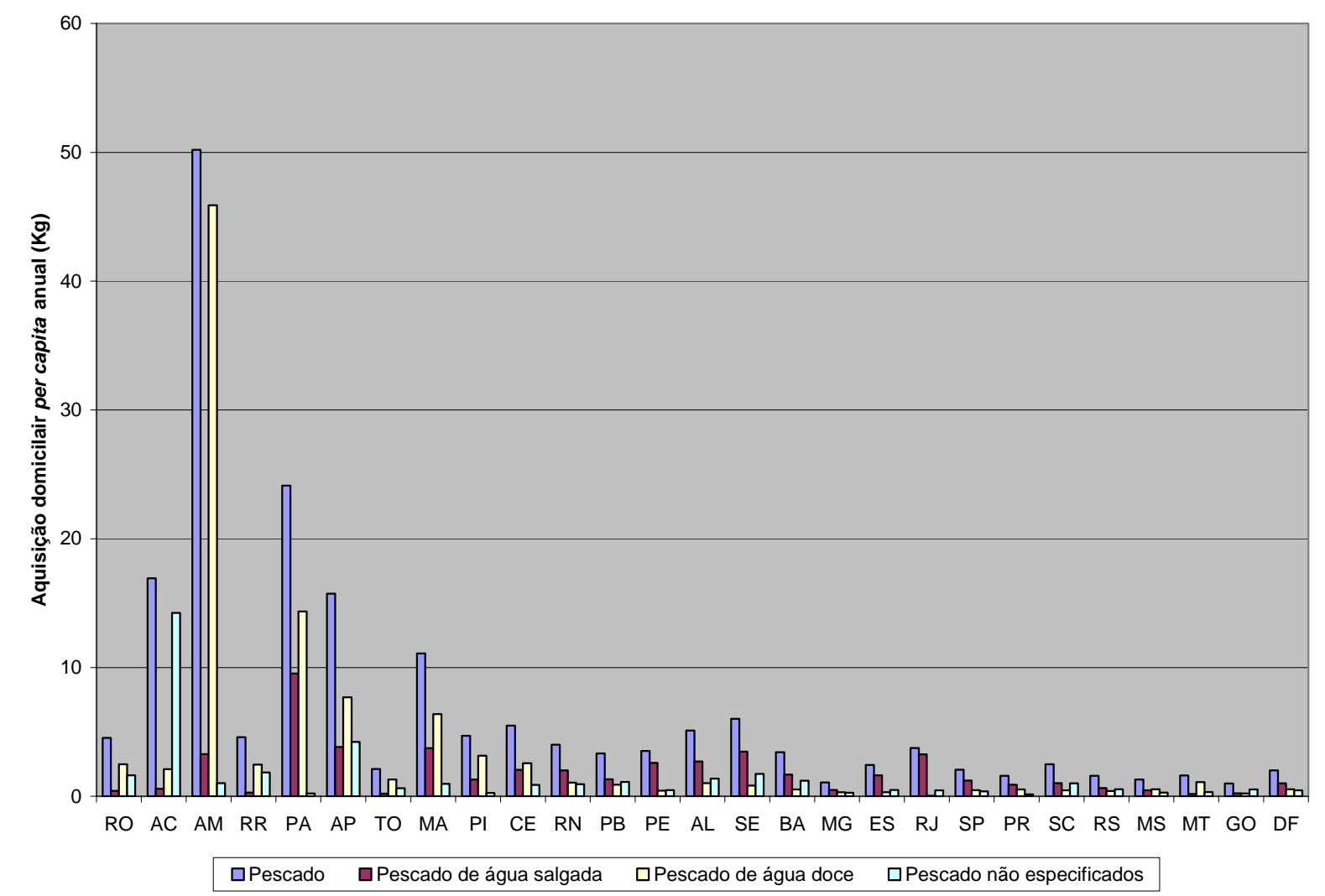

Fonte: IBGE, 2004a.

Gráfico 22 - Aquisição domiciliar de pescado per capita anual (Kg) - 2003

Em 2003, o meio rural brasileiro consumiu maior quantidade de pescado do que o meio urbano $(9,987 \mathrm{Kg} / \mathrm{hab} / \mathrm{ano}$ e $3,476 \mathrm{Kg} / \mathrm{hab} / \mathrm{ano}$, respectivamente), tendo como consumo predominante o pescado de água doce $(6,474 \mathrm{Kg} / \mathrm{hab} / \mathrm{ano})$. Já no meio urbano, apesar do consumo de pescado de água doce e de água salgada estarem muito próximos, este foi um pouco maior que aquele $(1,766 \mathrm{Kg} / \mathrm{hab} / \mathrm{ano}$ e $1,229 \mathrm{Kg} / \mathrm{hab} / \mathrm{ano}$, respectivamente). O padrão de maior consumo pelo meio rural com predominância de pescado de água doce, e o menor consumo pelo meio 
urbano com predominância de pescado de água salgada, também pode ser observado em cada uma das regiões brasileiras (Gráfico 23) (IBGE, 2004a).

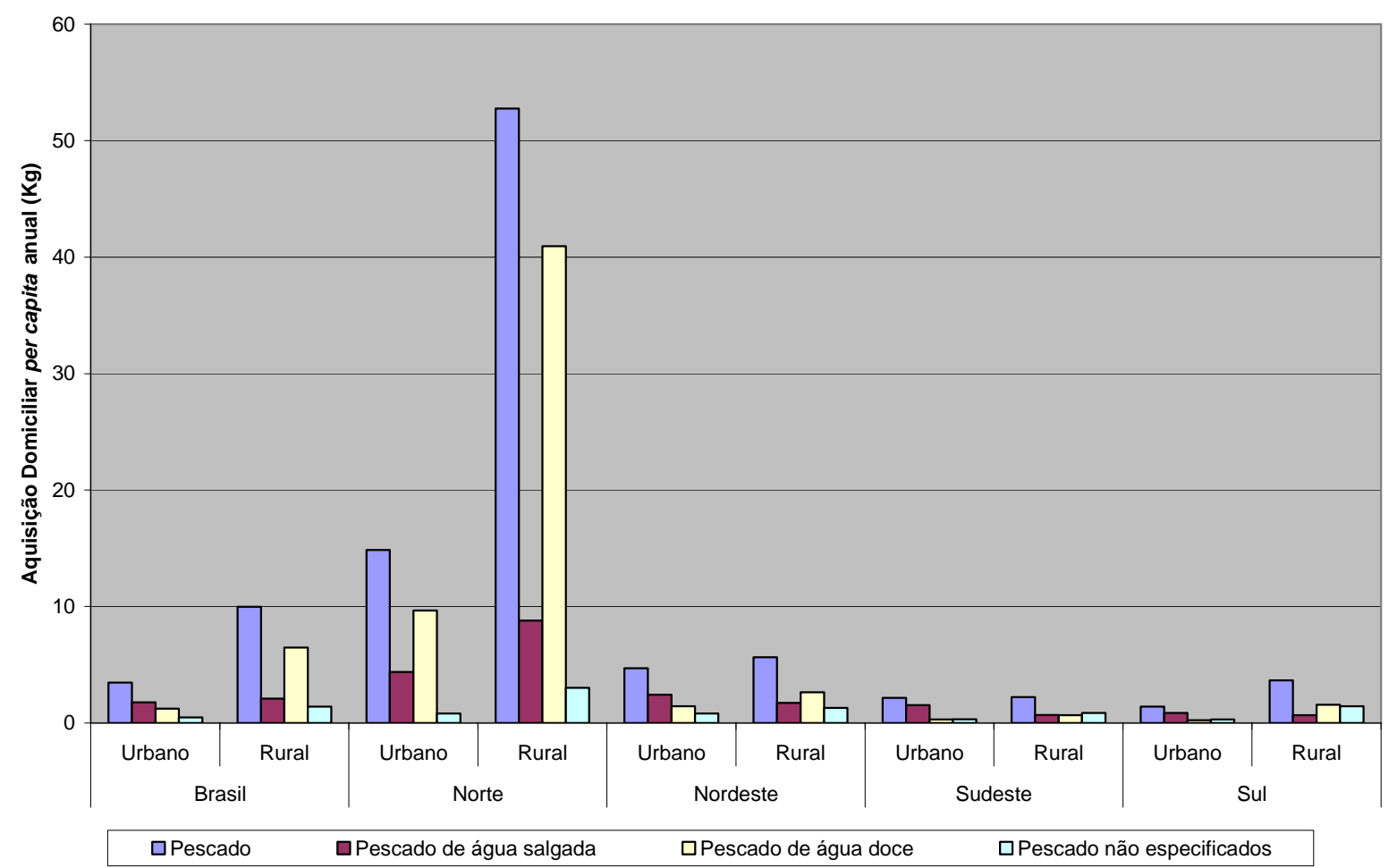

Fonte: IBGE, 2004a.

Gráfico 23 - Aquisição de pescado domiciliar per capita anual por situação do domicílio - 2003

Em pesquisa realizada em cidades da região Sul e Sudeste do Brasil, como São Paulo-SP, Belo Horizonte-MG, Florianópolis-SC, Ribeirão Preto-SP, Maringá-PR e Jaboticabal-SP, Macedo-Viegas et al. (2000) constataram que apenas $11,6 \%$ do total de pescado comercializado em supermercados e entrepostos de pescado eram provenientes de água doce, mostrando o predomínio do comércio do pescado de origem marinha.

A demanda por pescado varia de acordo com os rendimentos mensais das famílias. No ano de 2003, nas classes inferiores de renda, o consumo de pescado foi maior $(5,765 \mathrm{Kg} / \mathrm{hab} / \mathrm{ano}$ para a classe com rendimento até $\mathrm{R} \$ 400,00$ e 6,114Kg/hab/ano para a classe com rendimento entre $\mathrm{R} \$ 400,00$ e $\mathrm{R} \$ 600$ ), além da predominância do pescado de água doce. Já nas classes de maior rendimento, o consumo foi menor $(3,563 \mathrm{Kg} / \mathrm{hab} / \mathrm{ano}$ para a classe com rendimento entre $\mathrm{R} \$ 1.600,00$ e $\mathrm{R} \$ 3.000,00$ e 
$3,887 \mathrm{Kg} / \mathrm{hab} /$ ano para a classe com rendimento superior a $\mathrm{R} \$ 3.000,00$ ), além do predomínio do consumo do pescado de água salgada (Gráfico 24) (IBGE, 2004a).

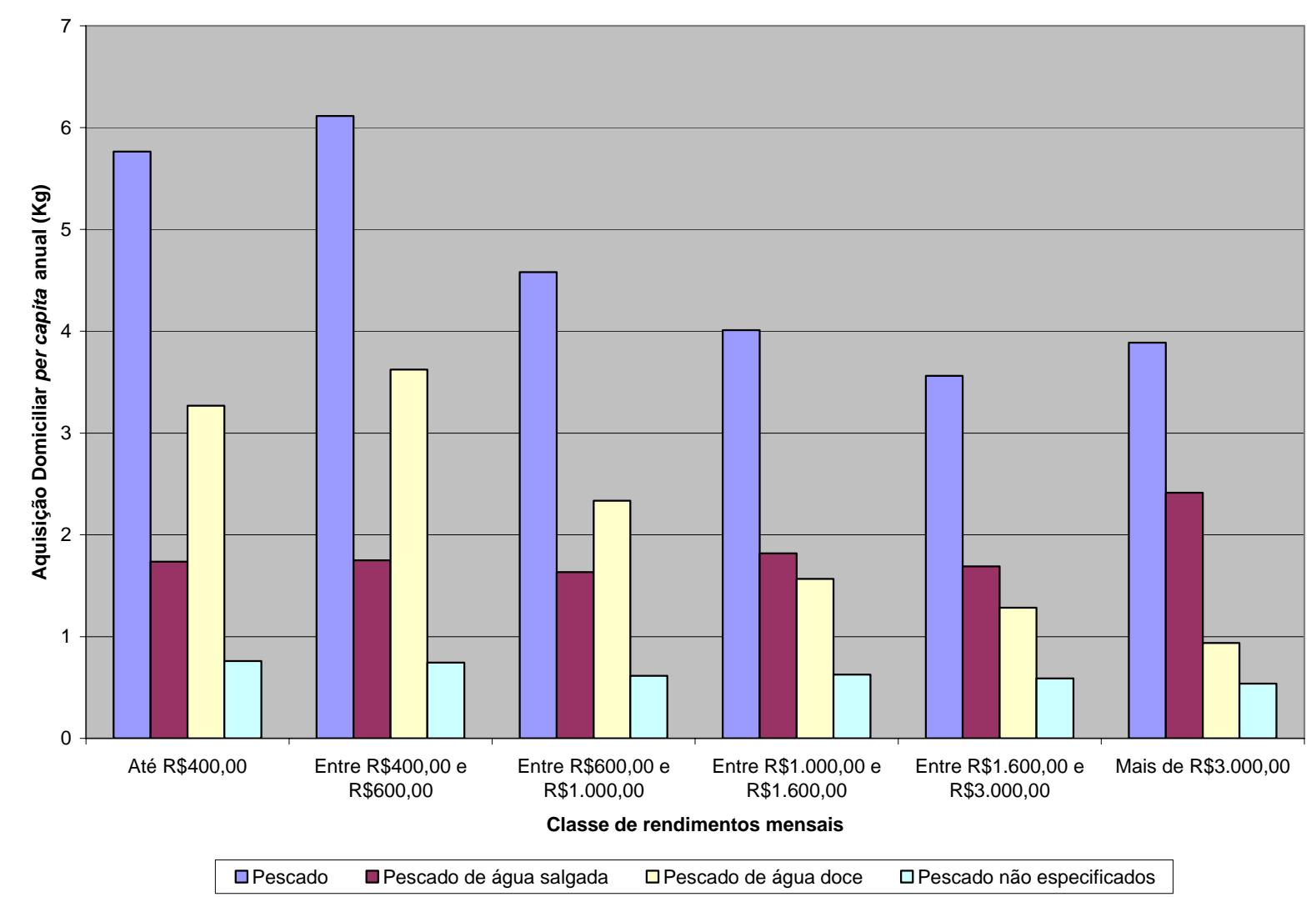

Fonte: IBGE, 2004a.

Gráfico 24 - Aquisição de pescado domiciliar per capita anual por classes de rendimento monetário e não monetário mensal familiar- 2003

De acordo com o IBGE ${ }^{16}$ (2004b) apud Sonoda (2006, p. 71), no ano de 2003 os super e hipermercados foram os tipos de estabelecimentos de maior representatividade para a comercialização de pescado (24,45\%). Apesar dessa alta representatividade, sua importância ficou diminuída quando da soma das participações dos pequenos estabelecimentos, como feiras, peixarias e mercados, que representou pouco mais de $40 \%$ das vendas. Também pode ser observado que pouco mais de $12 \%$ das aquisições ocorreram sob a forma natural ou de produção própria, vindo da pesca ou da aquicultura (Gráfico 25).

${ }^{16}$ IBGE. INSTITUTO BRASILEIRO DE GEOGRAFIA E ESTATístICA. Pesquisa de Orçamentos Familiares 2002-2003: microdados. Rio de Janeiro: IBGE, 2004b. 1 CD-ROM. 

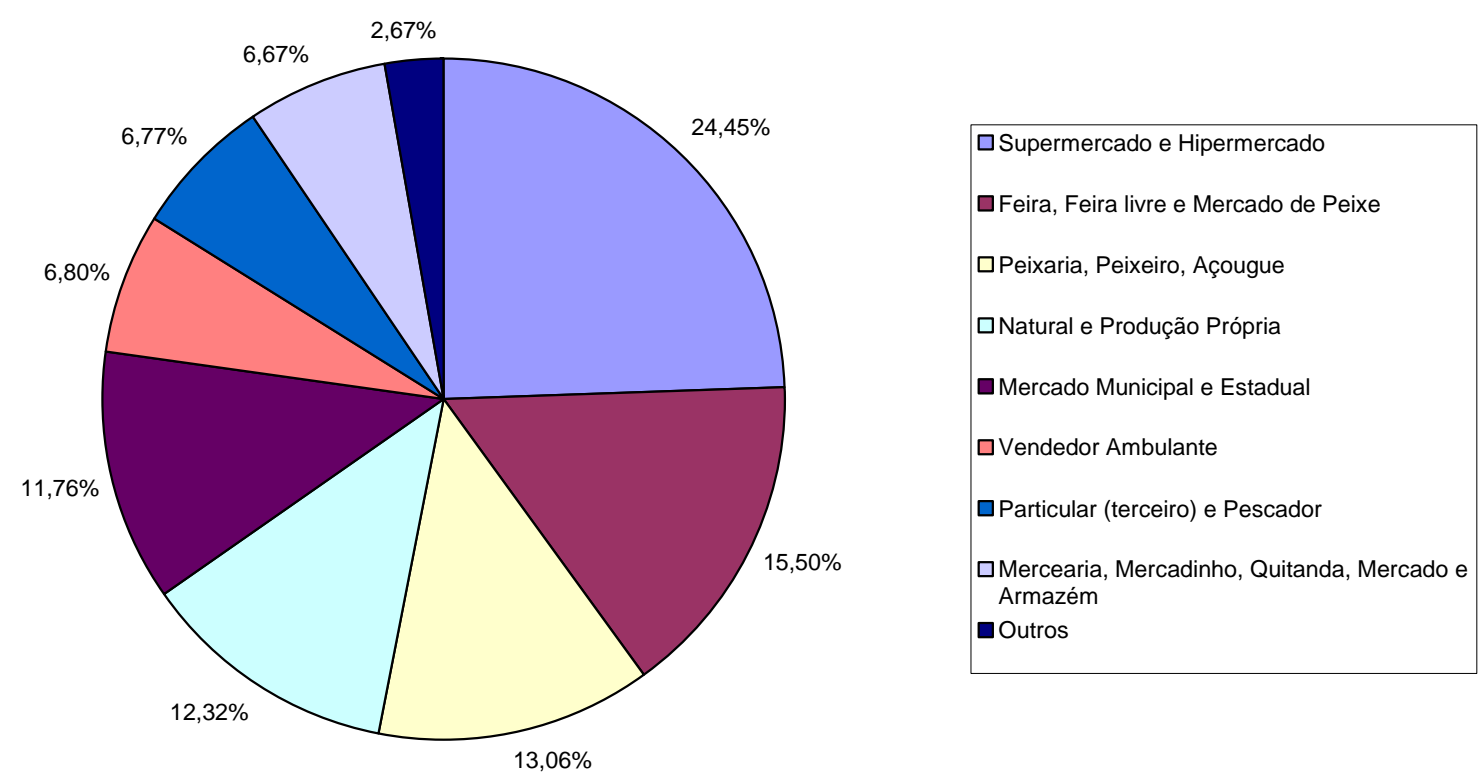

Fonte: IBGE (2004b) apud SONODA (2006).

Gráfico 25 - Percentual médio do dispêndio com pescado em relação aos locais de compra de pescado -2003

De acordo com Sonoda (2006), baseado nos dados da Pesquisa de Orçamentos Familiares 2002-2003, a elasticidade-preço da demanda por pescado no Brasil foi de $-0,7$, ou seja, o consumidor reduz a quantidade demandada de pescado em $0,7 \%$ para cada aumento de $1 \%$ nos preços do pescado, e a elasticidade-renda da demanda foi de 0,79 , ou seja, a quantidade demandada por pescado aumenta em $0,79 \%$ a cada incremento de $1 \%$ na renda disponível para consumo. Tais dados são interessantes, pois mostram que o consumidor brasileiro de pescado é um pouco mais sensível ao aumento da renda para que haja o aumento do consumo do que a redução dos preços dos produtos.

Sonoda (2006) ainda aponta que, em relação às fontes de proteína animal, os principais produtos concorrentes do pescado não são as carnes de aves e carnes vermelhas, mas sim o leite, os ovos e as proteínas prontas (produtos com maior grau de processamento, cujos insumos são proteínas de origem animal). Também afirma que, em relação aos bens substitutos (carne bovina, suína, aves, ovos e leite), 
ocorre uma maior demanda de pescado sempre que ocorre um aumento do preço daqueles bens.

Comparando o consumo de pescado com outros grupos de alimentos, no ano de 2003 o pescado foi o grupo de alimentos de menor consumo em cada região. Apenas na região Norte, seu consumo foi superior ao de hortaliças, frutas, panificados, aves e bebidas e infusões (Gráfico 26) (IBGE, 2004a).

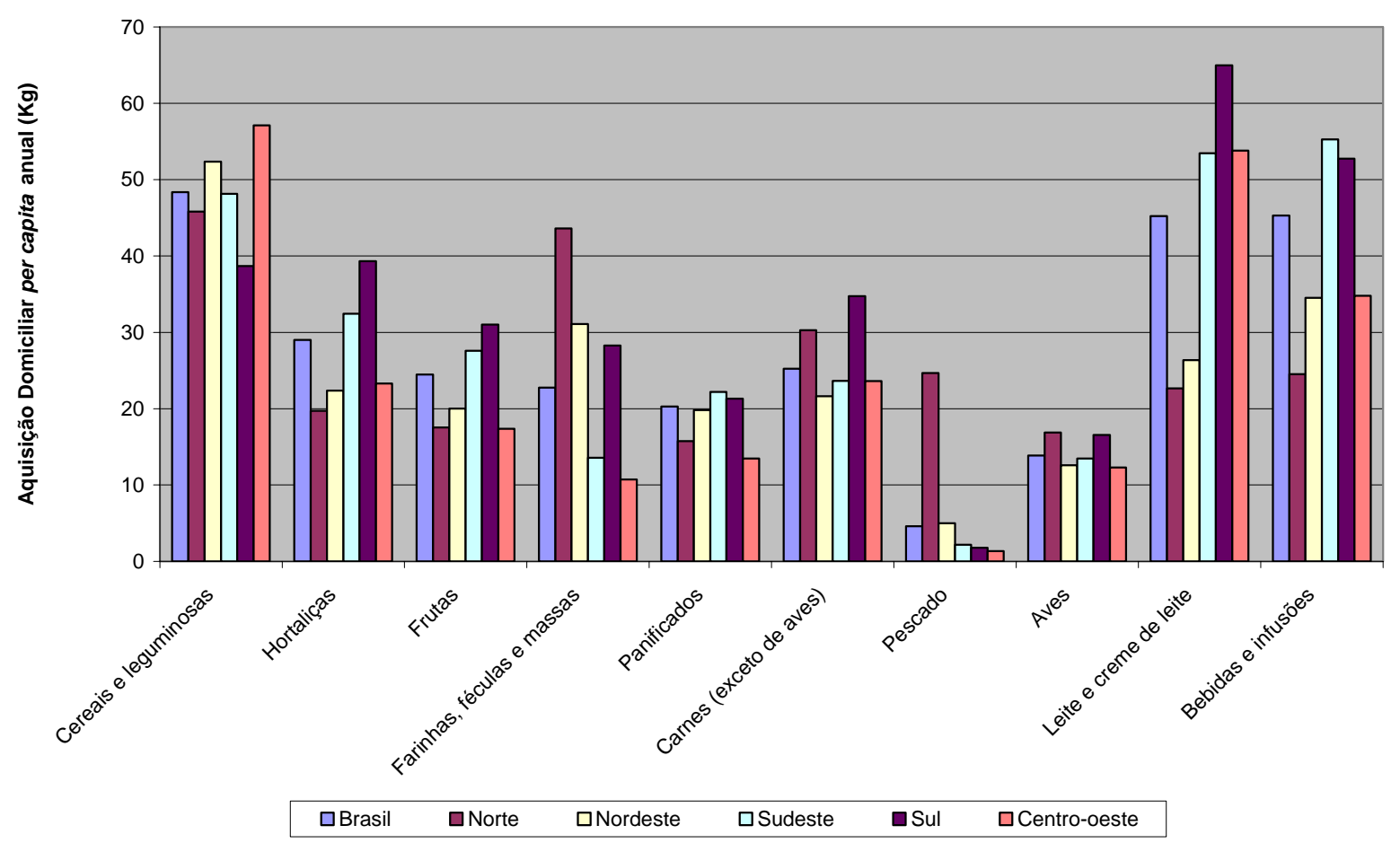

Fonte: IBGE, 2004a.

Gráfico 26 - Aquisição alimentar domiciliar per capita anual, por grandes regiões segundo grupos de produtos -2003

A participação relativa do pescado na alimentação, no ano de 2003 , foi de $0,52 \%$ no meio urbano e 0,99\% no meio rural, sendo o produto cárneo de menor consumo em todas as regiões do país, estando apenas na frente dos embutidos na região Norte e no meio rural da região Nordeste. A participação relativa do pescado na dieta no meio rural foi maior do que no meio urbano nas regiões Norte e Sul (Gráfico 27) (IBGE, 2004c). 


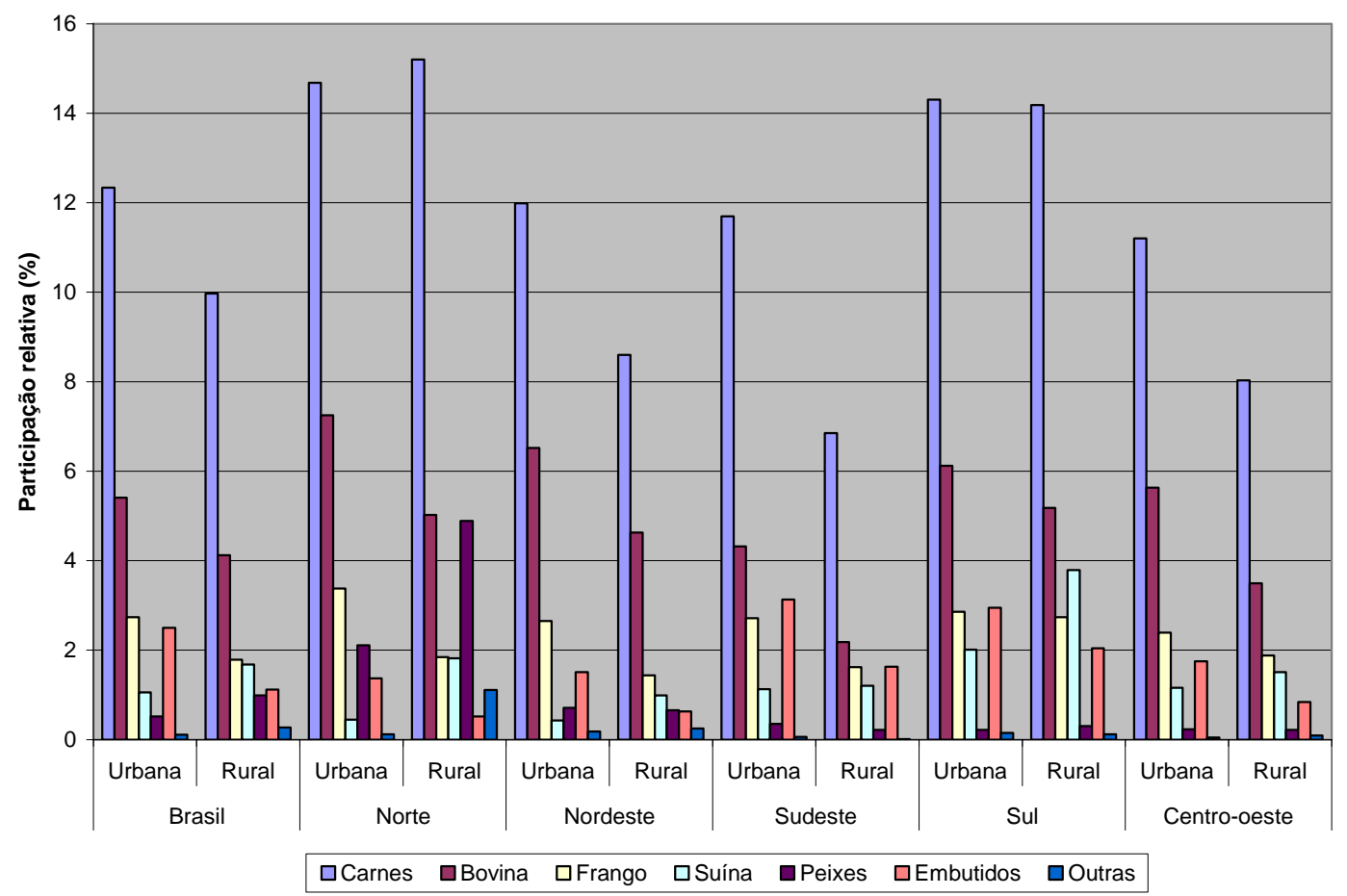

Fonte: IBGE, 2004c.

Gráfico 27 - Participação relativa de alimentos e grupos de alimentos no total de calorias determinado pela aquisição alimentar domiciliar, por grandes regiões e situação do domicílio - 2003

Nas cidades de São Paulo-SP, Belo Horizonte-MG, Florianópolis-SC, Ribeirão PretoSP, Maringá-PR e Jaboticabal-SP, em pesquisa realizada em supermercados e entrepostos de pescado no ano de 2000, foram encontrados de 18 a 146 diferentes tipos de produtos derivados de peixes marinhos, de 3 a 25 tipos de produtos derivados de peixes de água doce e de 17 a 91 tipos de produtos derivados de moluscos e crustáceos. As formas mais comuns de processamento encontradas no mercado foram: enlatado (37\%), congelado (29\%), fresco (29\%), defumado (3\%) e seco e salgado (2\%). Já em relação aos cortes dos peixes, as formas mais encontradas foram: filé com ou sem pele (67\%), peixe inteiro eviscerado ou não (15\%), postas (14\%) e tronco limpo com ou sem pele (4\%) (MACEDO-VIEGAS et al., 2000).

De forma geral, os produtos encontrados no Apêndice $C$, referente à produção das indústrias de pescado brasileiras, em sua maioria, podem ser encontrados no comércio nacional de produtos derivados do pescado. 
Já em relação ao comércio exterior, o MDIC oferece dados bem atualizados, chegando a apresentar um atraso de informação de apenas um mês. Contudo, levando-se em consideração alguns fatos ocorridos no ano de 2008 que podem ter prejudicado a produção e o comércio de pescado, como a crise econômica mundial e o período de enchentes na região de Santa Catarina, serão aqui utilizados os dados do ano de 2007. Neste ano, o Brasil exportou um total de 49.608,476 toneladas de peixes, crustáceos, moluscos e outros invertebrados aquáticos (não pertencendo à esta somatória os peixes ornamentais e os peixes destinados à reprodução), o equivalente a US\$ FOB 279.281.645,00 ${ }^{17}$ (BRASIL, [2008?d]).

O produto de maior representatividade para a exportação de pescado brasileiro, em termos de volume, foi o camarão inteiro congelado, totalizando 15.532,716 toneladas em 2007 (US\$ FOB 60.064.560,00), seguido por uma série de peixes frescos, refrigerados ou congelados, como atuns, bonitos-listrados, cavalas, cavalinhas, sardas, corvinas e pargos. O produto de maior representatividade financeira para a exportação de pescado foram as lagostas não inteiras, totalizando US\$ FOB 91.165.816,00 em 2007 (2.035,328 toneladas), seguida por camarões inteiros congelados, totalizando US\$ FOB 60.064.560,00 (15.532,716 toneladas) (BRASIL, [2008?d]).

No período entre 1997 e 2007, a balança comercial brasileira de produtos derivados do pescado apresentou momentos de déficits e superávits. A segunda metade dos anos 90 apresentou déficits continuados até o ano 2000. A partir de 2001, ocorreu a inversão da balança comercial, com superávits até o ano de 2005. Apesar disso, a partir de 2003, o saldo tem apresentado uma tendência declinante em função da queda da exportação e aumento da importação (Gráfico 28) (BRASIL, [2008?d]).

\footnotetext{
${ }^{17}$ Valor FOB: do inglês Free on Board, é o valor do produto no porto de origem, com todos os custos até o embarque, de responsabilidade do fornecedor. Não inclui o valor do frete, do desembarque no porto de destino, e custos do local de destino, de responsabilidade do comprador. Disponível em: $<$ http://www.aprendendoaexportar.gov.br>. Acesso em: 25/10/2008.
} 


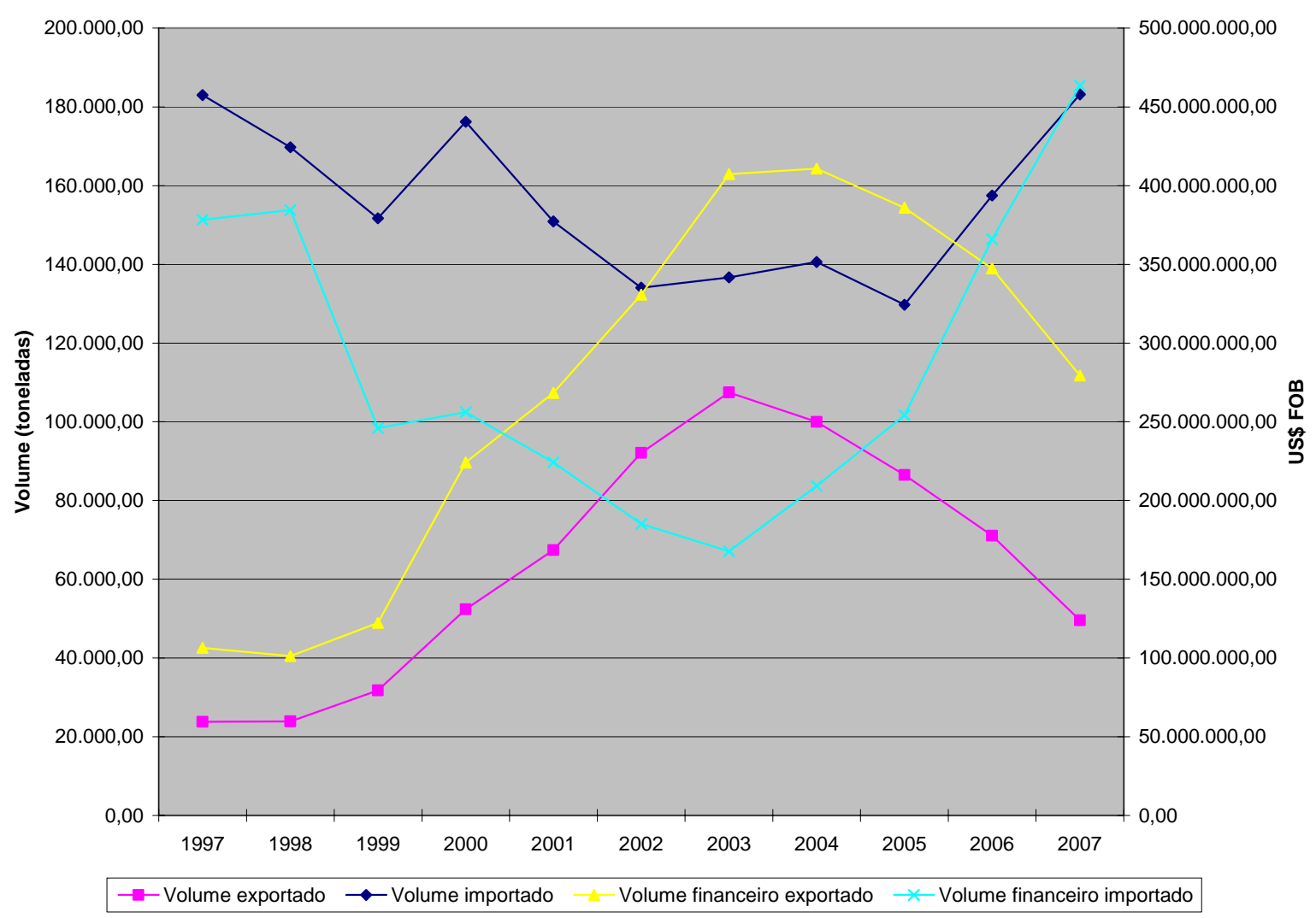

Fonte: BRASIL, [2008?d].

Gráfico 28 - Exportação e importação de pescado - 1997-2007

Uma vez que o MTE, através da RAIS-2005, não permite uma quantificação precisa dos estabelecimentos comerciais de pescado, pois o termo pescado é exclusivo em apenas uma das doze modalidades de comércio que podem oferecer o produto (descritas no início deste capítulo) e, como não é possível garantir a existência da comercialização do pescado nessas modalidades comerciais, para a realização deste trabalho optou-se pela quantificação apenas do comércio atacadista, evitando a quantificação dos locais de comércio e trabalhadores de estabelecimentos que possam não comercializar o pescado, superestimando o setor, conforme esclarecido no início deste capítulo.

Entre 1995 e 2005, o número de estabelecimentos e de trabalhadores do comércio atacadista de pescado no Brasil apresentou um aumento (17,12\% e 26,32\% respectivamente) (Gráfico 29). As regiões Norte, Sul e Centro-oeste apresentaram aumento em ambos os números, enquando que a região Nordeste apresentou um aumento do número de estabelecimentos e uma sensível queda do número de trabalhadores. A região Sudeste apresentou diminuição em ambos os números 
(MTE). Na literatura consultada não foram encontradas informações que permitissem explicar tais ocorrências. A evolução do número de comércio atacadista e trabalhadores das regiões Norte, Nordeste, Sudese, Sul e Centro-oeste é apresentada no Apêndice D pelos gráficos 51 a 55, respectivamente.

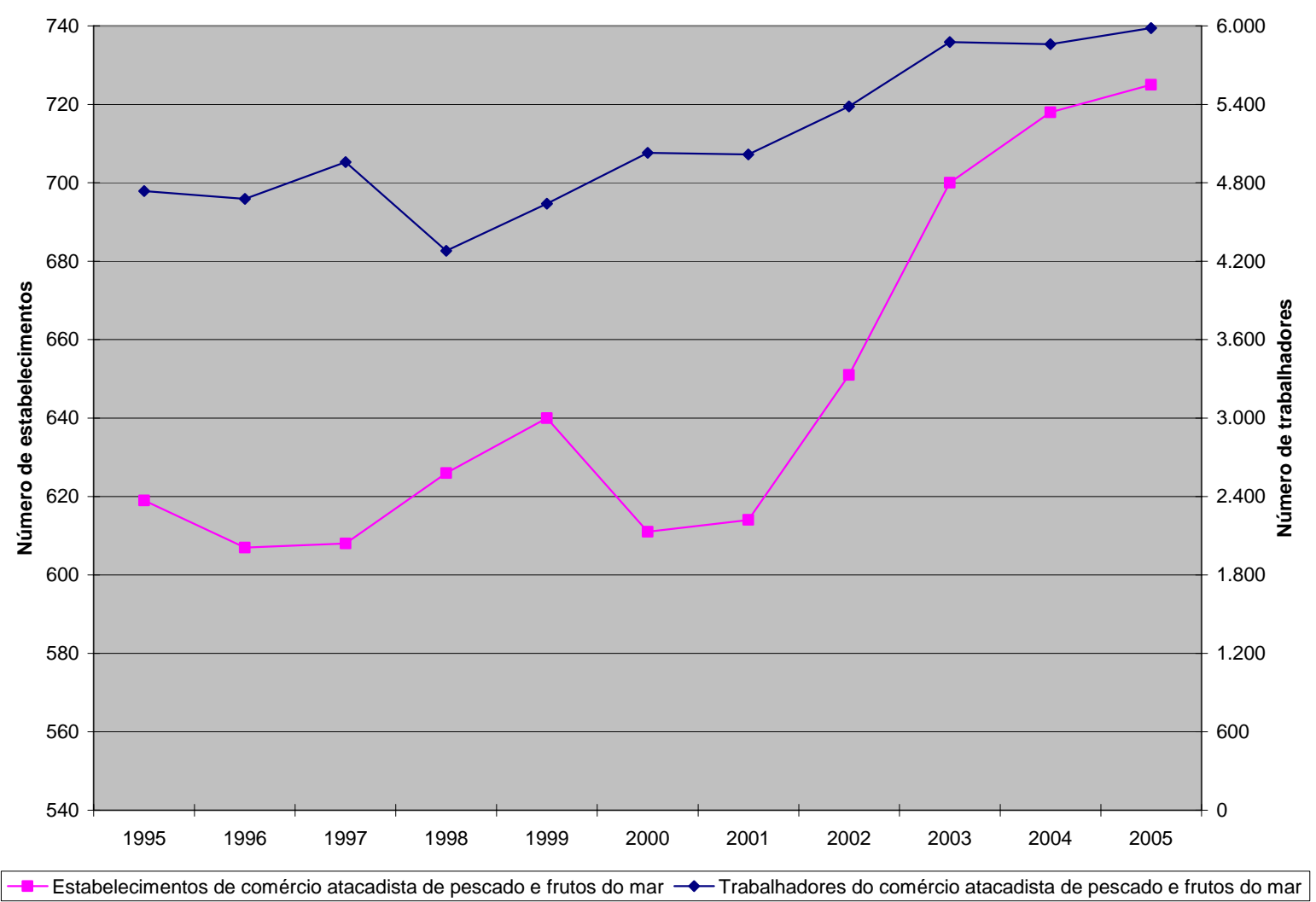

Fonte: BRASIL, [2008?c].

Gráfico 29 - Evolução do número de estabelecimentos e de trabalhadores do comércio atacadista de pescado brasileiro - 1995-2005

No ano de 2005, o Brasil apresentou um total de 725 comércios atacadistas de pescado. Os estados de São Paulo, Santa Catarina e Rio de Janeiro apresentaram um maior número (174, 110 e 86 estabelecimentos respectivamente), fazendo com que a região Sudeste concentrasse a maioria desses estabelecimentos, seguida pelas regiões Sul, Nordeste, Norte e Centro-oeste (44,55\%; 23,17\%; 21,66\%; 6,34\% e 4,28\%) (Gráfico 30) (BRASIL [2008?c]). Aparentemente, a concentração desse comércio nas diferentes regiões brasileiras está relacionada à concentração das indústrias de pescado, predominante nas regiões Sul e Sudeste. 


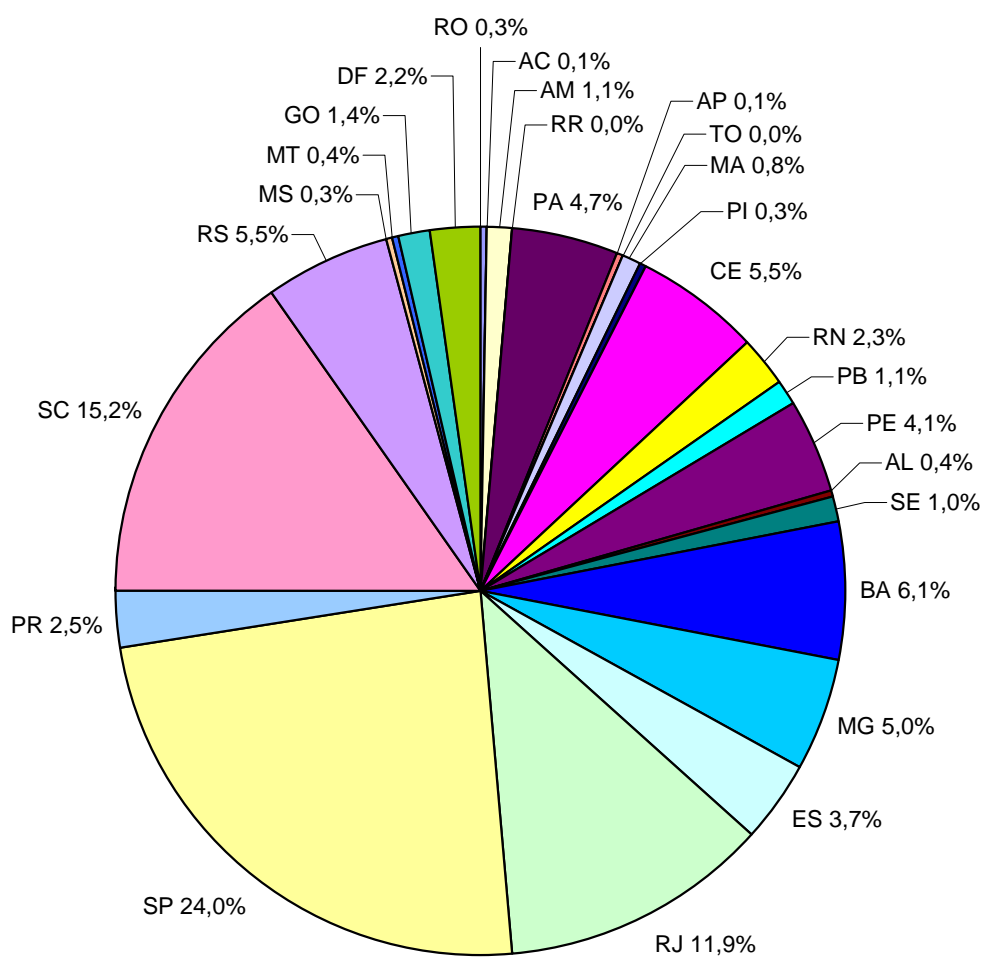

Fonte: MTE.

Gráfico 30 - Distribuição dos estabelecimentos de comércio atacadista de pescado por Unidade Federativa - 2005

Em relação à remuneração, no ano de 2005 , aproximadamente $78,49 \%$ dos trabalhadores do comércio atacadista de pescado estavam na faixa salarial entre 1,01 e 3,00 salários mínimos ${ }^{18}$ (Gráfico 31) (BRASIL, [2008?c]).

${ }^{18}$ De acordo com BRASIL (2005a), a partir de $1^{\circ}$ de maio de 2005, o valor do salário mínimo passou a ser de $\mathrm{R} \$ 300,00$ (trezentos reais), sendo esta lei posteriormente revogada pela Lei $n^{\circ} 11.321$, de 07/07/2006. 


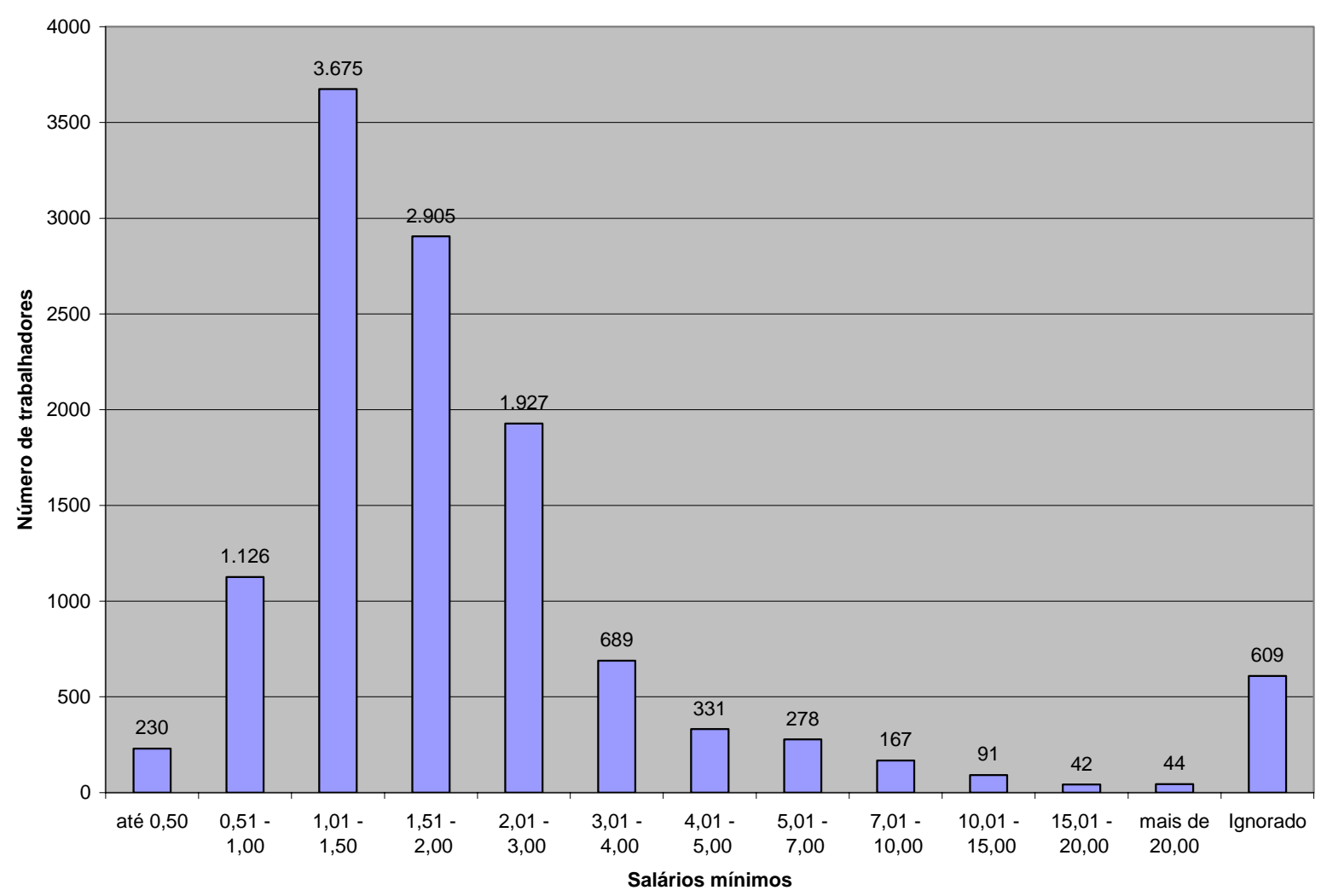

Fonte: MTE.

Gráfico 31 - Remuneração média dos trabalhadores brasileiros do comércio atacadista de pescado 2005

No ano de 2005, o setor atacadista de pescado empregou um total de 5.984 trabalhadores. Das 584 famílias ocupacionais relacionadas na RAIS, a família "Trabalhadores na fabricação e conservação de alimentos" foi a que apresentou maior número de trabalhadores, empregando um total de 1.325. Para a correta interpretação do Gráfico 32, é importante salientar que na denominação "Outros" ocorrem diversas ocupações cujas porcentagens individuais foram inferiores à 1,72\%, como por exemplo "Almoxarifes e armazenistas" (1,67\%), "Cozinheiros" $(0,9 \%)$ e "Diretores administrativos e financeiros" (0,03\%) (Gráfico 32) (BRASIL, [2008?c]). 


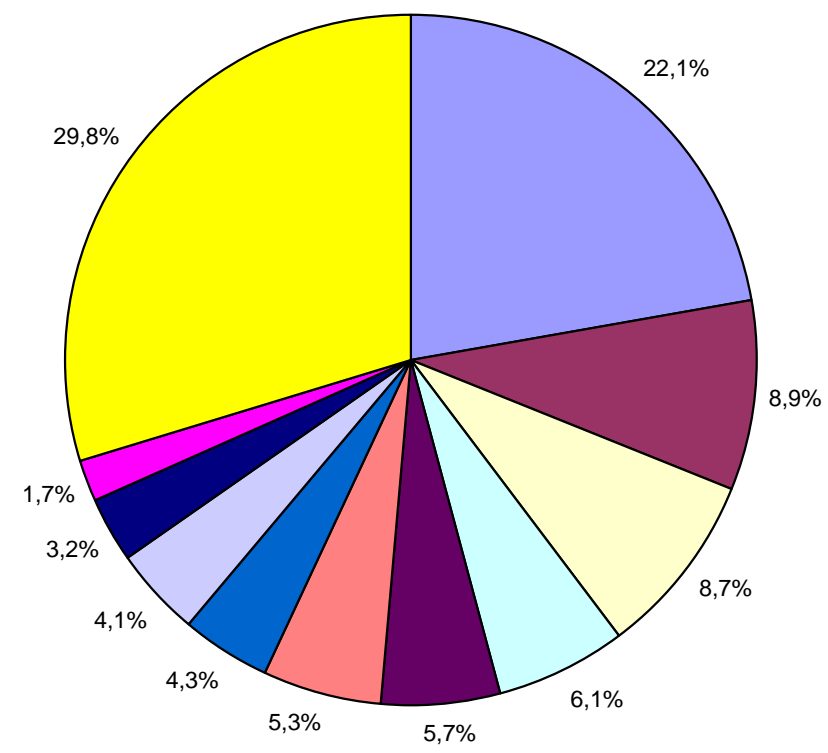

$\square$ Trabalhadores na fabricação e conservação de alimentos

口Operadores do comércio em lojas e mercados

$\square$ Escriturários em geral, agentes, assistentes e auxiliares administrativos

$\square$ Motoristas de veículos de cargas em geral

口Pescadores de água costeira e alto mar

$\square$ Trabalhadores nos serviços de manutenção e conservação de edifícios e logradouros

$\square$ Mantenedores de edificações

$\square$ Trabalhadores de cargas e descargas de mercadorias

- Motoristas de veículos de pequeno e médio porte

$\square$ Gerentes de operações comerciais e de assistência técnica

$\square$ Outros

Fonte: MTE.

Gráfico 32 - Principais ocupações do comércio atacadista de pescado - 2005

\subsection{DIFICULDADES, DESAFIOS E PERSPECTIVAS}

Durante o processo de caracterização do complexo agroindustrial do pescado brasileiro, foram evidenciadas algumas dificuldades existentes no setor, bem como foram encontradas diversas publicações relatando tais desafios como parte da atual realidade vivenciada por seus agentes. Por se tratar de um setor bastante diverso e que ocorre em uma área ampla, a realidade e as dificuldades existentes em cada região brasileira podem ser diferentes umas das outras. Assim, o presente capítulo não tem a intenção de discorrer sobre as peculiaridades de cada região, mas sim de abordar alguns dos principais problemas observados em nível nacional que se destacaram durante a consulta a materiais para a caracterização do complexo agroindustrial do pescado. 


\subsubsection{O setor pesqueiro em estado de sobrepesca}

A FAO estima que, em 2005, aproximadamente $23 \%$ dos estoques pesqueiros por ela monitorizados estavam sub ou moderadamente explotados ( $3 \%$ e $20 \%$, respectivamente), podendo talvez elevar a produção, enquanto que aproximadamente $52 \%$ estavam completamente explotados, produzindo muito próximo ou mesmo nos limites máximos da sustentabilidade, sem possibilidades de expansão produtiva. Por fim, os outros $25 \%$ ou estavam sobre-explotados, diminuídos ou em recuperação da depleção (17\%, 7\% e 1\%, respectivamente) (FAO, 2007).

No Brasil, a situação não é diferente. Dos 153 estoques pesqueiros monitorizados até 2006 para o REVIZEE, 55,6\% estavam plenamente ou sobre-explotados (22,9\% e $32,7 \%$, respectivamente), enquanto que $15,7 \%$ poderiam ter sua produção elevada por estarem sub ou não-explotados (4,6\% e 11,1\%, respectivamente) e 28,8\% foram avaliados de forma inconclusiva (BRASIL, 2006). De acordo com Altemir Gregolin, Ministro da Secretaria Especial da Aquicultura e Pesca, esse esgotamento dos estoques pesqueiros naturais é uma das dificuldades vivenciadas pelo setor (CRMVSP, 2008).

Para José Dias Neto, coordenador de gestão de recursos pesqueiros do Instituto Brasileiro do Meio Ambiente e dos Recursos Naturais Renováveis (IBAMA), o caso da sardinha-verdadeira (Sardinella brasiliensis) é um dos exemplos mais graves da exploração desordenada da pesca brasileira (GREENPEACE, 2008).

\subsubsection{O caso da sardinha-verdadeira}

Distribuída entre o Cabo de São Tomé-RJ (22 $\left.{ }^{\circ} \mathrm{S}\right)$ e o Cabo de Santa Marta GrandeSC $\left(28^{\circ} \mathrm{S}\right)$ (SACCARDO, ROSSI-WONGTSCHOWSKI, 1991), a sardinha-verdadeira é o principal recurso pesqueiro do Brasil em termos de volume de produção (VALENTINI; CARDOSO, 1991). Os primeiros registros dessa atividade são datados 
de 1910, mas apenas a partir de 1964 como atividade industrial, quando iniciaram os aumentos na captura (GASALLA; TUTUI, 2003). Sua importância pode ser observada ao definir valores desse complexo agroindustrial: mais de 300 embarcações de médio e grande porte, mão-de-obra direta de 7.000 pescadores e, no mínimo, 14.000 trabalhadores envolvidos em todas as etapas do complexo. Tal atividade é responsável pela manutenção do maior parque industrial conserveiro do país (VALENTINI, CARDOSO, 1991). No ano de 2006, representou $11,83 \%$ do total produzido pela pesca marinha, ficando atrás apenas da categoria que envolve todos os crustáceos (12,29\%) (IBAMA, 2008).

A frota pesqueira industrial da sardinha expandiu-se, principalmente entre as décadas de 70 e 80 , dobrando seu tamanho neste período. De forma geral, no estado do Rio de Janeiro, a frota manteve-se estável em torno de 266 embarcações. Porém, nos estados de Santa Catarina e São Paulo, entre 1973 e 1988, a frota passou de 54 para 105 unidades e de 55 para 120 unidades, respectivamente. Com os subsídios do governo estimulando a atividade no início da década de 70 (GASALLA; TUTUI, 2003), o volume de sardinha capturado por esses três estados apresentou forte aumento até 1973 , ano em que houve o maior volume capturado (228.037 toneladas). Desde então, esse volume tem apresentado tendência declinante até a década de 90, alternado entre períodos de queda e de estabilização (Gráfico 33) (SACCARDO; ROSSI-WONGTSCHOWSKI, 1991; VALENTINI; CARDOSO, 1991; GASALLA; TUTUI, 2003). O excessivo esforço de pesca aplicado sobre as formas juvenis foi considerado um fator determinante para a redução da captura total da sardinha-verdadeira (VALENTINI; CARDOSO, 1991). 


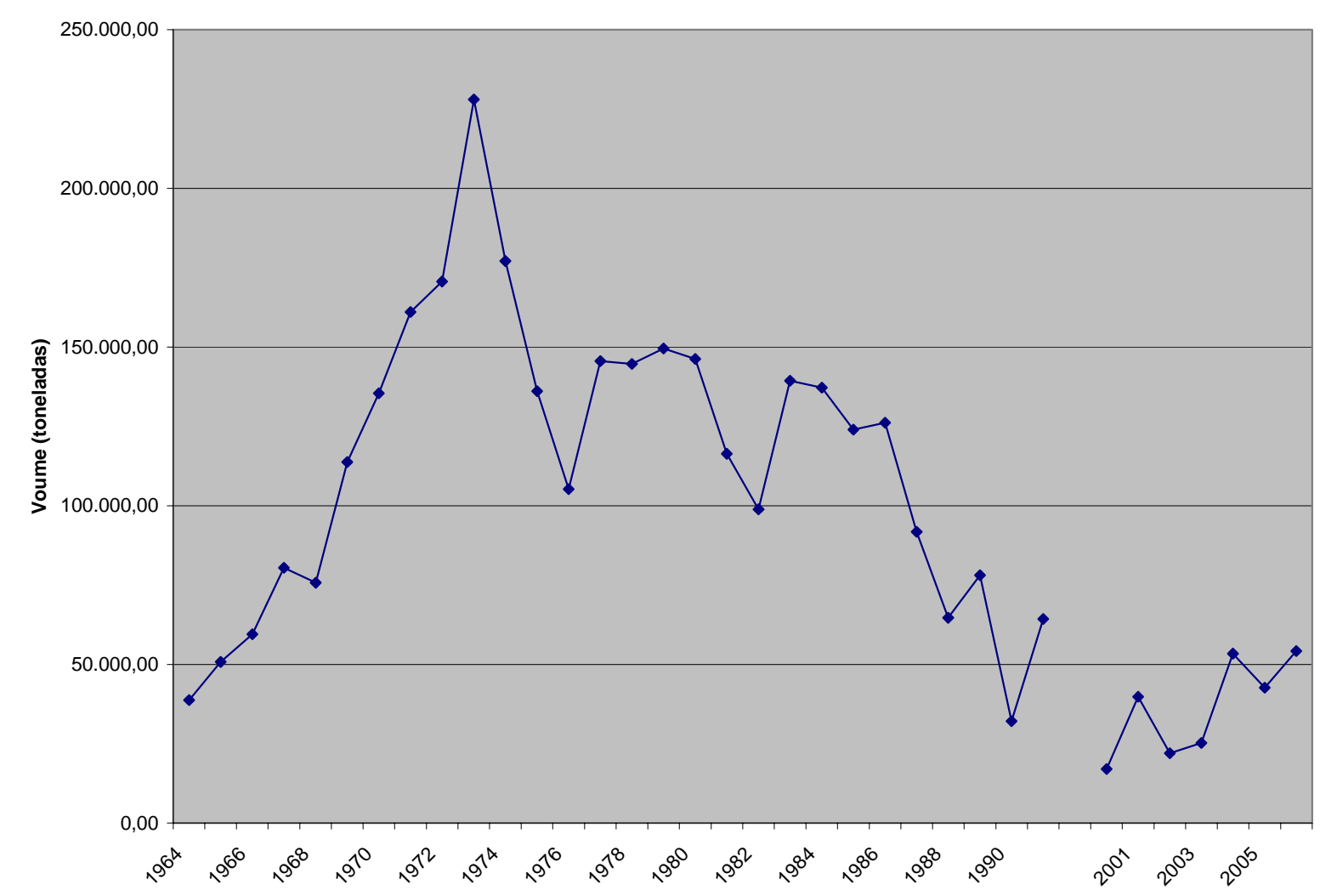

Fonte: Instituto da Pesca DPM/Santos-SP e COREGs/SUDEPE (RJ, SC e SP) apud VALENTINI, CARDOSO, 1991 (dados até 1988) e IBAMA, 1992 (dados de 1989 até 1991), IBAMA, [2001 ou 2002] (dado de 2000), IBAMA, 2003 (dado de 2001), IBAMA, 2004a (dado de 2002), IBAMA, 2004b (dado de 2003), IBAMA, 2005 (dado de 2004), IBAMA, 2007 (dado de 2005) e IBAMA, 2008 (dado de 2006)

Gráfico 33 - Evolução das capturas de Sardinella brasiliensis nos estados do Rio de Janeiro, Santa Catarina e São Paulo - 1964-1991 e 2000-2006.

Alterações na estrutura das populações desses estoques pesqueiros foram observadas a partir de 1980. A captura de indivíduos jovens, de comprimento inferior a 17 centímetros, foi superior aos $15 \%$ do peso total da captura regulamentado em 1980, 1982, 1985 e 1988, o que levou a uma queda de produção nos anos subsequentes (SACCARDO; ROSSI-WONGTSCHOWSKI, 1991). Também foi observado que a área de distribuição da sardinha tem ficado mais restrita, estando o estoque mais concentrado na porção sul da área de ocorrência, entre Itajaí-SC e o Cabo de Santa Marta-SC (ROSSI-WONGTSCHOWSKI; SACCARDO; CERGOLE, 1995).

Em diversas reuniões do Grupo Permanente de Estudos sobre a Sardinha, entidade pertencente ao IBAMA, o esforço excessivo de pesca sobre as formas jovens da sardinha foi apontado como um fator importante para a redução dos estoques, bem 
como para a redução do peso das capturas (IBAMA, 1991a; IBAMA 1991b; IBAMA 1992).

Durante o período de 1976 a 1990, a regulamentação da pesca da sardinha incluía um período de defeso de três meses (correspondente ao período de desova da espécie, entre dezembro e fevereiro), estabelecimento de comprimento mínimo de captura de 17 centímetros (equivalente ao comprimento médio de maturação reprodutiva da sardinha), tolerância de captura de 15\% em peso de indivíduos com comprimento inferior a 17 centímetros e controle do esforço de pesca através da atividade permissionada. Uma vez que tais medidas se mostraram ineficazes, com evidências do colapso desse setor pesqueiro (VALENTINI; CARDOSO, 1991), em 1991 algumas medidas foram reformuladas. Foram adotados dois períodos de defeso (correspondendo aos períodos de desova e de recrutamento da sardinha, entre junho e agosto), redução da tolerância de captura de 15\% em peso de indivíduos com comprimento inferior a 17 centímetros para 5\%, além do controle do esforço de pesca (ROSSI-WONGTSCHOWSKI; SACCARDO; CERGOLE, 1995).

Após 1990, ano em que houve o pico de menor produção (32.081 toneladas), as capturas mostraram algum sinal de recuperação na década de 90, atingindo aproximadamente 100.000 toneladas em 1997 (GASALLA; TUTUI, 2003).

Gasalla e Tutui (2003) fizeram uma revisão sobre a regulamentação federal e recomendações de grupos técnicos sobre a pesca da sardinha durante o período de 1977 e 1997. De modo geral, os grupos técnicos recomendavam o período de defeso nas fases de desova, o controle do esforço da pesca, a determinação do comprimento mínimo de 17 centímetros dos indivíduos capturados, os estudos sobre a funcionalidade do licenciamento da frota, o melhoramento de dados estatísticos da pesca, a revogação de licenças, a fiscalização do cumprimento da não comercialização de indivíduos jovens, as pesquisas e a monitorização da estrutura da população dos estoques, a redução da fração do peso total de captura que poderia ser de indivíduos de comprimento inferior a 17 centímetros para 5\% e a proibição da pesca por 2,5 anos. Muitas destas recomendações foram acatadas pelos órgãos públicos, formando uma política pesqueira da sardinha baseada na determinação de períodos de defeso durante as fases de desova e de recrutamento, 
na determinação do comprimento mínimo de 17 centímetros dos indivíduos capturados, com posterior limitação dessa fração para 15\% e 10\% do peso total de captura, na limitação do tamanho da frota pesqueira e ora no fornecimento de licenças para a atividade, ora na revogação das mesmas.

Ainda em relação ao trabalho de Gasalla e Tutui (2003), em entrevistas realizadas com diversos expertos do setor pesqueiro, o tamanho excessivo da frota pesqueira e sua modernização foram considerados os principais fatores responsáveis pela sobrepesca da sardinha, sugerindo que a regulamentação da pesca é considerada um importante tópico para a conservação dessa espécie. Em relação às medidas consideradas efetivas para a regulamentação do setor, a limitação do número da frota foi considerada a mais importante. A regulamentação vigente foi considerada inadequada para a atual necessidade do setor, sendo sugeridas outras medidas de gestão da atividade, como existência de quotas de pesca. Por fim, na opinião dos expertos consultados, a pesquisa identificou que os principais problemas estão relacionados à gestão, legislação e fiscalização da pesca, conforme Quadro 1.

(continua)

\begin{tabular}{|c|c|c|}
\hline \multicolumn{2}{|c|}{ Principais tópicos } & Principais problemas \\
\hline \multirow[t]{13}{*}{ Gestão } & $\begin{array}{c}\text { Estrutura } \\
\text { administrativa }\end{array}$ & $\begin{array}{c}\text { Centralização das responsabilidades e } \\
\text { regulamentação em nível Federal } \\
\text { Integração e coordenação entre os órgãos } \\
\text { governamentais Federal, Estadual e } \\
\text { Municipal }\end{array}$ \\
\hline & & $\begin{array}{c}\text { Mudanças estruturais em instituições } \\
\text { governamentais responsáveis pela pesca } \\
\text { Gestão pesqueira não leva em conta as } \\
\text { características regionais }\end{array}$ \\
\hline & & $\begin{array}{c}\text { Estrutura burocrática do órgão ambiental } \\
\text { Federal }\end{array}$ \\
\hline & & $\begin{array}{c}\text { Pouca ajuda do setor produtivo nas medidas } \\
\text { regulatórias }\end{array}$ \\
\hline & & $\begin{array}{c}\text { Os investidores não apreciam a necessidade } \\
\text { de regulamentação }\end{array}$ \\
\hline & & Falha na regulamentação da frota \\
\hline & & Escassez de estatísticas pesqueiras \\
\hline & & Falha na monitorização de estoques \\
\hline & & $\begin{array}{c}\text { Desacordo entre o progresso científico e o } \\
\text { processo tomador de decisão }\end{array}$ \\
\hline & & $\begin{array}{c}\text { Existência de regulamentações de } \\
\text { fiscalização impraticáveis }\end{array}$ \\
\hline & & Falha na legislação \\
\hline & & Fiscalização deficitária \\
\hline & & $\begin{array}{c}\text { Realização de gestão sem avaliação de } \\
\text { performance }\end{array}$ \\
\hline
\end{tabular}


(continua)

\begin{tabular}{|c|c|c|}
\hline \multicolumn{2}{|c|}{ Principais tópicos } & \multirow{2}{*}{$\begin{array}{c}\text { Principais problemas } \\
\text { Falha nos sistemas de monitorização como } \\
\text { um todo }\end{array}$} \\
\hline Gestão & $\begin{array}{c}\text { Estrutura } \\
\text { administrativa }\end{array}$ & \\
\hline & \multirow[t]{9}{*}{ Políticas } & $\begin{array}{l}\text { Insignificante importância econômica dada } \\
\text { ao setor pesqueiro em nível Federal } \\
\text { Falha na participação do setor produtor }\end{array}$ \\
\hline & & $\begin{array}{l}\text { Mudanças em instituições governamentais } \\
\text { responsáveis pela administração da pesca }\end{array}$ \\
\hline & & $\begin{array}{l}\text { Necessidade de mais pesquisas científicas } \\
\text { voltadas a procedimentos de gestão } \\
\text { Descontinuidade de projetos de pesquisa }\end{array}$ \\
\hline & & Falha nos acordos entre os grupos usuários \\
\hline & & $\begin{array}{l}\text { Forte influência de lobbies no processo de } \\
\text { tomada de decisão }\end{array}$ \\
\hline & & $\begin{array}{c}\text { Falha nas análises e políticas } \\
\text { sócioeconômicas }\end{array}$ \\
\hline & & $\begin{array}{l}\text { Falha na regulamentação de política voltada } \\
\text { para a demanda }\end{array}$ \\
\hline & & $\begin{array}{c}\text { Investidores devem pagar pela utilização dos } \\
\text { recursos }\end{array}$ \\
\hline & & $\begin{array}{l}\text { Necessidade de considerar critérios } \\
\text { ecológicos e capacidade dos ecossistemas }\end{array}$ \\
\hline & Educação & $\begin{array}{c}\text { Falha na educação e treinamento dos } \\
\text { funcionários públicos } \\
\text { Necessidade de educação ambiental para a } \\
\text { sociedade em geral }\end{array}$ \\
\hline \multirow[t]{13}{*}{ Legislação } & \multirow[t]{3}{*}{ Elaboração } & $\begin{array}{c}\text { Modelo regulatório orientado de cima para } \\
\text { baixo }\end{array}$ \\
\hline & & Legislação antiquada \\
\hline & & $\begin{array}{l}\text { Falha na mobilização e participação da } \\
\text { sociedade e investidores } \\
\text { Presença de lobbies voltados ao processo de } \\
\text { elaboração }\end{array}$ \\
\hline & \multirow[t]{6}{*}{ Base } & $\begin{array}{l}\text { Não fundamentação em resultados } \\
\text { científicos recentes }\end{array}$ \\
\hline & & $\begin{array}{c}\text { Diversas preocupações apontadas por } \\
\text { cientistas não são contempladas na } \\
\text { legislação }\end{array}$ \\
\hline & & $\begin{array}{c}\text { Períodos de defeso com falhas ambientais e } \\
\text { biológicas }\end{array}$ \\
\hline & & $\begin{array}{c}\text { Retardo entre resultados da ciência e } \\
\text { aplicação da lei }\end{array}$ \\
\hline & & $\begin{array}{c}\text { Falha na legislação específica em termos de } \\
\text { espécies }\end{array}$ \\
\hline & & É mais extensa do que a área de referência \\
\hline & \multirow[t]{4}{*}{ Aplicabilidade } & Problemas relativos à complementação da lei \\
\hline & & $\begin{array}{l}\text { Falha na avaliação no impacto } \\
\text { sócioeconômico }\end{array}$ \\
\hline & & $\begin{array}{l}\text { Falha na estrutura para as leis } \\
\text { complementares }\end{array}$ \\
\hline & & Falha do sistema de fiscalização \\
\hline \multirow[t]{3}{*}{ Fiscalização } & \multirow[t]{3}{*}{ Estrutura } & Falha na fiscalização \\
\hline & & $\begin{array}{c}\text { Falha na monitorização da ação da } \\
\text { fiscalização }\end{array}$ \\
\hline & & $\begin{array}{c}\text { Não participação da marinha na vigilância } \\
\text { das pescarias costeiras }\end{array}$ \\
\hline
\end{tabular}


(conclusão)

\begin{tabular}{ccc}
\hline \multicolumn{2}{c}{ Principais tópicos } & Principais problemas \\
\hline Fiscalização & Estrutura & Insuficiente número de pessoal fiscalizador \\
\cline { 2 - 3 } & Operação & Falha no treinamento do recurso humano \\
& envolvido no processo \\
& & Diferenças regionais na legislação e \\
& interpretação
\end{tabular}

Fonte: GASALLA, TUTUI, 2003.

Quadro 1 - Principais problemas na regulamentação pesqueira no Sul do Brasil

\subsubsection{O caso do camarão-rosa}

Outro exemplo histórico da exploração desenfreada no setor pesqueiro ocorreu com a pesca do camarão-rosa (Farfantepenaeus brasiliensis e Farfantepenaeus paulensis), que levou à falência muitas empresas que o exploraram (MATSUURA, 1977).

O camarão-rosa da espécie Farfantepenaeus brasiliensis apresenta uma área de distribuição geográfica muito ampla, estendendo-se do Cabo Hatteras na Carolina do Norte, Estados Unidos da América $\left(35^{\circ} \mathrm{N}\right)$, até a Lagoa dos Patos-RS, Brasil (29 `S). Já a espécie Farfantepenaeus paulensis está distribuída ao longo do litoral brasileiro, do Cabo Frio-RJ até o Nordeste Argentino (PÉREZ FARFANTE, 1969).

O camarão-rosa é um importante recurso pesqueiro brasileiro, uma vez que o camarão inteiro congelado é o principal produto pesqueiro exportado em termos de volume, totalizando $15.532,716$ toneladas, e o segundo mais importante em termos financeiros, totalizando US\$ FOB 60.064.560,00 em 2007, ficando atrás somente das lagostas não inteiras (BRASIL, [2008?d]).

O ciclo de vida de ambas as espécies é semelhante. A reprodução ocorre em mar aberto, a profundidades de 40 a 100 metros, seguido pelo desenvolvimento inicial até a fase de pós-larvas. A partir desta fase, os indivíduos migram para as áreas estuarinas, onde completam seu desenvolvimento até as fases juvenil e pré-adulto. Após esse evento, a migração de recrutamento ocorre, com os indivíduos retornando ao oceano para o desenvolvimento, maturação das gônadas e 
reprodução (NEIVA, 1966). O conhecimento do ciclo de vida do camarão-rosa é importante para a compreensão dos efeitos das diferentes modalidades de pesca para a situação atual desse recurso pesqueiro.

Nessa atividade, é importante diferenciar as duas modalidades de pesca. A pesca artesanal é realizada nos criadouros, através da captura das formas juvenis e préadultas, enquanto a pesca industrial é realizada no oceano, através da captura das formas adultas (VALENTINI et al., 1991).

O volume de camarão-rosa capturado nas regiões Sudeste e Sul do Brasil atingiu o pico máximo no ano de 1972, com 16.028,00 toneladas. Desde então apresentou tendência declinante, com menor valor em 1998, totalizando 2.008 toneladas. Conforme observado por Valentini et al. (1991), os valores máximo e mínimo da pesca total estavam diretamente relacionados aos valores máximo e mínimo obtidos pela pesca artesanal (Gráfico 34). Vale observar que os melhores resultados da pesca industrial do camarão-rosa ocorreram nos anos de 1969 e 1972, quando prevaleceu a política de incentivos fiscais à pesca, que, nas regiões Sudeste e Sul, concentrou a maior parte das aplicações na atividade camaroneira, tendo em vista o elevado valor econômico do produto e a exportação (VALENTINI et al., 1972). A instalação de indústrias e o aumento da frota camaroneira, proporcionaram um aumento de $693 \%$ no esforço da pesca total, o que corresponde a um incremento de $395 \%$ da frota atuante, tendo como reflexo uma queda de aproximadamente $66 \%$ na abundância do camarão-rosa entre 1965 e 1972 (VALENTINI et al., 1991). 


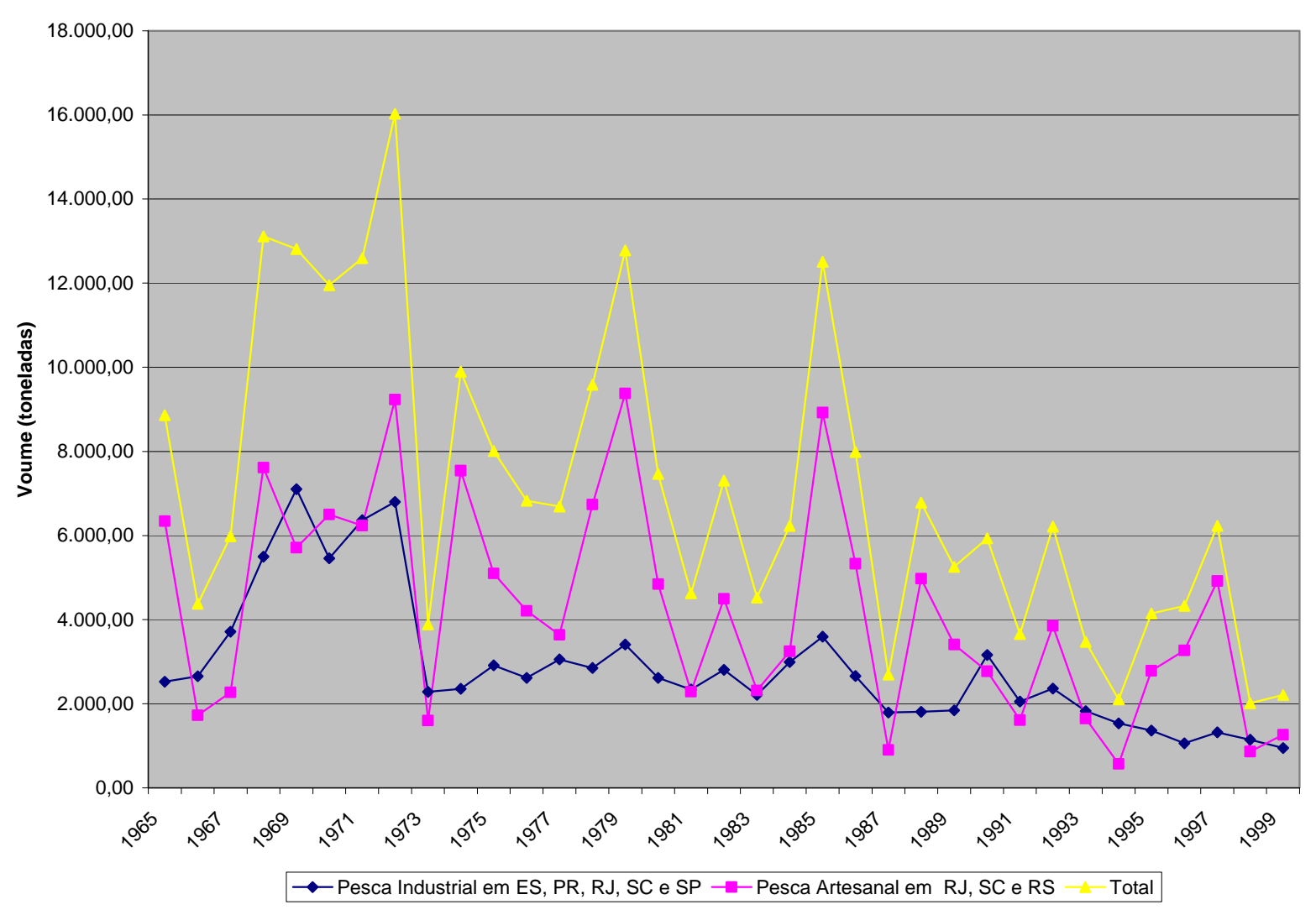

Fonte: Instituto de Pesca/SP e IBAMA/ES-PR-RJ-SC-SP apud D'INCAO, VALENTINI, RODRIGUES, 2002.

Gráfico 34 - Evolução das diferentes modalidades de captura de Camarão-rosa nos estados do Espírito Santo, Paraná, Rio de Janeiro, Santa Catarina e São Paulo - 1965-1999

O aumento da intensidade da pesca artesanal, uma das causas da queda do rendimento sustentável, o impedimento do recrutamento das formas jovens e préadultas pelo estoque adulto e a notória falta de informações básicas sobre a captura e o esforço de pesca, foram apontados como fatores que explicam o desordenamento e a falta de perspectiva de controle, demonstrando a ineficácia da regulamentação e/ou da fiscalização do setor (VALENTINI et al., 1991).

Assim, Valentini et al. (1991) observaram que, durante o período de queda na captura do camarão-rosa, alguns grupos técnicos sobre o camarão, como por exemplo o Grupo Permanente de Estudos sobre o Camarão-rosa, pertentente ao Centro de Pesquisa e Gestão de Recursos Pesqueiros do Litoral Sudeste e Sul (CEPSUL) do IBAMA, recomendavam ações, tais como a adoção de um período de defeso entre os meses de fevereiro a maio (período o qual ocorre o recrutamento) abrangendo toda a área de mar aberto das regiões Sudeste e Sul, além de envolver tanto a categoria de pesca artesanal quanto industrial, incluindo a proibição da 
pesca de outras espécies cujas áreas de ocorrência sejam percorrida pelo camarãorosa em seu processo de migração.

Embora a regulamentação do camarão-rosa, visando proteger o recrutamento, tenha sido baseada na determinação de um comprimento mínimo de captura, na concessão de licenças especiais permitindo a atividade pesqueira e na proibição da atividade por dado período, as recomendações feitas pelos grupos de pesquisa não foram completamente atendidas pela administração pesqueira das regiões Sudeste e Sul. Ao adotar medidas diferentes das recomendadas, como a adoção de um período de defeso inferior ao sugerido (como a Portaria da SUDEPE N-50 de 1983, que determinou um período de defeso entre 01/03/1984 a 30/04/1984), a inconstância da proibição durante o período de defeso (conforme a Portaria da SUDEPE N-71 de 1985, que permitiu a pesca em dias alternados durante o defeso), a não abrangência de todo o litoral das regiões Sudeste e Sul (a exemplo da Portaria da SUDEPE N-50 de 1983, que abrangeu do sul de Abrolhos-BA, 1800'S, a Tramandaí-RS, $30^{\circ} 00^{\prime} S$, não incluindo a região litorânea entre esta cidade e a cidade de Chuí-RS, $33^{\circ} 40^{\prime}$ ), a exclusão da proibição de algumas categorias de embarcações (como a Portaria da SUDEPE N-06 de 1986, que excluiu da proibição as embarcações impulsionadas por motor de até 24 H.P.) e a não proibição da pesca de outras espécies cujas áreas de ocorrência eram percorridas pelo camarãorosa (conforme ocorreu em todas as Portarias citadas anteriormente), a administração pesqueira das regiões Sul e Sudete impossibilitaram que o objetivo básico de preservação do estoque fosse alcançado (VALENTINI et al., 1991).

\subsubsection{Outras espécies}

Além da sardinha-verdadeira e do camarão-rosa, diversas outras espécies aquáticas estão sobre-explotadas, ameaçadas de sobrepesca, ou ainda ameaçadas de extinção. O Governo brasileiro, reconhecendo a situação do estoque de algumas dessas espécies, determinou a proibição imediata da captura das espécies ameaçadas de extinção e o desenvolvimento de planos para a recuperação das mesmas. Já para as espécies sobre-explotadas ou ameaçadas de sobrepesca, foi 
determinado o desenvolvimento de planos de gestão desses estoques (BRASIL, 2004a, BRASIL, 2005b). Nos Anexos C e D são apresentadas as espécies divulgadas pela Instrução Normativa n. 5 do MMA, de 21/05/2004, já atualizada pela Instrução Normativa n. 52 do MMA, de 08/11/2005.

\subsubsection{Os entraves da legislação pesqueira}

Em todo o mundo, os governos dispõem de uma série de medidas para proteger os estoques pesqueiros ameaçados, como o controle do acesso à pesca, limitação por cota de captura, limitação da eficiência dos aparelhos de pesca, fechamento de estação de pesca, fechamento de áreas para pesca, proteção de reprodutores, determinação de tamanho mínimo para captura, restrição sobre os aparelhos utilizados, entre outros. Em certos aspectos, o Brasil possui uma eficiente legislação, como a que determina o tamanho das redes e malhas em determinadas pescarias, mas, no geral, a estrutura reguladora se mostra insuficiente. O Código de Pesca, que rege a atividade pesqueira no Brasil, é datado de 1967, quando o cenário do setor era diferente do atual. Nos dias de hoje, devido à sobreposição de órgãos que lidam com a atividade e à existência de conflitos na regulamentação, essa legislação se tornou confusa. Somando-se à insuficiente regulamentação do setor, a falta de fiscalização do cumprimento das leis também é um fator importante para a determinação do estado de sobrepesca do setor pesqueiro brasileiro (GREENPEACE, 2008).

Para se ter dimensão da quantidade de instituições governamentais envolvidas com o setor primário pesqueiro, pode-se citar a SEAP, que atua, de forma geral, na formulação de políticas públicas para o desenvolvimento do setor; o MAPA, tendo a questão sanitária e a fiscalização dos insumos como principal competência no complexo agroindustrial do pescado; o MMA e o IBAMA, que trabalham as questões ambientais do setor. Todos esses órgãos foram dicutidos no sexto capítulo da Revisão da Literatura. 
O arcabouço institucional da gestão do setor pesqueiro é insustentável. Um exemplo desta sobreposição de funções dos órgãos públicos pode ser observado quando da definição das competências do MMA, do IBAMA e da SEAP: enquanto os dois primeiros são responsáveis pela gestão dos recursos pesqueiros em estado de sobre-explotação (BRASIL, 2003a, BRASIL, 2005c), cabe ao último a gestão dos recursos sub-explotados ou passíveis de explotação (BRASIL, 2003a). Outro exemplo é a divisão de tarefas, que pode ser observada na atribuição ao IBAMA da definição da quantidade de embarcações que pode explorar determinado recurso (BRASIL, 2003a), enquanto que cabe à SEAP a concessão de licenças para a atividade (BRASIL, 2004b) e, por fim, ao IBAMA cabe a fiscalização (BRASIL, 1967).

Uma vez que existe uma indefinição quanto à responsabilidade pela gestão do setor pesqueiro, dividida entre a SEAP, que busca o desenvolvimento da produtividade do setor (BRASIL, 2003), e o IBAMA, que visa à conservação dos estoques pesqueiros (BRASIL, 1989), ou seja, de interesses divergentes, fica dificultada a elaboração de uma política de recuperação dos estoques ameaçados e de desenvolvimento sustentável da pesca.

\subsubsection{Sugestões para o ordenamento do setor}

Tendo em vista todos os entraves oriundos da existência de diferentes órgãos na regulamentação do setor pesqueiro, bem como na indefinição de funções de cada órgão, é entendida como urgente a necessidade de uma reorganização institucional do segmento, definindo uma governança que realize um trabalho sério e efetivo, visando à recuperação dos estoques em estado de sobrepesca e ao desenvolvimento sustentável do setor. Também é vista como de fundamental importância a necessidade de tornar a fiscalização mais eficiente, através da contratação de recursos humanos capacitados e treinados, evitando o não cumprimento da legislação, como observado nos casos da sardinha-verdadeira e do camarão-rosa, e o colapso dos estoques pesqueiros. Por fim, uma reavaliação da legislação torna-se urgente. 
Além disso, a pesquisa apresenta um papel central na correta gestão pesqueira. Estudos contínuos sobre a biologia da pesca, com a finalidade de conhecer a situação atual dos estoques e controlar a atividade de captura, bem como de avaliações dos estoques pesqueiros prévias à exploração, podem auxiliar na tomada de decisões, evitando a utilização inadequada dos recursos pesqueiros (MATSUURA, 1977). Portanto, tais estudos devem, obrigatoriamente, ser realizados previamente à explotação dos recursos naturais.

Segundo Gordon (1954) e Scott (1955), a gestão adequada dos recursos pesqueiros além ter um papel importante na prevenção do estabelecimento dos estados de sobrepesca, é também importante para combater a ineficiência econômica inerente ao setor, pois trata-se de uma atividade com a peculiar característica de propriedade comum e de livre acesso aos recursos naturais, o que leva a uma má alocação dos fatores de produção, além daquele ótimo que permitiria uma renda máxima.

Segundo Charles (2001), um sistema de gestão da pesca deve ser implantado a fim de garantir que todos os benefícios produtivos da atividade sejam atingidos. $O$ controle da atividade pesqueira é necessário devido ao potencial de depleção dos estoques; à necessidade de gerenciamento de aspectos biológicos, sociais, econômicos e culturais conflitantes e a necessidade de controle sobre a taxa de explotação sobre os estoques para balancear com as necessidades e sustentabilidade da atividade. A gestão da atividade pesqueira serve como um guia, sendo composta, basicamente, por quatro componentes:

a) Política e planejamento: devem estabelecer os objetivos gerais da atividade, políticas direcionadas para tais objetivos, legislação relacionada à gestão e regulação, decisões a respeito da estrutura de gestão, entre outros;

b) Gestão: deve estabelecer e rever as medidas de gestão para controle de impacto da atividade, realizar tomadas de decisão rotineiras para atingir o plano operacional, pesquisar e obter dados para promover o conhecimento básico necessário, entre outros;

c) Desenvolvimento: deve estabelecer as medidas para melhorar a infraestrutura física, capacidades tecnológicas, produtividade humana e/ou institucional do 
sistema; medidas para melhorar o fluxo de benefícios sustentáveis, como o desenvolvimento de marketing, controle de qualidade e de processos de distribuição; desenvolvimento de novas pescarias necessárias e desejáveis; entre outros;

d) Pesquisa: deve coletar, analisar e disseminar informações relevantes; determinar medidas para acessar e conservar estoques; entre outros.

Além da reorganização institucional, do melhoramento da fiscalização e da revisão da legislação, a criação de áreas marinhas protegidas foi identificada com uma ferramenta no auxílio da manutenção ou repovoamento dos estoques pesqueiros. Essas são quaisquer áreas entre as faixas de marés ou abaixo delas, junto de toda a camada de água e associada à flora, fauna, características históricas e culturais, que são protegidas por leis ou por outros meios efetivos com a intenção de resguardar parte ou todo do ambiente nela contida $\left(\right.$ IUCN $^{19}, 1988$ apud KELLEHER, 1999, p. XVIII). Assim, todos os ambientes marinhos estão inclusos nesse conceito, inclusive áreas costeiras e ilhas, bem como as características culturais e históricas da área. Além de abordar todo o conteúdo do fundo do oceano, toda a fauna e flora da coluna de água acima deste também é contemplada pelo conceito (KELLEHER, 1999).

Apesar dos recursos marinhos se moverem de forma livre na coluna de água, as áreas marinhas protegidas conservam a biodiversidade e o habitat, além de auxiliar na manutenção de pescarias viáveis. Ao proteger os habitats, os processos oceânicos vitais para a manutenção da vida são garantidos, como a fotossíntese, manutenção das cadeias alimentares, movimentação de nutrientes, degradação de poluentes e conservação da diversidade e produtividade biológicas. Dessa forma, o aumento dos estoques na reserva permite a saída de formas jovens pelas correntes oceânicas para outros estoques. Assim, em diversas regiões, houve um aumento nos estoques pesqueiros logo em seguida do estabelecimento de áreas protegidas, bem como houve um acréscimo das pescarias, promovendo um benefício econômico direto às indústrias pesqueiras. Diferentemente dos métodos convencionais de conservação dos estoques, através da tentativa de controlar o

19 IUCN. INTERNATIONAL UNION FOR CONSERVATION OF NATURE. Resolution $\mathbf{1 7 . 3 8}$ of the IUCN General Assembly, 1988. 
esforço de pesca e pesca total, geralmente sem sucesso, as áreas protegidas têm se mostrado efetivas em diversos estudos (KELLEHER, 1999).

A preocupação é tamanha, que desde o World Summit on Sustainable Development, realizado em 2002 pela United Nations, a necessidade de restabelecer os estoques pesqueiros depletados foi citada nos planos de implementação (WSSD, 2002). Tanto nesse encontro, quanto no $5^{\text {th }}$ World Park Congress, realizado em 2003 pela International Union for Conservation of Nature, a necessidade de implementar um sistema global de áreas marinhas protegidas é citada como um meio de proteção aos estoques pesqueiros (WPC, 2003). Nesse último, foi recomendada a existência de áreas marinhas protegidas em pelo menos 20 a 30\% das águas marítimas do mundo.

No âmbito federal brasileiro, das 31 Áreas de Proteção Ambiental, 11 estão relacionadas ao ambiente marinho, protegendo o equivalente a $0,17 \%$ da região oceânica nacional (Quadro 2) (BRASIL, [2008e]). Essas áreas são destinadas à proteção e conservação da qualidade ambiental e os sistemas naturais ali existentes, tendo em vista a melhoria da qualidade de vida da população local além de objetivar a proteção dos ecossistemas regionais. Para tal, essas áreas sempre apresentam um zoneamento econômico-ecológico, estabelecido de acordo com condições bióticas, geológicas, urbanísticas, agro-pastoris, extrativistas, culturais, entre outras. Também, devem existir nessas áreas as zonas de vida silvestre, onde o uso dos sistemas naturais é proibido ou regulado (BRASIL, 1988b). 


\begin{tabular}{|c|c|c|}
\hline Nome & Localização & Legislação \\
\hline $\begin{array}{c}\text { Área de Proteção Ambiental } \\
\text { Anhatomirim }\end{array}$ & Santa Catarina & $\begin{array}{l}\text { Criada pelo Decreto n. } 528 \text { de } \\
20 / 05 / 1992\end{array}$ \\
\hline $\begin{array}{l}\text { Área de Proteção Ambiental } \\
\text { Cananéia-Iguape-Peruíbe }\end{array}$ & São Paulo & $\begin{array}{c}\text { Criada pelo Decreto n. } 90.347 \text { de } \\
\text { 23/10/1984 e modificada pelo Decreto } \\
\text { n. } 91.892 \text { de } 06 / 11 / 1985\end{array}$ \\
\hline $\begin{array}{c}\text { Área de Proteção Ambiental da } \\
\text { Costa dos Corais }\end{array}$ & $\begin{array}{l}\text { Alagoas e } \\
\text { Pernambuco }\end{array}$ & Criada pelo Decreto de 23/10/1997 \\
\hline $\begin{array}{c}\text { Área de Proteção Ambiental da } \\
\text { Baleia Franca }\end{array}$ & Santa Catarina & Criada pelo Decreto de 14/09/2000 \\
\hline $\begin{array}{l}\text { Área de Proteção Ambiental da } \\
\text { Barra do Rio Mamanguape }\end{array}$ & Paraíba & $\begin{array}{c}\text { Criada pelo Decreto } n .924 \text { de } \\
\text { 10/09/1993 e modificada pelo Decreto } \\
\text { de } 07 / 04 / 1998\end{array}$ \\
\hline $\begin{array}{c}\text { Área de Proteção Ambiental de } \\
\text { Cairuçu }\end{array}$ & Rio de Janeiro & $\begin{array}{l}\text { Criada pelo Decreto n. } 89.242 \text { de } \\
27 / 12 / 1983\end{array}$ \\
\hline $\begin{array}{l}\text { Área de Proteção Ambiental de } \\
\text { Fernando de Noronha }\end{array}$ & Pernambuco & $\begin{array}{c}\text { Criada pelo Decreto } n .92 .755 \text { de } \\
\text { 05/06/1986 e modificada pelo Decreto } \\
\text { n. } 94.780 \text { de } 14 / 08 / 1987\end{array}$ \\
\hline $\begin{array}{c}\text { Área de Proteção Ambiental de } \\
\text { Guapi-Mirim }\end{array}$ & Rio de Janeiro & $\begin{array}{l}\text { Criada pelo Decreto n. } 90.225 \text { de } \\
\text { 25/09/1984 }\end{array}$ \\
\hline $\begin{array}{c}\text { Área de Proteção Ambiental de } \\
\text { Guaraqueçaba }\end{array}$ & Paraná & $\begin{array}{l}\text { Criada pelo Decreto n. } 90.883 \text { de } \\
\text { 31/101985 }\end{array}$ \\
\hline $\begin{array}{c}\text { Área de Proteção Ambiental de } \\
\text { Piaçabuçu }\end{array}$ & Alagoas & $\begin{array}{l}\text { Criada pelo Decreto } 88.421 \text { de } \\
21 / 06 / 1983\end{array}$ \\
\hline $\begin{array}{c}\text { Área de Proteção Ambiental Delta } \\
\text { do Parnaíba }\end{array}$ & $\begin{array}{l}\text { Piauí, Maranhão e } \\
\text { Ceará }\end{array}$ & Criada pelo Decreto de 28/08/1996 \\
\hline
\end{tabular}

Fonte: IBAMA.

Quadro 2 - Áreas de Proteção Ambiental relacionadas ao ambiente marinho

Publicações internacionais relatam o sucesso da implementação de áreas protegidas em diversos países. Na Nova Zelândia, onde a atividade pesqueira é proibida em qualquer área protegida, a densidade populacional e tamanho médio das lagostas da espécie Jasus edwardsii foi maior em áreas protegidas quando comparados aos valores obtidos em áreas não protegidas e, por consequência, a biomassa também mostrou-se mais elevada (KELLY et al., 2000). Na Argentina, a abundância do polvo da espécie Octopus tehuelchus foi duas vezes maior na área protegida quando comparada a um local pesqueiro de livre acesso (NARVARTE; GONZÁLEZ; FERNÁNDEZ, 2006). Nos Estados Unidos, o estoque de hadoque da espécie Melanogrammus aeglefinus, que já se encontrava em estado de sobrepesca desde a década de 90, atualmente está em estado de recuperação devido à adoção de medidas para a diminuição da mortalidade da espécie, como a determinação de áreas fechadas para a atividade pesqueira por um longo período no ano, restrição do esforço de pesca, entre outros, resultando na maior abundância de adultos, o que determinou a maior capacidade reprodutiva do estoque, bem como no aumento da biomassa (BRODZIAK et al., 2008). No mar Mediterrâneo, o efeito da área de proteção pôde ser observado pelo aumento da pesca por unidade de esforço nas 
proximidades da reserva, tanto na pesca total quanto na pesca de algumas espécies em particular, como os peixes das espécies Pagellus erythrinus e Mullus surmuletus (STELZENMÜLLER; MAYNOU; MARTÍN, 2007).

No Brasil, Ferreira e Maida (2007) relataram os resultados obtidos com a implementação da Área de Proteção Ambiental Marinha Costa dos Corais. Foi acompanhada a abundância de peixes, polvos e lagostas, como as famílias Lutjanidae, Serranidae, Acanthuridae, Holocentridae, Scaridae e Chaetodontidae, sendo todas alvo da atividade pesqueira, ao longo do primeiro ano após a determinação de proibição da pesca por um período de três anos. Quando comparada ao observado em áreas abertas próximas, a abundância do pescado sofreu um aumento de quatro vezes; cada família apresentou uma variação, como os peixes da família Lutjanidae, que aumentaram em 11 vezes a quantidade de indivíduos por área pesquisada. Além do aumento da quantidade de pescado, foram registradas algumas espécies que não foram observadas na região antes do fechamento, como o Lutjanus analis, Lutjanus cyanopterus, entre outras.

Floeter, Halpern e Ferreira (2006) analisaram a abundância de 114 espécies de peixes de recifes, com diferentes graus de pressão de pesca (sem pressão, leve ou elevada pressão de pesca), em locais com diferentes níveis de proteção (área protegida, parcialmente protegida ou não protegida), como os recifes de AbrolhosBA, as ilhas de Guarapari-ES, Arraial do Cabo-RJ, a ilha Laje de Santos-SP e Arvoredo-SC. Foi detectado que espécies muito exploradas foram mais abundantes em áreas com maior nível de proteção quando comparada à abundância em áreas menos protegidas, enquanto que em espécies pouco protegidas ou não exploradas ocorreu o contrário.

Além do estabelecimento de áreas protegidas marinhas, a frota pesqueira pode ser redirecionada para a explotação de diversos outros estoques pesqueiros com potencial para o uso sustentável, a fim de diminuir a pressão de pesca sobre as espécies em estado de sobrepesca. Estudos realizados para o REVIZEE apontaram que o Brasil dispõe de diversos estoques pesqueiros com potencial de explotação. Dos 153 estoques estudados para o programa, 15,7\% poderiam ter sua produção elevada por estarem sub ou não-explotados (4,6\% e 11,1\%, respectivamente), como 
o ariocó (Lutjanus synaguis) e a cabeçuda (Ctenosciaena gracilicirrhus) no Norte, o cherne (Epinephelus niveatus) e o caçonete (Mustelus canis) no Nordeste, o espadarte (Xiphias gladius) e a chicharra (Decapterus tabl) na região Central, a sardinha-laje (Opisthonema oglinum) e a anchoíta (Engraulis anchoita) no Sudeste e Sul do Brasil, entre outras espécies. Porém, para o uso sustentável desses estoques, são necessários estudos prévios à explotação dessas espécies, desenvolvendo o conhecimento relacionado à dinâmica populacional, à viabilidade dos estoques à exploração, aos limites sustentáveis para cada espécie, entre outros pontos de interesse peculiares, de modo a evitar um futuro estado de sobrepesca ou extinção (BRASIL, 2006).

\subsubsection{As dificuldades enfrentadas pela aquicultura}

Durante a pesquisa relacionada à aquicultura, não foram encontrados trabalhos relatando os entraves à atividade, mas sim, trabalhos técnico-científicos relacionados ao desempenho zootécnico, conforme avaliado por Scorvo Filho et al. (2008) e Tsuzuki, Cardoso e Cerqueira (2008); nutrição, como estudado por Silva, Gomes e Brandão (2007) e Oliveira et al. (2007); reprodução, como pesquisado por Cavalcante e Camara (2008), entre outros.

Contudo, foi encontrado o trabalho de Ostrensky e Boeger (2008), que discutiram as principais dificuldades enfrentadas pela aquicultura brasileira. Tais dificuldades foram identificadas após filtrarem 5.492 mensagens postadas no fórum eletrônico de discussão da revista Panorama da Aquicultura, principal revista brasileira relacionada à atividade, entre outubro de 2002 e outubro de 2006, e através dos 56 questionários respondidos que foram submetidos a 800 representantes de praticamente todos os setores do complexo agroindustrial aquícola nacional. Uma vez que esse foi o único trabalho encontrado sobre o panorama da aquicultura em nível nacional, a seguir são discutidos os principais relatos dos autores. 
$\mathrm{Na}$ primeira parte do trabalho, foram analisadas as mensagens veiculadas no fórum eletrônico. Houve predomínio de mensagens relacionadas à piscicultura, seguida pela aquicultura de forma geral, carcinicultura e malacocultura $(52,8 \%, 22,3 \%$, $16,6 \%$ e 1,5\%, respectivamente). Segundo os autores, o resultado obtido era esperado, visto que o número de pessoas envolvidas com a piscicultura no país é maior do que o de pessoas envolvidas com a carcinicultura ou com a malacocultura (OSTRENSKY; BOEGER, 2008).

Após a classificação do conteúdo em temas pertinentes centrais e exclusão das mensagens que abordavam questões de caráter individual (como a busca por informações técnicas para resolver problemas produtivos, locais para a aquisição de insumos e equipamentos e informações sobre a realização de eventos de caráter técnico-científico), foram identificadas e discutidas as principais dificuldades enfrentadas pela aquicultura nacional que foram debatidas ao longo de quatro anos nesta lista de discussão eletrônica (OSTRENSKY; BOEGER, 2008).

O grande problema enfrentado pela piscicultura, principalmente nas regiões Sul e Sudeste, é a busca por alternativas para substituir a pesca esportiva, por exemplo, o pesque-pague, como destino final dos peixes produzidos em cativeiro, que foi uma via de escoamento muito importante para o desenvolvimento da atividade até a fase atual. Para o crescimento e aprimoramento da atividade, agora é importante o processamento dessa produção (assunto de maior ocorrência), uma vez que a demanda da pesca esportiva é insuficiente para absorver aumentos significativos da oferta de peixes. A viabilidade econômica deste processamento está relacionada ao aumento da base produtiva, para que escalas industriais e localizadas de produção sejam atingidas. Uma das formas de expandir essa produção é através do fomento ao uso de tanques-rede (terceiro assunto de maior ocorrência), principalmente nos grandes reservatórios. Para a exequibilidade desse sistema, as questões relacionadas ao licenciamento ambiental devem ser resolvidas (décimo assunto de maior ocorrência). Também é necessário definir novas alternativas de comercialização e promover a abertura de novos mercados (oitavo e quinto assuntos de maior ocorrência, respectivamente). A exportação e o uso do pescado na merenda escolar são alternativas frequentemente citadas na lista de discussão 
(décimo quinto e décimo terceiro assuntos de maior ocorrência, respectivamente) (OSTRENSKY; BOEGER, 2008).

Em relação à carcinicultura, as questões de importância para o desenvolvimento da atividade também foram discutidas no fórum, como a questão das patogenias (segundo assunto de maior ocorrência), como o surgimento da Mionecrose Infecciosa Muscular na região Nordeste e a Síndrome da Mancha Branca na região Sul; os problemas de mercado (quinto assunto de maior ocorrência), como a queda do valor do dólar, aumento do custo de produção e a ação antidumping promovida pela Aliança Sulina de Pescadores de Camarão dos Estados Unidos e as questões ambientais (quarto assunto de maior ocorrência). Todas essas questões foram responsáveis pela diminuição do crescimento da atividade nos últimos anos (OSTRENSKY; BOEGER, 2008).

As questões relacionadas à malacoclutura também foram discutidas, como o processamento da produção (assunto de maior ocorrência) e definições de normas aplicáveis para o licenciamento ambiental (décimo assunto de maior ocorrência) (OSTRENSKY; BOEGER, 2008).

As políticas públicas também foram discutidas, como a existência de uma legislação confusa, burocrática e complexa para disciplinar o desenvolvimento da aquicultura; a falta de informações setoriais básicas e a dificuldade ou os custos para se obter financiamentos para investir no setor (OSTRENSKY; BOEGER, 2008).

$\mathrm{Na}$ segunda parte do trabalho, relacionada aos questionários enviados aos representantes do complexo agroindustrial aquícola, as dificuldades foram divididas em problemas técnicos; aspectos administrativos e de políticas públicas e aspectos econômicos e de mercado, onde os entrevistados deveriam colocar em grau de relevância os problemas que interferem no desenvolvimento da atividade. Também era possível adicionar outras questões não listadas em qualquer um dos grupos. Dos 800 questionários submetidos, 56 foram respondidos (OSTRENSKY; BOEGER, 2008). 
Em relação aos problemas técnicos, cada grupo de trabalho apresentou um tipo diferente de problema principal. No caso da malacocultura e do cultivo de algas, o principal problema enfrentado é a falta de estruturas apropriadas de produção ou processamento. Já para a carcinicultura, a qualidade da água é apontada como principal dificuldade, sendo, possivelmente, um reflexo da pressão que o setor recebe em relação às questões ambientais. A piscicultura, de forma semelhante à pesquisa realizada no fórum eletrônico, apresentou como principal dificuldade a falta de treinamento e de qualificação técnica, o que justifica a busca de soluções em listas de discussões por parte de pequenos produtores, que representam a maior parte da atividade, seguida pelas questões de processamento e de sanidade (OSTRENSKY; BOEGER, 2008).

Com esses achados, Ostrensky e Boeger (2008) discutiram a importância dos órgãos de extensão rural para o desenvolvimento da aqüicultura. Devido ao quadro profissional reduzido, tais órgãos apresentam atuações limitadas, repercutindo na falta de qualificação gerencial e empreendedora dos produtores. Os aturores também comentaram a necessidade em intensificar o processamento dos produtos aquícolas, que deve contribuir com a agregação de valor aos produtos e com a popularização do consumo.

A dificuldade de acesso ao crédito para investimento e o custeio do empreendimento foram considerados como sendo os principais entraves econômicos à aquicultura. Os autores discutiram a existência de diversas linhas de crédito disponíveis aos aquicultores, indústrias processadoras e comerciantes de produtos aquícolas; a redução do financiamento no setor nos últimos anos; a dificuldade em obter o crédito, devido à necessidade de demonstrar garantias reais que chegam a até $150 \%$ do valor do empréstimo; a situação não-licenciada da maioria dos carcinicultores, malacocultores e militicultores, o que impede a aquisição do crédito; as elevadas taxas de juros, entre outros. Outra questão econômica que dificulta 0 desenvolvimento do setor é a existência de formas de investimento alternativas, como a compra de títulos do governo, com lucratividade garantida e segura, tornando o crédito rural menos atrativo. Conclui-se que a política adotada pelo Banco Central inibe o crédito e desestimula a produção (OSTRENSKY; BOEGER, 2008). 
A falta de políticas públicas claras e eficientes foi o problema relacionado às políticas públicas mais citado, como a falta de treinamento e de qualificação técnica; a inexistência de programas de defesa sanitária para os animais aquáticos; a burocracia e o despreparo dos órgãos ambientais, entre outros. No caso da carcinicultura e da piscicultura continental, a falta de dados estatísticos completos e confiáveis sobre a produção foi o problema mais citado, o que dificulta o planejamento adequado para o desenvolvimento do setor (OSTRENSKY; BOEGER, 2008).

A carcinicultura ainda apresentou três problemas relacionados entre si, com a mesma relevância dada pelos entrevistados: a falta de políticas públicas, a falta de integração entre os órgãos de governo e a imagem negativa que a atividade tem perante a sociedade. Os autores discutem a inexistência de políticas públicas direcionadas ao desenvolvimento da atividade, o que fez com que a atividade crescesse devido às ações regionais e ao interesse de grandes investidores, sem o ordenamento dado pelos órgãos governamentais. Tal fato repercutiu na dificuldade de implantação das medidas para o desenvolvimento sustentável do setor, como a polarização entre os grupos que ressaltam os resultados econômicos e os que enfatizam os impactos ambientais (OSTRENSKY; BOEGER, 2008).

A piscicultura continental ainda apresentou um dado de interesse para o setor. $O$ segundo problema mais citado foi a falta de organização comunitária, que reflete na falta de força política e de representatividade do setor. Os caminhos para o desenvolvimento da piscicultura envolvem a agregação de valores, a diversificação da produção e a abertura de novos mercados, o que dificilmente será alcançado por pequenos ou médios produtores rurais isoladamente (OSTRENSKY; BOEGER, 2008).

São também discutidos outros problemas extrínsecos ao setor, mas que igualmente representam um entrave ao seu desenvolvimento, como o setor de logística, que apresenta elevado custo e falta de infraestrutura; a elevada carga tributária; a corrupção, que desvia o dinheiro público que poderia ser investido em setores fundamentais; o arcabouço legal e as indefinições e conflitos institucionais acerca da 
gestão, fiscalização e fomento da aquicultura, entre outros (OSTRENSKY; BOEGER, 2008).

Por fim, Ostrensky e Boeger (2008) recomendam ao Poder Público solucionar os três principais entraves detectados na pesquisa (a falta de treinamento e qualificação técnica, a dificuldade de acesso ao crédito e a falta de políticas públicas para o desenvolvimento do setor), sendo fundamental e prioritário para o desenvolvimento da atividade.

Borghetti e Ostrensky (2000) realizaram em levantamento semelhante ao anteriormente citado, a partir de uma oficina técnica realizada em Pirienópolis-GO, entre 24 e 26 de fevereiro de 1999, para a elaboração do Plano Estratégico de Apoio para o Departamento de Pesca e Aquicultura do Ministério da Agricultura e do Abastecimento; e a partir de reuniões realizadas diretamente com representantes do setor produtivo na região do Vale do Ribeira-SP, regiões Norte e Oeste do Paraná, região Nordeste do Rio Grande do Sul, região do Alto Uruguai-RS, região da Alta Araraquarense-SP, Goiânia-GO, região do Lago de Furnas-MG, Natal-RN e litoral Catarinense-SC, entre julho de 1997 e setembro de 1998. Os entraves detectados neste trabalho foram muito semelhantes àqueles observados e discutidos por Ostrensky e Boeger (2008), como os problemas com a legislação ambiental, a falta de pesquisa e desenvolvimento de novas tecnologias e melhoramento das já existentes, a falta de extensão rural, a baixa capacitação dos profissionais da área, a falta de linhas de crédito para o setor, as dificuldades na questão sanitária, a falta de estrutura do setor beneficiador, a elevada carga tributária, a falta de campanhas de marketing, a escassez de informações básicas sobre o setor, entre outros. Assim, é possível notar que, baseado em ambos os trabalhos, a situação do setor produtivo aquícola pouco se alterou no período entre a realização de ambos os trabalhos.

Vale aqui ressaltar alguns pontos importantes em relação ao trabalho de Ostrensky e Boeger (2008). O primeiro refere-se à peculiar metodologia utilizada no estudo, valendo-se de mensagens postadas em um fórum eletrônico de discussão, a fim de detectar e elencar as principais dificuldades enfrentadas pelo segmento aquícola nacional. Entende-se que a falta de trabalhos relacionados ao tema, conforme detectado e descrito nesta dissertação, levaram Ostrensky e Boeger (2008) a utilizar 
tal metodologia para a realização da pesquisa. Apesar de tal procedimento ser aqui visto de forma positiva por impulsionar as pesquisas relacionadas às dificuldades do segmento aquícola, o mesmo revela um problema maior: a falta de dados e informações setoriais.

Um segundo ponto importante é o baixo número de questionários respondidos $(0,07 \%)$. Conhecendo-se a finalidade do trabalho de Ostrensky e Boeger (2008), os agentes do complexo agroindustrial aquícola nacional são os principais interessados nesse tipo de pesquisa. Contraditoriamente, apesar dos questionários terem sido enviados a representantes dos diversos setores desse complexo agroindustrial, a colaboração foi baixa.

Algumas das dificuldades descritas por Ostrensky e Boeger (2008) merecem destaque, pois podem estar relacionadas não somente à aquicultura, mas sim a todo complexo agroindustrial do pescado. A atual necessidade de intensificar 0 processamento dos produtos aquícolas, pode aqui ser entendida como a necessidade de ampliar o processamento dos produtos derivados do pescado como um todo. Além de agregar valor, uma maior variedade de produtos poderia contribuir com a popularização dos mesmos, promovendo então, um aumento na demanda e estimulando ainda mais a produção primária e beneficiamento.

\subsubsection{Sugestões para melhoramento do setor aquícola}

Observando os trabalhos de Borghetti e Ostrensky (2000) e Ostrensky e Boeger (2008), nota-se que o setor aquícola brasileiro necessita de uma grande atenção por parte das autoridades. São diversas as dificuldades relacionadas direta ou indiretamente, as quais prejudicam o aumento da produção de pescado de qualidade e, principalmente, dificultam o desenvolvimento e posicionamento do segmento aquícola dentre as principais atividades produtoras de proteína animal para a alimentação humana no Brasil. 
Tendo em vista a função da SEAP de desenvolver a aquicultura, a função do MMA e do IBAMA de regulamentar as questões ambientais relacionadas à atividade, e a função do MAPA de regulamentar a sanidade animal, sugere-se uma atuação mais eficaz por parte dos órgãos oficiais, uma vez que, no período de quase 10 anos, praticamente os mesmos problemas foram relatados e discutidos nos dois trabalhos supracitados. De certa forma, isso mostra uma falha na atuação desses órgãos que ainda não conseguiram solucionar muitas das dificuldades apontadas pelos produtores há quase 10 anos.

Outro ponto de grande importância para a atividade é a questão das políticas públicas. Em ambos os trabalhos, a falta de políticas claras, objetivas e eficientes em detrimento da existência de uma legislação confusa, burocrática e complexa, foi um dos principais problemas discutidos. O desenvolvimento ordenado da atividade depende da criação de todo um arcabouço legislativo claro e objetivo. O IBAMA e o MMA, partindo do pressuposto que a atividade é impactante ao meio ambiente (BORGHETTI; OSTRENSKY, 2000), devem então regulamentar de forma menos complexa sobre a utilização dos recursos hídricos, carga de dejetos produzida, introdução de espécies no ambiente, entre outros, enquanto que o MAPA deve prioritariamente regulamentar um programa de defesa sanitária para os animais aquáticos.

As políticas públicas devem envolver também as questões econômicas, como a facilitação e incentivo à aquisição de crédito para o investimento no setor, uma vez que, segundo Ostrensky e Boeger (2008), as linhas de crédito existem, porém fica dificultada a aquisição do crédito por exigência de garantias muito elevadas, além da existência de outros investimentos de menor risco; e a questão tributária, que eleva o custo de produção e diminui a margem de lucro dos produtores. 


\subsubsection{A questão da qualidade higiênico-sanitária do pescado comercializado}

Durante a pesquisa sobre informações relacionadas ao segmento comercial de pescado, foi observado um grande número de publicações sobre a qualidade higiênico-sanitária do pescado comercializado no Brasil. Em sua maioria, os trabalhos descrevem a comercialização de produtos com baixa qualidade higiênicosanitária, bem como irregularidadas nos locais de fabricação, manipulação e comercialização do pescado. Devido ao risco à saúde pública da comercialização de produtos em não conformidade com a legislação vigente e à quantidade de publicações relacionadas ao tema, a questão da qualidade higiênico-sanitária do pescado comercializado foi identificada como um entrave ao complexo agroindustrial do pescado.

De acordo com a Organização Mundial da Saúde, Doenças Transmitidas por Alimentos (DTA) é o termo utilizado para as afecções geralmente de natureza infecciosa ou tóxica, causadas por agentes que adentram o organismo através da ingestão de alimentos. As principais doenças causadas por micro-organismos são: Salmonelose, Campilobacteriose, infecções por Escherichia coli entero-hemorrágica, Listeriose e Cólera. Além dos micro-organismos, outras causas são também importantes, como as toxinas naturais (tais como as micotoxinas e biotoxinas marinhas), os agentes não convencionais (como o príon da Encefalopatia Espongiforme Bovina), os poluentes orgânicos (como a dioxina) e os metais (como o mercúrio e o cádmio) (WHO, 2007).

A incidência mundial das DTA é de difícil estimativa. Porém, foi reportado que em 2005 , houve 1,8 milhões de óbitos por enfermidades com sintomas diarreicos, sendo grande parte atribuída à contaminação de alimentos e da água. Nos Estados Unidos, estima-se a ocorrência anual de 76 milhões de casos de DTA, resultando em 325 mil hospitalizações e 5 mil óbitos. Enquanto que a maioria dos casos é de ocorrência esporádica e não reportada, surtos podem ocorrer, levando a uma proporção de afetados ainda maior, como no surto de Salmonelose pela contaminação de sorvete, em 1994 nos Estados Unidos, com uma estimativa de 224 mil afetados, e o surto de 
Hepatite A pela contaminação de moluscos, em 1988 na China, com aproximadamente 300 mil afetados (WHO, 2007).

No Brasil, a vigilância epidemiológica das DTA teve início em 1999, sendo realizada somente quando da ocorrência de surtos, com exceção da febre tifóide, cólera e botulismo. Há um registro médio de 665 surtos por ano, afetando 13 mil pessoas (BRASIL, [2008?f]). Além dessa média anual, nenhum dado estatístico oficial divulgado pelo MS, Anvisa ou IBGE sobre a ocorrência de DTA foi identificado. Porém, uma apresentação sobre surtos de DTA no Brasil feita pela Coordenação de Vigilância das Doenças de Transmissão Hídrica e Alimentar (COVEH) da Secretaria de Vigilância em Saúde do MS foi disponibilizada pelo Grupo Técnico da Gerência de Inspeção e Controle de Riscos de Alimentos da Anvisa (informação verbal ${ }^{20}$ ), contendo informações mais específicas, que seguem a seguir.

Atualmente, a vigilância epidemiológica das DTA não está implantada em todas as unidades federativas do Brasil, fazendo com que o número de notificações esteja relacionado ao grau de implantação da vigilância nos municípios (informação verbal $^{20}$ ). O Gráfico 35 mostra o número de surtos e o de doentes registrados entre 1999 e 2007, e o Gráfico 36 mostra a porcentagem de notificação dos surtos por estado.

${ }^{20}$ Contato com o Grupo Técnico da Gerência de Inspeção e Controle de Riscos de Alimentos da Anvisa, através da sessão Fale Conosco do endereço eletrônico http://www.anvisa.gov.br, em 27/02/2009. 


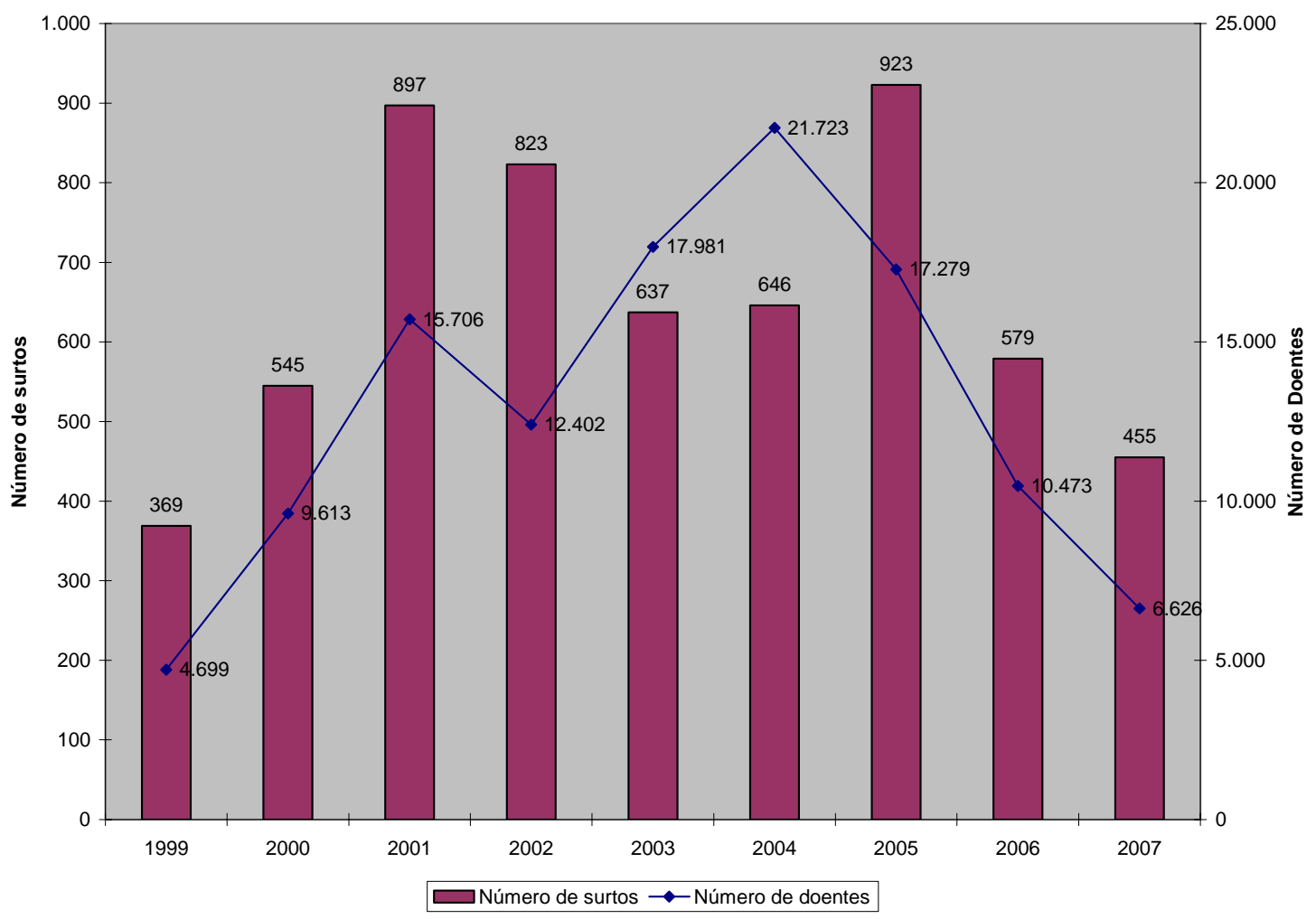

Fonte: Informação verbal ${ }^{20}$.

Gráfico 35 - Número de surtos e de doentes relacionados às doenças transmitidas por alimentos no Brasil - 1999-2007

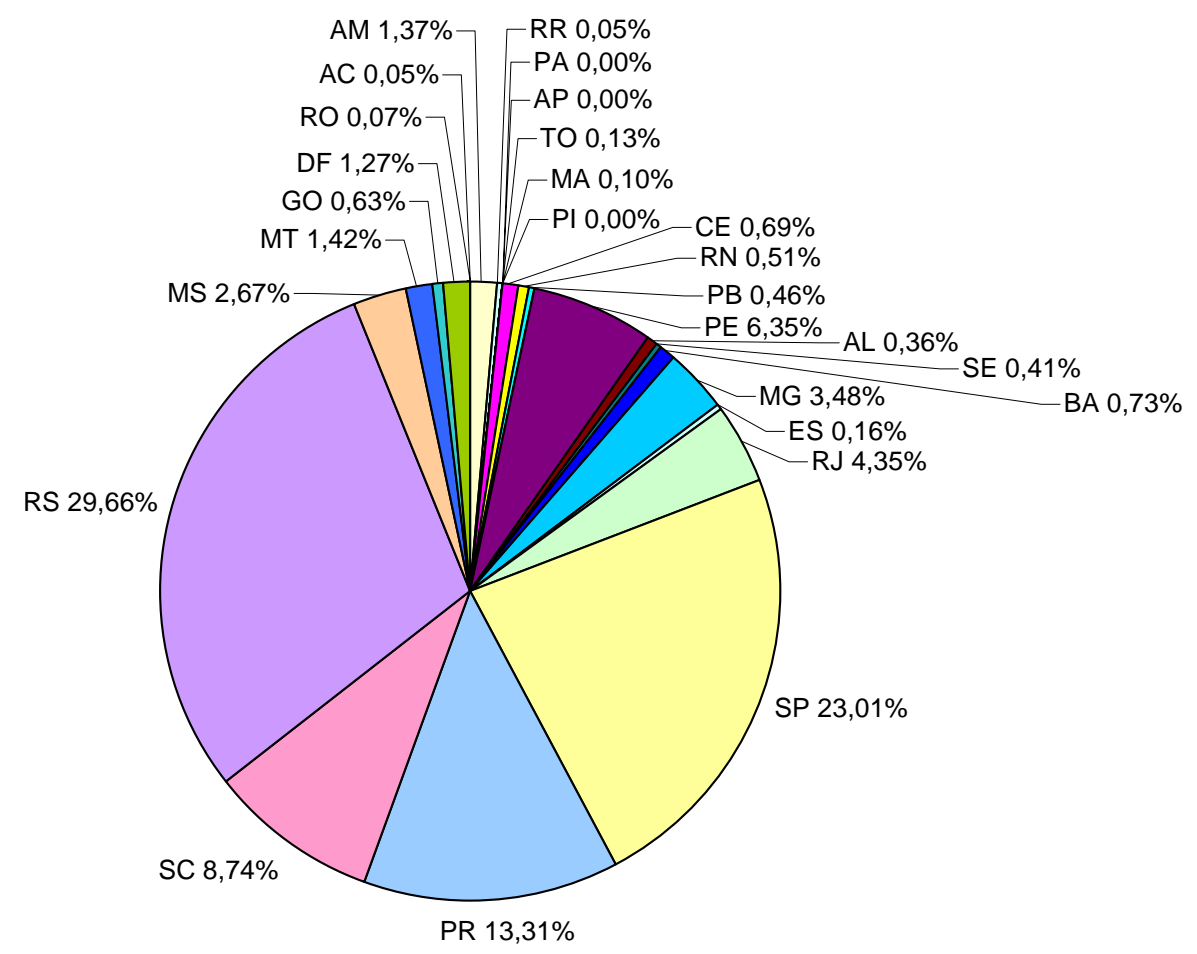

Fonte: Informação verbal ${ }^{20}$.

Gráfico 36 - Notificação de surtos de doenças transmitidas por alimentos no Brasil - 1999-ago. 2008 
Observa-se no Gráfico 36 que pouco mais de $82 \%$ das notificações de surtos de DTA ocorreram nas regiões Sul e Sudeste (informação verbal ${ }^{20}$ ). Como o sistema de vigilância epidemiológica das DTA ainda não está bem implantado em todas as unidades federativas, observando o Gráfico 36 é possível inferir que tal sistema está com baixo grau de implantação nas regiões Norte, Nordeste e Centro-Oeste, e com alto de grau de implantação nas regiões Sul e Sudeste.

Considerando os dados no período entre 1999 e agosto de 2008, no Brasil foram notificados 6.062 surtos de DTA, ou seja, episódios de duas ou mais pessoas com sintomas semelhantes após a ingestão de alimentos e/ou água de mesma origem. Nesses surtos registrou-se um total de 117.330 pessoas afetadas e 64 óbitos (informação verbal ${ }^{20}$ ).

Durante o mesmo período, em relação à pesquisa do agente etiológico dos surtos, tal informação foi ignorada em aproximadamente 51\% das notificações. Nos $49 \%$ dos casos em que o agente foi identificado, as bactérias foram as principais causadoras das ocorrências de surtos de DTA, conforme o Gráfico 37 (informação verbal $^{20}$ ). 


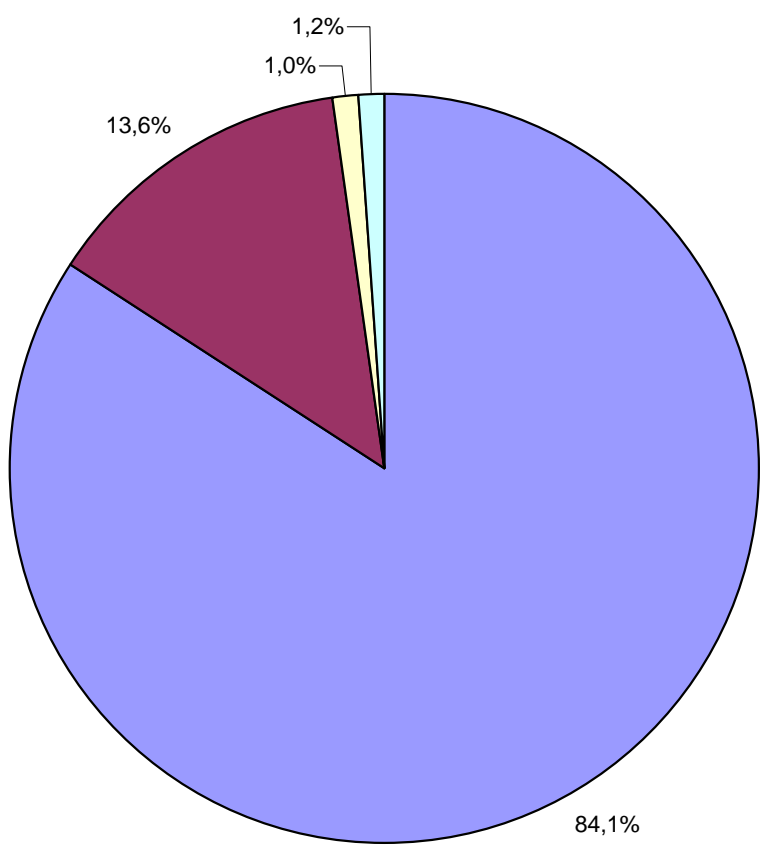

$\square$ Bactérias $\square$ Vírus $\square$ Parasitas $\square$ Químicos

Fonte: Informação verbal ${ }^{20}$.

Gráfico 37 - Principais causas dos surtos de doenças transmitidas por alimentos o Brasil - 1999-ago. 2008

A Salmonella spp foi o agente mais frequente na identificação das causas dos surtos de DTA, seguida pelo Staphylococcus sp e Bacillus cereus. Juntas, as três bactérias foram responsáveis por pouco mais de $50 \%$ dos casos em que houve a identificação dos agentes (Gráfico 38) (informação verbal ${ }^{20}$ ). 


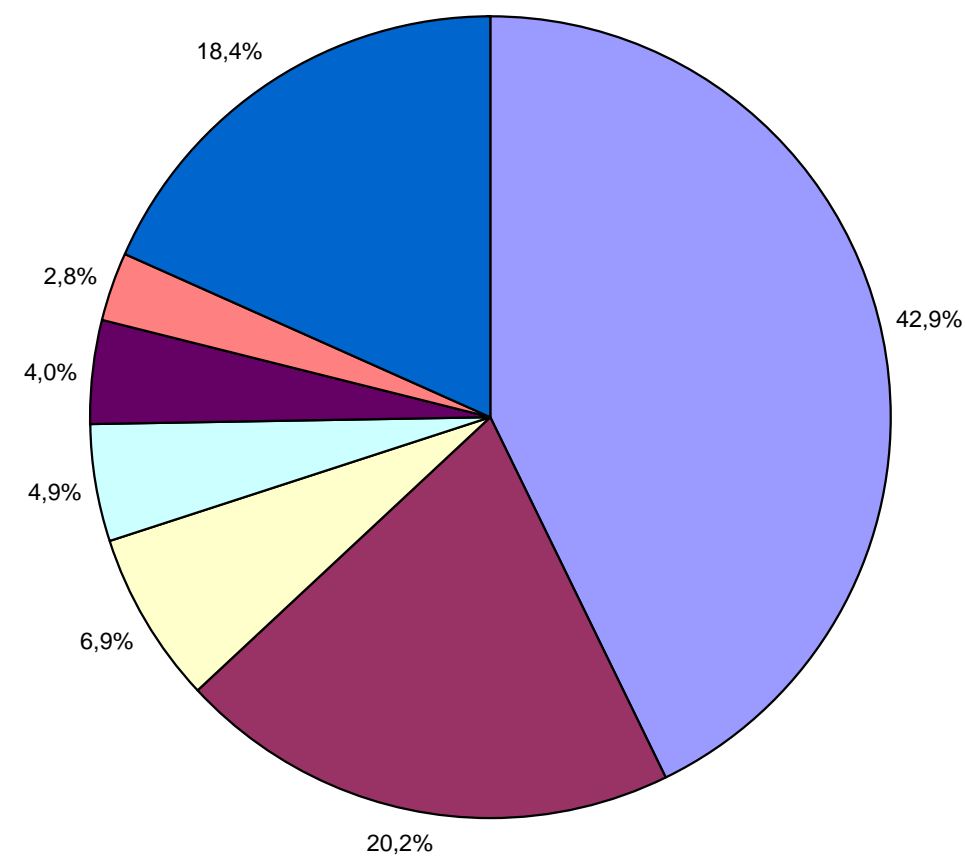

$\square$ Salmonella spp $\square$ Staphylococcus spp $\square$ Bacillus cereus $\square$ Clostridium perfringens - Salmonella enteritidis $\square$ Shigella sp $\square$ Outros

Fonte: Informação verbal ${ }^{20}$.

Gráfico 38 - Principais agentes causadores dos surtos de doenças transmitidas por alimentos o Brasil entre 1999 e agosto de 2008

De modo semelhante à identificação dos agentes, a identificação dos alimentos contaminados foi ignorada em $34,3 \%$ das notificações. Nos $65,7 \%$ dos casos em que houve a identificação do veículo, os alimentos contendo ovos crus e mal cozidos foram os mais frequentes veículos de agentes causadores de DTA (Gráfico 39) (informação verba| ${ }^{20}$ ). 


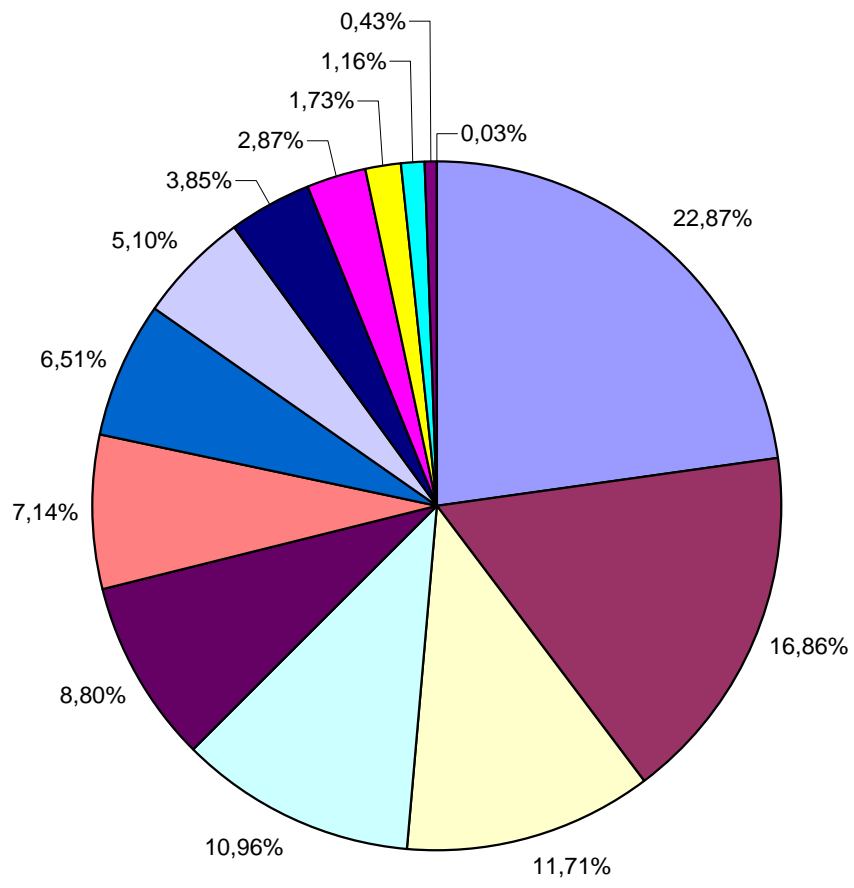

$\square$ Alimento com ovos crus e mal cozidos

$\square$ Alimentos mistos

$\square$ Carnes vermelhas

口Sobremesas

$\square$ Água

$\square$ Leite e derivados

$\square$ Alimentos compostos

$\square$ Carne de aves

-Farináceos

口Legumes e verduras

口Pescados

口Bebidas

arutas

- Produtos químicos

Fonte: Informação verbal ${ }^{20}$.

Gráfico 39 - Principais alimentos veículos de doenças transmitidas por alimentos - 1999-ago. 2008

Em relação ao pescado, o Gráfico 39 aponta o mesmo como responsável por veicular patógenos em $1,73 \%$ dos casos, sendo um dos produtos menos relacionados aos surtos registrados. É possível que tal fato seja atribuído ao baixo consumo de pescado pela população brasileira, se levarmos em conta que aproximadamente $82 \%$ das notificações ocorreram nas regiões Sul e Sudeste (Gráfico 36) e que ambas as regiões foram caracterizadas por apresentarem o menor consumo per capita de pescado do Brasil (Tabela 3).

Por fim, a identificação dos locais de ocorrência dos surtos de DTA também foi ignorada em $24,1 \%$ das notificações. Nos $75,9 \%$ dos casos em que houve a identificação da origem dos alimentos contaminados, as residências foram os locais mais frequentes (Gráfico 40) (informação verbal ${ }^{20}$ ). 


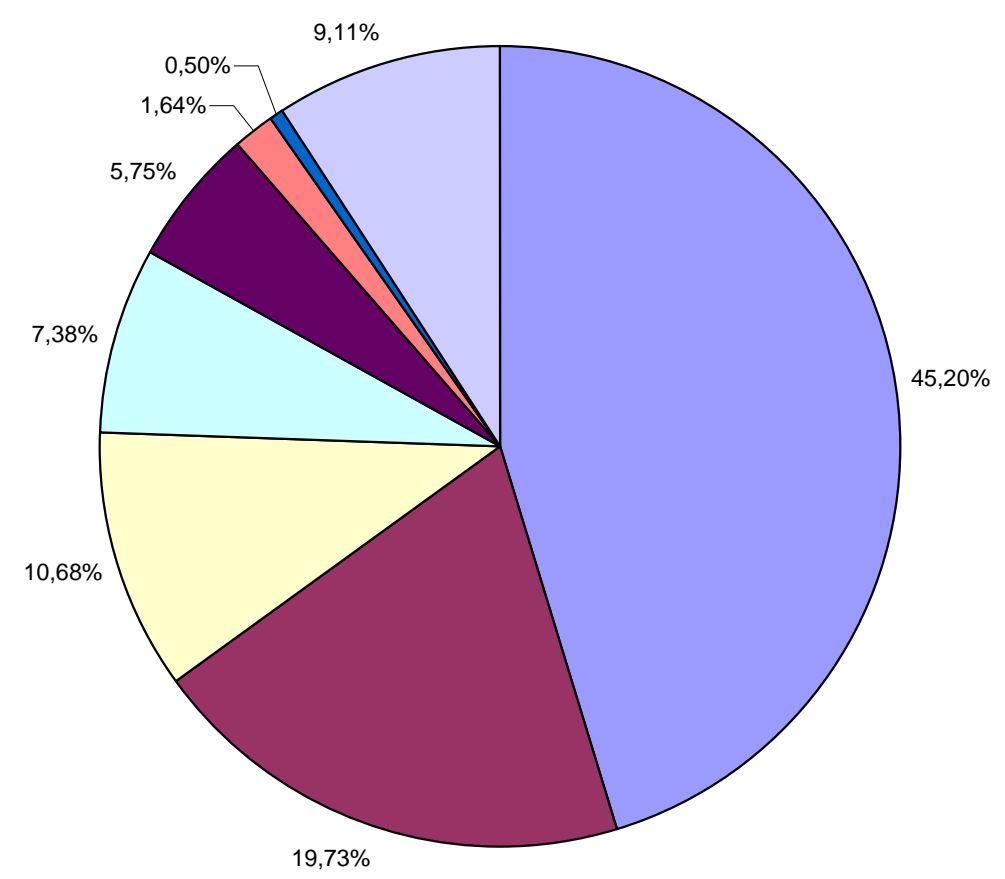

$\square$ Residências

$\square$ Restaurantes

$\square$ Instituições de ensino

$\square$ Refeitórios

a Festas

口Unidades de saúde

$\square$ Ambulantes

$\square$ Outros

Fonte: Informação verbal ${ }^{20}$.

Gráfico 40 - Principais locais de ocorrência de surtos de doenças transmitidas por alimentos - 1999ago. 2008

Vale ressaltar a importância da qualidade higiênico-sanitária dos alimentos, principalmente para o grupo de pessoas consideradas vulneráveis, que por razões fisiológicas ou outras, são mais suscetíveis às infecções de origem alimentar, como bebês e crianças pequenas, idosos, mulheres grávidas, pessoas desnutridas, pessoas doentes (como os diabéticos) e os imunocomprometidos devido a uma infecção (como a AIDS) ou por tratamento médico (como os pacientes com neoplasias) (WHO, 2000). Conforme observado no Gráfico 40, 12,3\% das ocorrências de surtos de DTA foram relacionadas às instituições de ensino e unidades de saúde, mostrando uma falta de cuidado com os grupos mais suscetíveis.

É importante observar a falha do serviço de vigilância epidemiológica ao ignorar informações relevantes quando da ocorrência de casos, como o agente etiológico dos surtos (em $51 \%$ das notificações), os alimentos contaminados (em $34,3 \%$ das notificações), e os locais de ocorrência dos casos (em 24,1\% das notificações). Além 
de mostrar o descaso dos órgãos oficiais com a saúde pública, a obtenção de informações completas em todos os casos poderia servir como ferramenta para traçar um perfil das notificações em cada região, auxiliando portanto na atuação dos serviços de inspeção municipais, além de permitir a identificação de produtos de má qualidade derivados de uma mesma origem.

Conforme citado anteriormente, o pescado é um dos produtos de origem animal mais suscetível ao processo de deterioração, uma vez que apresenta uma série de características que facilitam o processo, como um pH pouco ácido, elevada atividade de água nos tecidos, alto teor de nutrientes disponíveis, elevado teor de fosfolipídios e ação enzimática deteriorante acelerada (BRESSAN; PEREZ, 2001; VIEIRA, 2004). Portanto, as características do pescado, principalmente as sensoriais e de composição, são afetadas diretamente pelo modo como os produtos são armazenados (HUSS, 1995; MARTINSDÓTTIR, 2002). Com a finalidade de preservar o frescor e a qualidade higiênico-sanitária em todas as fases do complexo agroindustrial do pescado, é recomendada a utilização de gelo e/ou refrigeração a partir da atividade de captura ou despesca (RODRÍGUEZ et al., 2004), bem como a manipulação higiênica dos produtos (GERMANO; GERMANO; OLIVEIRA, 2001).

\subsubsection{Publicações sobre as condições higiênico-sanitárias do pescado comercializado}

A qualidade do pescado comercializado é tema de diversos trabalhos em todas as regiões do Brasil. A maior parte desses estudos tem como objetivo a verificação da qualidade do pescado disponibilizado ao consumidor e o cumprimento do Decreto $n^{\circ}$ 30.691 , de 29/03/52, que define as faixas de temperatura para acondicionamento resfriado e congelado, as características organolépticas do pescado fresco próprio para o consumo e os limites físico-químicas adequados (BRASIL, 1952), e da Portaria no 451 da SVS/MS, de 19/09/1997 (vigente até 10/01/2001), ou da Resolução RDC no 12 da Anvisa, de 02/01/2001 (viginte a partir de 10/01/2001), que determinam os padrões microbiológicos para alimentos (BRASIL, 1997; BRASIL, 2001). A seguir, alguns desses trabalhos são apontados, como forma de 
exemplificar as condições higiênico-sanitárias nas quais os produtos derivados do pescado são oferecidos à população.

$\mathrm{Na}$ análise físico-química e sensorial de 120 amostras de peixes adquiridas no mercado de Belo Horizonte-MG, divididas nas espécies Abrótea (Urophycis brasiliensis), Cação (várias espécies), Castanha (Umbrina sp), Congro rosa (Genypterus blacodes), Corvina (Micripogonias firnieri), Linguado (Paralichthys sp. e Pleuronectes sp), Merluza (Merluccius hubbsi), Namorado (Pseudopercis numida), Pescada (Macrodon oncylodon) e Pescadinha (Cynoscion striatus), todas estavam adequadas para o consumo, de acordo com a análise sensorial. Contudo, 79\% das amostras tiveram valores de Bases Voláteis Totais acima de 0,030g de N/100g de carne; 39\% das amostras estavam com valor de $\mathrm{pH}$ acima de 6,5; foi detectada a presença de gás sulfídrico em 62\% das amostras e de histamina acima de 0,01mg/100g de carne em 37\% das amostras (SOARES et al., 1998).

Em Goiânia-GO, Cardoso, André e Serafini (2003) observaram amostras de filés de peixe comercializadas em supermercados com características microbiológicas em não-conformidade com a legislação. Em 2,85\% das amostras foram identificadas contagens de coliformes fecais acima de $10^{2} \mathrm{UFC} / \mathrm{g}$; em 7,14\% foram identificadas contagens de Staphylococcus coagulase positivo acima de $10^{3} \mathrm{UFC} / \mathrm{g}$ e em 4,28\% das amostras foi detectada a presença de Salmonella sp. Além dos aspectos microbiológicos, $50 \%$ das amostras estavam com temperatura superior a $3{ }^{\circ} \mathrm{C}$ no momento da coleta.

Já em Maceió-AL, das 60 amostras coletadas em diferentes pontos comerciais do município, sendo 40 amostras de moluscos e 20 de peixes, 100\% dos moluscos e $55 \%$ dos peixes apresentaram contagem de coliformes fecais acima dos padrões legais. A presença de Salmonella sp foi descrita em $80 \%$ dos moluscos, resultando em $85 \%$ das amostras de pescado rejeitadas para o consumo. Identificou-se ainda uma pior qualidade microbiológica do pescado comercializado em feiras-livres e mercados, quando comparada à qualidade do pescado comercializado em supermercados (SILVA et al., 2002). 
Na região da Grande São Paulo-SP, das 36 amostras de peixe adquiridas em feiraslivres, 50\% tiveram contagem de coliformes fecais acima do padrão e em 33,3\% foi identificada a presença de Salmonella sp. Das 36 amostras adquiridas em supermercados, 50\% tiveram contagem de coliformes fecais acima do padrão e em $36,1 \%$ foi identificada a presença de Salmonella sp. Por fim, das 16 amostras obtidas na Companhia de Entrepostos e Armazéns Gerais de São Paulo (CEAGESP), 57,1\% tiveram contagem de coliformes fecais acima do padrão e em $43,8 \%$ das amostras foi identificada a presença de Salmonella sp (ÁLVARES et al., 2008).

Prado e Capuano (2006) analisaram a ocorrência de larvas de nematóides da família Anisakidae em bacalhau comercializado em Ribeirão Preto-SP. Das 11 amostras de bacalhau eviscerado, seco e salgado coletadas, 5 foram provenientes de denúncias de consumidores e colhidas no comércio pela Vigilância Sanitária e 6 foram solicitadas por particulares. Desse total de amostras, 64\% estavam em desacordo com a legislação por apresentar larvas de nematóides da família Anisakidae inseridos na musculatura, tornando os produtos impróprios para o consumo.

Os teores de metais pesados no pescado também foram foco de estudos. Morgano et al. (2007) avaliaram a quantidade de mercúrio presente em 257 amostras de diversas espécies de pescado in natura, adiquiridas entre 2005 e 2006. Os produtos foram coletados em barcos, entrepostos, indústrias, mercados municipais, peixarias, feiras livres e supermercados de oito cidades da região da Baixada Santista-SP e na CEAGESP. Apenas duas amostras (0,78\%), apresentaram concentração de mercúrio total acima dos limites estabelecidos pela legislação brasileira, sendo uma da espécie Xiphias gladius, coletada no entreposto em Santos, e a outra da espécie Genidens barbus, coletada em supermercado no Guarujá.

Produtos derivados do pescado também foram avaliados, como no trabalho de Barroso e Freitas (2008), onde foi avaliada a qualidade de produtos salgados em relação às características sensoriais e microbiológicas, em Belém-PA. Das 6 amostras de pirarucu salgado, uma não apresentou alterações organolépticas, 5 tiveram contagem de estafilococus e mesófilos como sendo "incontáveis" e todas excederam os limites legais permitidos para estafilococus; das 6 amostras de carne- 
de-sol, uma não mostrou alterações organolépticas, 5 apresentaram contagem de estafilococus como sendo "incontáveis" e uma com 2,3.10 3 UFC/g; das 6 amostras de charque, uma apresentou alterações de cor, odor, sabor e aspecto, e 50\% das amostras excederam os limites legais para estafilococus.

Os supermercados, peixarias e feiras livres do Distrito Federal foram avaliados em relação às condições higiênico-sanitárias de comercialização do pescado, com base na legislação federal e no roteiro de inspeção utilizado pelo órgão de fiscalização sanitária do Distrito Federal. As feiras livres apresentaram as mais precárias condições higiênico-sanitárias de comercialização de pescado, por apresentar vários pontos em desacordo com a legislação, como inexistência de pias suficientes e separadas para lavar utensílios e ambiente, lavatórios sem condições adequadas de utilização na área de manipulação, instalações sanitárias fora das condições necessárias para limpeza e higienização, vestiários insuficientes, falta de higiene de equipamentos, falta de equipamentos adequados para limpeza e higienização de utensílios, falta de organização no armazenamento, inobservância de temperatura adequada nas vitrines expositoras, produtos expostos ao ambiente sem refrigeração mecânica e sem gelo sobre o alimento, falta de treinamento e de asseio pessoal dos manipuladores, entre outros. Os supermercados e peixarias também apresentaram pontos em desacordo com a legislação, mas com menor frequência de observações (ALVES; CARVALHO; GUERRA, 2002).

Os restaurantes relacionados à venda de produtos derivados do pescado também foram avaliados em relação ao tempo e temperatura de distribuição dos alimentos. Em dois dos três restaurantes analisados no Rio de Janeiro-RJ, embora a água utilizada para manter os alimentos aquecidos no balcão estivesse com temperatura inferior ao recomendado pela legislação, o tempo de exposição era inferior ao máximo permitido, devido à rotatividade do local. Já no terceiro restaurante, que comercializava pescado cru filetado, o binômio tempo-temperatura não foi respeitado, com exposição acima de $10{ }^{\circ} \mathrm{C}$ por um período entre 4 e 5 horas, oferecendo um risco à saúde dos consumidores (SILVA; ROSA; CARVALHO, 2008). De modo semelhante, sushis e sashimis comercializados em shoppings dos municípios do Rio de Janeiro-RJ e Duque de Caxias-RJ foram avaliados em relação às condições de comercialização. Em $80 \%$ das amostras, a temperatura foi superior 
a $10{ }^{\circ} \mathrm{C}$ e inferior a $30{ }^{\circ} \mathrm{C}$ no momento da coleta; em $44 \%$ das amostras foi identificada a presença de histamina, sendo que em 11 delas foram identificados níveis superiores a 10mg/100g de carne (MÁRSICO et al., 2006).

Dessa forma, através dos trabalhos supracitados, as características higiênicosanitárias do pescado comercializado e dos locais de manipulação e comercialização dos mesmos são entendidas como uma preocupação, uma vez aponta para um risco à saúde pública.

\subsubsection{A questão da fiscalização no Brasil}

Conforme visto na sexta parte da Revisão de Literatura, a saúde pública e a vigilância epidemiológica e sanitária dos alimentos e dos locais de fabricação ou manipulação são responsabilidades dos órgãos oficiais, como o MS, Anvisa e os serviços de vigilância sanitária municipais.

Diversos trabalhos foram realizados com o objetivo de verificar a qualidade higiênico-sanitária dos produtos derivados do pescado oferecidos pelo comércio. Todos os trabalhos aqui citados apresentaram ao menos uma irregularidade no que se refere à qualidade higiênico-sanitário dos produtos. Frente a essa situação, alguns autores sugeriram a aplicação das boas práticas durante o processamento. SILVA et al. (2002) recomendaram a aplicação de práticas higiênicas durante o beneficiamento dos produtos, bem como condições adequadas de transporte e comercialização, com a manutenção de baixas temperaturas. MÁRSICO et al. (2006), por sua vez, sugeriram a monitorização de todas as etapas do processamento do pescado pós-captura, com manutenção da cadeia de frio até o momento do consumo.

De acordo com Gagleazzi et al. (2002), devido a problemas sanitários e tecnológicos, como a dificuldade em encontrar produtos frescos ou com boa aparência e a existência de produtos pouco elaborados e de difícil preparo, ocorre uma reduzida frequência de escolha da carne de pescado por parte do consumidor. 
Em alguns desses trabalhos, além de concluírem a inadequação das condições de comercialização dos produtos em relação aos regulamentos, os autores também apontaram a falta de fiscalização e recomendaram uma atuação mais eficiente das autoridades. Barroso e Freitas (2008) observaram a comercialização de produtos salgados sem rótulo, podendo indicar a origem clandestina dos mesmos. SILVA et al. (2002) sugeriram um maior rigor por parte da vigilância sanitária em relação à inspeção dos produtos. Prado e Capuano (2006) recomendaram ações mais efetivas e exigentes por parte dos órgãos fiscalizadores, bem como a adoção de políticas mais severas. Tenuta Filho (2003) afirma que a comercialização do pescado sem qualidade só persiste por falta de uma fiscalização voltada para o consumidor e, por isso, é necessário um trabalho de conscientização popular sobre os riscos à saúde ao consumir esse tipo de produto.

Peixoto et al. (2006) concluíram que a baixa eficiência, eficácia e efetividade da vigilância sanitária são resultados da falta de atenção com a legislação e com a correta qualificação técnico-profissional-legal dos agentes fiscalizadores. Além disso, há desinteresse político-econômico por conta de alguns governantes e legisladores, ao entender de maneira equivocada que as ações preventivas seriam menos vistas em suas atuações.

Um dos benefícios da atuação na prevenção das DTA é o econômico, através da redução dos custos diretos e indiretos da ocorrência das doenças. Nos Estados Unidos, estima-se que as DTA tenham um custo de 5 a 6 bilhões de dólares em gastos diretos e perda de produtividade. No Brasil, entre 1999 e 2004, o custo médio anual com casos de internação por DTA foram de R\$46 milhões (CARMO et al., 2005).

Peixoto et al. (2006) também concluíram que as ações voltadas para a prevenção na área de saúde é ainda insipiente no Brasil, não despertando a sensibilidade da maioria das autoridades, caracterizando uma real atitude de descaso pela qualidade de vida do cidadão brasileiro. De forma a apoiar as conclusões acima citadas, vale relembrar que o início da atuação da vigilância epidemiológica das DTA no Brasil ocorreu em 1999 (BRASIL, [2008f]), e ainda hoje não está completamente 
implantada em todas as unidades federativas (informação verba ${ }^{20}$ ). $\mathrm{O}$ atraso por parte das autoridades em relação à segurança alimentar pode ser comparado ao mesmo serviço de outros países, como por exemplo, nos Estados Unidos, onde as DTA eram notificadas e investigadas desde a década de 1920, motivadas pela alta morbidade e mortalidade causadas pela febre tifóide e diarréia infantil (UNITED STATES OF AMERICA ${ }^{21}, 1925$ apud LYNCH et al., 2006).

\subsubsection{Sugestões para a oferta de pescado com melhor qualidade higiênico- sanitária ao consumidor}

Apesar da existência de um arcabouço jurídico composto por leis, decretos, portarias, normas e outros dispositivos legais, como o Regulamento Técnico para Inspeção Sanitária de Alimentos (BRASIL, 1993), o Regulamento de Inspeção Industrial e Sanitária de Produtos de Origem Animal (BRASIL, 1952), o Regulamento Técnico Sobre Padrões Microbiológicos para Alimentos (BRASIL, 2001) entre outros, que determinam as características higiênico-sanitárias dos processos de produção e seus produtos, quando consultada a literatura relacionada à qualidade do pescado oferecido ao consumidor, como Barroso e Freitas (2008), Silva et al. (2002), Gutierre e Silva (2001), Romão (2001), Tancredi (2001), São Clemente (1993) e outros, observa-se que a falta de atuação da fiscalização sanitária é um dos principais responsáveis por permitir a comercialização de produtos de baixa qualidade higiênico-sanitária.

Portanto, a fim de melhorar a qualidade higiênico-sanitária dos produtos derivados do pescado comercializados, é fundamental a existência de uma fiscalização atuante em todo o complexo agroindustrial, da produção primária e beneficiamento ao comércio. A atuação da fiscalização em todo o sistema tem em vista garantir a qualidade dos produtos que serão oferecidos à população, uma vez que existe a possibilidade de contaminação em todas as etapas de processamento do pescado.

\footnotetext{
${ }^{21}$ UNITED STATES OF AMERICA. Public Health Service. Annual report of the Surgeon on the Public Health Service of the United States for the fiscal year 1924-1925. Washington, DC: Government Printing Office, 1925.
} 
Para combater os problemas citados por Peixoto et al. (2006), como a falta de atenção com a legislação e com a correta qualificação técnico-profissional-legal dos agentes fiscalizadores, os agentes do Estado devem ser treinados, de modo que atuem de uma forma efetiva para um melhoramento da qualidade dos produtos ofertados, e devem ser constantemente atualizados em relação à legislação que regulamenta a inspeção e qualidade dos produtos alimentares. A contratação de recursos humanos capacitados para ampliar o contingente fiscalizador também é vista como necessária para atender à demanda do serviço de inspeção.

Aos governantes e legisladores que acreditam que as ações de prevenção são pouco vistas durante suas atuações (PEIXOTO et al., 2006), vale ressaltar o benefício econômico gerado por tais ações, com redução dos custos diretos e indiretos da ocorrência das doenças (CARMO et al., 2005).

Outro ponto interessante, levantado por Gagleazzi et al. (2002), é a redução da frequência de escolha da carne de pescado por parte do consumidor, devido aos problemas sanitários e tecnológicos. Baseado nessa afirmação, acredita-se que a partir da existência de uma fiscalização mais atuante, haveria uma melhoria na qualidade higiênico-sanitária do pescado, elevando então a frequência de escolha e o consumo e, consequentemente, estímulo à produção e beneficiamento do pescado.

\subsubsection{A escassez de informações publicadas e as dificuldades na obtenção de dados sobre o complexo agroindustrial do pescado}

Durante o processo de busca por informações para a descrição do complexo agroindustrial do pescado no Brasil, foi observada a escassez de dados oficiais publicados, o que dificultou o processo de caracterização do sistema. Além da dificuldade em obter tais informações, por vezes, a qualidade delas era questionável, conforme apresentado por Silva (2008) ao afirmar que o "Brasil continua sem um 
inventário confiável de seus recursos pesqueiros, o que dificulta uma estimativa exata da produção ${ }^{22}$."

A atualização dos dados publicados também foi um aspecto negativo observado durante a presente pesquisa. A última publicação do IBAMA sobre a produção do setor primário do complexo agroindustrial do pescado é relacionada à produção de 2006, apesar de ter sido publicada em 2008. O banco de dados da RAIS, utilizado para a quantificação dos números de trabalhadores e estabelecimentos, faixas salariais e cargos ocupados pelos empregados, apresenta os dados de 2007 como os mais atuais. Entretanto, a quantificação do setor ficou dificultada, uma vez que desde 2006 é utilizada uma diferente versão de classificação das atividades econômicas, que não apresenta nenhuma atividade comercial exclusiva de pescado, impossibilitando a inclusão de dados numéricos sobre o mesmo. Desse modo, foram utilizadas informações menos atuais.

O desinteresse em divulgar informações ou o real desconhecimento por parte dos órgãos oficiais, fez com que os segmentos industrial e comercial não fossem caracterizados quanto ao volume de produção/venda e volume financeiro gerado pela produção/venda.

Diversos órgãos governamentais foram consultados com a finalidade de se obter informações relacionadas ao complexo agroindustrial do pescado durante a realização deste trabalho, conforme relacionado no capítulo Material e Método. Porém, poucos foram os órgãos que colaboraram com a divulgação de dados, como o IBAMA (através das publicações anuais Estatísticas da Pesca), o IBGE (através das publicações Pesquisas de Orçamentos Familiares) e o MTE (permitindo o acesso ao banco de dados da RAIS), ao passo que outros órgãos, como a DIPES e a SEAP, não atenderam aos diversos contatos realizados por correio eletrônico e por telefone ou negaram o conhecimento das informações solicitadas. Por outro lado, instituições não-governamentais foram contatadas na busca por dados, como a ABIA, a ABRAS, o SINDIPI e o SIPESCA, e mais uma vez, a falta de conhecimento

\footnotetext{
22 "Brazil remains without a reliable inventory of its fisheries resources, which makes it difficult to estimate exact production."
} 
sobre informações de volume de produção/vendas e financeiro inviabilizou a pesquisa.

É importante observar que existe uma falsa idéia entre os funcionários dos órgãos oficiais e das instituições consultadas a respeito da centralização de dados sobre o complexo agroindustrial do pescado pela SEAP. De forma geral, acredita-se que a SEAP apresenta toda a diversidade de dados relacionados ao pescado, porém, são poucas as informações geradas e divulgadas por ela. Os dados sobre produção e comercialização (importação e exportação), por exemplo, são gerados pelo IBAMA e pelo MDIC, respectivamente, e, possivelmente, são disponibilizados nos endereços eletrônicos desses órgãos antes mesmo de serem divulgados pela SEAP. Pode-se citar o boletim Estatística da Aquicultura e Pesca 2006 Brasil (IBAMA, 2008) como exemplo, publicado desde novembro de 2008 nos endereços eletrônicos do CONEPE e do IBAMA, enquanto ainda não estava presente no endereço eletrônico da SEAP até junho de 2009.

Ainda, vale ressaltar o desinteresse do setor privado em gerar conhecimento sobre o segmento produtivo. Apesar da garantia da preservação da fonte das informações, a colaboração com a divulgação de dados durante a execução do projeto-piloto desta dissertação foi negada. Durante o primeiro semestre de 2008, foram convidadas a participar do projeto 6 empresas do comércio varejista e 16 empresas beneficiadoras registradas no SIF, mas todas recusaram-se a colaborar com qualquer tipo de informação, o que impossibilitou a conduta do trabalho sob a forma de entrevistas, conforme descrito por Neves et al. (2004).

\subsubsection{Sugestões para g geração e divulgação de dados}

A geração e divulgação de dados setoriais são importantes para o desenvolvimento das cadeias produtivas, pois servem, por exemplo, como ferramenta para a definição de estratégias eficientes e coerentes com a realidade do mercado em que as empresas se situam e auxiliam na formulação de políticas públicas e privadas (BATALHA, 1997). No complexo agroindustrial da laranja no Brasil (NEVES; LOPES; 
2005), os próprios agentes das cadeias produtivas, percebendo os prejuízos que a falta de conhecimento sobre o mercado trazem às suas empresas, queixaram-se sobre a escassez de informações sobre o setor. De forma semelhante, Borghetti e Ostrensky (2000) e Ostrensky e Boeger (2008) também apontaram essas queixas por parte de alguns entrevistados, que citam a falta de dados estatísticos completos e confiáveis sobre a produção da carcinicultura e da piscicultura como um dos entraves à política pública relacionada à aquicultura, dificultando o planejamento adequado ao desenvolvimento do setor.

Contraditoriamente, todas as 22 empresas consultadas no projeto-piloto do presente trabalho negaram-se a colaborar com a geração de conhecimento a respeito do complexo agroindustrial do pescado no Brasil, como visto anteriormente. Tal atitude é aqui vista como incoerente, pois o setor privado é o principal interessado na geração de informações mercadológicas. Portanto, as empresas relacionadas à produção, industrialização e comercialização de pescado devem estar sempre atentas à ocorrência de pesquisas sobre o segmento, participando ativamente através da divulgação de informações, para colher, posteriormente, os benefícios da exitência de dados setoriais e mercadológicos.

Sendo a SEAP o órgão responsável por assessorar e formular as políticas e diretrizes para o desenvolvimento e o fomento da produção pesqueira e aquícola, é aqui entendido que esse órgão deve servir como centralizador e divulgador do maior número possível de informações sobre o setor. Para tal, as informações existentes devem ser atualizadas e as pesquisas que promovam o conhecimento sobre os diversos segmentos do complexo agroindustrial do pescado, estimuladas. As informações geradas devem atingir todas as cadeias produtivas, tornando fundamental a existência de uma estruturada e atuante assitência técnica agropecuária, para que o conhecimento obtido em trabalhos técnico-científicos possa ser aplicado nos diferentes segmentos, melhorando as técnicas de produção, manejo, processamento ou comercialização. 
A questão do baixo consumo de produtos derivados do pescado é aqui entendida como um problema, por duas razões principais: a primeira é a população consumir pouco um alimento de excelente qualidade nutricional, como o benefício da ingestão dos ácidos graxos da série ômega-3 (KRIS-ETHERTON; HARRIS; APPEL, 2002; MOZAFFARIAN et al., 2003; PARRA et al., 2007; ROSS; SEGUIN; SIESWERDA, 2007; LEE et al., 2008), conforme destacado na primeira parte da Revisão de Literatura; a segunda é relacionada ao baixo estímulo que os segmentos produtor e industrializador têm em elevar a produção, devido ao baixo consumo no mercado interno.

Como visto anteriormente, apesar do elevado potencial produtor do complexo agroindustrial do pescado, o consumo interno brasileiro é baixo quando comparado a países industrializados (média anual de 6,8 Kg per capita contra 29,7 Kg per capita, respectivamente) (SEAP; FAO, 2007). No trabalho de Kubitza e Guimarães-Lopes (2002), onde foram entevistadas 246 pessoas em supermercados, feiras livres e mercados municipais das cidades de São Paulo-SP, Piracicaba-SP, Jundiaí-SP, Aracaju-SE, Fortaleza-CE, Rio de Janeiro-RJ e Campo Grande-MS, teve-se como objetivo conhecer o hábito de consumo, bem como as preferencias e restrições em relação à compra de peixes. Foi identificado que, para aproximadamente $60 \%$ dos entrevistados, o pescado faz parte de $5 \%$ ou menos das refeições possíveis em um mês. As principais razões pela opção do consumo de peixes foram o prazer de comer o produto $(45,7 \%)$ e o benefício à saúde $(30,6 \%)$. Os principais locais de aquisição foram as peixarias e supermercados $(83,8 \%)$, obtendo um resultado diferente do apresentado pelo IBGE $^{23}$ (2004b) apud Sonoda (2006, p. 71), discutido no ítem 4.1.3 deste trabalho. Em relação aos fatores que dificultam a decisão de comprar o peixe, a inabilidade em determinar se o pescado é fresco $(27,6 \%)$, o preço elevado em relação a outros tipos de carnes (24,5\%), a presença de espinhas na carne $(18,32 \%)$ e a necessidade de limpar o peixe em casa $(17,8 \%)$ foram apontados como os principais entraves à decisão de compra.

${ }^{23}$ IBGE. INSTITUTO BRASILEIRO DE GEOGRAFIA E ESTATíSTICA. Pesquisa de Orçamentos Familiares 2002-2003: microdados. Rio de Janeiro: IBGE, 2004b. 1 CD-ROM. 
Kubitza e Guimarães-Lopes (2002) concluíram que existe um elevado potencial para o incremento no consumo de pescado, uma vez que $60 \%$ dos entrevistados o consomem em 5\% ou menos das refeições possíveis. A questão do preço foi confrontada com as motivações que levam ao consumo de pescado, como o prazer e os benefícios à saúde. Foi sugerida a criação de campanhas de marketing para realçar tais aspectos. Para enfrentar os demais fatores de não opção pelo pescado na compra de produtos, foi sugerida a oferta constante de produtos frescos; 0 atendimento das expectativas do consumidor, oferencendo, no caso, peixes sem espinhas e declarar em embalagens tal característica do produto; a oferta de uma maior variedade de produtos à base de pescado, com diferentes formas de preparo e a promoção do consumo entre crianças para criar o hábito de consumo, com foco na merenda escolar.

Um ponto interessante que Kubitza e Guimarães-Lopes (2002) levantaram é a questão da criação de campanhas de marketing sobre o pescado. O marketing institucional tem como objetivo trabalhar a identidade, a formação e a consolidação da imagem de um programa, de um projeto ou de todo um setor. Portanto, o marketing institucional pode influenciar positivamente a atratividade do setor, através de ações coordenadas envolvendo propaganda, relações públicas, assessoria de imprensa e informações embasadas cientificamente. São exemplos de marketing institucional: a criação de campanhas para popularização de produtos, veiculadas em jornal, rádio, televisão, outdoors, entre outros meios de comunicação; a participação de representantes do setor como palestrantes em eventos de grande repercussão; entre outros (PESTANA; OSTRENSKY, 2008).

Um caso de marketing institucional de grande sucesso no mundo é a campanha Got Milk?, promovida pelo California Milk Processors Board. Preocupados com a queda na comercialização de leite por um longo período, em 1993 os processadores de leite fluido da Califórnia concordaram em alocar 3 centavos de cada galão processado para subsidiar campanhas que promovessem o consumo do leite, através de marketing, propaganda e relações públicas. Após a realização de pesquisas de mercado, com a criação da marca Got Milk? e as campanhas publicitárias, houve o primeiro aumento nas vendas em uma década. Além de atingir 
o objetivo de promover o produto, o CMPB criou uma campanha muito apreciada e popular, que se estende até os dias de hoje (CMPB, [2008?]). Em 2001 foi iniciada uma campanha em espanhol, uma vez que 32\% da população da Califórnia era composta por latino-americanos (HOLT, 2002).

No setor aquícola brasileiro, o caso mais bem sucedido se deu com a Associação Brasileira de Criadores de Camarão. Nos últimos anos, a associação realizou grandes investimentos em marketing, tendo em vista conquistar novos mercados consumidores. Os investimentos envolveram a participação do setor da carcinicultura em feiras internacionais de alimentação em diversos países, como Estados Unidos, Bélgica, França, Japão, dentre outros; campanhas de marketing e publicidade, através de cartazes e degustações, além da montagem de estandes para exposição em feiras nacionais e no exterior (PESTANA; OSTRENSKY, 2008).

As histórias de sucesso mostram a utilização do marketing institucional como uma importante ferramenta para o desenvolvimento setorial. Contudo, há a necessidade da existência de instituições fortes, pois sem elas não é possível trabalhar adequadamente ações de marketing institucional. As entidades interessadas devem se estruturar e agregar em torno de si as marcas, pessoas, setores e instituições a que se propõe representar (PESTANA; OSTRENSKY, 2008).

A SEAP, na tentativa de incentivar a produção e o consumo de pescado, promove algumas campanhas que envolvem desde o produtor/pescador até o comerciante. Alguns exemplos de campanhas são:

a) Feira do Peixe: com a finalidade de diminuir o número de intermediários na distribuição do pescado, que influencia diretamente no rendimento do produtor e no preço final repassado ao consumidor final, o programa beneficia os micro e pequenos aquicultores e pescadores artesanais, através da disponibilização de equipamentos e estruturas adequadas, como caixa isotérmica, tanque, tenda desmontável, balcão de aço inox, luvas, dentre outros, para a comercialização direta dos produtos. Para isso, são necessários a entrega de documentação, como a proposta de participação, um parecer favorável emitido 
pelo conselho municipal regulamentar, entre outros, e a organização e representação dos interessados através de entidades;

b) Semana do Peixe: promovido desde 2003, o evento anual tem como objetivos incentivar o consumo regular do pescado através da divulgação dos benefícios à saúde; informar sobre como escolher, conservar e preparar o alimento com qualidade e segurança e estimular as comunidades pesqueiras e aquícolas a comercializarem diretamente seus produtos, reduzindo 0 número de atravessadores. Para atingir tais objetivos, a campanha desenvolve as seguintes ações: distribuição de material publicitário contendo informações nutricionais e de qualidade do pescado; festivais gastronômicos em diversas capitais envolvendo restaurantes; campanhas promocionais em supermercados em parceria com a ABRAS; distribuição de material publicitário em pontos de consumo e comercialização; divulgação de iniciativas de sucesso no âmbito da produção e comercialização; veiculação da campanha na mídia, inclusive em programas de culinária e gastronomia; divulgação da campanha nas escolas públicas, através da alimentação contendo pescado, atividades educadoras, dias de campo, concurso de redação, entre outras atividades;

c) Programa Promoção do Pescado na Alimentação Escolar: criado através de um acordo de cooperação técnica entre a SEAP e o Fundo Nacional de Desenvolvimento da Educação (FNDE), em dezembro de 2007, visa à promoção do pescado na alimentação escolar de escolas públicas de todo o país, oferecendo aos alunos um alimento de alto valor nutritivo, além de criar novas oportunidades para o escoamento da produção, principalmente da pesca artesanal e da aquicultura familiar.

Das campanhas apresentadas, as duas últimas merecem comentários. Em relação à utilização do pescado na alimentação escolar, Ostrensky e Boeger (2008) identificaram a citação desse canal de comercialização na lista de discussão da revista Panorama da Aquicultura, como uma alternativa de comercialização do pescado. Kubitza e Guimarães-Lopes (2002) e Soares (2007) citam a mesma utilização como forma de criar o hábito nas crianças de comer pescado. Contudo, Pestana e Ostrensky (2008) discutiram a viabilidade econômica da utilização de 
peixes cultivados na merenda escolar, relacionando as características nutricionais das refeições e a verba repassada para a compra dos alimentos, ambos determinados pelo Programa Nacional de Alimentação Escolar do Ministério da Educação. Os autores chegaram à conclusão que a utilização do pescado oriundo da piscicultura é economicamente inviável, pois o preço médio do filé de tilápia (principal produto da piscicultura nacional) é muito superior ao preço médio das demais proteínas animais utilizadas pelo programa. Devido ao elevado custo, a quantidade de pescado por refeição seria diminuída, reduzindo assim a quantidade de proteína para limites inferiores aos recomendados pelo FNDE. A utilização de subprodutos, como a polpa de peixe, também é dificultada por dois fatores: o elevado custo de produção das indústrias, que diminui a remuneração ao produtor, e a necessidade de um aumento na escala de produção do produto principal, para viabilizar o processamento de subprodutos. Além disso, cogita-se a possibilidade do segmento extrativista conseguir fornecer o pescado para a alimentação escolar pública, porém, tal situação não foi avaliada.

Em relação à Semana do Peixe, que talvez seja o principal programa de incentivo ao consumo de pescado promovido pela SEAP, a campanha tem apresentado bons resultados. De acordo com Sussumu Honda, presidente da ABRAS, "a Semana do Peixe é um excelente momento para promover esse importante produto" (ABRAS, 2007). Em 2008, a campanha envolveu 1.500 lojas de supermercados (70 redes de supermercados), 200 restaurantes em 11 cidades do Brasil e contou com a participação de indústrias, associações, colônias, cooperativas, escolas e institutos de ensino técnico e a mídia. Segundo dados da ABRAS, entre 2006 e 2007, o faturamento das peixarias dos supermercados cresceu $21 \%$, enquanto o volume de vendas aumentou 15\%. A Semana do Peixe tem contribuído para a consolidação da posição do pescado como uma alternativa viável ao consumo de proteína animal, além de contribuir com informações aos consumidores, que começam a se conscientizar sobre a importância e potencial de produção de pescado no Brasil (informação verbal ${ }^{24}$ ).

\footnotetext{
${ }^{24}$ Informação fornecida por Guilherme Crispim Hundley, Coordenador Geral de Comercialização e Promoção Comercial da Secretaria Especial de Aquicultura e Pesca, através do correio eletrônico guilhermecrispim@seap.gov.br em novembro de 2008.
} 


\subsubsection{Sugestões para o aumento do consumo de pescado}

Conforme visto anteriormente, a existência de campanhas promovendo o pescado como alimento e apontando os benefícios à saúde são vistas como positivas ao aumento do consumo interno. Sendo o setor privado o maior interessado no aumento da aquisição de pescado, esse deve promover o marketing institucional, coordenando as atividades entre os diferentes segmentos do sistema, diversificando e agregando marcas aos produtos e estimulando o consumo. As campanhas promovidas pela SEAP, como a Semana do Peixe, são excelentes oportunidades para tal, e já mostraram resultados positivos ao complexo agroindustrial.

Apesar da importância da realização do marketing institucional, outros fatores também devem ser trabalhados para estimular o aumento do consumo de pescado no Brasil. A garantia da qualidade dos produtos ofertados é fundamental, uma vez que a dificuldade em encontrar produtos frescos ou com boa aparência foi um dos entraves ao consumo apontados por Gagleazzi et al. (2002). Portanto, além da aplicação de práticas higiênicas de manipulação e fabricação nos estabelecimentos, é fundamental a existência de uma fiscalização atuante, dificultando a comercialização de produtos que ofereçam riscos à saúde. Soares (2007) cita a verticalização das empresas beneficiadoras como um fator positivo ao melhoramento da qualidade do pescado ofertado.

Os problemas tecnológicos existentes no complexo agroindustrial do pescado também devem ser eliminados, uma vez que, segundo Gagleazzi et al. (2002), a dificuldade dos consumidores em encontrar produtos elaborados e de fácil preparo reduz a frequência de escolha da carne de pescado. A intensificação do processamento do pescado deve contribuir com a agregação de valor e com a popularização do consumo desses produtos (OSTRENSKY; BOEGER, 2008). Portanto, estimular a produção de pescado, para que escalas industriais sejam atingidas, viabilizando o processamento, é um passo fundamental para elevar o consumo interno. O fomento à aquicultura, o desenvolvimento de novas pescarias a partir de estoques viáveis à explotação sustentável, a facilidade de acesso às linhas 
de crédito e o incentivo fiscal às indústrias, são algumas possíveis ações que podem ser tomadas pelo governo, a fim de estimular o aumento da produção industrial e consumo.

A falta de infraestrutura de beneficiamento, armazenagem e estocagem, segundo Soares (2007), inibe a possibilidade de expansão do pescado no mercado interno, por diminuir a capacidade de preservação dos produtos. Portanto, é dever dos órgãos oficiais garantir a existência e o adequado funcionamento de tais estruturas, como a CEAGESP, o maior centro comercial de peixes com selo de qualidade (SIF) da América Latina.

Soares (2007) identificou o potencial das pescarias subexplotadas, como a pesca oceânica de atuns, e da aquicultura no aumento da oferta de pescado no mercado interno. Porém, é reforçada a necessidade da existência de toda uma infraestrutura de armazenagem e transporte para preservar a qualidade dos produtos. Assim, é resposnsabilidade do Estado o incentivo às pesquisas sobre os estoques pesqueiros, englobando os aspectos biológicos das espécies, os limites sustentáveis de explotação, a quantificação desses estoques, entre outros; bem como a promoção de pesquisas para o desenvolvimento da aquicultura, como a utilização de novas técnicas de cultivo, o desenvolvimento de rações específicas, e outros.

\subsubsection{Síntese dos entraves existentes ao complexo agroindustrial do pescado no Brasil}

Conforme visto anteriormente, as dificuldades discutidas até este ponto do trabaho estavam relacionadas à sobre-explotação dos recursos pesqueiros, à falta de políticas públicas e de qualificação técnica e a dificuldade na obtenção de crédito para a atividade aquícola, à questão da baixa qualidade higiênico-sanitária dos produtos comercializados, à escassez de informações e dificuldade em obtê-las e à questão do baixo consumo de pescado. Porém, nota-se que dentro de cada entrave relatado exitem diversos problemas menores que contribuem para a sua existência. 
Ainda, é possível observar que muitos desses problemas estão correlacionados, conforme visto a seguir.

O estado de sobrepesca de diversos recursos e as dificuldades enfrentadas pela aquicultura nacional são verdadeiras barreiras à produção de pescado no Brasil. Com uma menor produção primária, não há estímulos para a criação de um setor industrial bem estruturado, diminuindo a variedade de produtos ofertados. Uma das causas apontadas para a baixa demanda por produtos derivados do pescado é exatamente a falta de diversificação dos produtos.

Além da oferta de produtos variados, a criação de campanhas de marketing enaltecendo as características nutricionais do pescado, é uma eficiente ferramenta para estimular o aumento da demanda. Porém, a qualidade higiênico-sanitária dos estabelecimentos de processamento e comércio e dos produtos devem ser atingidas, a fim de garantir a oferta de produtos seguros à saúde pública.

A falta de informações setoriais confiáveis, presente em todos os segmentos do complexo agroindsutrial do pescado no Brasil, é um fator negativo para o desenvolvimento do setor. Inibe o desenvolvimento de novas plantas industriais, pelo desconhecimento da real produtividade do setor primário, diminuindo então a capacidade de processar o produto e diversificar a oferta. Também dificulta a criação de campanhas publicitárias, as quais necessitam de certo grau de coordenação entre os segmentos do setor.

Além da correlação entre os diferentes entraves ao setor, por vezes, os problemas se repetem em cada tópico discutido. Tanto no setor primário, quanto no setor comercial, a falta de fiscalização foi considerada como um dos responsáveis para a ocorrência do estado de sobrepesca de diversas espécies marinhas e para a comercialização de produtos com baixa qualidade higiênico-sanitária. A falta de políticas públicas e de coodenação entre os serviços oficiais, principalmente entre a SEAP e o MMA/IBAMA, foram considerados importantes tópicos de reavaliação para a pesca e aquicultura. 
A fim de sintetizar os principais entraves ao complexo agroindustrial do pescado no Brasil, o Quadro 3 resume as dificuldades de cada segmento discutidas neste trabalho.

\begin{tabular}{|c|c|c|c|}
\hline Segmento & $\begin{array}{l}\text { Principal } \\
\text { entrave }\end{array}$ & Dificuldades relacionadas & Soluções propostas \\
\hline \multirow[t]{5}{*}{ Pesca } & $\begin{array}{l}\text { Estado de } \\
\text { sobre- }\end{array}$ & $\begin{array}{l}\text { Sobreposição de funções dos } \\
\text { órgãos gestores }\end{array}$ & $\begin{array}{l}\text { Reorganização institucional e } \\
\text { definição de governança }\end{array}$ \\
\hline & explotação & Falta de fiscalização & $\begin{array}{l}\text { Contratação de recursos } \\
\text { humanos capacitados e } \\
\text { treinamento }\end{array}$ \\
\hline & & Legislação antiga & Atualização da legislação \\
\hline & & Falta de pesquisa & $\begin{array}{l}\text { Incentivo à pesquisa prévia à } \\
\text { explotação }\end{array}$ \\
\hline & & Estoques ameaçados & Criação de áreas protegidas \\
\hline \multirow[t]{6}{*}{ Aquicultura } & \multirow[t]{4}{*}{$\begin{array}{l}\text { Políticas } \\
\text { públicas }\end{array}$} & $\begin{array}{c}\text { Falta de políticas claras e } \\
\text { eficientes }\end{array}$ & Definição de políticas \\
\hline & & $\begin{array}{c}\text { Inexistência de programas } \\
\text { sanitários }\end{array}$ & $\begin{array}{c}\text { Criação de um programa de } \\
\text { defesa sanitária para animais } \\
\text { aquáticos }\end{array}$ \\
\hline & & Burocracia dos órgãos ambientais & $\begin{array}{l}\text { Maior coordenação entre } \\
\text { SEAP e MMA/IBAMA }\end{array}$ \\
\hline & & Falta de qualificação técnica & $\begin{array}{l}\text { Contratação de recursos } \\
\text { humanos capacitados e } \\
\text { treinamento para o } \\
\text { extensionista }\end{array}$ \\
\hline & \multirow[t]{2}{*}{$\begin{array}{l}\text { Acesso ao } \\
\text { crédito }\end{array}$} & $\begin{array}{l}\text { Necessidade de demonstrar } \\
\text { garantias muito elevadas }\end{array}$ & $\begin{array}{c}\text { Revisão da política do Banco } \\
\text { Central }\end{array}$ \\
\hline & & $\begin{array}{l}\text { Existência de outras formas de } \\
\text { investimento }\end{array}$ & $\begin{array}{c}\text { Revisão da política do Banco } \\
\text { Central }\end{array}$ \\
\hline Comercial & $\begin{array}{l}\text { Qualidade dos } \\
\text { produtos } \\
\text { ofertados }\end{array}$ & Falta de fiscalização & $\begin{array}{l}\text { Contratação de recursos } \\
\text { humanos capacitados e } \\
\text { treinamento }\end{array}$ \\
\hline \multirow[t]{3}{*}{ Consumidor } & \multirow[t]{3}{*}{ Baixo consumo } & $\begin{array}{l}\text { Inexistência de marketing } \\
\text { institucional efetivo }\end{array}$ & $\begin{array}{c}\text { Maior coordenação entre os } \\
\text { segmentos das cadeias } \\
\text { produtivas }\end{array}$ \\
\hline & & Qualidade dos produtos ofertados & $\begin{array}{l}\text { Resolver o problema da falta } \\
\text { de fiscalização }\end{array}$ \\
\hline & & $\begin{array}{c}\text { Baixa diversidade de produtos } \\
\text { derivados }\end{array}$ & $\begin{array}{l}\text { Incentivar o aumento da } \\
\text { produção primária e da } \\
\text { criação de plantas industriais }\end{array}$ \\
\hline Todos & $\begin{array}{l}\text { Escassez de } \\
\text { informações } \\
\text { setoriais }\end{array}$ & & $\begin{array}{l}\text { SEAP deve centralizar e } \\
\text { divulgar informações sobre o } \\
\text { sistema e promover os } \\
\text { trabalhos sobre o mesmo }\end{array}$ \\
\hline
\end{tabular}

Quadro 3 - Principais entraves ao complexo agroindustrial do pescado no Brasil

Apesar dos sistemas agroindustriais serem dinâmicos e diferentes entre si, talvez alguns dos achados e soluções adotadas em outros sistemas e cadeias possam ser extrapolados para o complexo agroindustrial brasileiro do pescado, como visto a seguir. 
No Brasil, Kubitza e Guimarães-Lopes (2002) identificaram os estímulos e restrições ao consumo de pescado: os benefícios à saúde como fator estimulante e preço, presença de espinhas, necessidade de limpar o produto e questões de qualidade como fatores de restrição à compra. Em Pernambuco, Barros (2001) identificou a existência de dois grupos distintos de consumidores de pescado: o primeiro demanda por adequada apresentação dos produtos, regularidade da oferta e qualidade, adquirindo os produtos em supermercados e grandes butiques de pescado; o segundo demanda por preço, importando-se menos com a regularidade de oferta e qualidade dos produtos, obtendo o pescado em mercados, feiras públicas e peixarias. Em ambos os trabalhos, nota-se as diferentes exigências dos consumidores que podem ser percebidas pelo segmento comercial.

Assim como Grunert et al. (2005) identificaram que o setor comercial de bacalhau congelado da Noruega possui informações valiosas sobre os consumidores e não disseminam tal conhecimento, o que, aparentemente, também ocorre no Brasil. Na Noruega, optou-se pela criação de associações comerciais e órgãos semigovernamentais para atuar na criação e disseminação das percepções dos consumidores pelos segmentos iniciais do complexo agroindustrial, a fim de auxiliar a tomada de decisão para melhor atender às exigências do mercado. Já no Reino Unido, Lindgreen e Hingley (2003) concluíram que a integração entre o varejo e os segmentos industrial e produtor apresentou um resultado positivo na tentativa das cadeias atenderem às necessidades e demandas dos consumidores, pois permitiu um maior grau de comunicação entre os agentes. Portanto, seja através da criação de serviços que disseminem informações ao longo do complexo agroindustrial ou da maior integração entre o comércio e os setores industrial e produtor, existe no Brasil a necessidade de desenvolver e divulgar informações setoriais para melhor atender à demanda dos consumidores.

Muitas das dificuldades discutidas por Castro et al. (2005) sobre o setor primário do complexo agroindsutrial do pescado no litoral do estado de São Paulo, também foram identificadas e detalhadas aqui, como a questão da falta de agregação de valor aos produtos e de qualificação técnica no setor, a questão do acesso ao crédito, a falta de políticas públicas claras, a burocracia dos órgãos gestores, entre 
outros. Apesar de cada região ter suas características e apresentar peculiaridades em relação aos complexos agroindustriais, é possível que, de forma geral, os problemas aqui identificados retratem os entraves mais amplos existentes no setor de cada região.

Os trabalhos de Martins e Martins (1999), sobre o complexo agroindustrial do pescado na região do Reservatório de Itaipu-PR e de Chaves, Pichler e Robert (2002), sobre a atividade pesqueira na Baía de Guaratuba-PR, chegaram a conclusões muito próximas. Em ambos, foram detectados o baixo nível tecnológico utilizado para a atividade e as condições sócioeconômicas das populações que não têm conhecimentos mínimos de negócios. Esses entraves em comum, talvez possam ocorrer, de forma geral, em boa parte do complexo agroindustrial do pescado no Brasil. As condições sócioeconômicas dos trabalhadores autônomos devem refletir diretamente sobre o nível tecnológico utilizado na atividade. Assim, como pôde ser visto na parte referente ao setor produtivo pesqueiro e aquícola em Resultados e Discussão, o setor primário de pescado no Brasil é caracterizado por baixos salários, o que provavelmente reflete na produção. Com menor renda e dificuldade na obtenção de créditos, espera-se que os trabalhadores do setor produtivo primário empreguem práticas de baixo nível tecnológico, resultando em produtos de qualidade inferior.

Além disso, principalmente no estudo de Martins e Martins (1999), detectou-se a falta de instrução dos trabalhadores na área de economia, administração e gestão, o que impede a formulação de estratégias para atingir novos mercados consumidores. Em outros trabalhos utilizados nesta pesquisa, diversos pontos abordados podem ser também entendidos como consequência da falta de visão de negócios, conforme visto a seguir.

No estudo realizado por Ostrensky e Boeger (2008), de certa forma, é possível notar a postura amadora e a forma de produção familiar dos aquicultores do Brasil. Um primeiro ponto observado é a utilzação de fóruns de discussão em endereços eletrônicos relacionados à atividade, por parte dos produtores, para solucionar problemas técnicos (aproximadamante 10\% das mensagens analisadas por esses autores, sendo o tema de maior ocorrência), ao invés de buscar uma assitência 
técnica profissional. A segunda questão é a ocorrência e disseminação de doenças na carcinicultura, como a Mionecrose Infecciosa Muscular na região Nordeste e a Síndrome da Mancha Branca nas regiões Sul e Nordeste, que podem ser aqui entendidas como consequência da não utilização de assistência técnica profissional qualificada. Um último ponto é a fragmentação do setor em pequenos produtores e a não organização em cooperativas e associações para fortalecer o poder de compra e venda dos aquicultores, conforme observado por Pestana, Pie e Pilchowski (2008). As três questões discutidas podem ser interpretados como falta de visão de negócios na aquicultura nacional. Porém, o próprio segmento colabora com a situação, por apresentar qualificação técnica deficiente e a escassez de profissionais, conforme discutido por Ostrensky e Boeger (2008).

A questão da falta de visão de negócios também ocorre na atividade extrativista. Conforme relatado por Valentini et al. (1991), o aumento da intensidade da pesca artesanal do camarão-rosa foi uma das principais causas para a queda do rendimento sustentável do estoque. Ao explorar tal recurso de forma desordenada e acima dos limites sustentáveis, os pescadores condenaram a explotação do camarão-rosa ao colapso, o que limitou a produção nos anos subsequentes.

\subsubsection{Pespectivas}

Trabalhos sobre o setor de pescado no Brasil citam constantemente o exemplo do complexo agroindsutrial do frango como um caso de sucesso a ser seguido. Ostrensky, Boeger e Chammas (2008) e Ostrensky e Boeger (2008) falam sobre a expansão e consolidação do segmento do frango após a identificação da necessidade de processamento da produção, que permitiu não só agregar valor aos produtos, mas também diversificar a apresentação e contribuir com a popularização dos mesmos. Certamente, esse é um bom exemplo de setor que evoluiu e hoje é destaque na produção nacional, pois o Brasil é o terceiro maior produtor avícola de corte e o maior exportador mundial de carne de aves (ANUALPEC, 2006). 
Os potenciais para o desenvolvimento e consolidação do complexo agroindustrial de pescado no Brasil são muitos, desde características geográficas, como a extensa área marítima para explotação e o grande volume de água doce disponível (SEAP; GEOBRASIL, 2002), até características de mercado, como um potencial mercado consumidor interno (SOARES, 2007) e o elevado valor dos produtos comercializados (DONOVAN; CASWELL; SALAY, 2001).

Contudo, o setor ainda apresenta diversos entraves, que necessitam da atenção tanto por parte do setor privado, quanto do público. Este deve, principalmente, reorganizar as instituições gestoras das atividades primárias, desburocratizando as ações públicas; criar políticas claras voltadas para o desensenvolvimento do setor; atuar fortemente na fiscalização; incentivar pesquisas e divulgar informações confiáveis e atualizadas sobre o setor; entre outras medidas. Ao setor privado cabe a contribuição com a geração e divulgação de dados e o desenvolvimento de campanhas para promover um maior consumo de pescado no mercado interno.

O Presidente da República, Luiz Inácio Lula da Silva (apud PIMENTEL, 2008), definiu como uma "vergonha" o fato do Brasil produzir apenas um milhão de toneladas de pescado ao ano, quando comparado com países de menores costas litorâneas, como o Peru, que tem uma produção de 9 milhões de toneladas. Para incentivar o desenvolvimento do setor, foi lançado o Mais Pesca e Aquicultura Plano de Desenvolvimento Sustentável, contendo metas para o período entre 2008 e 2011. Dentre elas, pretende-se elevar a produção nacional em 40\%, sendo a aquicultura responsável por 75\% dessa produção; a construção de 20 terminais pesqueiros públicos e de 120 centros integrados de pesca artesanal; o cultivo em 40 reservatórios de águas da União; linhas de crédito no valor de $\mathrm{R} \$ 1,5$ bilhão para a modernização dos navios pesqueiros; campanhas de promoção do consumo de pescado; dentre outras (PIMENTEL, 2008). Segundo o Ministro da SEAP, Altemir Gregolin (apud PIMENTEL, 2008), a intenção é "transformar o peixe no frango das águas do nosso Brasil, em termos de rentabilidade." 


\section{CONCLUSÕES}

O presente trabalho teve como objetivo geral descrever o complexo agroindustrial do pescado no Brasil, identificar os principais entraves ao seu desenvolvimento e analisar a atuação governamental perante tais problemas. O desenvolvimento deste estudo permitiu responder às duas questões elaboradas no início do trabalho:

a) Quais são as características do complexo agroindustrial do pescado no Brasil?

b) Como os órgãos e serviços oficiais atuam em relação às principais dificuldades e entraves vivenciados pelos agentes do setor?

Em relação às características do complexo agroindustrial do pescado no Brasil, assunto bastante extenso e melhor detalhado no capítulo Resultados e Discussão desta dissertação, pode-se resumir como sendo um setor amplo, composto por duas principais atividades primárias, a pesca e a aquicultura, as indústrias de transformação e o comércio. O segmento primário é o que apresenta maior número de informações, devido às prublicações do IBAMA sobre a produção por espécies em cada estado da federação. Em 2006, a pesca representou aproximadamente $74 \%$ da produção total, contudo, o setor aquícola foi o que apresentou o maior crescimento da produção desde 1997. O número de estabelecimentos e trabalhadores do setor primário apresentou incremento entre 1995 e 2005 e, neste ano, contava com 2.564 estabelecimentos e 23.176 trabalhadores. O recorde de produção ocorreu em 2006, quando o setor produziu 1.050 .808 toneladas de pescado, aproximadamente $R \$ 3.294 .604 .130,05$. Os estados de Santa Catarina e Pará foram os maiores produtores nesta mesma data, bem como em relação ao segmento extrativista. Os estados do Ceará, Rio Grande do Norte e Santa Catarina forma os maiores produtores no segmento aquícola, com foco na produção de crustáceos.

Os setores industrial e comercial de pescado foram pouco caracterizados, devido à escassez de dados divulgados tanto pelos órgãos públicos, quanto pelo próprio setor privado, associações e sindicatos. O número de indústrias de benficiamento de pescado e trabalhadores sofreu queda entre 1997 e 2005, com expressiva saída dos 
mesmos da região Sudeste, enquanto que o número de comércios atacadistas e trabalhadores, nesse mesmo período, apresentou aumento. Em 2005, foram registradas 289 indústrias, empregando 12.114 trabalhadores, e 725 atacados, empregando 5.984 funcionários.

O mercado interno também foi descrito, sendo caracterizado pelo baixo consumo per capita de pescado quando comparado a países industrializados. Algumas marcantes características do hábito de consumo de pescado pela população brasileira foram observadas, como uma maior aquisição pela população do meio rural em todas as regiões do país; marcante regionalização do consumo, com maior obtenção na região Norte; e o hábito de maior consumo pela população de menor renda, quando comparado ao consumo das classes de maior receita.

Os principais problemas identificados neste trabalho foram o estado de sobrepesca dos estoques pesqueiros, a falta de políticas públicas e a dificuldade de acesso ao crédito na aquicultura, a baixa qualidade higiênico-sanitária do pescado ofertado à população, o baixo consumo interno de produtos derivados do pescado e a escassez de informações setoriais publicadas. Contudo, diversas dificuldades menores, relacionadas diretamente com cada um desses problemas. O complexo como um todo apresenta como característica a falta de informações geradas e divulgadas, impossibilitando estudos detalhados sobre as cadeias produtivas e dificultando a organização do setor. Observa-se que o segmento sofre com a falta de políticas públicas claras e com a burocracia e sobreposição de funções dos órgãos reguladores, principalmente no setor primário. A pesca e o comércio sofrem com a falta de fiscalização, o que permite o estado de sobrepesca e a comercialização de produtos de baixa qualidade. Os agentes do complexo agroindustrial, principalmente a aquicultura e a indústria, são afetados pela dificuldade na obtenção de crédito devido à atual política do Banco Central, o que inibe o investimento no desenvolvimento da produção e processamento do pescado.

Os órgãos e serviços oficiais atuam de diversas formas perante tais problemas. Determinam regulamentações sobre a pesca, criando períodos de defeso, limite mínimo do comprimento das espécies exploradas, limitando o tamanho da frota, dentre outros; regulamentam os padrões de qualidade dos produtos 
comercializados; disponibilizam linhas de crédito para os produtores e indústrias; promovem campanhas de incentivo ao consumo de pescado; dentre outros mecanismos. Porém, é possível que a forma como tal atuação vem sendo feita não esteja adequada à realidade do setor. Muitos dos entraves à aquicultura observados na décadade de 90 são ainda motivos de reclamação por parte dos produtores. As pesquisas sobre os estoques pesqueiros, que propõem sugestões para a explotação, nem sempre são levadas em consideração na formulação da regulamentação da pesca. As linhas de crédito, apesar de existirem, são inacessíveis aos produtores. Os órgãos governamentais desempenham um papel pouco relevante na divulgação de dados setoriais, desmotivando o setor privado a investir em algo que não é bem conhecido. Sem informações setoriais básicas, fica prejudicado o dimensionamento de plantas industriais de processamento de pescado, bem como as estimtivas sobre a demanda dos consumidores.

Desde sua criação, a SEAP concentrou esforços para o desenvolvimento do setor de pescado, quando comparado ao período em que a gestão da pesca e aquicultura era competência do MMA/IBAMA. Porém, o complexo agroindsustrial do pescado no Brasil ainda enfrenta muitos problemas, detalhados ao longo deste trabalho, que devem ser solucionados a fim de desenvolver suas cadeias produtivas e elevar o Brasil a um nível de maior importância na produção mundial de pescado. 


\section{REFERÊNCIAS}

ÁLVARES, P. P.; MARTINS, L.; BORGHOFF, T.; SILVA, W. A. da; ABREU, T. Q. de; GONÇALVES, F. B. Análise das características higiênico-sanitárias microbiológicas de pescado comercializado na grande São Paulo. Higiene Alimentar. São Paulo, v. 22, n. 161, p. 88-93, 2008.

ALVES, C. L.; CARVALHO, F. de L. N.; GUERRA, W. M. C. Comercialização de pescado no Distrito Federal: avaliação das condições. Higiene Alimentar. São Paulo, v. 16, n. 102/103, p. 41-49, 2002.

ANUALPEC: Anuário da pecuária brasileira 2006. São Paulo: Instituto FNP, 2006. $369 \mathrm{p}$.

ABIA. ASSOCIAÇÃO BRASILEIRA DAS INDÚSTRIAS DA ALIMENTAÇÃO. 0 sistema e a indústria agroalimentar no Brasil: diagnóstico de competitividade, indicadores e tendências. São Paulo: ABIA, 1993. 272 p.

ABIA. ASSOCIAÇÃO BRASILEIRA DAS INDÚSTRIAS DA ALIMENTAÇÃO. Anuário Brasileiro das indústrias de alimentação. São Paulo: Segmento, 2007a. 234 p.

ABIA. ASSOCIAÇÃO BRASILEIRA DAS INDÚSTRIAS DA ALIMENTAÇÃO. Indústria da alimentação: balanço anual 2006 e perspectivas para 2007. Associação Brasileira das Indústrias da Alimentação, 2007b. Disponível em: <http://www.abia.org.br>. Acesso em: 17 ago. 2008.

ABRAS. ASSOCIAÇÃO BRASILEIRA DE SUPERMERCADOS. Prepare-se para a $4^{\mathrm{a}}$ Semana do Peixe. Superhiper. São Paulo, n. 378, 2007.

BARROS, A. R. Fundamentos econômicos da dinâmica da pesca em Pernambuco. Revista Econômica do Nordeste. Fortaleza, v. 32, n. especial, p. 569-591, 2001.

BARROSO, R.; FREITAS, J. de A. Qualidade de derivados de salgados de carne de peixe comercializado em Belém - Pará. Higiene Alimentar. São Paulo, v. 22, n. 163, p. 76-82, 2008.

BATALHA, M. O. Sistemas Agroindustriais: definições e correntes metodológicas. In: BATALHA, M. O. (Coord.). Gestão Agroindustrial. Volume 1. São Paulo: Atlas, 1997. $573 \mathrm{p}$. 
BOEGER, W. A.; BORGHETTI, J. R. O papel do poder público no desenvolvimento da aquicultura. In: OSTRENSKY, A.; BORGHETTI, J. R.; SOTO, D. (edit.). Aquicultura no Brasil: o desafio é crescer. Brasília: FAO, 2008. 276 p.

BORGHETTI, J. R.; OSTRENSKY, A. A cadeia produtiva da aquicultura brasileira. In: VALENTI, W. C. V. (edit.). Aquicultura no Brasil: bases para um desenvolvimento sustentável. Brasília: CNPq/Ministério da Ciência e Tecnologia, 2000. 399 p.

BORGHETTI, J. R.; SILVA, U. A. T. da. Principais sistemas produtivos empregados comercialmente. In: OSTRENSKY, A.; BORGHETTI, J. R.; SOTO, D. (edit.). Aquicultura no Brasil: o desafio é crescer. Brasília: FAO, 2008. 276 p.

BRASIL. Decreto n. 30.691, de 29/03/1952. Diário Oficial - República Federativa do Brasil. Brasília, DF, 1952. Disponível em:

<http://www.planalto.gov.br/ccivil_03/decreto/1950-1969/D30691.htm>. Acesso em: 14 mar. 2007.

BRASIL. Decreto-lei n. 221, de 28/02/1967. Diário Oficial - República Federativa do Brasil. Brasília, DF, 1967. Disponível em:

<http://www.planalto.gov.br/ccivil_03/Decreto-Lei/Del0221.htm>. Acesso em: 17 fev. 2009.

BRASIL. Lei n. 6.437, de 20/08/1977. Diário Oficial - República Federativa do Brasil. Brasília. Brasília, DF, 1977. Disponível em:

<http://www.planalto.gov.br/ccivil_03/LEIS/L6437.htm>. Acesso em: 17 fev. 2009.

BRASIL. Constituição da República Federativa do Brasil de 1988. Diário Oficial. Brasília, DF, 1988a. Disponível em:

<http://www.planalto.gov.br/ccivil_03/Constituicao/Constituiçao.htm>. Acesso em: 17 fev. 2009.

BRASIL. Resolução CONAMA n. 10 de 14/12/1988. Diário Oficial - República Federativa do Brasil. Brasília, DF, 1988b. Disponível em:

<http://www.mma.gov.br/port/conama/legiabre.cfm?codlegi=74>. Acesso em: 17 fev. 2009.

BRASIL. Lei n. 7.735, de 22/02/1989. Diário Oficial - República Federativa do Brasil. Brasília, DF, 1989. Disponível em:

<http://www.planalto.gov.br/ccivil_03/LEIS/L7735.htm>. Acesso em: 17 fev. 2009. 
BRASIL. Lei n. 8.080, de 19/09/1990. Diário Oficial - República Federativa do Brasil. Brasília, DF, 1990. Disponível em:

<http://www.planalto.gov.br/ccivil_03/LEIS/L8080.htm>. Acesso em: 23 abr. 2009.

BRASIL. MS. Portaria n. 1.428, de 26/11/1993. Diário Oficial - República

Federativa do Brasil. Brasília, DF, 1993. Disponível em: <http://e-

legis.anvisa.gov.br/leisref/public/showAct.php?id=661>. Acesso em: 23 abr. 2009.

BRASIL. Ministério do Meio Ambiente, dos Recursos Hídricos e da Amazônia Legal. Os principais macrovetores de desenvolvimento. In: Os ecossistemas brasileiros e os principais macrovetores de desenvolvimentos: subsídios ao planejamento da gestão ambiental. Brasília: MMA, 1996. 188p.

BRASIL. MS. Portaria n. 451, de 19/09/1997. Diário Oficial - República Federativa do Brasil. Brasília, DF, 1997. Disponível em: <http://elegis.anvisa.gov.br/leisref/public/showAct. php?id=681\&word=>. Acesso em: 23 abr. 2009.

BRASIL. Lei n. 9.649, de 27/05/1998. Diário Oficial - República Federativa do Brasil. Brasília, DF, 1998a. Disponível em:

<http://www.planalto.gov.br/ccivil_03/LEIS/L9649orig.htm>. Acesso em: 17 fev. 2009.

BRASIL. Decreto n. 2.681, de 21/07/1998. Diário Oficial - República Federativa do Brasil. Brasília, DF, 1998b. Disponível em: <http://www.planalto.gov.br/ccivil_03/decreto/D2681.htm>. Acesso em: 17 fev. 2009.

BRASIL. Lei n. 9.695, de 20/08/1998. Diário Oficial - República Federativa do Brasil. Brasília, DF, 1998c. Disponível em:

<http://www.planalto.gov.br/ccivil_03/LEIS/L9695.htm>. Acesso em: 17 fev. 2009.

BRASIL. Lei n. 9.782, de 26/01/1999. Diário Oficial - República Federativa do Brasil. Brasília, DF, 1999. Disponível em:

<http://www.planalto.gov.br/ccivil_03/LEIS/L9782.htm>. Acesso em: 23 abr. 2009.

BRASIL. Anvisa. Resolução RDC n. 12, de 02/01/2001. Diário Oficial - República Federativa do Brasil. Brasília, DF, 2001. Disponível em: <http://elegis. anvisa.gov.br/leisref/public/showAct. php?id=144\&word=>. Acesso em: 23 abr. 2009. 
BRASIL. Comissão Nacional de Classificação. [2002?]. Disponível em: $<$ http://www.cnae.ibge.gov.br/estrutura.asp?TabelaBusca=CNAE_110@CNAE\%201. 0\%20/\%20CNAE\%20FISCAL1.1@1@cnae@1>. Acesso em: 28 set. 2008.

BRASIL. Lei n. 10.683, de 28/05/2003. Diário Oficial - República Federativa do Brasil. Brasília, DF, 2003a. Disponível em:

<http://www.planalto.gov.br/ccivil_03/LEIS/2003/L10.683.htm>. Acesso em: 17 fev. 2009.

BRASIL. Lei n. 10.779, de 25/11/2003. Diário Oficial - República Federativa do Brasil. Brasília, DF, 2003b. Disponível em:

<http://www.planalto.gov.br/ccivil_03/LEIS/2003/L10.779.htm>. Acesso em: 17 fev. 2009.

BRASIL. MMA. Instrução normativa n. 5, de 21/05/2004. Diário Oficial - República Federativa do Brasil. Brasília, DF, 2004a. Disponível em:

<http://www.cbic.org.br/arquivos/in102004.pdf>. Acesso em: 17 fev. 2009.

BRASIL. SEAP. Instrução normativa n. 3, de 12/05/2004. Diário Oficial - República Federativa do Brasil. Brasília, DF, 2004b. Disponível em:

<http://200.198.202.145/seap/pdf/in/in03_120504.pdf>. Acesso em: 17 fev. 2009.

BRASIL. Lei no 11.164, de 18/08/2005. Diário Oficial - República Federativa do Brasil. Brasília, DF, 2005a. Disponível em:

<http://www.planalto.gov.br/ccivil_03/_Ato2004-2006/2005/Lei/L11164.htm>. Acesso em: 17 fev. 2009.

BRASIL. MMA. Instrução normativa n. 52, de 08/11/2005. Diário Oficial República Federativa do Brasil. Brasília, DF, 2005b. Disponível em: <http://200.198.202.145/seap/conape/planejamento/IN\%20MMA\%2052-05.pdf>. Acesso em: 17 fev. 2009.

BRASIL. Decreto n. 5.583, de 16/11/2005. Diário Oficial - República Federativa do Brasil. Brasília, DF, 2005c. Disponível em:

<http://www.planalto.gov.br/ccivil_03/_Ato2004-2006/2005/Decreto/D5583.htm>. Acesso em: 17 fev. 2009.

BRASIL. MINISTÉRIO DO MEIO AMBIENTE. Programa REVIZEE: avaliação do potencial sustentável de recursos vivos na zona econômica exclusiva: relatório técnico. MMA, Secretaria de Qualidade Ambiental. Brasília: MMA, 2006. 280p. 
BRASIL. Secretaria Especial de Aquicultura e Pesca. [2008?a]. Disponível em: $<$ http://www.presidencia.gov.br/estrutura_presidencia/seap/>. Acesso em: $10 \mathrm{dez}$. 2007.

BRASIL. Ministério do Trabalho e Emprego. Relação Anual de Informações Sociais. [2008?b]. Disponível em: <http://www.mte.gov.br/rais/default.asp>. Acesso em: 28 set. 2008.

BRASIL. Ministério do Trabalho e Emprego. Base estatística RAIS. [2008?]. Disponível em: <http://sgt.caged.gov.br/index.asp>. Acesso em: 28 set. 2008.

BRASIL. Ministério do Desenvolvimento, Indústria e Comércio Exterior. Sistema de Análise das Informações de Comércio Exterior (AliceWeb). [2008?d]. Disponível em: <http://www.aliceweb.desenvolvimento.gov.br/>. Acesso em: 25 out. 2008.

BRASIL. Instituto Brasileiro do Meio Ambiente e dos Recursos Naturais Renováveis. [2008?e]. Site. Disponível em: <http://www.ibama.gov.br/siuweb>. Acesso em: 20 fev. 2008.

BRASIL. Ministério da Saúde. [2008?f]. Glossário de doenças. Disponível em: <http://www.portal.saude.gov.br>. Acesso em 25 fev. 2009.

BRESSAN, M. C.; PEREZ, J. R. O. Tecnologia de carnes e pescado. Lavras: UFLA/FAEPE, 2001. $240 \mathrm{p}$.

BRODZIAK, J.; CADRIN, S. X.; LEGAULT, C. M.; MURAWSKI, S. A. Goals and strategies for rebuilding New England groudfish stocks. Fisheries Research. New York, v. 94, n. 3, p. 355-366, 2008.

CMPB. CALIFORNIA MILK PROCESSOR BOARD. [2008?]. Disponível em: <http://www.gotmilk.com/>. Acesso em: 01 maio 2009.

CARDOSO, N. L. C.; ANDRÉ, M. C. D. P. B.; SERAFINI, A. B. Avaliação microbiológica de carnes de peixe comercializado em supermercados da cidade de Goiânia, GO. Higiene Alimentar. São Paulo, v. 17, n. 109, p. 81-87, 2003.

CARMO, G. M. I do; OLIVEIRA, A. A.; DIMECH, C. P.; SANTOS, D. A. dos; ALMEIDA, M. G. de; BERTO, L. H.; ALVES, R. M. de S.; CARMO, E. H. Vigilância epidemiológica das doenças transmitidas por alimentos no Brasil, 1999-2004.

Boletim eletrônico Epidemiológico. São Paulo, n. 6, 2005. Disponível em: 
<http://portal.saude.gov.br/portal/arquivos/pdf/bol_epi_6_2005_corrigido.pdf>. Acesso em: 14 dez. 2007.

CASTRO, L. A. B. de; YAMANAKA, N.; ARFELLI, C. A.; SECKENDORFF, R. W. von. Situação atual da cadeia produtiva do pescado no litoral do estado de São Paulo.

Série Relatórios Técnicos do Instituto da Pesca. São Paulo, n. 21, p. 1-55, 2005. Disponível em: <ftp://ftp.sp.gov.br/ftppesca/serreltec_21.pdf>. Acesso em: 13 abr. 2008.

CATO, J. C. Seafood safety: economics of Hazard Analysis and Critical Control Point (HACCP) programmes. Fisheries Technical Paper. Rome, n. 381, 1998. 70 p. Disponível em: <http://www.fao.org/docrep/003/x0465e/X0465E00.HTM>. Acesso em: 08 nov. 2007.

CAVALCANTE, P. H.; CAMARA, M. R. Use of freeze-fried embryos and Artemia flakes in the post-larval culture of Litopenaeus vannamei (Boone, 1931). Acta Scientiarum: Bilogical Sciences. Maringá, v. 30, n. 1, p. 17-21, 2008.

CEN. COMITÉ EUROPÉEAN DE NORMALISATION. Traceability of fishery products: specification on the information to be recorded in farmed fish distribution chains. CWA 14659, European Committee for Standardization, Brussels. 2003

CHARLES, A. T. Sustainable fishery systems. Oxford: Blackwell Science, 2001. $370 \mathrm{p}$.

CHAVES, P.; PICHLER, H.; ROBERT, M. Biological, technical and socioeconomic aspects of the fishing activity in a Brazilian estuary. Journal of Fish Biology: Supplement A. London, v. 61, p. 52-59, 2002.

CRMVSP. CONSELHO REGIONAL DE MEDICINA VETERINÁRIA DO ESTADO DE SÃO PAULO. Brasil, o país do pescado. Info CRMV-SP. São Paulo, ano XV, n. 37, p. 6-7, 2008.

CÔNSOLI, M. A.; NEVES, M. F. (coord.). Estratégias para o leite no Brasil. São Paulo: Atlas, 2006. 303 p.

COUNCIL, L .R.; HANRAHAN, C. E. Brazil's agricultural production and exports: selected data. Washington, CRS Reports, 2006. 22 p. Disponível em: <http://www.ncseonline.org/NLE/CRS/abstract.cfm?NLEid=1762>. Acesso em: 10 nov. 2007. 
DAVIS, J. H.; GOLDBERG, R. A. A concept of agribusiness. Boston: Division of Research, Graduate School of Business Administration, Harvard University, 1957. $136 \mathrm{p}$.

DIAS NETO, J. DORNELLES, L. D. C. Diagnóstico da pesca marítima do Brasil. Brasília: IBAMA, 1996. 165p.

DIEGUES, A. C. S. (Org.). Povos e águas: inventário de áreas úmidas. $2^{\mathrm{a}}$ ed. São Paulo: NUPAUB, 2002. 597 p.

D'INCAO, F.; VALENTINI, H.; RODRIGUES, L. F. Avaliação da pesca de camarões nas regiões Sudeste e Sul do Brasil, 1965-1999. Atlântica. Rio Grande, v. 24, n. 2, p.103-116, 2002.

DONOVAN, J. A.; CASWELL, J. A.; SALAY, E. The effect of stricter foreign regulations on food safety levels in developing countries: a study of Brazil. Review of Agricultural Economics. Oxford, v. 23, n. 1, p. 163-175, 2001.

DUTRA, A. S.; AZEVEDO, D. B. de; ELIAS, S. A. Integração das atividades produtivas em uma agroindústria de peixe: uma aplicação da teoria de Filiére. Organizações Rurais \& Agroindustriais. Lavras, v. 10, n. 1, p. 88-99, 2008.

FIRETTI, R.; GARCIA, S. M.; SALES, D. S.; SANTOS, V. B. dos. Mercado é favorável, mas há riscos consideráveis: a aquicultura ainda não está madura e há dificuldades para a consolidação da cadeia produtiva. In: ANUALPEC: Anuário da pecuária brasileira 2006. São Paulo: Instituto FNP, 2006. 369 p.

FISHBASE. Disponível em: <http://www.fishbase.org.> Acesso em: 28 set. 2008.

FLOETER, S. R.; HALPERN, B. S.; FERREIRA, C. E. L. Effects of fishing and protection on Brazilian reef fishes. Biological Conservation. Barking, v. 128, n. 3, p. 391-402, 2006.

FAO. FOOD AND AGRICULTURE ORGANIZATION OF THE UNITED NATIONS. Fishery and aquaculture country profile - Brazil. 2001. Disponível em: <http://www.fao.org/fishery/countrysector/FI-CP_BR/en>. Acesso em: 21 ago. 2008.

FAO. FOOD AND AGRICULTURE ORGANIZATION OF THE UNITED NATIONS. In: WORLD FOOD SUMMIT, November $13^{\text {th }}$ to $17^{\text {th }}, 1996$, Rome. Rome Declaration 
on World Food Security and World Food Summit Plan of Action. Rome: FAO, 1996.

FAO. FOOD AND AGRICULTURE ORGANIZATION OF THE UNITED NATIONS. The State of World Fisheries and Aquaculture 2006. Rome: FAO Fisheries and Aquaculture Department, 2007. Disponível em:

<http://www.fao.org/docrep/009/A0699e/A0699e00.htm>. Acesso em: 10 dez. 2007.

FAO. FOOD AND AGRICULTURE ORGANIZATION OF THE UNITED NATIONS. The State of World Fisheries and Aquaculture 2008. Rome: FAO Fisheries and Aquaculture Department, 2009. 176 p. Disponível em:

<ftp://ftp.fao.org/docrep/fao/011/i0250e/i0250e.pdf>. Acesso em: 27 maio 2009.

FORD, D. Enfoques conceptuales y sistemas de información sobre seguridad alimentaria. In: POLÍTICAS DE SEGURIDAD ALIMENTARIA Y NUTRICIÓN EN AMÉRICA LATINA, 30-31 de outubro de 2003, Campinas. Ponencia realizada para el seminário... Campinas: Unicamp, 2003.

GAGLEAZZI, U. A.; GARCIA, F. T.; BLISKA, F. M. M.; ARIMA, H. K. Caracterização do consumo de carnes no Brasil. Revista Nacional da Carne. São Paulo, v. 26, n. 310, p. 152-160, 2002.

GANDRA, A. Sudeste perde espaço na indústria. A Tribuna: Cidades. Piracicaba, São Pedro, Rio das Pedras, 25/06/2008. Disponível em:

$<$ http://www.tribunatp.com.br/modules/news/article.php?storyid=578>. Acesso em: 22 abr. 2009.

GASALLA, M. A.; TUTUI, S. L. S. Critical constraints to regulate fishing capacity for sustainable harvest in Southeastern Brazil: notes from the Brazilian sardine fishery experience. FAO Fisheries Technical Paper: Measuring Capacity in Fisheries. Rome, n. 445, p. 81-90, 2003.

GERMANO, P. M. L.; GERMANO, M. I. S. Qualidade das matérias-primas. In: . Higiene e vigilância sanitária de alimentos. $2^{a}$ Ed. São Paulo: Livraria Varela, 2001. 655 p.

GERMANO, P. M. L.; GERMANO, M. I. S.; OLIVEIRA, C. A. F. de. Qualidade do pescado. In: GERMANO, P. M. L.; GERMANO, M. I. S. Higiene e vigilância sanitária de alimentos. 2a Ed. São Paulo: Livraria Varela, 2001. 655 p. 
GORDON, H. S. The economic theory of a common-property resource: the fishery. The Journal of Political Economy. Chicago, v. 62, n. 2, p. 124-142, 1954.

GREENPEACE. À deriva: um panorama dos mares brasileiros. São Paulo: Greenpeace, 2008. 44 p. Disponível em:

$<w w w . g r e e n p e a c e . o r g . b r / e n t r e n e s s a o n d a / d o c / r e l O C E f i n a l W E B . p d f>$. Acesso em: 26 nov. 2008.

GRUNERT, K. G.; JEPPENSEN, L. F.; JESPERSEN, K. R.; SONNE, A. M; HANSEN, K.; TRONDSEN, T.; YOUNG, J. A. Market orientations of value chains: a conceptual framework based on four case studies from the food industry. European Journal of Marketing. West Yorkshire, v. 39, n. 5/6, p. 428-455, 2005.

HENDRICKSON, M.; HEFFERNAN, W. D.; HOWARD, P. H.; HEFFERNAN, J. B. Consolidation in food retailing and dairy. British Food Journal. Bradford, v. 103, n. 10, p. 715-728, 2001.

HOLT, D. B. Got milk? Advertising Educational Foundation. 2002. Disponível em: $<$ http://www.aef.com/on_campus/classroom/case_histories/3000 >. Acesso em: 01 maio. 2009.

HUSS, H. H. Quality and quality changes in fresh fish. FAO Fisheries Technical Paper. Rome, n. 348. 1995. Disponível em:

<http://www.fao.org/docrep/v7180e/V7180E00.HTM>. Acesso em: 22 nov. 2007.

IBGE. INSTITUTO BRASILEIRO DE GEOGRAFIA E ESTATÍSTICA. Anuário estatístico do Brasil: 1987/88. Rio de Janeiro: IBGE, v. 48, 1988. 736 p.

IBGE. INSTITUTO BRASILEIRO DE GEOGRAFIA E ESTATÍSTICA. Pesquisa de Orçamentos Familiares 2002-2003: aquisição alimentar domiciliar per capita. Rio de Janeiro: IBGE, 2004a. 251 p. Disponível em:

$<$ http://www1.ibge.gov.br/home/estatistica/populacao/condicaodevida/pof/2002aquisi cao/aquisicao.pdf>. Acesso em: 30 set. 2008.

IBGE. INSTITUTO BRASILEIRO DE GEOGRAFIA E ESTATÍSTICA. Pesquisa de Orçamentos Familiares 2002-2003: microdados. Rio de Janeiro: IBGE, 2004b. 1 CD-ROM.

IBGE. INSTITUTO BRASILEIRO DE GEOGRAFIA E ESTATÍSTICA. Pesquisa de Orçamentos Familiares 2002-2003: análise da disponibilidade domiciliar de alimentos e do estado nutricional no Brasil. Rio de Janeiro: IBGE, 2004c. 76 p. 
Disponível em:

<http://www1.ibge.gov.br/home/estatistica/populacao/condicaodevida/pof/2002analis e/analise.pdf>. Acesso em: 30 set. 2008.

IBGE. INSTITUTO BRASILEIRO DE GEOGRAFIA E ESTATÍSTICA. Pesquisa Industrial: empresa. Rio de Janeiro: IBGE, v. 25, n. 1, 2006. 271 p. Disponível em: $<$ http://www1.ibge.gov.br/home/estatistica/economia/industria/pia/empresas/emp200 6.pdf>. Acesso em: 22 abr. 2009.

IBAMA. INSTITUTO BRASILEIRO DO MEIO AMBIENTE E DOS RECURSOS NATURAIS RENOVÁVEIS. Relatório técnico do Grupo Permanente de Estudos sobre a Sardinha. Itajaí: IBAMA/CEPSUL. 1991a. 31 p.

IBAMA. INSTITUTO BRASILEIRO DO MEIO AMBIENTE E DOS RECURSOS NATURAIS RENOVÁVEIS. Relatório da reunião do Grupo Permanente de Estudos sobre a Sardinha. Itajaí: IBAMA/CEPSUL. 1991b. 16 p.

IBAMA. INSTITUTO BRASILEIRO DO MEIO AMBIENTE E DOS RECURSOS NATURAIS RENOVÁVEIS. Relatório da reunião técnica sobre sardinha. Itajaí: IBAMA/CEPSUL. 1992. 8p.

IBAMA. INSTITUTO BRASILEIRO DO MEIO AMBIENTE E DOS RECURSOS NATURAIS RENOVÁVEIS. Estatística da pesca 2000 Brasil: grandes regiões e unidades da Federação. Brasília: IBAMA, [2001 ou 2002]. 16p. Disponível em: <http://www.ibama.gov.br/recursos-pesqueiros/wp-content/files/estati2000.pdf>. Acesso em: 10 dez. 2007.

IBAMA. INSTITUTO BRASILEIRO DO MEIO AMBIENTE E DOS RECURSOS NATURAIS RENOVÁVEIS. Estatística da pesca 2001 Brasil: grandes regiões e unidades da Federação. Brasília: IBAMA, 2003. 124p. Disponível em:

<http://www.ibama.gov.br/recursos-pesqueiros/wp-content/files/estati2001.pdf>. Acesso em: 10 dez. 2007.

IBAMA. INSTITUTO BRASILEIRO DO MEIO AMBIENTE E DOS RECURSOS NATURAIS RENOVÁVEIS. Estatística da pesca 2002 Brasil: grandes regiões e unidades da Federação. Brasília: IBAMA, 2004a. 129p. Disponível em: <http://www.ibama.gov.br/recursos-pesqueiros/wp-content/files/estati2002.pdf>. Acesso em: 10 dez. 2007.

IBAMA. INSTITUTO BRASILEIRO DO MEIO AMBIENTE E DOS RECURSOS NATURAIS RENOVÁVEIS. Estatística da pesca 2003 Brasil: grandes regiões e unidades da Federação. Brasília: IBAMA, 2004b. 137p. Disponível em: 
<http://www.ibama.gov.br/recursos-pesqueiros/wp-content/files/estati2003.pdf>. Acesso em: 10 dez. 2007.

IBAMA. INSTITUTO BRASILEIRO DO MEIO AMBIENTE E DOS RECURSOS NATURAIS RENOVÁVEIS. Estatística da pesca 2004 Brasil: grandes regiões e unidades da Federação. Brasília: IBAMA, 2005. 136p. Disponível em:

$<$ http://www.ibama.gov.br/recursos-pesqueiros/wp-content/files/estati2004.pdf>. Acesso em: 10 dez. 2007.

IBAMA. INSTITUTO BRASILEIRO DO MEIO AMBIENTE E DOS RECURSOS NATURAIS RENOVÁVEIS. Estatística da pesca 2005 Brasil: grandes regiões e unidades da Federação. Brasília: IBAMA, 2007. 147p. Disponível em: $<$ http://www.ibama.gov.br/recursos-pesqueiros/wp-content/files/estati2005.pdf>. Acesso em: 10 dez. 2007.

IBAMA. INSTITUTO BRASILEIRO DO MEIO AMBIENTE E DOS RECURSOS NATURAIS RENOVÁVEIS. Estatística da pesca 2006 Brasil: grandes regiões e unidades da Federação. Brasília: IBAMA, 2008. 181p. Disponível em:

<http://www.conepe.org.br/sistema/arquivos_pdf/ibama/estatisiticadapesca2006ibam a.pdf>. Acesso em: 13 nov. 2008.

IUCN. INTERNATIONAL UNION FOR CONSERVATION OF NATURE. Resolution 17.38 of the IUCN General Assembly, 1988.

JOHSON, E. A.; CHANTZ, E. J. Seafood toxins. In: CLIVER, D. O.; RIEMANN, H. P (edit.). Foodborne disease. $2^{\text {nd }}$ ed. London, San Diego, California: Academic Press, 2002. $411 \mathrm{p}$.

KELLEHER, G. (ed.). Guidelines for marine protected areas. Cambridge: IUCN, 1999. 107 p. Disponível em: <http://www.iucn.org>. Acesso em 06 jan. 2009.

KELLY, S.; SCOTT, D.; MACDIARMID, A. B.; BABCOCK, R. C. Spiny lobster, Janus edwardsii, recovery in New Zealand marine reserves. Biological Conservation. Barking, v. 92, p. 359-369, 2000.

KIETZMANN, U.; PRIEBE, K.; RAKOW, D.; REICHSTEIN, K. Inspección de peces, crustáceos y moluscos. In: . Inspección veterinaria de pescados: manual para la inspección de peces, crustáceos y moluscos como alimento. Zaragoza: Acribia, 1974. 325 p. 
KRIS-ETHERTON, P. M.; HARRIS, W. S.; APPEL, L. J. Fish consumption, fish oil, omega-3 fatty acids, and cardiovascular disease. Circulation. Dallas, n. 106, v. 21, p. 2747-2757. 2002.

KUBITZA, F.; GUIMARÃES-LOPES, T. G. Com a palavra, os consumidores. Panorama da Aquiculura. Rio de Janeiro, v. 12, n. 69, p. 48-53, 2002.

LEE, J. H.; O'KEEFE, J. H.; LAVIE, C. J.; MARCHIOLI, R.; HARRIS, W. S. Omega-3 fatty acids for cardioprotection. Mayo Clinic Proceedings. Rochester, n. 83, v. 3, p. 324-332. 2008.

LINDGREEN, A.; HINGLEY, M. The impact of food safety and animal welfare policies on supply chain management: the case of the Tesco meat supply chain. British Food Journal. Bradford, v. 105, n. 6, p. 328-349, 2003.

LUCAS, J. S.; SOUTHGATE, P. C. Aquaculture: farming aquatic animals and plants. Cambridge: Fishing News Books, 2003. 502 p.

LYNCH, M.; PAINTER, J.; WOODRUFF, R.; BRADEN, C. Surveillance for foodborne-disease outbreaks: United States, 1998-2002. Morbidity and Mortality Weekly Report: Surveillance Summaries. Atlanta, v. 55, n. 10, p. 1-34, 2006.

MACEDO-VIEGAS, E. M.; SOUZA, M. L. R. de; BACCARIN, A. E.; BORBA, M. R. de; ARAÚJO, M. C. de; VAZ, M. M.; DIAS, M. T. Aspectos mercadológicos de pescados e derivados em algumas cidades das regiões sul e sudeste do Brasil. INFOPESCA Internacional. Montevideo, n. 6, p. 13-22. 2000.

MALASSIS, L. Economie agro-alimentaire. Paris: Cujas, 1979.

MÁRSICO, E. T.; OLIVEIRA, C. M. de; FERREIRA, P. V.; ANTUNES, L.; SOBREIRO, L.G. Avaliação da qualidade de sushis e sashimis comercializados em shoppings centers. Higiene Alimentar. São Paulo, v. 20, n. 147, p. 63-65, 2006.

MARTINDÓTTIR, E. Quality management of stored fish. In: BREMNER, A. H. (Ed.). Safety and quality issues in fish processing. Cambridge: Woodhead Publishing Limited, 2002. 507 p.

MARTINS, G. de A. (coord.). Manual para formatação e edição de dissertações e teses. São Paulo: CPG-FEA, 2004. 128 p. Disponível em: 
<http://www.ead.fea.usp.br/eadonline/pos/arquivos/Manual\%20nov\%202004.doc>. Acesso em: 12 nov. 2008.

MARTINS, R. V.; MARTINS, R. S. Levantamento da cadeia produtiva do pescado do reservatório de Itaipu. Teoria e Evidência Econômica. Passo Fundo, v. 7, n. 13, p. 25-52, 1999.

MATSUURA, Y. O ciclo da sardinha-verdadeira: introdução à oceanografia pesqueira. Instituto Oceanográfico: Publicação Especial do Instituto Oceanográfico. São Paulo, n. 4, p. 1-146, 1977.

MERCK. Manual Merck: saúde para a família. 2005. Disponível em: <http://www.msd-brazil.com/msdbrazil/patients/manual_Merck/sumario.html>. Acesso em: 22 nov. 2007.

MONTORO FILHO, A. F. Teoria elementar do funcionamento do mercado. In: PINHO, D. B.; VASCONCELLOS, M. A. S. (Org.). Manual de economia. $5^{a}$ ed. São Paulo: Saraiva, 2004. 606 p.

MORGANO, M. A.; PEREZ, A. C. A. de; MILANI, R. F.; MANTOVANI, D. M. B.; NEIVA, C. R. P.; FURLAN, E. F.; TOMITA, R. Y.; LOPES, R. da G.; NETOS, M. J. L. Mercúrio total em pescado da cadeia produtiva da Baixada Santista, estado de São Paulo, Brasil. Revista do Instituto Adolfo Lutz. Campinas, v. 66, n. 2, p. 164-171, 2007.

MOZAFFARIAN, D.; LEMAITRE, R. N.; KULLER, L. H.; BURKE, G. L.; TRACY, R. P.; SISCOVICK, D. S. Cardiac benefits of fish consumption may depend on the type of fish meal consumed. Circulation. Dallas, n. 107, p. 1372-1377, 2003.

MÜLLER, G. Novas situações e a tragédia do desenvolvimento. In:

Complexo agroindustrial e modernização agrária. São Paulo: HUCITEC: EDUC, 1989. 149p.

NARVARTE, M.; GONZÁLEZ, R.; FERNÁNDEZ, M. Comparison of Tehuelche octopus (Octopus tehuelches) abundance between an open-acess fishing ground and a marine protected area: evidence from a direct development species. Fisheries research. New York, n. 79, p. 112-119, 2006.

NEIVA, G. S. Alguns aspectos, sobre a biologia e a pesca do "camarão-rosa" da região Centro-Sul do Brasil. Revista Nacional da Pesca. São Paulo, v. 52, p. 9-12, 1966. 
NETTLETON, J. Nutrients and substances in fresh seafood. In: Seafood nutrition: facts, issues and marketing of nutrition in fish and shellfish. New York: Osprey Books, 1985. 280 p.

NEVES, M. F.; LOPES, F. F (org.). Estratégias para a laranja no Brasil. São Paulo: Atlas, 2005. 225 p.

NEVES, M. F.; ROSSI, R. M. THOMÉ e CASTRO, L.; LOPES, F. F.; MARINO, M. K. A framework for mapping and quantifying food \& agribusiness chains towards collective actions. In: EUROPEAN MARKETING ACADEMY CONFERENCE, n. 33, March $18^{\text {th }}, 2004$, Murcia, Spain. Disponível em: <http://www.um.es/mk/emac2004>. Acesso em: 18 abr. 2008.

OGAWA, M.; MAIA, E. L. Manual de Pesca: ciência e tecnologia de pescados. São Paulo: Livraria Varela, 1999. 430 p.

ÓLAFSDÓTTIR, G.; MARTINSDÓTTIR, E.; OEHLENSCHAGER, J.; DALGAARD, P.; JENSEN, B.; UNDELAND, I.; MACKIE, I. M.; HENEHAN, G.; NIELSEN, J.;

NIELSEN, $H$. Methods to evaluate fish freshness in research and industry. Trends in Food Science and Technology. Cambridge, v. 8, n. 8, p. 258-269, 1997.

OLIVEIRA, G. R. de; LOGATO, P. V. R.; FREITAS, R. T. F. de; RODRIGUES, P .B.; FIALHO, E. T.; DIODATTI, F. C. Digestibilidade de nutrientes em ração com complexo enzimático para tilápia-do-nilo. Revista Brasileira de Zootecnia. Viçosa, v. 36, n. 6, p. 1945-1952, 2007.

OSTRENSKY, A.; BOEGER, W. A. Principais problemas enfrentados atualmente pela aquicultura brasileira. In: OSTRENSKY, A.; BORGHETTI, J. R.; SOTO, D. (edit.). Aquicultura no Brasil: o desafio é crescer. Brasília: FAO, 2008. 276 p.

OSTRENSKY, A.; BOEGER, W. A.; CHAMMAS, M. A. Potencial para o desenvolvimento da aquicultura no Brasil. In: OSTRENSKY, A.; BORGHETTI, J. R.; SOTO, D. (edit.). Aquicultura no Brasil: o desafio é crescer. Brasília: FAO, 2008. $276 \mathrm{p}$.

PARRA, D.; BANDARRA, N. M.; KIELY, M.; THORSDOTTIR, I.; MARTÍNEZ, J. A. Impact of fish intake on oxidative stress when included into a moderate energyrestricted program to treat obesity. European Journal of Nutrition. Darmstadt, v. 46, n. 8, p. 460-467. 2007. 
PEIXOTO, S. T.; PEDREIRO, J. D.; ESTEVES, T.; PEREIRA, C. R. H. A vigilância sanitária e a municipalização: atribuições e competências. Higiene Alimentar. São Paulo, v. 20, n. 144, p.25-33, 2006.

PÉREZ FARFANTE, I. Western Atlantic shrimps of the genus Penaeus. Fishery Bulletin. Washington, v. 67, n. 3, p. 461-591, 1969.

PESTANA, D.; OSTRENSKY, A. Aspectos da viabilidade econômica da aquicultura em pequena e média escala. In: OSTRENSKY, A.; BORGHETTI, J. R.; SOTO, D. (edit.). Aquicultura no Brasil: o desafio é crescer. Brasília: FAO, 2008. 276 p.

PESTANA, D.; PIE, M. R.; PILCHOWSKI, R. W. Organização e administração do setor para o desenvolvimento da aquicultura. In: OSTRENSKY, A.; BORGHETTI, J. R.; SOTO, D. (edit.). Aquicultura no Brasil: o desafio é crescer. Brasília: FAO, 2008. 276 p.

PIMENTEL, C. Lula cria o Ministério da Pesca. Agência Brasil. Brasília, 29/07/2008. Disponível em: <http://www.agenciabrasil.gov.br/noticias/2008/07/29/materia.200807-29.9770013773/view>. Acesso em: 01 jun. 2009.

POTTER, N. N. Seafoods. In: Food science. $4^{\text {th }}$ ed. New York: Avi, 1989. 735 p.

PRADO, S. de P. T.; CAPUANO, D. M. Relato de nematóides da família Anisakidae em bacalhau comercializado em Ribeirão Preto, SP. Revista da Sociedade Brasileira de Medicina Tropical. Rio de Janeiro, v. 39, n. 6, p. 580-581, 2006.

RODRÍGUEZ, O.; LOSADA, V.; AUBOURG, S. P.; BARROS-VELÁZQUEZ, J. Enhanced shelf-life of chilled European hake (Merluccius merluccius) stored in slurry ice as determined by sensory analysis and assessment of microbiological activity. Food Research International. Essex, v. 37, p. 749-757, 2004.

ROEST, J.; KLETER, G.; MARVIN, H. J. P.; VOS, B.; HURKENS, R. R. C. M.; SCHELVIS-SMIT, A. A. M.; BOOJI, K. Options for pro-actively identifying emerging risk in the fish production chain. Project number 772.317.01, Report 2007.006, Institute of Food Safety, Wageningen University and Reserach Centre. Disponível em: <http://library.wur.nl/way/bestanden/clc/1844973.pdf>. Acesso em: 17 ago. 2008. 
ROSS, B. M.; SEGUIN, J.; SIESWERDA, L. E. Omega-3 fatty acids as treatments for mental illness: which disorder an which fatty acid? Lipids in Health and Disease. London, v. 6, n. 21, p. 1-19. 2007.

ROSSI, R. M.; NEVES, M. F. (coord.). Estratégias para o trigo no Brasil. São Paulo: Atlas, 2004. 224p.

ROSSI-WONGTSCHOWSKI, C. L. del B.; SACCARDO, S. A.; CERGOLE, M. C. Situação do estoque da sardinha (Sardinella brasiliensis) no litoral Sudeste e Sul do Brasil. Itajaí: IBAMA. Centro de Pesquisas e Extensão Pesqueira das Regiões Sudeste e Sul. Coleção Meio Ambiente. Série Estudos Pesca, n. 17. 1995. $50 \mathrm{p}$.

RUITER, A. El pescado y los productos derivados de la pesca: composicíon, propriedades nutritivas y estabilidad. Zaragoza: Ed. Acribia, Zaragoza, 1995. 416 p.

SACCARDO, S. A.; ROSSI-WONGTSCHOWSKI, C. L del B. Biologia e avaliação do estoque da sardinha Sardinella brasiliensis: uma compilação. Atlântica. Rio Grande, v. 13, n. 1, p. 29-43, 1991.

SAES, M. S. M. Organizações e Instituições. In: ZYLBERSZTAJN, D.; NEVES, M. F. (org.). Economia e Gestão de Negócios Agroalimentares: indústria de alimentos, indústria de insumos, produção agropecuária, distribuição. São Paulo, Pioneira, 2000. 428 p.

SALINAS, R. D. Produtos da pesca. In: Alimentos e nutrição: introdução à bromatologia. Porto Alegre: Ed. Artmed, 2002. 278 p.

SANTOS, M. A. S. dos. A cadeia produtiva da pesca artesanal no Estado do Pará: estudo de caso no Nordeste Paraense. Amazônia: ciência e tecnologia. Belém, v. 1, n. 1, p. 61-82, 2005.

SCHULZE, B.; SPILLER, A.; THEUVESEN, L. A broader view on vertical coordination: lessons from German pork production. Journal on Chain and Network Science. Wageningen, v. 7, n. 1, p. 35-53, 2007.

SCORVO FILHO, J. D.; ROMAGOSA, E.; AYROZA, L. M. da S.; FRASCÁ-SCORVO, C. M. D. Desempenho produtivo do pintado, Pseudoplatystoma corruscans (SPIX \& AGASSIZ, 1829), submetidos a diferentes densidades de estocagem em dois sistemas de criação: intensivo e semi-intensivo. Boletim do Instituto da Pesca. São Paulo, v. 34, n. 2, p. 181-188, 2008. 
SCOTT, A. The fishery: the objectives of sole ownership. The Journal of Political Economy. Local, v. 63, n. 2, p. 116-124, 1955.

SENNESET, G.; FORAS, E; FREMME, K. M. Challenges regarding implementation of electronic chain traceability. British Food Journal. Bradford, v. 109, n. 10, p. 805818, 2007.

SILVA, C. R.; GOMES, L. C.; BRANDÃO, F. R. Effect of feeding rate and frequency on tambaqui (Colossoma macroporum) growth, production and feeding costs during the first growth phase in cages. Aquaculture. Amsterdam, v. 264, n. 1-4, p. 135-139, 2007.

SILVA, E. M. M. da; ROSA, S. V.; CARVALHO, L. M. J. de. Avaliação das boas práticas, relacionadas ao tempo e temperatura, na distribuição de pescado em restaurantes. Higiene Alimentar. São Paulo, v. 22, n. 158, p. 48-53, 2008.

SILVA, J. F. Brazil fishery products: annual fisheries report - 2008. GAIN Report $\mathrm{n}$. BR8601, USDA Foreign Agricultural Service, 2008. 12p. Disponível em: <http://www.fas.usda.gov/gainfiles/200802/146293687.pdf>. Acesso em: 14 jul. 2008.

SILVA, M. C. D. da; NORMANDE, A. C. L.; FERREIRA, M. V.; RAMALHO, L. S. Avaliação da qualidade microbiológica de pescado comercializado em Maceió-AL. Higiene Alimentar. São Paulo, v. 16, n. 96, p. 60-64, 2002.

SOARES, A. L. de S. Melhoramento dos mercados internos de produtos pesqueiros na América Latina e no Caribe. Projeto TCP/RLA/3111 da FAO, 2007. 64 p. Disponível em: <http://www.infopesca.org/sitio_externo/TCP_RLA_3111Website/papers/BRASILINFORME_562.doc>. Acesso em: 17 abr. 2008.

SOARES, V. F. M.; VALE, S. R.; JUNQUEIRA, R. G.; GLÓRIA, M. B. A. Teores de histamina e qualidade físico-química e sensorial de filé de peixe congelado. Ciência e Tecnologia de Alimentos. Local, v. 18, n. 4, p. 462-467, 1998.

SONODA, D. Y. Demanda por pescados no Brasil entre 2002 e 2003. Piracicaba, 2006. Tese (Doutorado em Ciências) - Programa de Pós-Graduação em Ciências, Escola Superior de Agricultura Luiz de Queiroz da Universidade de São Paulo. 117p. 
STELZENMÜLLER, V.; MAYNOU, F.; MARTÍN, P. Spatial assessment of benefits of a coastal Mediterranean Marine Protected Area. Biological Conservation. Barking, v. 136, n. 4, p. 571-583, 2007.

TENUTA FILHO, A. A qualidade duvidosa do pescado e a necessária conscientização do consumidor. Revista Nacional da Carne. São Paulo, v. 27, n. 318, p. 192, 2003.

TILBURG, A.; TRIENEKENS, J.; RUBEN, R.; BOEKEL, M. Governance for quality management in tropical food chains. Journal on Chain and Network Science. Wageningen, v. 7, n. 1, p. 1-9, 2007.

TOBAR, F.; YALOUR, M. R. Como fazer teses em saúde pública: conselhos e idéias para formatar projetos e redigir teses e informes de pesquisa. Rio de Janeiro: Editora Fiocruz, 2001. 172 p.

TSUZUKI, M. Y.; CARDOSO, R. F.; CERQUEIRA, V. R. Growth of juvenile fat snook Centropomus parallelus in cages at three stocking densities. Boletim Instituto da Pesca. São Paulo, v. 34, n. 2, p. 319-324, 2008.

UNITED STATES OF AMERICA. Public Health Service. Annual report of the Surgeon on the Public Health Service of the United States for the fiscal year 1924-1925. Washington, DC: Government Printing Office, 1925.

VALENTINI, H.; CARDOSO, R. de D. Análise da pesca da sardinha-verdadeira, Sardinella brasiliensis, na costa Sudeste-Sul do Brasil. Atlântica. Rio Grande, v. 13, n. 1, p. 45-54, 1991.

VALENTINI, H.; D'INCAO, F.; RODRIGUES, L. F.; REBELO NETO, J. E.; RAHN, E. Análise da pesca do camarão-rosa (Penaeus brasiliensis e Penaeus paulensis) nas regiões Sudeste e Sul do Brasil. Atlântica. Rio Grande, v. 13, n. 1, p. 143-157, 1991.

VALENTINI, H.; NEIVA, G. S.; BARKER, J. M. B.; STERMPNIEWSKI, H. L. Considerações sobre a pesca no estado de São Paulo. Boletim do Instituo da Pesca. São Paulo, v. 1, p. 1-28, 1972.

VALENTI, W. C.; POLI, C. R.; PEREIRA, J. A.; BORGHETTI, J. R. (edit.). Aquicultura no Brasil: bases para um desenvolvimento sustentável. Brasília: CNPq/Ministério da Ciência e Tecnologia, 2000. 399 p. 
VIEIRA, R. H. S. dos F. Microbiologia, higiene e qualidade do pescado. São Paulo: Livraria Varela, 2004. 380 p.

WIEFELS, R. Consumo de pescado y estrategias de comercializacíon para los productos acuícolas. Infopesca Internacional. Montevideo, n. 6, 2003. Disponível em: < http://www.infopesca.org/articulos/art10.pdf >. Acesso em: 03 ago. 2008.

WORLD HEALTH ORGANIZATION - WHO. Foodborne disease: a focus for health education. Geneva: WHO, 2000. 198 p.

WHO. WORLD HEALTH ORGANIZATION. Food safety and foodborne illness. Fact sheet, n. 237, 2007. Disponível em <http://www.who.int>. Acesso em: 23 fev. 2009.

WORLD PARK CONGRESS - WPC, Recommendations. In: WORLD PARK CONGRESS, n. 5, September $8^{\text {th }}$ to $17^{\text {th }}, 2003$, Durban, South Africa. Disponível em: $<$ http://cmsdata.iucn.org/downloads/recommendationen.pdf>. Acesso em: 06 jan. 2009.

WORLD SUMMIT ON SUSTAINABLE DEVELOPMENT. Plan of implementation of the World Summit on Sustainable Development. In: WORLD SUMMIT ON SUSTAINABLE DEVELOPMENT, August $26^{\text {th }}$ to September $4^{\text {th }}, 2002$, Johannesburg, South Africa. Disponível em: <http://www.worldsummit2002.org>. Acesso em: 06 jan. 2009.

ZANI, R. M. F.; PESTANA, M. C. (coord.). Diretrizes para apresentação de dissertações e teses na Faculdade de Medicina Veterinária e Zootecnia da Universidade de São Paulo. 4ª Ed. São Paulo: SBD, 2003. 84 p. Disponível em: <http://www.fmvz.usp.br/index.php/site/content/download/2888/15125/file/diretrizes.p df>. Acesso em: 12 nov. 2008.

ZYLBERSZTAJN, D. Economia das Organizações. In: ZYLBERSZTAJN, D.; NEVES, M. F. (org.). Economia e gestão de negócios agroalimentares: indústria de alimentos, indústria de insumos, produção agropecuária, distribuição. São Paulo: Pioneira, 2000a. 428 p.

. Conceitos Gerais, Evolução e Apresentação do Sistema Agroindustrial. In: ZYLBERSZTAJN, D.; NEVES, M. F. (org.).Economia e gestão dos negócios agroalimentares: indústria de alimentos, indústria de insumos, produção agropecuária, distribuição. São Paulo: Pioneira, 2000b. 428 p. 
Firmas, cadeias e redes de agronegócio. In: NEVES, M. F.;

ZYLBERSZTAJN, D.; NEVES, E. M. Agronegócio do Brasil. São Paulo: Saraiva, 2005. 152p. 


\section{APÊNDICES}

APÊNDICE A - GRÁFICOS SOBRE A EVOUÇÃO DO NÚMERO DE ESTABELECIMENTOS E TRABALHADORES DO SETOR PRODUTIVO DE PESCADO POR REGIÃO BRASILEIRA

APÊNDICE B - GRÁFICOS SOBRE A EVOUÇÃO DO NÚMERO DE ESTABELECIMENTOS E TRABALHADORES DO SETOR INDUSTRIAL DE PESCADO POR REGIÃO BRASILEIRA

APÊNDICE C - PRODUTOS DERIVADOS DOS PESCADO PRODUZIDOS PELAS INDÚSTRIAS BRASILEIRAS

APÊNDICE D - GRÁFICOS SOBRE A EVOUÇÃO DO NÚMERO DE ESTABELECIMENTOS E TRABALHADORES DO SETOR ATACADISTA DE PESCADO POR REGIÃO BRASILEIRA 


\section{APÊNDICE A - GRÁFICOS SOBRE A EVOLUÇÃO DO NÚMERO DE ESTABELECIMENTOS E TRABALHADORES DO SETOR PRIMÁRIO DE PESCADO POR REGIÃO BRASILEIRA}

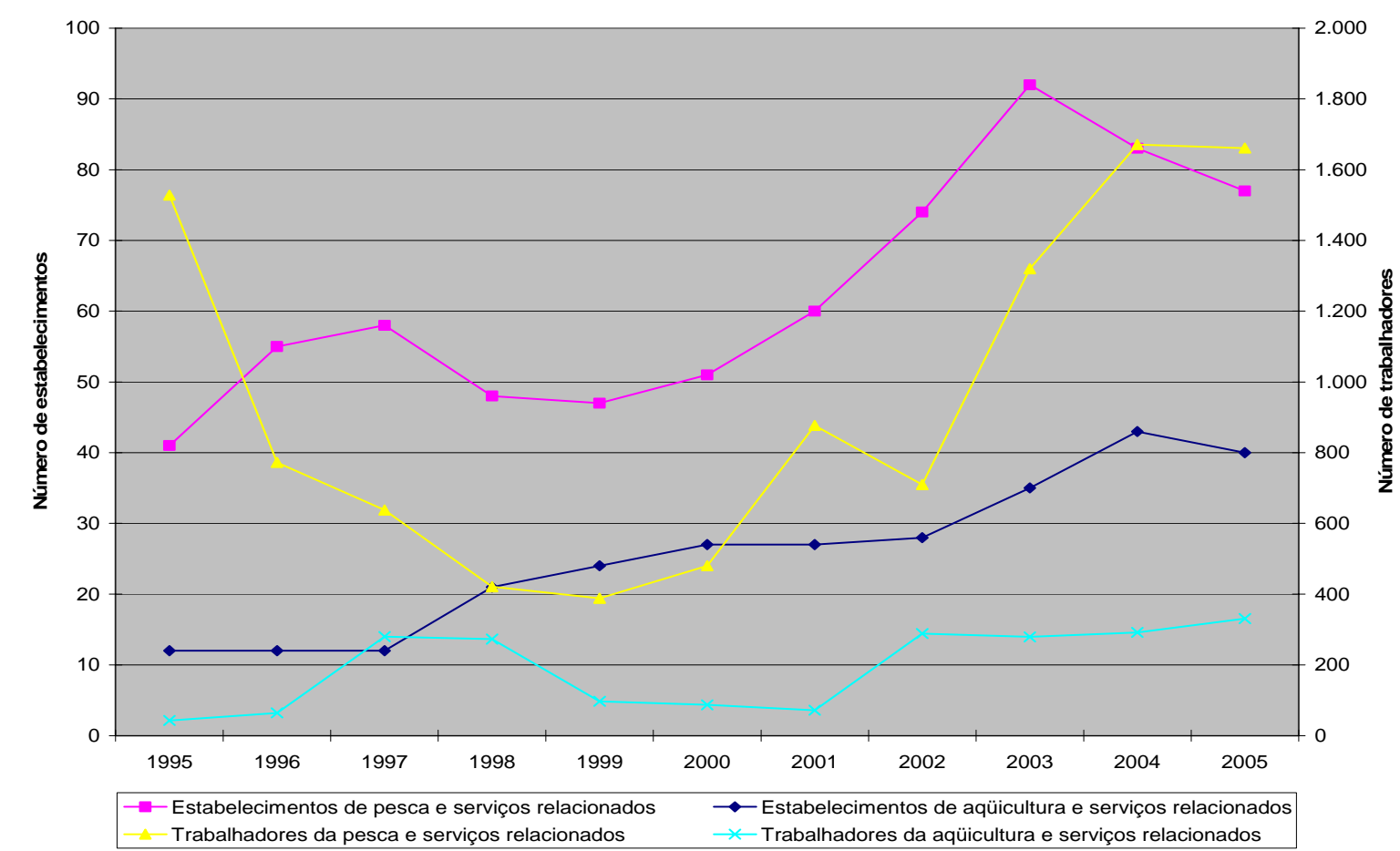

Fonte: BRASIL, [2008?c].

Gráfico 41 - Evolução do número de estabelecimentos e de trabalhadores do setor primário de pescado da região Norte do Brasil - 1995-2005

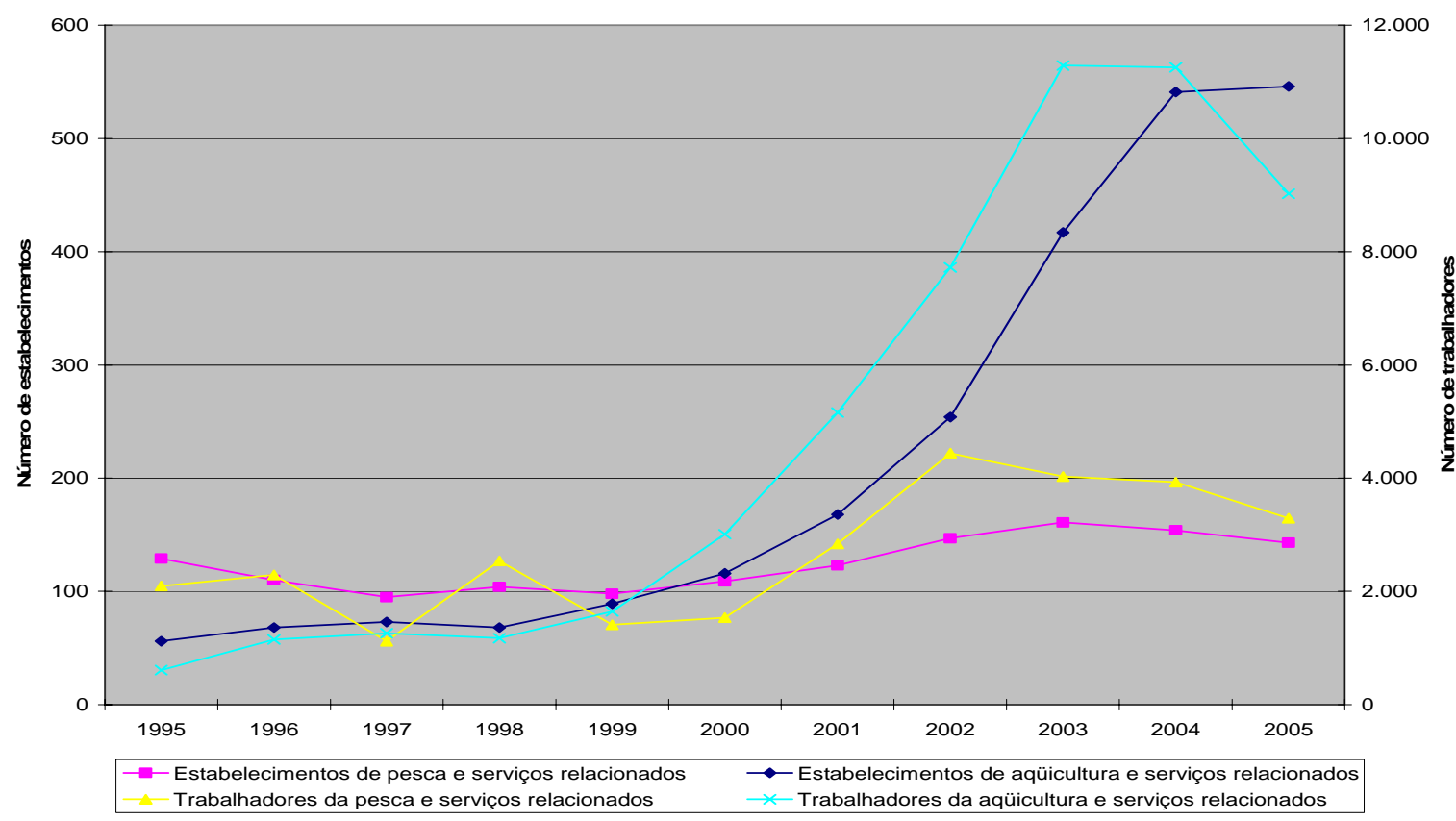

Fonte: BRASIL, [2008?c].

Gráfico 42 - Evolução do número de estabelecimentos e de trabalhadores do setor primário de pescado da região Nordeste do Brasil - 1995-2005 


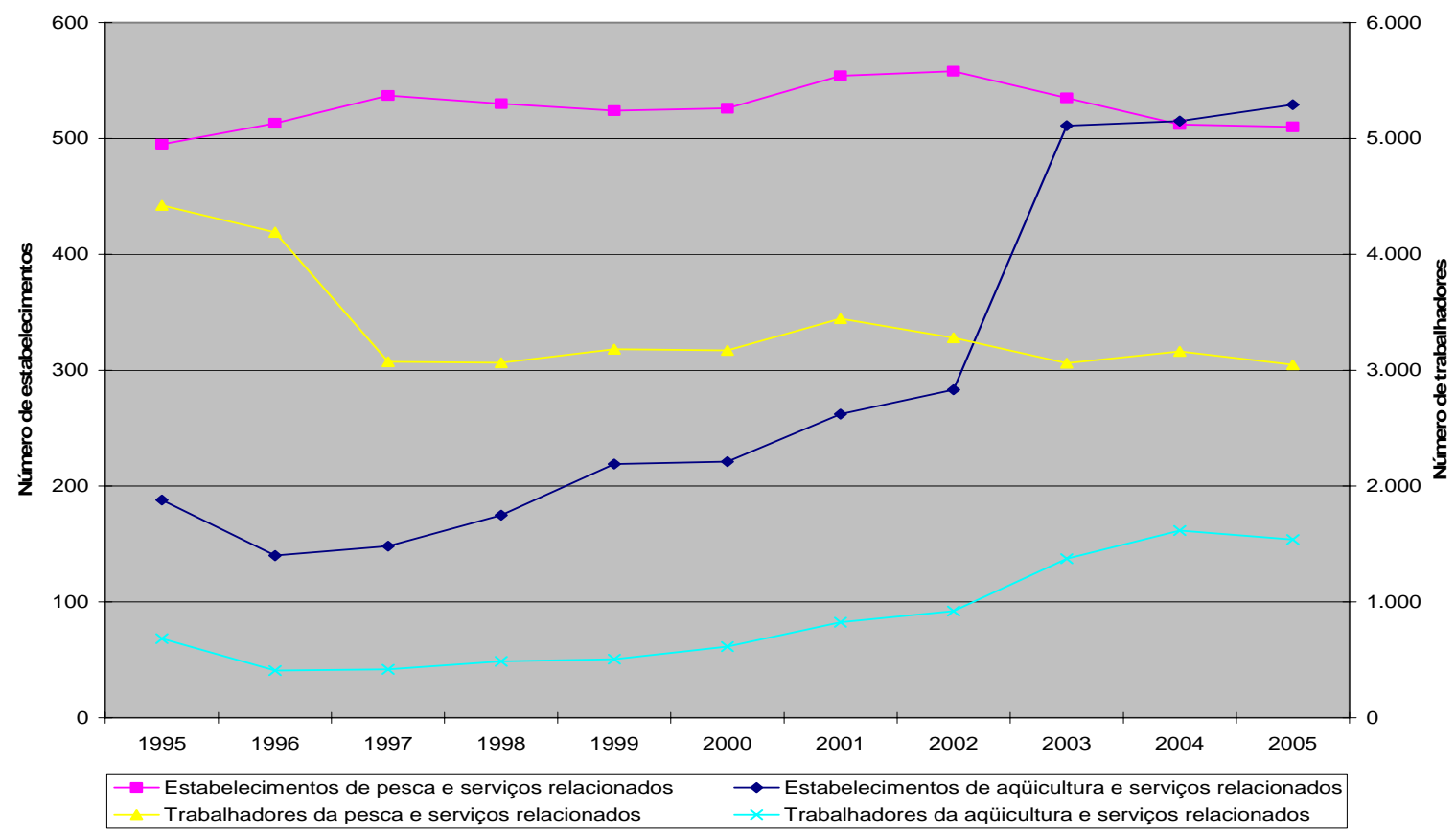

Fonte: BRASIL, [2008?c].

Gráfico 43 - Evolução do número de estabelecimentos e de trabalhadores do setor primário de pescado da região Sudeste do Brasil - 1995-2005

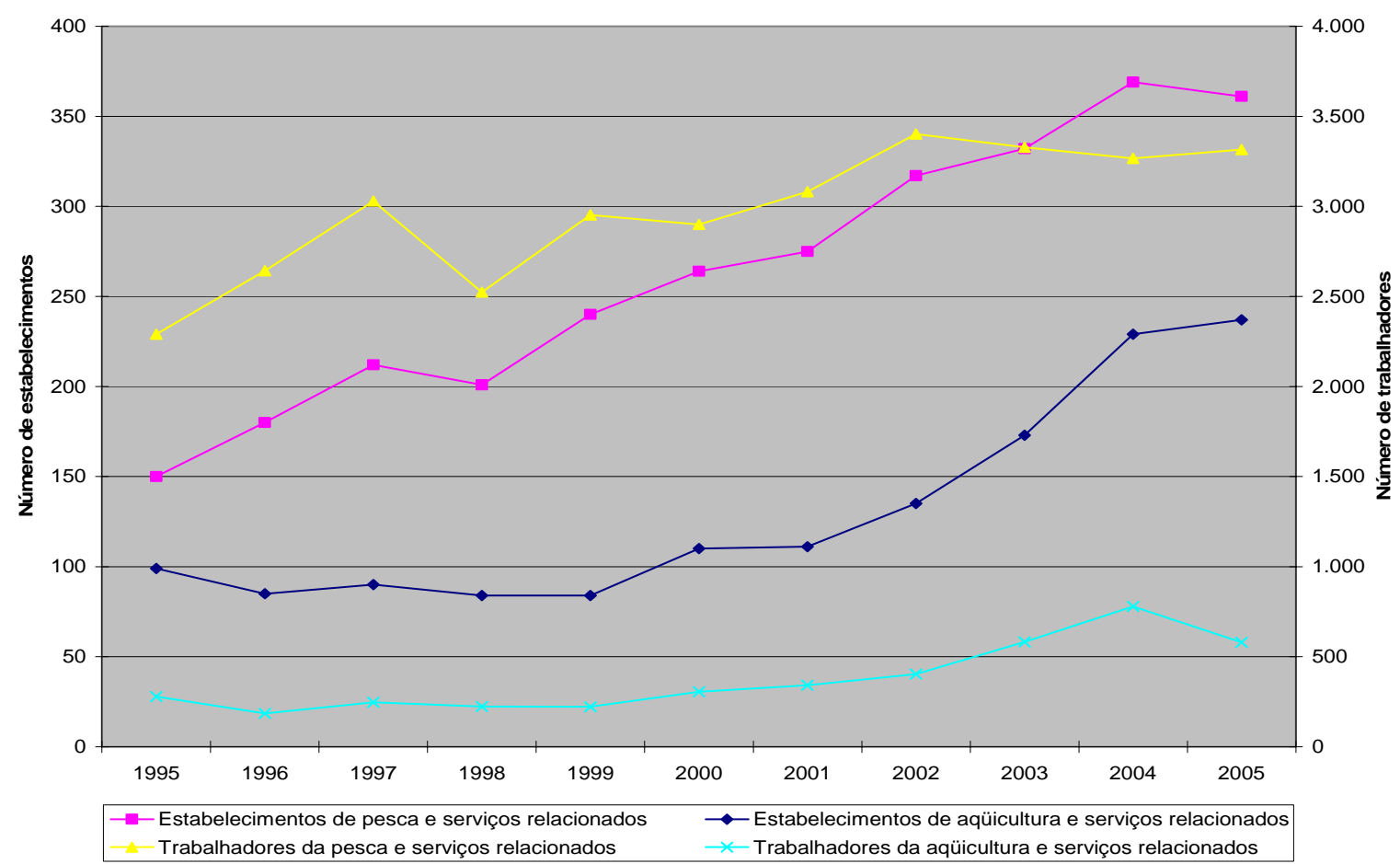

Fonte: BRASIL, [2008?c].

Gráfico 44 - Evolução do número de estabelecimentos e de trabalhadores do setor primário de pescado da região Sul do Brasil - 1995-2005 


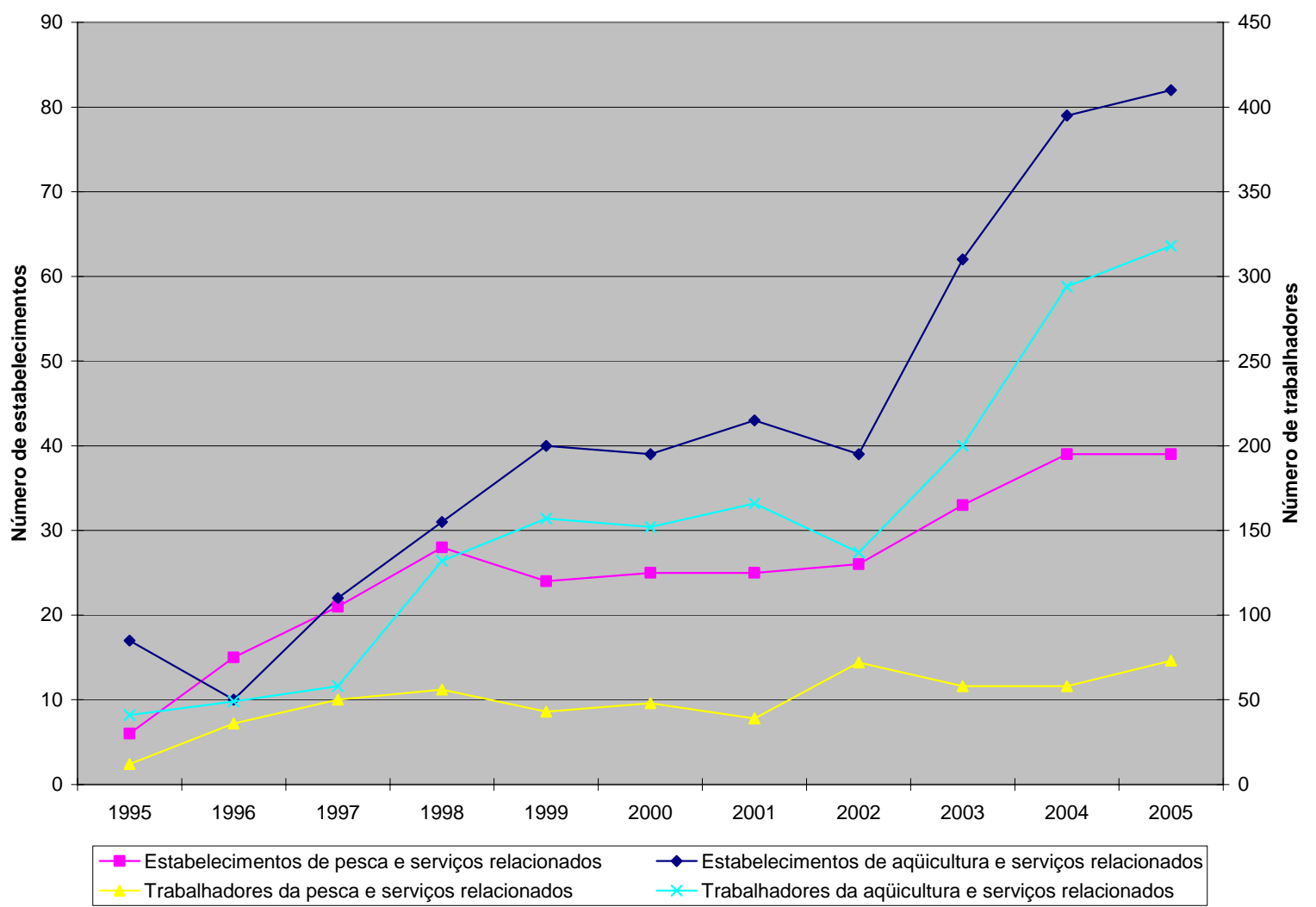

Fonte: BRASIL, [2008?c].

Gráfico 45 - Evolução do número de estabelecimentos e de trabalhadores do setor primário de pescado da região Centro-oeste do Brasil - 1995-2005. 


\section{APÊNDICE B - GRÁFICOS SOBRE A EVOLUÇÃO DO NÚMERO DE ESTABELECIMENTOS E TRABALHADORES DO SETOR INDUSTRIALDE PESCADO POR REGIÃO BRASILEIRA}

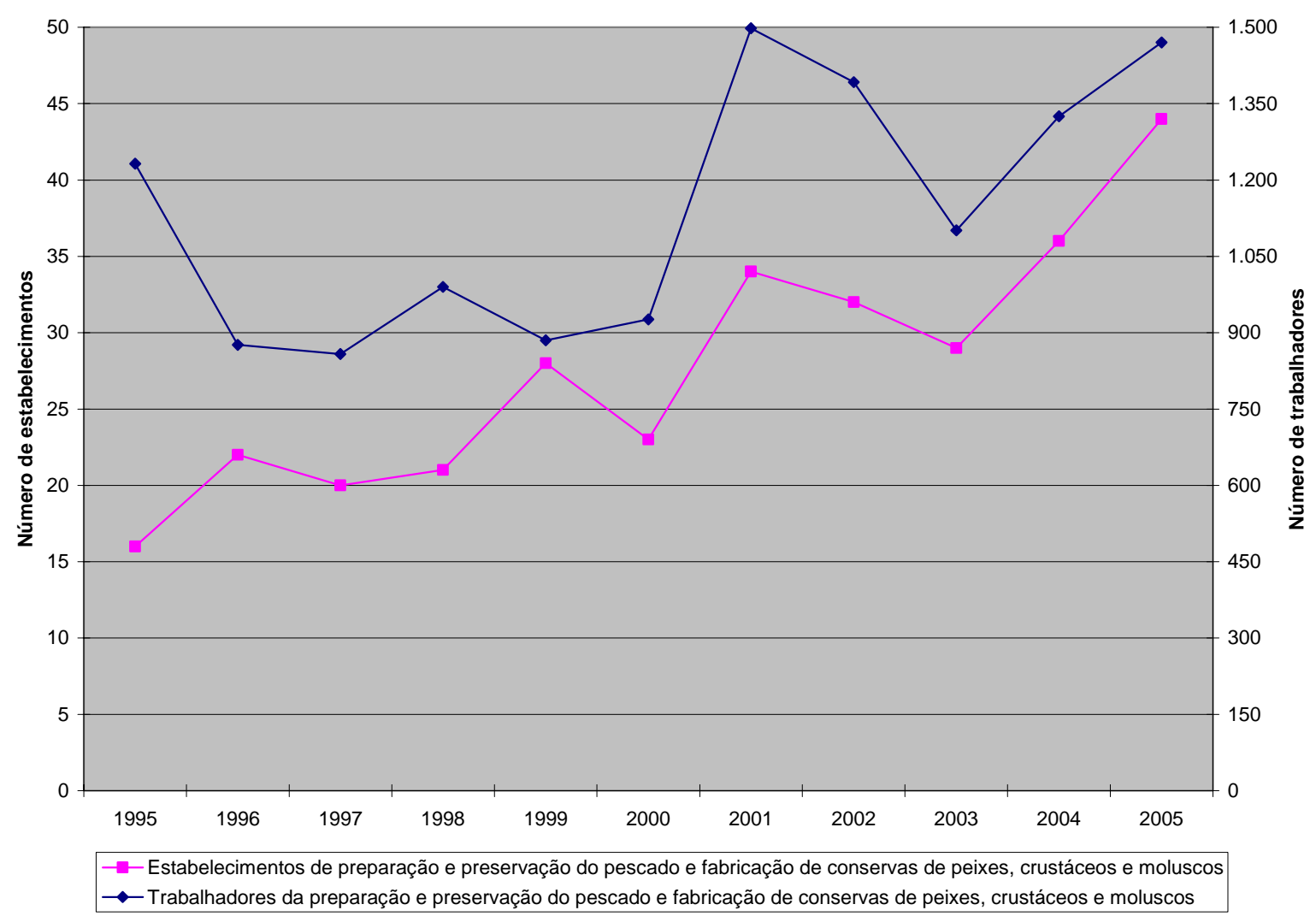

Fonte: BRASIL, [2008?c].

Gráfico 46 - Evolução do número de estabelecimentos e de trabalhadores do setor industrial de pescado da região Norte do Brasil - 1995-2005. 


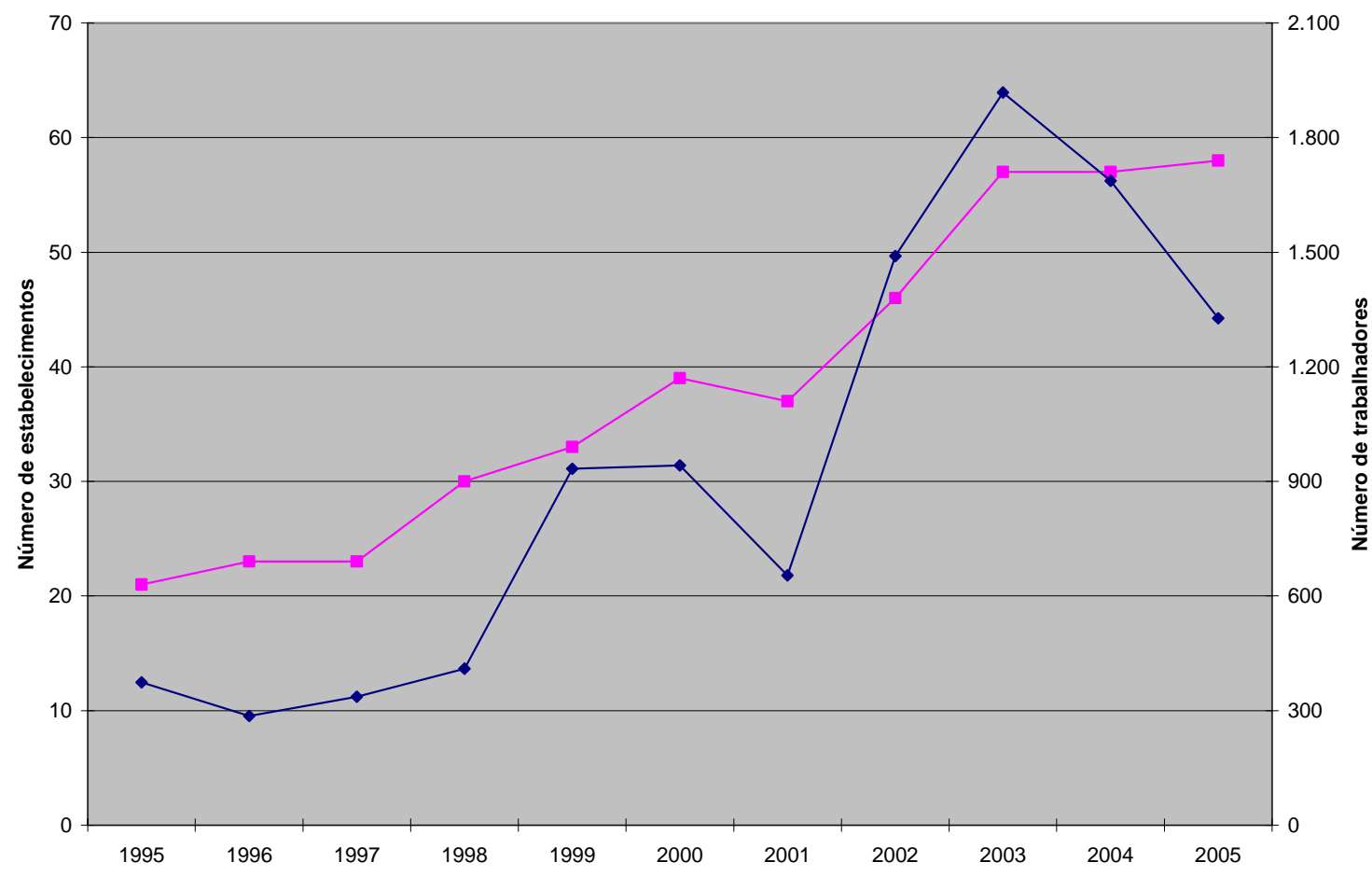

\section{לั}

- Estabelecimentos de preparação e preservação do pescado e fabricação de conservas de peixes, crustáceos e moluscos

- Trabalhadores da preparação e preservação do pescado e fabricação de conservas de peixes, crustáceos e moluscos

Fonte: BRASIL, [2008?c].

Gráfico 47 - Evolução do número de estabelecimentos e de trabalhadores do setor industrial de pescado da região Nordeste do Brasil - 1995-2005.

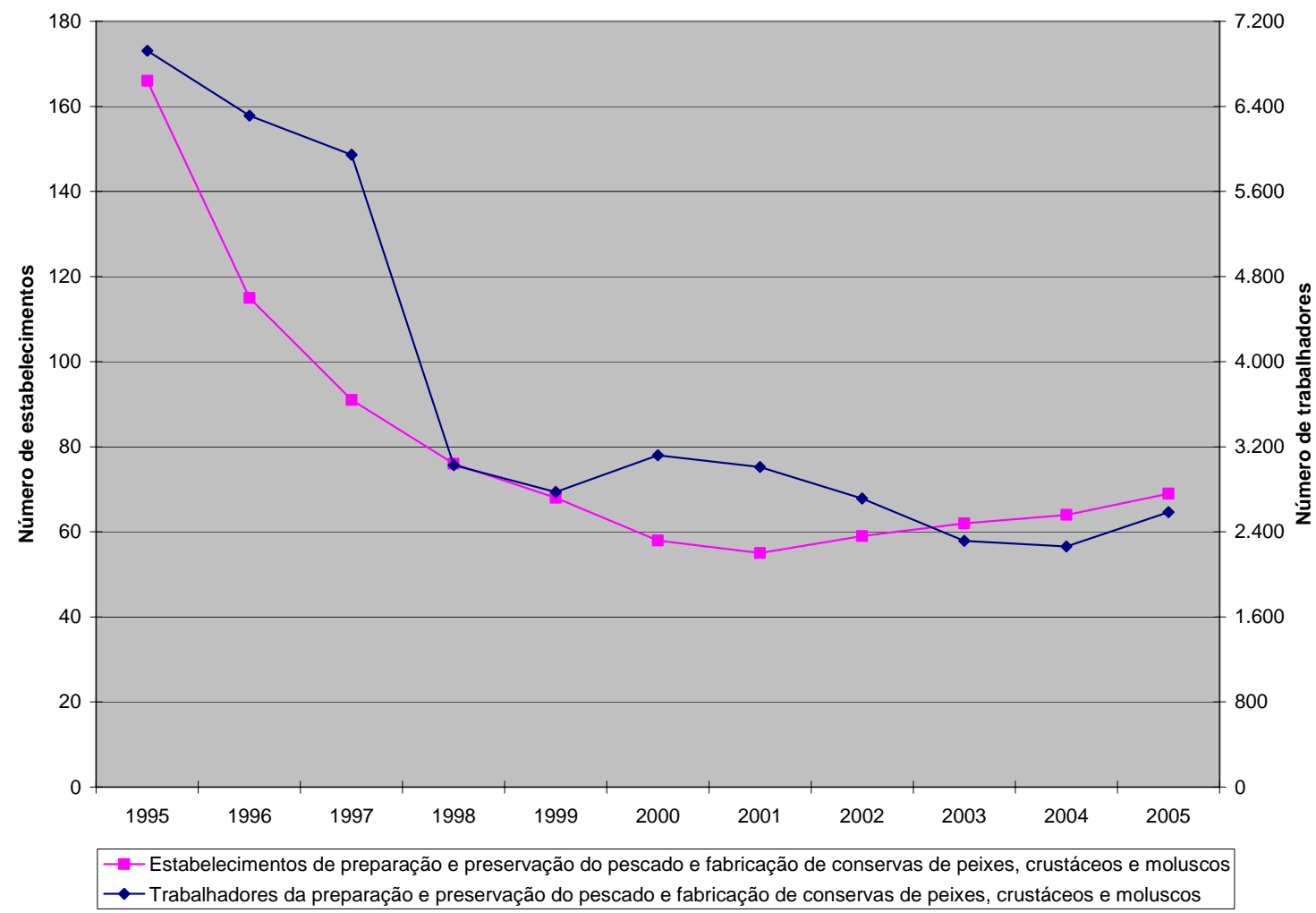

Fonte: BRASIL, [2008?c].

Gráfico 48 - Evolução do número de estabelecimentos e de trabalhadores do setor industrial de pescado da região Sudeste do Brasil - 1995-2005. 


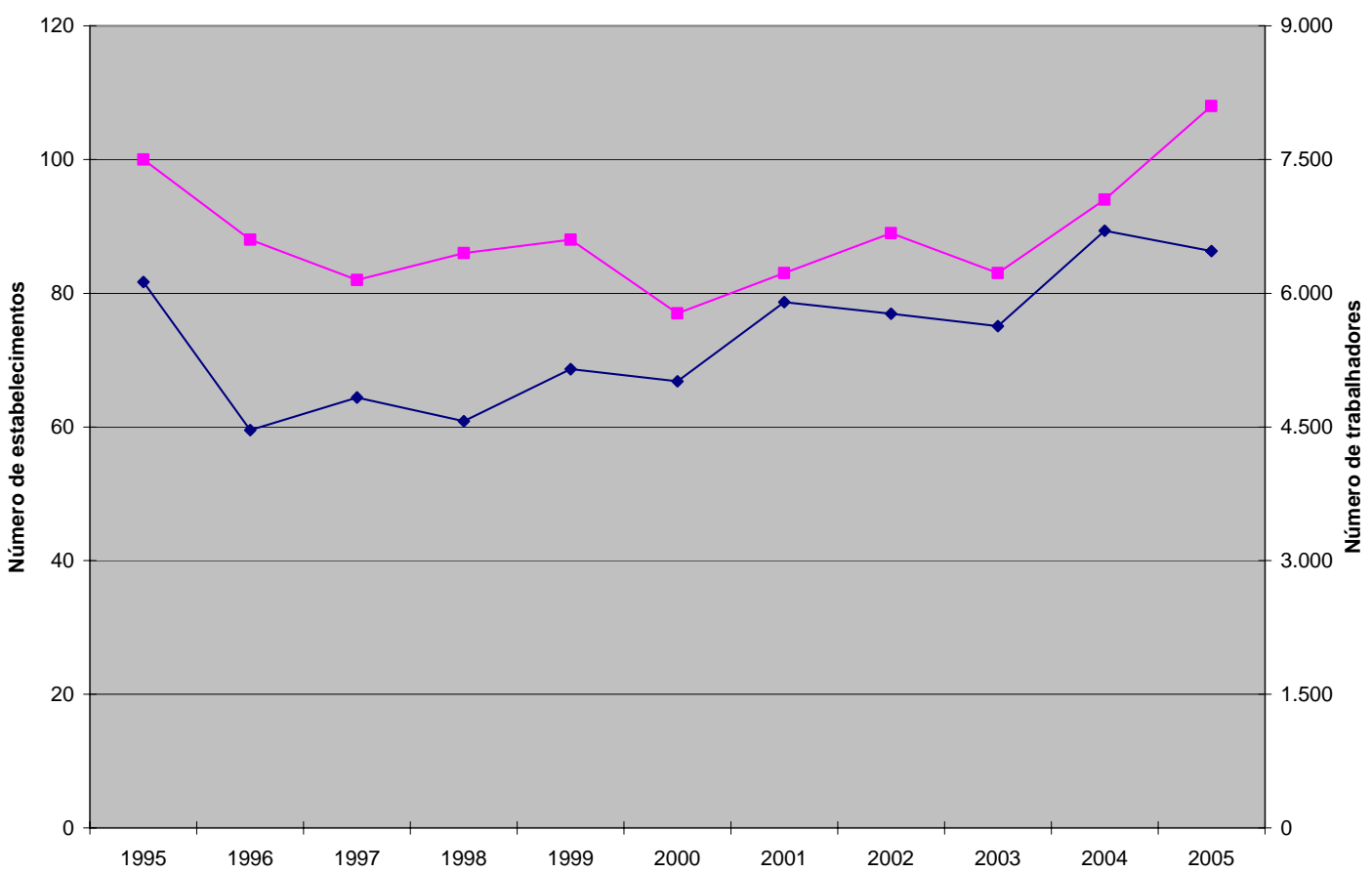

- Estabelecimentos de preparação e preservação do pescado e fabricação de conservas de peixes, crustáceos e moluscos - Trabalhadores da preparação e preservação do pescado e fabricação de conservas de peixes, crustáceos e moluscos

Fonte: BRASIL, [2008?c].

Gráfico 49 - Evolução do número de estabelecimentos e de trabalhadores do setor industrial de pescado da região Sul do Brasil - 1995-2005.

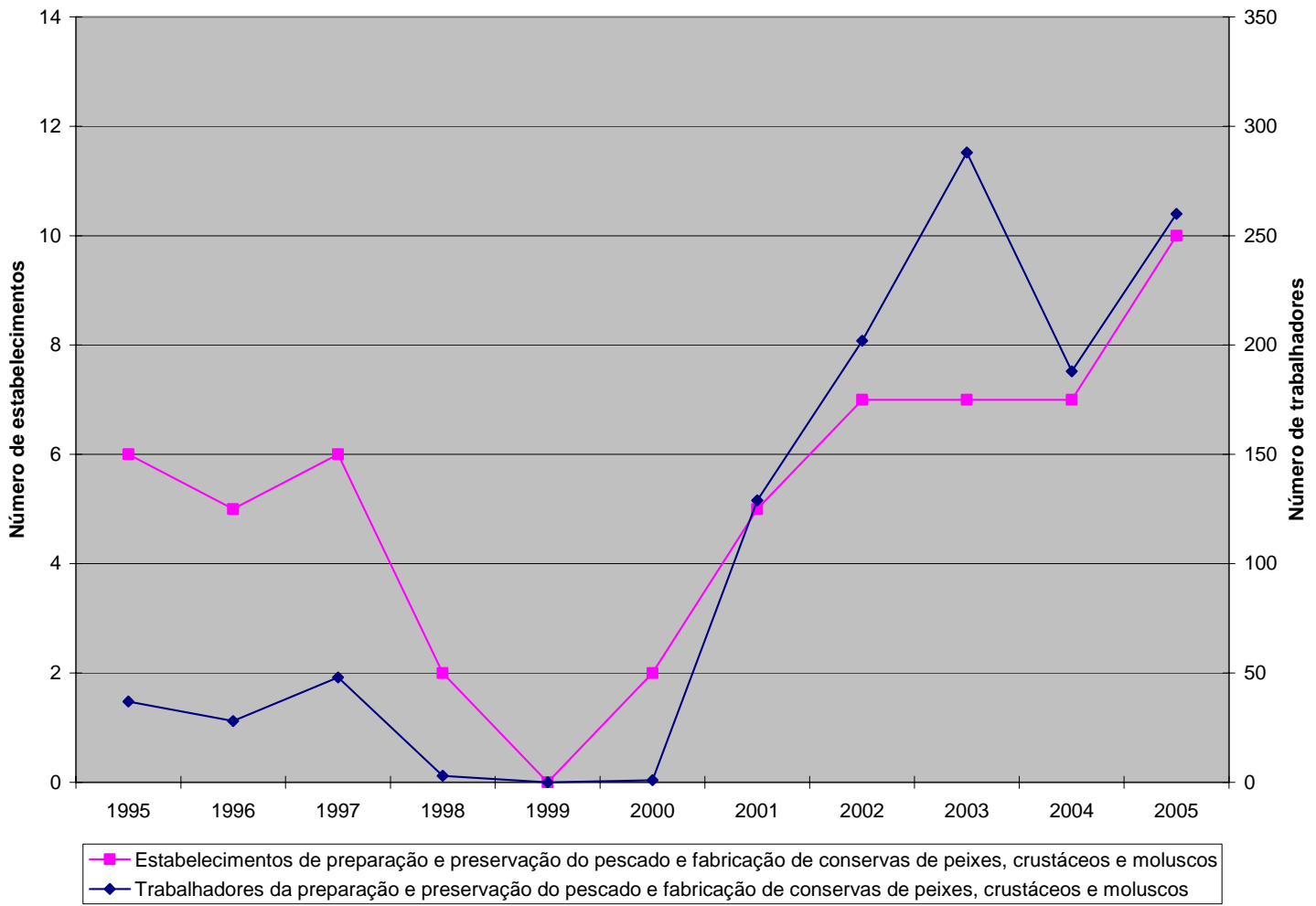

Fonte: BRASIL, [2008?c].

Gráfico 50 - Evolução do número de estabelecimentos e de trabalhadores do setor industrial de pescado da região Centro-oeste do Brasil - 1995-2005. 


\section{APÊNDICE C - PRODUTOS DERIVADOS DO PESCADO PRODUZIDOS PELAS INDÚSTRIAS BRASILEIRAS}

Pesquisa realizada pelo autor em novembro de 2008, através de busca em endereço eletrônico ou de contato por correio eletrônico, junto as 19 empresas relacionadas no caderno Índice de Fornecedores do Anuário Brasileiro das Indústrias da Alimentação (ABIA, 2007a) e junto a 96 das 364 empresas registradas no Serviço de Inspeção Federal (informação verbal ${ }^{25}$ ).

\begin{tabular}{|c|c|}
\hline Matéria-prima & Produtos \\
\hline Peixes (frescos, refrigerados e & Peixe inteiro \\
congelados) & Peixe eviscerado com cabeça \\
Peixe eviscerado sem cabeça & Espalmado de peixe \\
Manta de peixe \\
Postas com pele \\
Postas sem pele \\
Ventrecha com pele (tipo de posta) \\
Ventrevha sem pele \\
Lombo inteiro \\
Lombo sem pele \\
Lombo defumado \\
Costela inteira \\
Costela em pedaços \\
Costela em pedaços empanados \\
Cauda de peixe \\
Fatia de peixe defumada \\
Pedaços de peixe \\
Pedaços sem pele \\
Peixe em cubos \\
Iscas de peixe \\
Peixe ralado \\
Filé com pele \\
Filé sem pele \\
Filé defumado \\
Filé marinado \\
Peixe salgado com cabeça \\
Peixe salgado espalmados \\
Peixe salgado prensados \\
Peixe salgado em postas \\
Peixe salgado desfiado \\
Medalhão \\
\hline
\end{tabular}

\footnotetext{
${ }^{25}$ Informação fornecida por Guilherme Crispim Hundley, Coordenador Geral de Comercialização e Promoção Comercial da Secretaria Especial de Aquicultura e Pesca, através do correio eletrônico guilhermecrispim@seap.gov.br em novembro de 2008.
} 


\begin{tabular}{|c|c|}
\hline & $\begin{array}{c}\text { Hambúrguer } \\
\text { Espetinho com pele } \\
\text { Espetinho sem pele } \\
\text { Massa pronta (ex.: bolinho de bacalhau) } \\
\text { Empanados (ex.: hambúrguer, iscas, steak, } \\
\text { bolinhos) } \\
\text { Casquinha com peixe } \\
\text { Carpaccio } \\
\text { Carpaccio defumado } \\
\text { Conservas } \\
\text { Enlatados com temperos } \\
\text { Enlatados sem temperos } \\
\text { Surimi (Kani Kama) } \\
\text { Bolinhos de Surimi } \\
\text { Molhos à base de peixe (ex.: molho para } \\
\text { strogonoff ou pizza) } \\
\text { Recheios prontos (ex.: atum refogado) } \\
\text { Pasta pronta (ex.: pasta de bacalhau) } \\
\text { Patê de peixe } \\
\text { Fígado } \\
\text { Ovas } \\
\text { Patê de ovas } \\
\text { Pratos prontos (ex.: Moqueca) } \\
\text { Barbatana de tubarão } \\
\text { Farinha de peixe } \\
\text { Couro }\end{array}$ \\
\hline $\begin{array}{l}\text { Crustáceos (vivos, frescos, } \\
\text { refrigerados e congelados) }\end{array}$ & $\begin{array}{c}\text { Camarão inteiro } \\
\text { Camarão com casca e sem cabeça } \\
\text { Camarão descascado } \\
\text { Camarão descascado com cauda } \\
\text { Camarão devenado } \\
\text { Camarão sem cauda cozido } \\
\text { Camarão descascado cozido } \\
\text { Camarão descascado pré-cozido } \\
\text { Camarão empanado } \\
\text { Recheios prontos (ex.: camarão refogado) } \\
\text { Pasta pronta (ex.: pasta de camarão) } \\
\text { Pratos prontos (ex.: Lasanha e Camarão } \\
\text { ao molho) } \\
\text { Massa pronta (ex.: croquete de camarão) } \\
\text { Bolinhos de camarão } \\
\text { Lagosta inteira } \\
\text { Cauda de lagosta } \\
\text { Carpaccio de lagosta } \\
\text { Caranguejo inteiro } \\
\text { Pata de caranguejo } \\
\text { Siri inteiro } \\
\text { Carne de siri } \\
\text { Casquinha de siri }\end{array}$ \\
\hline
\end{tabular}




\begin{tabular}{|c|c|}
\hline Moluscos (vivos, frescos, refrigerados & Lula inteira \\
e congelados) & Lula eviscerada \\
& Tentáculos de lula \\
Anéis de lula & Carpaccio de lula defumada \\
Polvo inteiro & Polvo eviscerado \\
& Tentáculos de polvo \\
& Carpaccio de polvo \\
& Tubos de calamar \\
& Anéis de calamar \\
& Vôngole inteiro \\
& Mexilhão inteiro \\
& Mexilhão descascado \\
& Marisco descascado \\
& Marisco meia concha \\
& Carne de Vieira \\
& Carpaccio de Vieiras ovadas \\
& Carpaccio de ostras \\
\hline Anfíbios & Rã inteira \\
& Coxas de rã \\
\hline Mistura & Iscas de rã \\
& Polpa de rã \\
\hline
\end{tabular}




\section{APÊNDICE D - GRÁFICOS SOBRE A EVOLUÇÃO DO NÚMERO DE ESTABELECIMENTOS E TRABALHADORES DO SETOR ATACADISTA DE PESCADO POR REGIÃO BRASILEIRA}

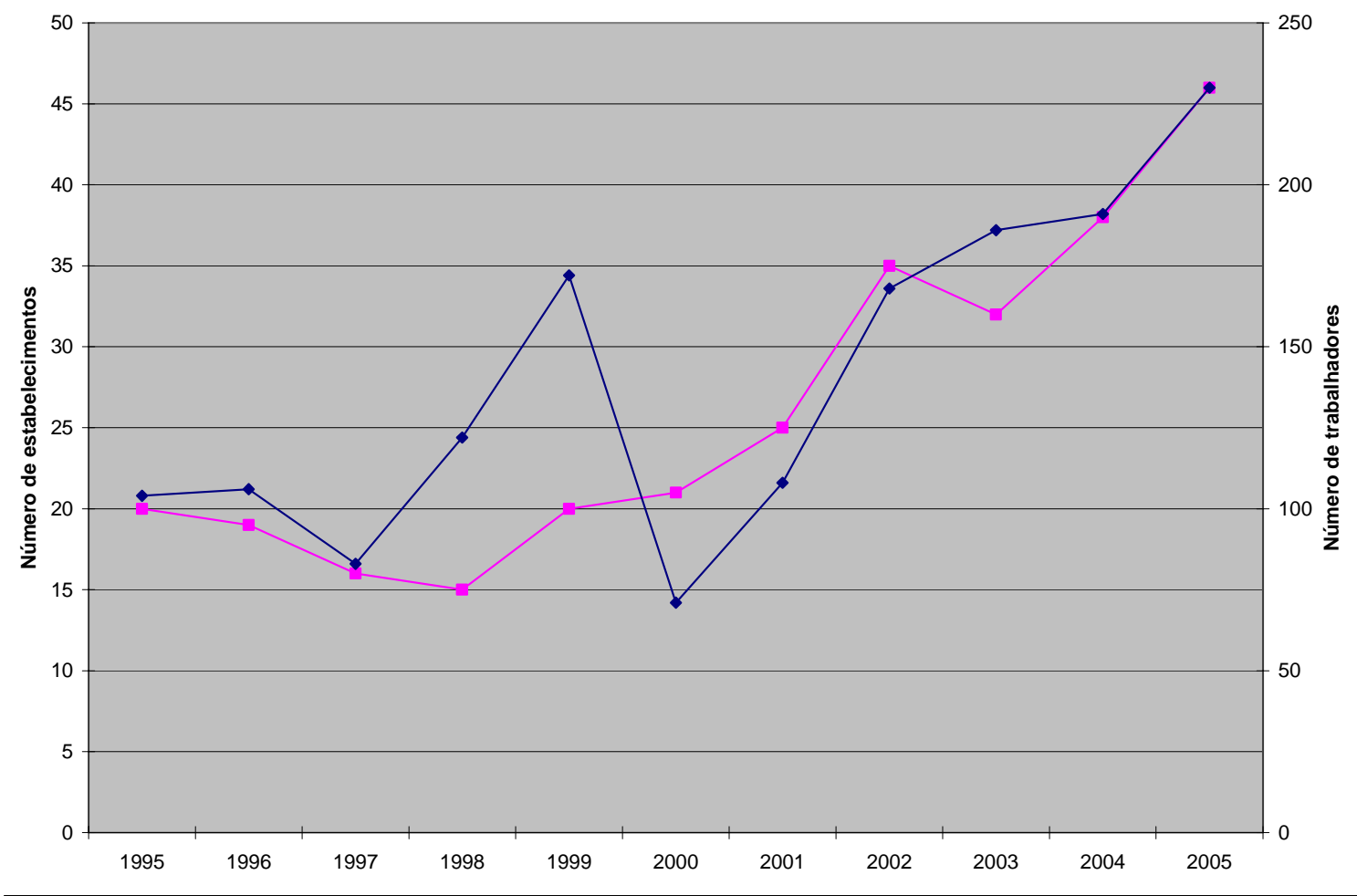

- Estabelecimentos de comércio atacadista de pescado e frutos do mar $\multimap \bullet$ Trabalhadores do comércio atacadista de pescado e frutos do mar

Fonte: BRASIL, [2008?c].

Gráfico 51 - Evolução do número de estabelecimentos e de trabalhadores do comércio atacadista de pescado da região Norte do Brasil - 1995-2005. 


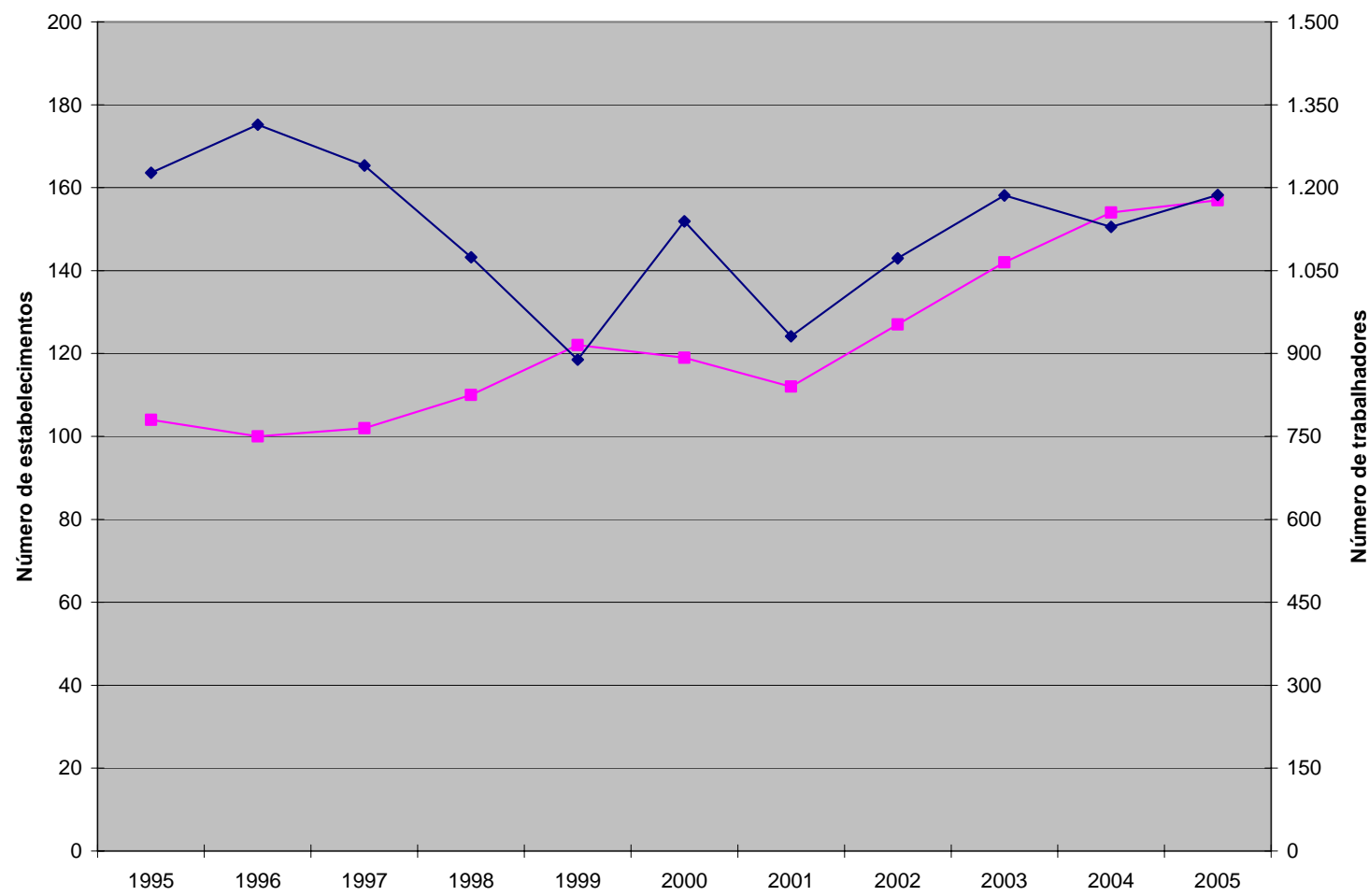

- Estabelecimentos de comércio atacadista de pescado e frutos do mar $\multimap \bullet$ Trabalhadores do comércio atacadista de pescado e frutos do mar

Fonte: BRASIL, [2008?c].

Gráfico 52 - Evolução do número de estabelecimentos e de trabalhadores do comércio atacadista de pescado da região Nordeste do Brasil - 1995-2005.

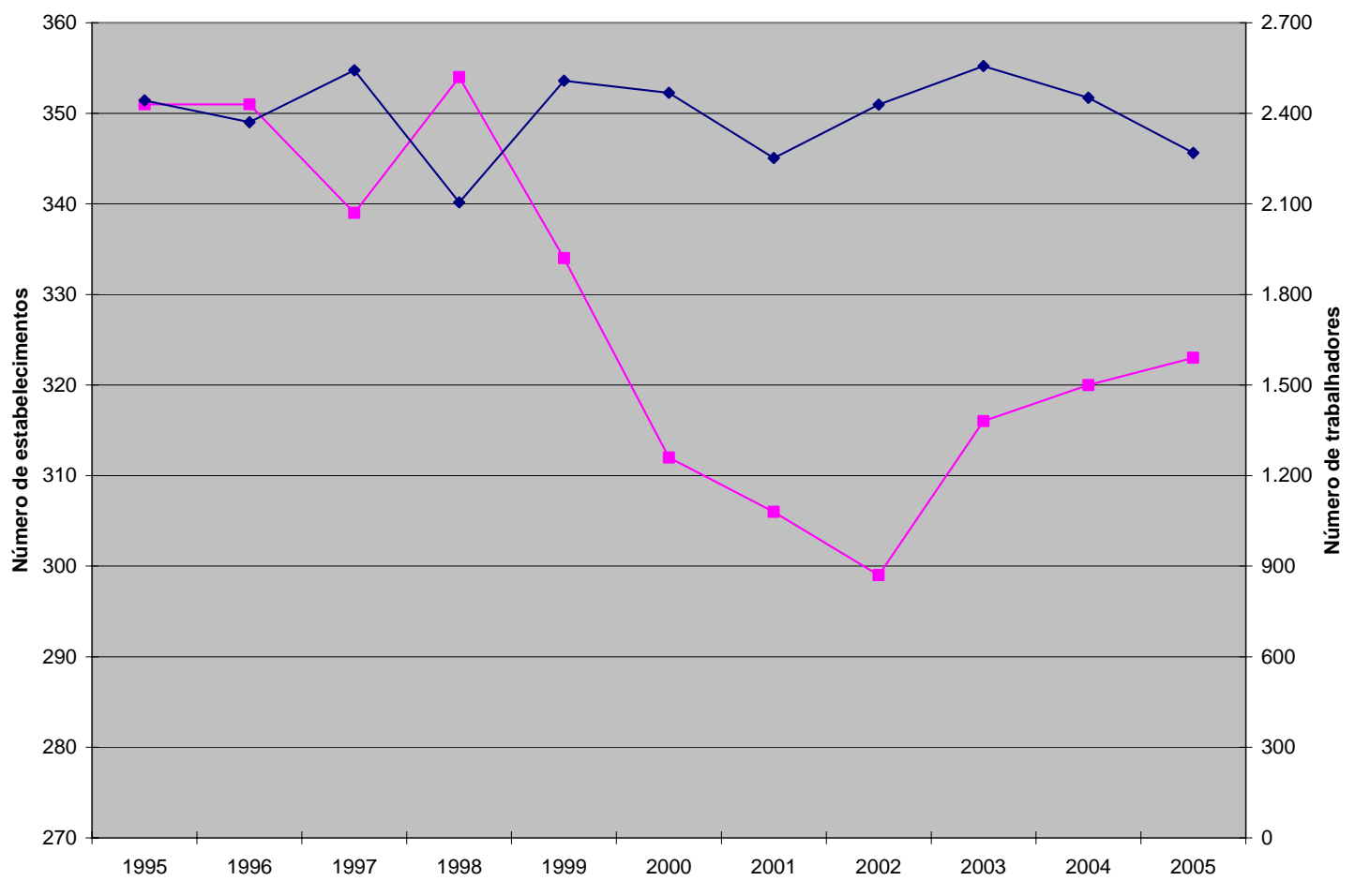

-Estabelecimentos de comércio atacadista de pescado e frutos do mar $\multimap-$ Trabalhadores do comércio atacadista de pescado e frutos do mar

Fonte: BRASIL, [2008?c].

Gráfico 53 - Evolução do número de estabelecimentos e de trabalhadores do comércio atacadista de pescado da região Sudeste do Brasil - 1995-2005. 


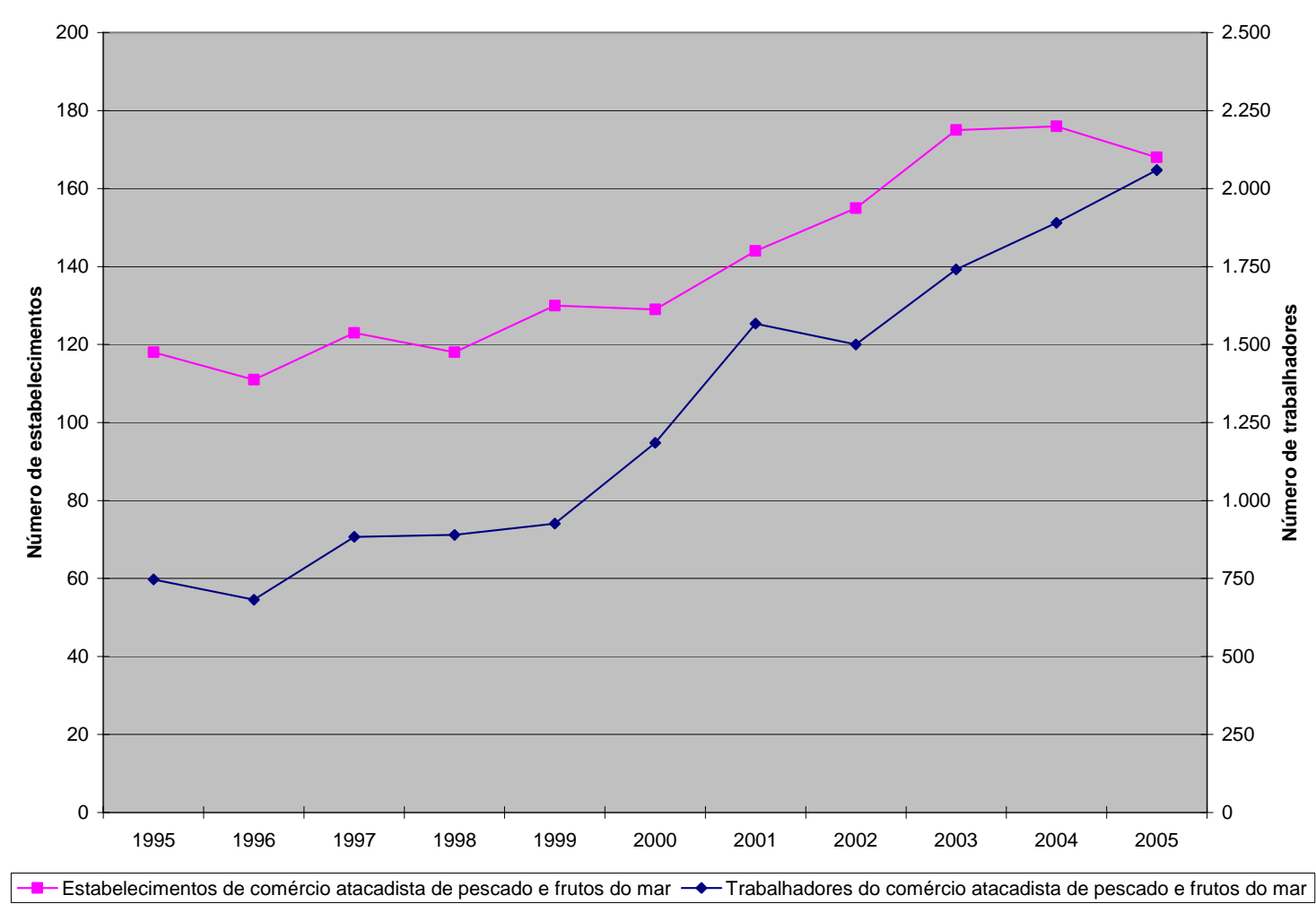

Fonte: BRASIL, [2008?c].

Gráfico 54 - Evolução do número de estabelecimentos e de trabalhadores do comércio atacadista de pescado da região Sul do Brasil - 1995-2005.

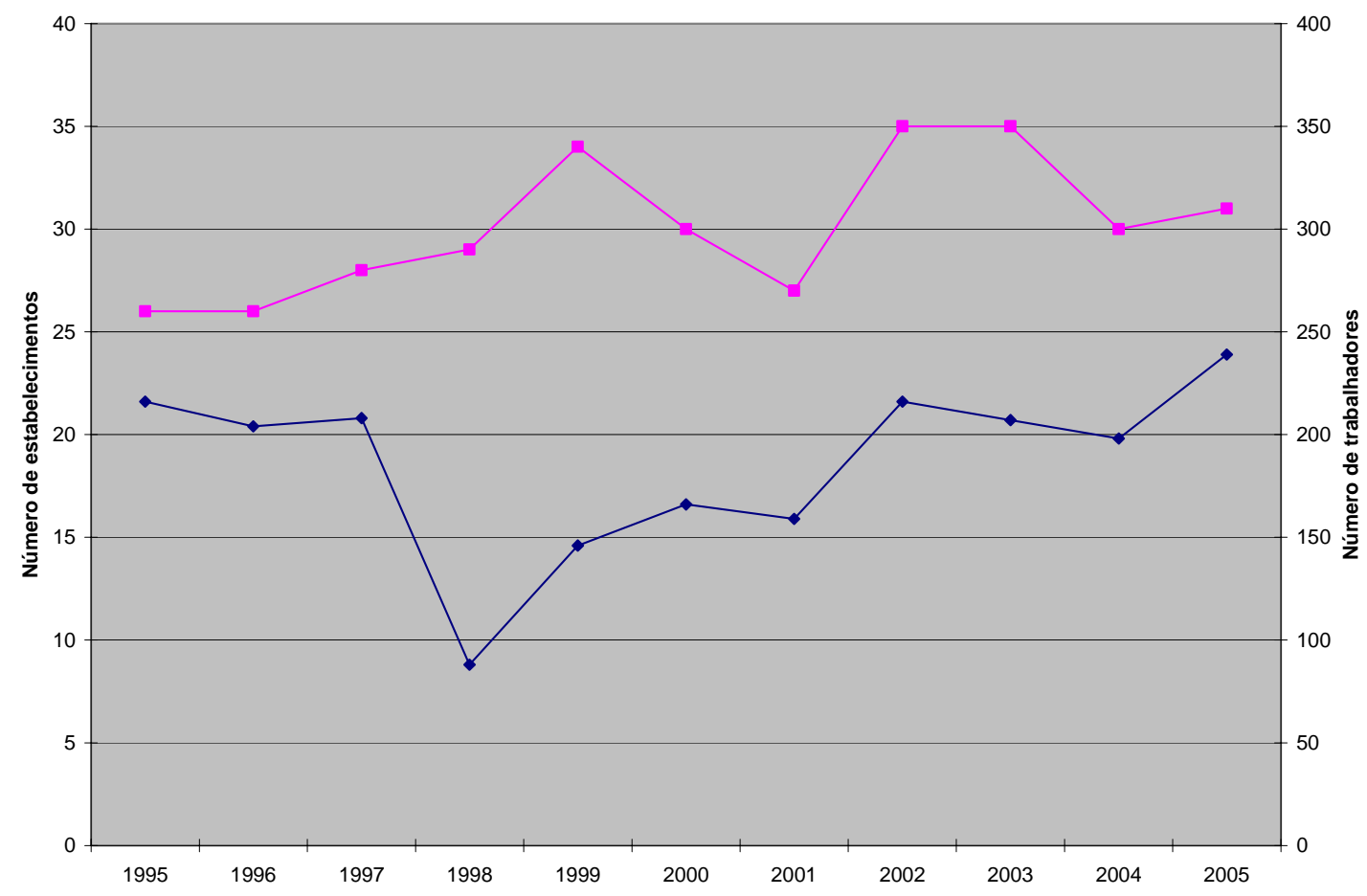

-Estabelecimentos de comércio atacadista de pescado e frutos do mar $\bullet-$ Trabalhadores do comércio atacadista de pescado e frutos do mar

Fonte: BRASIL, [2008?c].

Gráfico 55 - Evolução do número de estabelecimentos e de trabalhadores do comércio atacadista de pescado da região Centro-oeste do Brasil - 1995-2005. 


\section{ANEXOS}

ANEXO A - PRINCIPAIS ESPÉCIES DA ATIVIDADE PESQUEIRA BRASILEIRA

ANEXO B - PRINCIPAIS ESPÉCIES DA ATIVIDADE AQUÍCOLA BRASILEIRA

ANEXO C - LISTA NACIONAL DAS ESPÉCIES DE INVERTEBRADOS AQUÁTICOS E PEIXES AMEÇADAS DE EXTINÇÃO

ANEXO D - LISTA NACIONAL DAS ESPÉCIES DE INVERTEBRADOS AQUÁTICOS E PEIXES SOBRE-EXPLOTADOS OU AMEAÇADOS DE SOBREEXPLOTAÇÃO 


\section{ANEXO A - PRINCIPAIS ESPÉCIES DA ATIVIDADE PESQUEIRA BRASILEIRA}

Lista retirada de IBAMA (2008).

Peixes marinhos

\begin{tabular}{|c|c|}
\hline Nome popular & Nome científico \\
\hline Abrótea & $\begin{array}{l}\text { Urophycis brasiliensis } \\
\text { Urophycis cirrata }\end{array}$ \\
\hline Agulha & $\begin{array}{l}\text { Strongylura marina } \\
\text { Hemiramphus brasiliensis } \\
\text { Hyporhamphus unifasciatus }\end{array}$ \\
\hline Agulhão & $\begin{array}{l}\text { Tetrapturus albidus } \\
\text { Tetrapturus albidus } \\
\text { Tetrapturus pfluegeri } \\
\text { Makaira nigricans } \\
\text { Istiophorus albicans }\end{array}$ \\
\hline Agulhão-branco & Tetrapturus albidus \\
\hline Agulhão-negro & Makaira nigricans \\
\hline Agulhão-vela & Istiophorus albicans \\
\hline Albacora & $\begin{array}{l}\text { Thunnus obesus } \\
\text { Thunnus alalunga } \\
\text { Thunnus albacares } \\
\text { Thunnus atlanticus }\end{array}$ \\
\hline Albacora-bandolim & Thunnus obesus \\
\hline Albacora-branca & Thunnus alalunga \\
\hline Albacora-lage & Thunnus albacares \\
\hline Albacorinha & Thunnus atlanticus \\
\hline Arabaiana & $\begin{array}{l}\text { Elagatis bipinnulata } \\
\text { Seriola fasciata } \\
\text { Seriola dumerili } \\
\text { Seriola lalandi }\end{array}$ \\
\hline Aracimbora & Caranx latus \\
\hline Arenque & Anchoa spp \\
\hline Ariacó & Lutjanus synagris \\
\hline Arraia & $\begin{array}{l}\text { várias espécies das famílias Rajidae, } \\
\text { Rhinobatidae, Myliobatidae, Gymnuridae, } \\
\text { Narcinidae, Dasyatidae }\end{array}$ \\
\hline Atum & $\begin{array}{l}\text { Thunnus obesus } \\
\text { Thunnus alalunga } \\
\text { Thunnus albacares } \\
\text { Thunnus atlanticus }\end{array}$ \\
\hline Badejo & Mycteroperca spp \\
\hline Bagre & $\begin{array}{l}\text { Bagre bagre } \\
\text { Bagre marinus } \\
\text { Bagre panamensis } \\
\text { Bagre pinnimaculatus }\end{array}$ \\
\hline
\end{tabular}




\begin{tabular}{|l|l|}
\hline Nome popular & Nome científico \\
\hline Baiacu & Lagocephalus laevigatus \\
\hline Bandeirado & $\begin{array}{l}\text { Bagre bagre } \\
\text { Bagre marinus }\end{array}$ \\
\hline Batata & $\begin{array}{l}\text { Lopholatilus villarii } \\
\text { Caulolatilus chrysops }\end{array}$ \\
\hline Beijupirá & Rachycentron canudum \\
\hline Bicuda & Sphyraena tome \\
\hline Biquara & Haemulon plumieri \\
\hline Boca-torta & Larimus breviceps \\
\hline Bonito & $\begin{array}{l}\text { Auxis thazard } \\
\text { Katsuwonus pelamis } \\
\text { Euthynnus alletteratus }\end{array}$ \\
\hline Bonito-cachorro & Auxis thazard \\
\hline Bonito-listrado & Katsuwonus pelamis \\
\hline Bonito-pintado & Euthynnus alletteratus \\
\hline Budião & Sparisoma spp \\
\hline Cabra & Prionotus spp \\
\hline Cação & $\begin{array}{l}\text { várias espécies das famílias Lamnidae, } \\
\text { Carcharhinidae, Triakidae, } \\
\text { Odontaspididae, Sphyrnidae, Alopiidae e } \\
\text { Squalidae }\end{array}$ \\
\hline Cambéua & Notarius grandicassis \\
\hline Cambuba & Haemulon flavolineatum \\
\hline Camurupim & Tarpon atlanticus \\
\hline Cangatá & $\begin{array}{l}\text { Aspistor quadricutis } \\
\text { Aspistor parkeri } \\
\text { Aspistor luniscutis }\end{array}$ \\
\hline Caranha (vermelho) & $\begin{array}{l}\text { Lutjanus spp } \\
\text { Rhomboplites aurorubens }\end{array}$ \\
\hline Carapeba & $\begin{array}{l}\text { Diapterus auratus } \\
\text { Eugerres brasilianus } \\
\text { Eucinostomus argenteus }\end{array}$ \\
\hline Carapitanga & Lutjanus spp \\
\hline Nome popular & Nome científico \\
\hline Castanha & Umbrina canosai \\
\hline Cavala & $\begin{array}{l}\text { Scomberomorus cavalla } \\
\text { Acanthocybium solandri }\end{array}$ \\
\hline Cavalinha & Scomber japonicus \\
\hline Cherne & $\begin{array}{l}\text { Epinephelus spp } \\
\text { Epinephelus flavolimbatus } \\
\text { Polyprion americanus }\end{array}$ \\
\hline Cioba & $\begin{array}{l}\text { Lutjanus analis } \\
\text { Ocyurus chrysurus }\end{array}$ \\
\hline & \\
\hline
\end{tabular}




\begin{tabular}{|c|c|}
\hline Nome popular & Nome científico \\
\hline Congro & $\begin{array}{l}\text { Conger orbignianus } \\
\text { Genypterus blacodes } \\
\text { Cynoponticus savanna } \\
\text { Echiophis intertinctus } \\
\text { Myrophis punctatus } \\
\text { Ophidion holbrookii } \\
\text { Ariosoma selenops } \\
\text { Raneya brasiliensis }\end{array}$ \\
\hline Congro-rosa & Genypterus brasiliensis \\
\hline Corcoroca & $\begin{array}{l}\text { Haemulon spp } \\
\text { Pomadasys spp } \\
\text { Orthopristis ruber }\end{array}$ \\
\hline Coro & Conodon nobilis \\
\hline Corvina & Micropogonias furnieri \\
\hline Dentão & Lutjanus jocu \\
\hline Dourado & Coryphaena hippurus \\
\hline Enchova & Pomatomus saltatrix \\
\hline Enguia & $\begin{array}{l}\text { Anguilla spp } \\
\text { Ahlia egmontis } \\
\text { Myrophis punctatus } \\
\text { Gymnothorax moringa }\end{array}$ \\
\hline Espada & Trichiurus lepturus \\
\hline Espadarte & Xiphias gladius \\
\hline Galo & Selene spp \\
\hline Garacimbora & Caranx latus \\
\hline Garajuba & Caranx crysos \\
\hline Garapau & Selar crumenophthalmus \\
\hline Garoupa & Epinephelus spp \\
\hline Goete & Cynoscion jamaicensis \\
\hline Guaiúba & Ocyurus chrysurus \\
\hline Guaravira & $\begin{array}{l}\text { Trichiurus lepturus } \\
\text { Oligoplites saurus }\end{array}$ \\
\hline Guaraximbora & Caranx latus \\
\hline Gurijuba & Arius sp \\
\hline Jurupiranga & $\begin{array}{l}\text { Amphiarius rugispinis } \\
\text { Aspistor luniscutis }\end{array}$ \\
\hline Linguado & $\begin{array}{l}\text { Paralichthys spp } \\
\text { Bothus spp } \\
\text { Gymnachirus spp } \\
\text { Scyacium spp } \\
\text { Etropus spp } \\
\text { Citharichthys spp } \\
\text { Cyclopsetta spp }\end{array}$ \\
\hline Manjuba & $\begin{array}{l}\text { Anchoa spp } \\
\text { Centengraulis edentulus } \\
\text { Anchoviella spp } \\
\text { Lycengraulis grossidens }\end{array}$ \\
\hline
\end{tabular}




\begin{tabular}{|l|l|}
\hline Nome popular & Nome científico \\
\hline Merluza & Merluccius hubbsi \\
\hline Mero & Epinephelus itajara \\
\hline Mororó & $\begin{array}{l}\text { Gobionellus oceanicus } \\
\text { Gymmothorax moringa }\end{array}$ \\
\hline Namorado & Pseudopercis spp \\
\hline Olhete & Seriola lalandi \\
\hline Olho-de-boi & Seriola dumerili \\
\hline Olho-do-cão & Priacanthus spp \\
\hline Oveva & Larimus breviceps \\
\hline Pacamão & Amphicthys cryptocentrus \\
\hline Palombeta & Chloroscombrus chrysurus \\
\hline Pampo & Trachinotus spp \\
\hline Papa-terra & Menticirrhus spp \\
\hline Pargo & Lutjanus purpureus \\
\hline Pargo-rosa & Pagrus pagrus \\
\hline Paru & Chaetodipterus faber \\
\hline Peixe-galo & $\begin{array}{l}\text { Alectis ciliaris } \\
\text { Zenopsis conchifer } \\
\text { Selene spp }\end{array}$ \\
\hline Peixe-pedra & Genyatremus luteus \\
\hline Peixe-rei & $\begin{array}{l}\text { Odontesthes argentinensis } \\
\text { Odontesthes spp } \\
\text { Atherinella brasiliensis }\end{array}$ \\
\hline Peixe-sapo & Lophius gastrophysus \\
\hline Peixe-voador & $\begin{array}{l}\text { Hirundichthys affinis } \\
\text { Cheilopogon cyanopterus }\end{array}$ \\
\hline Peroá & $\begin{array}{l}\text { Aluterus monoceros } \\
\text { Balistes capriscus }\end{array}$ \\
\hline Pescada & $\begin{array}{l}\text { Macrodon spp } \\
\text { Cynoscion spp } \\
\text { Cynoscion acoupa }\end{array}$ \\
\hline Pescada-amarela & Cynoscion virescens \\
\hline Pescada-cambuçu & Cynoscion guatucupa \\
\hline Pescada-olhuda & Cynoscion leiarchus \\
\hline Pescada-branca & Macrodon ancylodon \\
\hline Pescadinha-real & $\begin{array}{l}\text { Anchovia clupeoides } \\
\text { Chloroscombrus chrysurus }\end{array}$ \\
\hline Pilombeta & Kyphosus spp \\
\hline Pirajica & $\begin{array}{l}\text { Megalops atlanticus } \\
\text { Priacanthus arenatus }\end{array}$ \\
\hline Pirapema & Lobotes surinamensis \\
\hline Prejereba & Centropomus spp \\
\hline Robalo & Conodon nobilis \\
\hline Roncador & $\begin{array}{l}\text { Haemulon spp } \\
\text { Orthopristis ruber }\end{array}$ \\
\hline Sapuruna & Pseudupeneus maculatus \\
\hline Saramonete & Sarda sarda \\
\hline Sarda & Triportheus spp \\
\hline Sardinha & \\
\hline
\end{tabular}




\begin{tabular}{|l|l|}
\hline Nome popular & Nome científico \\
\hline Sardinha-laje & Opisthonema oglinum \\
\hline Sardinha-verdadeira & Sardinella brasiliensis \\
\hline Sardinha-cascuda & Harengula spp \\
\hline Savelha & Brevoortia spp \\
\hline Serra & $\begin{array}{l}\text { Scomberomorus spp } \\
\text { Auxis thazard thazard } \\
\text { Sarda sarda } \\
\text { Pristis perotteti }\end{array}$ \\
\hline Sirigado & Mycteroperca spp \\
\hline Sororoca & Scomberomorus brasiliensis \\
\hline Tainha & Mugil spp \\
\hline Tira-vira & Percophis brasiliensis \\
\hline Tortinha & Isopisthus parvipinnis \\
\hline Trilha & Mullus argentinae \\
\hline Tubarão & várias espécies \\
\hline Uritinga & Sciades proops \\
\hline Xaréu & Caranx hippos \\
\hline Xerelete & Caranx latus \\
\hline Xixarro & Trachurus trachurus \\
\hline
\end{tabular}

Crustáceos marinhos

\begin{tabular}{|l|l|}
\hline Nome popular & Nome científico \\
\hline Aratu & Goniopsis cruentata \\
\hline Camarão-barba-ruça & Artemesia longinaris \\
\hline Camarão-branco & Litopenaeus schimitti \\
\hline Camarão-rosa & $\begin{array}{l}\text { Farfantepenaeus paulensis } \\
\text { Farfantepenaeus brasiliensis }\end{array}$ \\
\hline Camarão-santana & Pleoticus muelleri \\
\hline Camarão-sete-barbas & Xiphopenaeus kroyeri \\
\hline Caranguejo-uçá & Ucides cordatus \\
\hline Caranguejo-de-profundidade & $\begin{array}{l}\text { Chaceon romosae } \\
\text { Chaceon notialis }\end{array}$ \\
\hline Guaiamum & Cardisoma guanhumim \\
\hline Lagosta & $\begin{array}{l}\text { Panulirus laevicauda } \\
\text { Panulirus argus } \\
\text { Panulirus echnatus } \\
\text { Scyllarides brasiliensis }\end{array}$ \\
\hline Lagostim & Metanephrops rubellus \\
\hline Siri & Callinectes spp \\
\hline
\end{tabular}


Moluscos marinhos

\begin{tabular}{|l|l|}
\hline Nome popular & Nome científico \\
\hline Calamar-argentino & Illex argentinus \\
\hline Lula & $\begin{array}{l}\text { várias espécies das famílias Loliginidae } \\
\text { e Ommastrephidae }\end{array}$ \\
\hline Mexilhão & Perna perna \\
\hline Maçunim & Anomalocardia brasiliana \\
\hline Ostra & Crassostrea spp \\
\hline Polvo & $\begin{array}{l}\text { Eledone spp } \\
\text { Octopus spp }\end{array}$ \\
\hline Sururu & Mytella spp \\
\hline Vieira & Euvola ziczac \\
\hline
\end{tabular}

Peixes de água-doce

\begin{tabular}{|l|l|}
\hline Nome popular & Nome científico \\
\hline Acará & Geophagus spp \\
\hline Acaratinga & Geophagus proximus \\
\hline Acari-bodó & Pterygoplichthys sp \\
\hline Apaiari & Astronotus ocelatus \\
\hline Apapá & Pellona flavipinnis \\
\hline Aracu & Leporinus sp \\
\hline Armado & Peterodoras granulosus \\
\hline Arraia & $\begin{array}{l}\text { Potamotrygon falkneri } \\
\text { Potamotrygon motoro }\end{array}$ \\
\hline Arenque & Anchoa spp \\
\hline Aruanã & Osteoglossum bicirrhosum \\
\hline Avoador & Hemiodus microlepis \\
\hline Bacu & Platydoras costatus \\
\hline Bagre (mandi) & Pimelodus spp \\
\hline Bagre-amarelo & $\begin{array}{l}\text { Aspistor spp } \\
\text { Cathorops spixii } \\
\text { Bagre marinus } \\
\text { Pimelodus blochii }\end{array}$ \\
\hline Barbado & Pinirampus pirinampu \\
\hline Branquinha & Curimata spp \\
\hline Cachara & Pseudoplatystoma fasciatum \\
\hline Cachorra & Hydrolicus spp \\
\hline Cará & Geophagus brasiliensis \\
\hline Carpa & Cyprinus carpio \\
\hline Cascudo & Hypostomus spp \\
\hline & \\
\hline
\end{tabular}




\begin{tabular}{|l|l|}
\hline Nome popular & Nome científico \\
\hline Charuto & Hemiodus spp \\
& Apareiodon affinis \\
& Sardinella janeiro \\
& Atherinella brasiliensis \\
& Anodus elongatus \\
\hline Corvina & Pachyurus spp \\
\hline Cuiú-cuiú & Oxydoras niger \\
\hline Curimatã & Prochilodus spp \\
\hline Dourada & Brachyplatystoma rousseauxii \\
\hline Dourado & Salminus spp \\
\hline Filhote & Brachyplatystoma filamentosum \\
\hline Jaraqui & Semaprochilodus spp \\
\hline Jaú & Zungaro zumgaro \\
& Zungaro jahu \\
\hline Jundiá & Rhamdia sp \\
\hline Jeju & Hoplerythrinus unitaeniatus \\
& Erythirinus erythrinus \\
\hline Jurupoca & Hemisorubim platyrhynchos \\
\hline Jatuarana & Argonectes longiceps \\
\hline Lambari & Astyanax spp \\
\hline Linguado & Catathyridium jenynsii \\
\hline Mandubé & Ageneiosus spp \\
\hline Mapará & Hipophthalmus marginatus \\
\hline Matrinxã & Brycon melanopterus \\
\hline Muçum & Ophichthus spp \\
\hline Synbranchus marmoratus \\
\hline Pacu & Metynnis spp \\
\hline Peixe-cachorro & Lophiosilurus alexandri \\
\hline Peixe-rei & Hidrolycus scomberoides \\
\hline Perna-de-moça & Odontesthes spp \\
\hline Pescada & Hypophthalmus edentatus \\
\hline Piaba & Plagioscon spp \\
\hline Piau & Moenkhausia spp \\
Poptella brevispina \\
Knodus breviceps \\
Spintherobolus papilliferus \\
\hline Piava & Leporinus spp \\
\hline Pirado & Schyzodon spp \\
\hline Piracanjuba & Pseudoplatystoma corruscans \\
\hline Piramutaba & Conorhynchus conirostris \\
\hline Piranha & Brycon orbignyanus \\
\hline Pirapitinga & Brachyplatystoma vaillant \\
\hline Piraputanga & Serrasalmus spp \\
\hline Pirarara & Brycon nattereri \\
\hline Pirarucu & Brycon hilariii \\
\hline & Phractocephalus hemioliopterus \\
\hline Arapaima gigas \\
\hline
\end{tabular}




\begin{tabular}{|l|l|}
\hline Nome popular & Nome científico \\
\hline Sardinha & Triportheus spp \\
\hline Surubim & Pseudoplatystoma spp \\
\hline Tambaqui & Colossoma macropomum \\
\hline Tambicu & Oligosarcus hepsetus \\
\hline Tamoata & Hoplosternum spp \\
\hline Tilápia & $\begin{array}{l}\text { Oreochromis niloticus } \\
\text { Tilapia rendalli }\end{array}$ \\
\hline Traíra & Hoplias spp \\
\hline Truta & Oncorhynchus mykiss \\
\hline Tubarana & Salminus hilarii \\
& Elops saurus \\
& Albula vulpes \\
\hline Tucunaré & Cichla spp \\
\hline Urubara & Anodus elongatus \\
\hline Viola & Loricariichthys anus \\
\hline
\end{tabular}

Crustáceos de água-doce

\begin{tabular}{|l|l|}
\hline Nome popular & Nome científico \\
\hline Camarão & Macrobrachium rosenbergii \\
\hline
\end{tabular}




\section{ANEXO B - PRINCIPAIS ESPÉCIES DA ATIVIDADE AQUÍCOLA BRASILEIRA}

Lista retirada de IBAMA (2008).

Peixes marinhos

\begin{tabular}{|l|l|}
\hline Nome popular & Nome científico \\
\hline Carapeba & $\begin{array}{l}\text { Diapterus auratus } \\
\text { Eugerres brasilianus } \\
\text { Eucinostomus argenteus }\end{array}$ \\
\hline Curimã & Mugil spp \\
\hline Mero & Epinephelus itajara \\
\hline Pescada & diversas espécies da família Sciaenidae \\
\hline Robalo & Centropomus spp \\
\hline Tainha & Mugil spp \\
\hline
\end{tabular}

Crustáceos marinhos

Nome popular

Camarão

Moluscos marinhos

\begin{tabular}{|l|l|}
\hline Nome popular & Nome científico \\
\hline Coquile & Nodipecten nodosus \\
\hline Mexilhão & Perna perna \\
\hline Ostra & Crassostrea spp \\
\hline Vieira & Euvola ziczac \\
\hline
\end{tabular}

Peixes de água-doce

\begin{tabular}{|l|l|}
\hline Nome popular & Nome científico \\
\hline Aracu & Leporinus sp \\
\hline Bagre-africano & Clarias gariepinus \\
\hline Bagre-americano & Ictalurus punctatus \\
\hline Carpa & Cyprinus carpio \\
\hline Cascudo & Hypostomus spp \\
\hline Curimatã & Prochilodus nigricans \\
\hline
\end{tabular}




\begin{tabular}{|l|l|}
\hline Nome popular & Nome científico \\
\hline Lambari & Astyanax spp \\
\hline Jundiá & Rhamdia sp \\
\hline Matrinxã & Brycon melanopterus \\
\hline Pacu & Piaractus mesopotamicus \\
\hline Piau & Leporinus spp \\
\hline Pirarucu & Arapaima gigas \\
\hline Pirapitinga & Piaractus spp \\
\hline Piraputanga & Brycon microlepis \\
\hline Pintado & Pseudoplatystoma corruscans \\
\hline Tambacu & $\begin{array}{l}\text { híbrido entre Piaractus mesopotamicus e } \\
\text { Colossoma macropomum }\end{array}$ \\
\hline Tambaqui & Colossoma macropomum \\
\hline Tambatinga & $\begin{array}{l}\text { híbrido entre Piaractus brachypomus e } \\
\text { Colossoma macropomum }\end{array}$ \\
\hline Tilápia & $\begin{array}{l}\text { Oreochromis niloticus } \\
\text { Oreochromis niloticus } \\
\text { Oreochromis spp }\end{array}$ \\
\hline Traíra & Hoplias spp \\
\hline Truta & Oncorhynchus mykiss \\
\hline
\end{tabular}

Crustáceos de água-doce

\begin{tabular}{|l|l|}
\hline Nome popular & Nome científico \\
\hline Camarão & Macrobrachium rosenbergii \\
& Macrobrachium amazonicum \\
& Macrobrachium rosenbergii \\
\hline
\end{tabular}

Anfíbios

\begin{tabular}{|l|l|}
\hline Nome popular & Nome científico \\
\hline Rã & Rana catesbeiana \\
\hline
\end{tabular}




\section{ANEXO C - LISTA NACIONAL DAS ESPÉCIES DE INVERTEBRADOS AQUÁTICOS E PEIXES AMEÇADAS DE EXTINÇÃO}

Lista retirada da Instrução Normativa n. 5 do Ministério do Meio Ambiente, de 21/05/2004 (BRASIL, 2004a), atualizada pela Instrução Normativa n. 52 do Ministério do Meio Ambiente, de 08/11/2005 (BRASIL, 2005b).

\begin{tabular}{|c|c|}
\hline Nome científico & Nome popular \\
\hline Condylactis gigantea & Anêmona-do-mar \\
\hline \multicolumn{2}{|l|}{ Cerianthomorphe brasiliensis } \\
\hline \multicolumn{2}{|l|}{ Cerianthus brasiliensis } \\
\hline Phillogorgia dilatata & Orelha-de-elefante \\
\hline Coscinasterias tenuispina & Estrela-do-mar \\
\hline Astropecten braziliensis & Estrela-do-mar \\
\hline Astropecten cingulatus & Estrela-do-mar \\
\hline Astropecten marginatus & Estrela-do-mar \\
\hline Luidia clathrata & Estrela-do-mar \\
\hline Luidia ludwigi scotti & Estrela-do-mar \\
\hline Luidia senegalensis & Estrela-do-mar \\
\hline Echinaster (Othilia) brasiliensis & Estrela-do-mar \\
\hline Echinaster (Othilia) echinophorus & Estrela-do-mar \\
\hline Echinaster (Othilia) guyanensis & Estrela-do-mar \\
\hline Asterina stellifera & Estrela-do-mar \\
\hline Linckia guildingii & Estrela-do-mar \\
\hline Narcissia trigonaria & Estrela-do-mar \\
\hline Oreaster reticulatus & Estrela-do-mar \\
\hline Castalia undosa & Concha-borboleta \\
\hline Diplodon caipira & Marisco-de-água-doce \\
\hline Diplodon dunkerianus & Marisco-de-água-doce \\
\hline \multicolumn{2}{|l|}{ Diplodon expansus } \\
\hline \multicolumn{2}{|l|}{ Diplodon fontainianus } \\
\hline Diplodon greeffeanus & Marisco-de-água-doce \\
\hline Diplodon iheringi & Marisco-barrigudinho \\
\hline Diplodon koseritzi & Marisco-do-junco \\
\hline Diplodon martensi & Marisco-de-água-doce \\
\hline Diplodon pfeifferi & Marisco-de-água-doce \\
\hline Diplodon rotundus & Concha-disco \\
\hline Anodontites elongates & Marisco-pantaneiro \\
\hline Anodontites ensiformis & Estilete \\
\hline Anodontites ferrarisii & Redondo-rajado \\
\hline Anodontites iheringi & Alongado-rajado \\
\hline Anodontites soleniformes & Marisco-de-água-doce \\
\hline Anodontites tenebricosus & Marisco-rim \\
\hline Anodontites trapesialis & Prato, saboneteira \\
\hline Anodontites trapezeus & Marisco-de-água-doce \\
\hline Bartlettia stefanensis & Ostra-de-rio \\
\hline Fossula fossiculifera & Fóssula \\
\hline Leila blainvilliana & Leila \\
\hline Leila esula & Leila \\
\hline
\end{tabular}




\begin{tabular}{|c|c|}
\hline Nome científico & Nome popular \\
\hline Monocondylaea paraguayana & Cofrinho \\
\hline Mycetopoda legumen & Faquinha-arredondada \\
\hline Mycetopoda siliquosa & Faquinha-truncada \\
\hline Oncosclera jewelli & Feltro-d'água \\
\hline \multicolumn{2}{|l|}{ Uruguaya corallioides } \\
\hline \multicolumn{2}{|l|}{ Sterrastrolepis brasiliensis } \\
\hline Anheteromeyenia ornata & Geléia-de-água \\
\hline \multicolumn{2}{|l|}{ Corvoheteromeyenia australis } \\
\hline \multicolumn{2}{|l|}{ Corvoheteromeyenia heterosclera } \\
\hline \multicolumn{2}{|l|}{ Corvospongilla volkmeri } \\
\hline \multicolumn{2}{|l|}{ Heteromeyenia insignis } \\
\hline \multicolumn{2}{|l|}{ Houssayella iguazuensis } \\
\hline \multicolumn{2}{|l|}{ Racekiela sheilae } \\
\hline \multicolumn{2}{|l|}{ Metania kiliani } \\
\hline Cassidulus mitis & Ouriço-do-mar-irregular \\
\hline Eucidaris tribuloides & Ouriço-satélite \\
\hline Paracentrotus gaimardi & Ouriço-do-mar \\
\hline \multicolumn{2}{|l|}{ Willeya loya } \\
\hline \multicolumn{2}{|l|}{ Potamolithus troglobius } \\
\hline Natica micra & Búzio \\
\hline \multicolumn{2}{|l|}{ Petaloconchus myrakeenae } \\
\hline Synaptula secreta & Pepino-do-mar \\
\hline Isostichopus badionotus & Pepino-do-mar, holotúria \\
\hline Millepora alcicornis & Coral-de-fogo \\
\hline \multicolumn{2}{|l|}{ Hyalella caeca } \\
\hline \multicolumn{2}{|l|}{ Aegla cavernicola } \\
\hline \multicolumn{2}{|l|}{ Aegla leptochela } \\
\hline \multicolumn{2}{|l|}{ Aegla microphtalma } \\
\hline Atya gabonensis & Coruca \\
\hline Atya scabra & Coruca \\
\hline Gecarcinus lagostoma & Caranguejo-ladrão \\
\hline \multicolumn{2}{|l|}{ Percnon gibbesi } \\
\hline Macrobrachium carcinus & Pitu, lagosta-de-água-doce, lagosta-de-são-fidelis \\
\hline \multicolumn{2}{|l|}{ Minyocerus angustus } \\
\hline Eurythoe complanata & Verme-de-fogo \\
\hline \multicolumn{2}{|l|}{ Eunice sebastiani } \\
\hline \multicolumn{2}{|l|}{ Diopatra cuprea } \\
\hline Isogomphodon oxyrhynchus & Quati \\
\hline \multicolumn{2}{|l|}{ Negaprion brevirostris } \\
\hline Galeorhinus galeus & Cação-bico-doce \\
\hline Mustelus schmitti & Cação-cola-fina, caçonete \\
\hline Cetorhinus maximus & Tubarão-peregrino \\
\hline Ginglymostoma cirratum & Cação-lixa, tubarão-lixa, lambaru \\
\hline Rhincodon typus & Tu b a rão-bale i a \\
\hline Pristis perotteti & Peixe-serra \\
\hline Pristis pectinata & Peixe-serra \\
\hline Rhinobatus horkelii & Raia-viola \\
\hline Squatina guggenheim & Cação-anjo-espinhoso \\
\hline Squatina occulta & Cação-anjo-liso \\
\hline Potamobatrachus trispinosus & Mangangá \\
\hline Leporinus thayeri & Piau \\
\hline
\end{tabular}




\begin{tabular}{|c|c|}
\hline Nome científico & Nome popular \\
\hline \multicolumn{2}{|l|}{ Sartor tucuruiense } \\
\hline Astyanax gymnogenys & Lambari \\
\hline Brycon devillei & Piabanha \\
\hline Brycon insignis & Piabanha \\
\hline Brycon nattereri & Pirapitinga \\
\hline Brycon opalinus & Pirapitinga, pirapitinga-do-sul \\
\hline Brycon orbignyanus & Piracanjuba, piracanjuva, bracanjuva \\
\hline Brycon vermelha & Vermelha \\
\hline Bryconamericus lambari & Lambari \\
\hline \multicolumn{2}{|l|}{ Coptobrycon bilineatus } \\
\hline \multicolumn{2}{|l|}{ Glandulocauda melanogenys } \\
\hline \multicolumn{2}{|l|}{ Glandulocauda melanopleura } \\
\hline Hasemania maxillaris & Lambari \\
\hline Hasemania melanura & Lambari \\
\hline Henochilus wheatlandii & Andirá, anjirá \\
\hline \multicolumn{2}{|l|}{ Hyphessobrycon duragenys } \\
\hline Hyphessobrycon flammeus & Engraçadinho \\
\hline Hyphessobrycon taurocephalus & Lambari \\
\hline Lignobrycon myersi & Piaba-faca \\
\hline \multicolumn{2}{|l|}{ Mimagoniates lateralis } \\
\hline \multicolumn{2}{|l|}{ Mimagoniates rheocharis } \\
\hline \multicolumn{2}{|l|}{ Mimagoniates sylvicola } \\
\hline Mylesinus paucisquamatus & Pacu \\
\hline Myleus tiete & Pacu-prata \\
\hline \multicolumn{2}{|l|}{ Nematocharax venustus } \\
\hline Ossubtus xinguense & Pacu \\
\hline \multicolumn{2}{|l|}{ Ossubtus xinguense } \\
\hline \multicolumn{2}{|l|}{ Rachoviscus crassiceps } \\
\hline \multicolumn{2}{|l|}{ Rachoviscus graciliceps } \\
\hline \multicolumn{2}{|l|}{ Spintherobolus ankoseion } \\
\hline \multicolumn{2}{|l|}{ Spintherobolus broccae } \\
\hline \multicolumn{2}{|l|}{ Spintherobolus leptoura } \\
\hline \multicolumn{2}{|l|}{ Spintherobolus papilliferus } \\
\hline \multicolumn{2}{|l|}{ Stygichthys typhlops } \\
\hline Characidium grajahuensis & Canivetinho, mocinha \\
\hline Characidium lagosantensis & Canivete \\
\hline \multicolumn{2}{|l|}{ Characidium vestigipinne } \\
\hline Phalloptychus eigenmanni & Barrigudinho \\
\hline Phallotorynus fasciolatus & Guarú \\
\hline Phallotorynus jucundus & Guarú \\
\hline \multicolumn{2}{|l|}{ Austrolebias adloffi } \\
\hline Austrolebias affinis & Peixe anual \\
\hline Austrolebias alexandri & Peixe anual \\
\hline \multicolumn{2}{|l|}{ Austrolebias carvalhoi } \\
\hline Austrolebias charrua & Peixe anual \\
\hline Austrolebias cyaneus & Peixe anual \\
\hline \multicolumn{2}{|l|}{ Austrolebias ibicuiensis } \\
\hline Austrolebias luteoflammulatus & Peixe anual \\
\hline Austrolebias minuano & Peixe anual \\
\hline Austrolebias nigrofasciatus & Peixe anual \\
\hline Austrolebias periodicus & Peixe anual \\
\hline
\end{tabular}




\begin{tabular}{|c|c|}
\hline Nome científico & Nome popular \\
\hline \multicolumn{2}{|l|}{ Campellolebias brucei } \\
\hline \multicolumn{2}{|l|}{ Campellolebias chrysolineatus } \\
\hline \multicolumn{2}{|l|}{ Campellolebias dorsimaculatus } \\
\hline \multicolumn{2}{|l|}{ Cynolebias griseus } \\
\hline \multicolumn{2}{|l|}{ Leptolebias citrinipinnis } \\
\hline \multicolumn{2}{|l|}{ Leptolebias cruzi } \\
\hline \multicolumn{2}{|l|}{ Leptolebias fractifasciatus } \\
\hline \multicolumn{2}{|l|}{ Leptolebias leitaoi } \\
\hline \multicolumn{2}{|l|}{ Leptolebias marmoratus } \\
\hline \multicolumn{2}{|l|}{ Leptolebias minimus } \\
\hline \multicolumn{2}{|l|}{ Leptolebias opalescens } \\
\hline \multicolumn{2}{|l|}{ Leptolebias splendens } \\
\hline \multicolumn{2}{|l|}{ Maratecoara formosa } \\
\hline \multicolumn{2}{|l|}{ Megalebias wolterstorffi } \\
\hline \multicolumn{2}{|l|}{ Nematolebias whitei } \\
\hline \multicolumn{2}{|l|}{ Plesiolebias xavantei } \\
\hline \multicolumn{2}{|l|}{ Simpsonichthys alternatus } \\
\hline \multicolumn{2}{|l|}{ Simpsonichthys auratus } \\
\hline \multicolumn{2}{|l|}{ Simpsonichthys boitonei } \\
\hline \multicolumn{2}{|l|}{ Simpsonichthys bokermanni } \\
\hline \multicolumn{2}{|l|}{ Simpsonichthys constanciae } \\
\hline \multicolumn{2}{|l|}{ Simpsonichthys flammeus } \\
\hline Simpsonichthys fulminantis & \\
\hline Simpsonichthys ghisolfi & \\
\hline Simpsonichthys hellneri & \\
\hline Simpsonichthys izecksohni & \\
\hline Simpsonichthys magnificus & \\
\hline Simpsonichthys marginatus & \\
\hline Simpsonichthys multiradiatus & \\
\hline Simpsonichthys myersi & \\
\hline Simpsonichthys notatus & \\
\hline Simpsonichthys parallelus & \\
\hline Simpsonichthys perpendicularis & \\
\hline Simpsonichthys rosaceus & \\
\hline Simpsonichthys rufus & \\
\hline Simpsonichthys santanae & \\
\hline Simpsonichthys similis & \\
\hline Simpsonichthys stellatus & \\
\hline Simpsonichthys trilineatus & \\
\hline Simpsonichthys zonatus & \\
\hline Spectrolebias semiocellatus & \\
\hline Sternarchorhynchus britskii & Ituí \\
\hline Eigenmannia vicentespelaea & Ituí \\
\hline Prognathodes obliquus & Peixe-borboleta \\
\hline Crenicichla cyclostoma & Jacundá \\
\hline Crenicichla jegui & Jacundá \\
\hline Crenicichla jupiaiensis & Joaninha \\
\hline Teleocichla cinderella & \\
\hline Gymnogeophagus setequedas & Acará \\
\hline Elacatinus figaro & Neon \\
\hline Gramma brasiliensis & Grama \\
\hline
\end{tabular}




\begin{tabular}{|c|c|}
\hline Nome científico & Nome popular \\
\hline Bodianus insularis & Bodião-Ilhéu \\
\hline Stegastes sanctipauli & Donzelinha \\
\hline \multicolumn{2}{|l|}{ Scarus guacamaia } \\
\hline \multicolumn{2}{|l|}{ Anthias salmopunctatus } \\
\hline \multicolumn{2}{|l|}{ Tatia boemia } \\
\hline \multicolumn{2}{|l|}{ Corydoras macropterus } \\
\hline \multicolumn{2}{|l|}{ Lepthoplosternum tordilho } \\
\hline Kalyptodoras bahiensis & Peracuca \\
\hline Chasmocranus brachynema & Bagrinho \\
\hline \multicolumn{2}{|l|}{ Heptaterus multiradiatus } \\
\hline Pimelodella kronei & Bagre-cego \\
\hline Rhamdia jequitinhonha & Bagre, jundiá \\
\hline Rhamdiopsis microcephala & Bagrinho \\
\hline Taunaya bifasciata & Bagrinho \\
\hline Ancistrus formoso & Cascudo \\
\hline Delturus parahybae & Cascudo-laje \\
\hline Harttia rhombocephala & Cascudo \\
\hline Hemiancistrus chlorostictus & Cascudo \\
\hline Hemipsilichthys garbei & Cascudo \\
\hline Hemipsilichthys mutuca & Cascudo \\
\hline Hypancistrus zebra & Cascudo-zebra \\
\hline Pogonopoma parahybae & Cascudo \\
\hline Pseudotocinclus tietensis & Cascudinho \\
\hline \multicolumn{2}{|l|}{ Aguarunichthys tocantinsensis } \\
\hline Conorhynchos conirostris & Pirá, pirá-tamanduá \\
\hline Steindachneridion amblyura & Surubim \\
\hline Steindachneridion doceana & Surubim-do-doce \\
\hline Steindachneridion parahybae & Surubim-do-paraíba \\
\hline Steindachneridion scripta & Surubim \\
\hline Homodiaetus graciosa & Cambeba \\
\hline \multicolumn{2}{|l|}{ Homodieatus passarelii } \\
\hline Listrura campos & Candiru, bagre-mole \\
\hline \multicolumn{2}{|l|}{ Listrura nematopteryx } \\
\hline \multicolumn{2}{|l|}{ Listrura tetraradiata } \\
\hline Microcambeva barbata & Cambeva \\
\hline \multicolumn{2}{|l|}{ Trichogenes longipinnis } \\
\hline Trichomycterus castroi & Cambeva \\
\hline Trichomycterus itacarambiensis & Cambeva \\
\hline Trichomycterus paolence & Cambeva \\
\hline
\end{tabular}




\section{ANEXO D - LISTA NACIONAL DAS ESPÉCIES DE INVERTEBRADOS AQUÁTICOS E PEIXES SOBRE-EXPLOTADOS OU AMEAÇADOS DE SOBRE- EXPLOTAÇÃO}

Lista retirada da Instrução Normativa n. 5 do Ministério do Meio Ambiente, de 21/05/2004 (BRASIL, 2004a), atualizada pela Instrução Normativa n. 52 do Ministério do Meio Ambiente, de 08/11/2005 (BRASIL, 2005b).

\begin{tabular}{|c|c|}
\hline Nome científico & Nome popular \\
\hline Strombus goliath & Búzio-de-chapéu \\
\hline Cardisoma guanhumi & Guaiamum, goiamú, gaiamú \\
\hline Ucides cordatus & $\begin{array}{c}\text { Ucá, caranguejo-uçá, caranguejo-verdadeiro, caranguejo-de- } \\
\text { mangue, catanhão }\end{array}$ \\
\hline Panulirus argus & Lagosta \\
\hline Panulirus laevicauda & Lagosta \\
\hline Farfantepenaeus brasiliensis & Camarão-rosa \\
\hline Farfantepenaeus paulensis & Camarão-rosa \\
\hline Farfantepenaeus subtilis & Camarão-rosa \\
\hline Litopenaeus schimitti & Camarão-branco \\
\hline Xiphopenaeus kroyeri & Camarão-sete-barbas \\
\hline Callinectes sapidus & Siri; siri-azul \\
\hline Carcharhinus longimanus & Tubarão-estrangeiro, tubarão-galha-branca-oceânico \\
\hline Carcharhinus porosus & Tubarão-junteiro, tubarão-azeiteiro \\
\hline Carcharhinus signatus & Tu barão-toninha \\
\hline Prionace glauca & Tu barão-azul \\
\hline Sphyrna lewini & Tubarão-martelo \\
\hline Sphyrna tiburo & $\begin{array}{l}\text { Cação-martelo-da-aba-curta, panã-da-aba-curta, cação- } \\
\text { martelo, cambeva-pata }\end{array}$ \\
\hline Sphyrna zygaena & Tubarão-martelo liso \\
\hline Carcharias taurus & Mangona \\
\hline Colossoma macropomum & Ta m b a qui \\
\hline Semaprochilodus insignis & Jaraqui \\
\hline Semaprochilodus taeniurus & Jaraqui \\
\hline Sardinella brasiliensis & Sardinha \\
\hline Hippocampus erectus & Cavalo-marinho \\
\hline Hippocampus reidi & Cavalo-marinho \\
\hline Lophius gastrophysus & Peixe-sapo \\
\hline Arapaima gigas & Pirarucu \\
\hline Lutjanus analis & Caranha, cioba, vermelho, vermelho-cioba \\
\hline Lutjanus purpureus & Pargo, vermelho \\
\hline Ocyurus chrysurus & Cioba, guaiúba \\
\hline Rhomboplites aurorubens & Realito, paramirim \\
\hline Mugil liza & Tainha \\
\hline Mugil platanus & Ta in ha \\
\hline Pseudopercis numida & Namorado \\
\hline Pomatomus saltatrix & Anchova \\
\hline Cynoscion guatucupa & Pescada-olhuda \\
\hline Macrodon ancylodon & Pescadinha-real \\
\hline Micropogonias furnieri & Corvina \\
\hline Umbrina canosai & Castanha \\
\hline
\end{tabular}




\begin{tabular}{|c|c|}
\hline Nome científico & Nome popular \\
\hline Epinephelus itajara & Mero, canapu, merote (jovem), bodete (jovem) \\
\hline Epinephelus marginatus & Garoupa \\
\hline Epinephelus morio & Cherne \\
\hline Epinephelus niveatus & Badejo; badejo-quadrado \\
\hline Mycteroperca bonaci & Cherne-poveiro \\
\hline Polyprion americanus & P a rg o - r o s a \\
\hline Pagrus pagrus & Bagre \\
\hline Genidens barbus & Piramutaba \\
\hline Brachyplatystoma vaillantii & Dourada \\
\hline Brachyplatystoma rousseauxii & Jaú \\
\hline Zungaro zungaro & \\
\hline
\end{tabular}

